\title{
AVALIAÇÃO DA QUALIDADE DA ASSISTÊNCIA AMBULATORIAL EM SAÚDE MENTAL: UM ESTUDO DAS RELAÇÕES ENTRE PROCESSO E RESULTADO FINAL
}

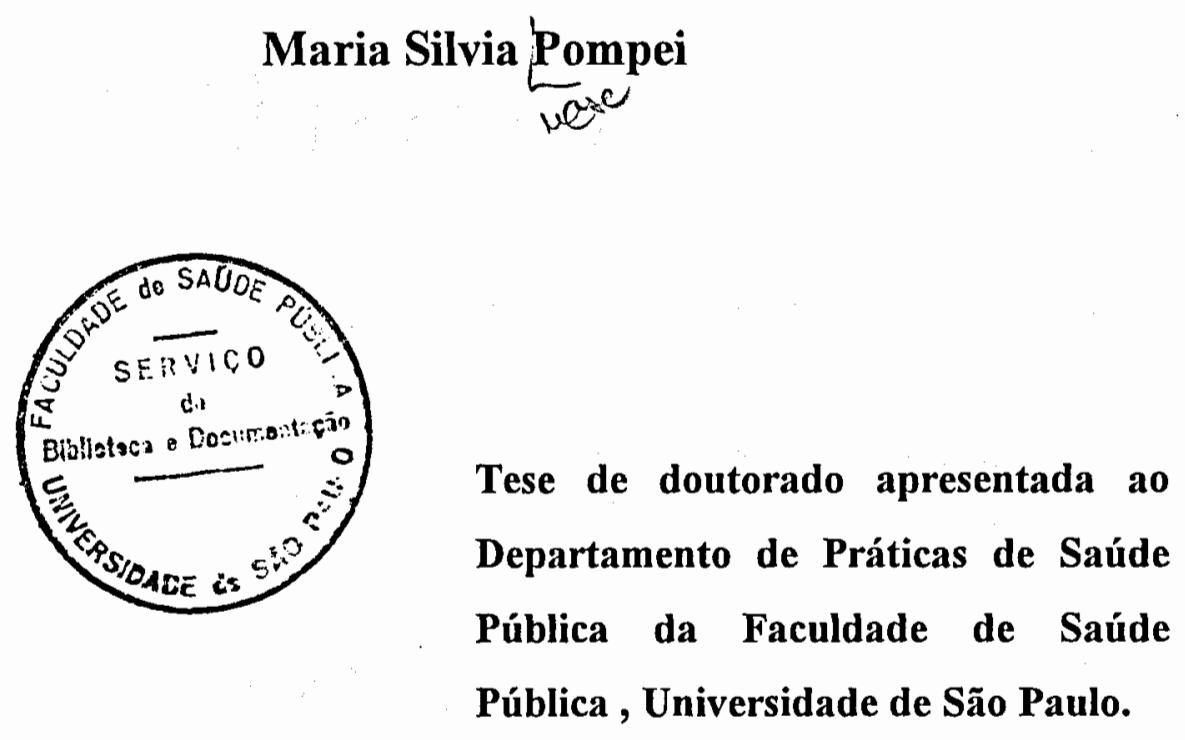

São Paulo 


\section{AVALIAÇÃO DA QUALIDADE DA ASSISTÊNCIA AMBULATORIAL EM SAÚDE MENTAL: UM ESTUDO DAS RELAÇÕES ENTRE PROCESSO E RESULTADO FINAL}

Tese de doutorado apresentada ao Departamento de Práticas de Saúde Pública da Faculdade de Saúde Pública , Universidade de São Paulo

Maria Silvia Pompei

Orientador: Francisco Bernardini Tancredi

São Paulo

1996 
Para Camila e Daniel

BIBLIOTECA.

FACULDADE DE SAUUDE PÚBLICh 


\section{Agradecimentos}

Ao Prof. Dr. Francisco Bernardini Tancredi, orientador desta tese, por sua supervisão, colaboração, ensinamentos e compreensão na elaboração desta tese. Agradeço a atenção que me dispensou, mesmo em condições bastante adversas para orientação. Foi, durante esse período, uma importante fonte de apoio e incentivo.

À Prof. Dra. Florence Kerr-Corrêa, uma das responsáveis por minha formação psiquiátrica, por acreditar neste trabalho, por estimular seu desenvolvimento, e por ter sido de muita ajuda em determinadas fases deste projeto.

À Prof. Dra. Cecília Magaldi, pelo exemplo como professora e como pessoa. Também por sua supervisão durante o período de estágio em serviços de saúde mental no município de Botucatu.

À Ana Teresa de Abreu Ramos Cerqueira, por seu apoio e pela influência que, como docente e membro da equipe, teve sobre a aluna e companheira. Sua atuação, durante o mestrado, foi de fundamental importância para que este projeto se realizasse.

À Albina Rodrigues Torres, por sua colaboração desde o início, e por seus constantes sinais de ânimo até o final, ainda que "desde lejos". Sua presença me fez sentir acompanhada.

À Sumaia Inaty Smaira, Ronaldo Rossini, Maria Graziela Cavichioli, Gimol Benzaquen Perosa e Massako Iyda, por sua ajuda em distintos momentos desta tese.

À Maria Eunice Carreiro Lima e Nair Isabel Lapenta de Oliveira, pela gentileza ao permitirem a realização dos testes prévios de questionário em seus grupos. 
Aos vários amigos docentes, funcionários e residentes do Departamento de Neurologia e Psiquiatria da Faculdade de Medicina de Botucatu, pelas sugestões e encorajamento.

À Valquíria de Cássia Possani, Francisco José Burzaca e demais funcionários da secretaria, que forneceram suporte técnico na elaboração de formulários e outros trabalhos.

Aos funcionários da recepção do Ambulatório de Saúde Mental da Faculdade de Medicina de Botucatu, por ajudarem na obtenção de dados sobre os agendamentos. Também agradeço a todos os funcionários do Serviço de Arquivo Médico que se ocuparam da seleção de prontuários.

À Marisa Antonia Macedo, Rosângela Giarola e equipe de entrevistadoras, pelo papel fundamental que tiveram durante o trabalho de campo.

Aos amigos Verena e Francisco H. A. Maffei, pela amizade constante, pela ajuda em períodos dificeis, pelo incentivo, e pelos valores que, como docentes, souberam nos transmitir.

À Arlete e Julio C. A. Pompei, pelo auxílio na pesquisa em São Manuel.

À Clodette Safady Hossne, que me ajudou a "crescer". Obrigada por ter ouvido, apoiado, ensinado, influenciado em minha carreira, e por acreditar na profissional incipiente.

Aos vários docentes da Faculdade de Saúde Pública da USP que, no período de elaboração do projeto de tese, deram sugestões que se mostraram muito úteis. Ao José Carlos Tancler e Jaime Garcia pelos seus conselhos na análise estatística.

À Bela e Otávio Tafner, pela ajuda "burocrática" e por constantemente estimularem o término deste estudo. Agradeço o apoio em todo o período, mas principalmente neste final.

$\grave{A}$ todos os familiares e amigos que nestes últimos anos desde que Camila era pequena, forneceram ajuda "estrutural" para que esta tese pudesse ser feita. 
Ao Daniel, que teve muita paciência, e soube transmitir energia, compreensão, apoio, orientação, além de ajuda efetiva em vários momentos da elaboração deste trabalho. Foi uma constante fonte de amor e de incentivo para fazer e terminar.

Aos meus pais, sou eternamente grata pelo estímulo à perseverança, confiança, capacidade para fomentar a curiosidade e o sentido de igualdade, e pelo apoio discreto que sempre souberam manifestar.

À Camila, por oferecer-me contínuas mostras de carinho. Espero que me perdoe pelo tempo que não pude lhe dedicar nesta última fase.

Finalmente, gostaria de agradecer aos pacientes que aceitaram voluntariamente responder à entrevista domiciliar. Sua colaboraçao foi muito importante, e espero que seus comentários sirvam para que o serviço oferecido seja aprimorado.

Com certeza, estou me esquecendo de muitas pessoas que, em alguma fase participaram na elaboração deste trabalho. Peço-lhes desculpas.

Esta tese foi financiada parcialmente por uma bolsa de auxílio à pesquisa da FAPESP. 


\section{"In Memoriam"}

Gostaria de recordar Bruno Lima. Foi orientador, amigo, professor e uma pessoa de uma enorme energia vital. Soube estimular o interesse pela investigação, e era dessas pessoas que conseguiam aglutinar com seu otimismo, pesquisadores de diversos países, em torno de um tema em comum.

Com Bruno, compartilhamos períodos dos mais dificeis e tristes, mas também, dos mais felizes e proficuos de nossas vidas. Durante o período de minha estada na Johns Hopkins University, foi um marco de referência fundamental, permanecendo depois, a amizade, o exemplo, e o trabalho em comum. Infelizmente, já não podemos desfrutar de sua companhia. Não pudemos despedir-nos. Resta, contudo, a lembrança, a saudade, e o respeito. 


\section{Índice}

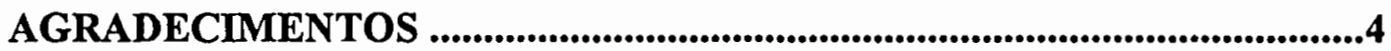

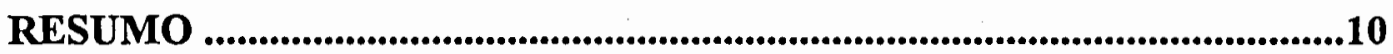

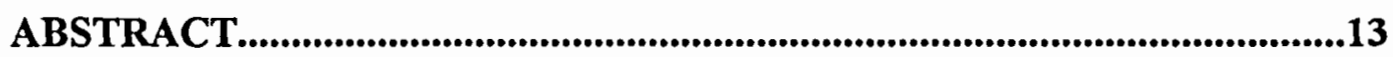

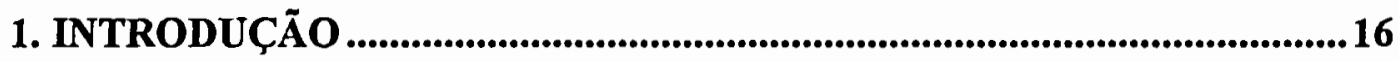

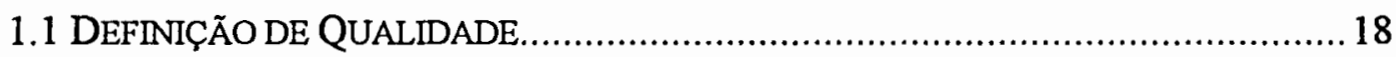

1.2 AVALIAÇÃo Da QUALIDADE NOS SERVIÇOS DE SAÚDE ...............................24

1.3 TIPOS DE ABORDAGEM PARA A AVALIAÇÃo DA QUALIDADE ......................28

1.4 A AValiação da Qualidade EM SaÚde MENTAL .................................... 35

2. DEFINIÇÃO DE HIPÓTESES E OBJETIVOS ....................................46

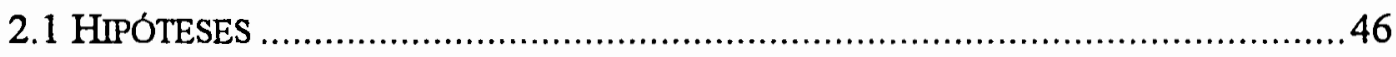

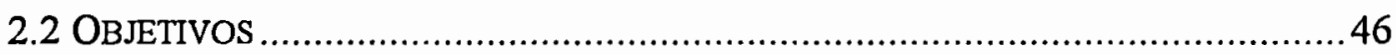

3. SUJEITOS E MÉTODOS ................................................................4 47

3.1 DESCRIÇÃO DO SERVIÇO ........................................................... 47

3.2 PROCEDIMENTOS METODOLÓGICOS ....................................................51

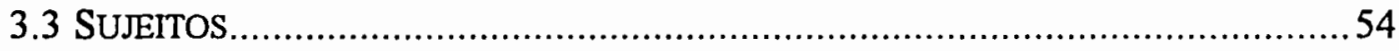

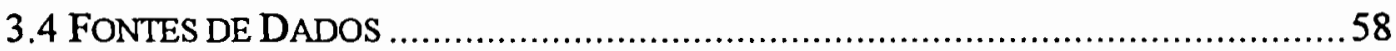

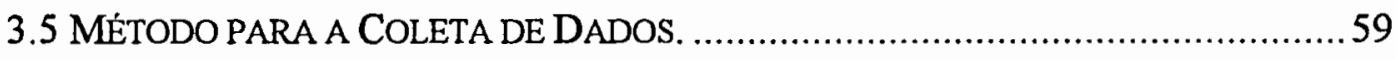

3.5.1 Revisão de Prontuários.....................................................................59

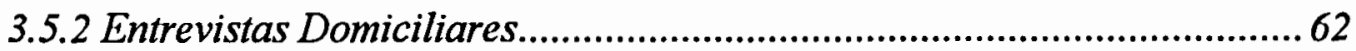

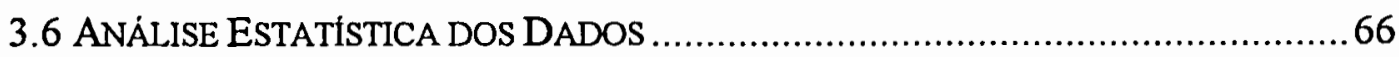




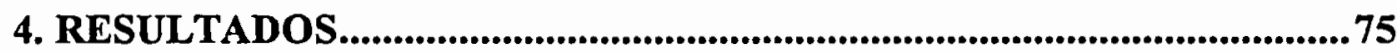

4.1 RESUlTADOS DA ANÁlise MUlTIVARIADA ........................................ 142

5. COMENTÁRIOS FINAIS E CONCLUSÕES ..................................... 151

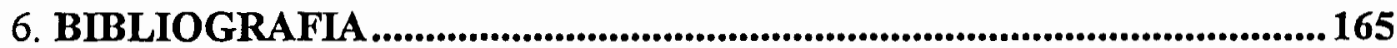

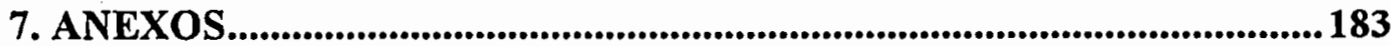




\section{Resumo}

A qualidade da assistência médica e dos serviços de saúde é uma questão que nas últimas décadas passou a ser motivo de crescente interesse tanto nos meios científicos e políticos, como na sociedade como um todo. À medida que foram se tornando conhecidos uma grande quantidade de problemas que afetam a prestação de serviços de saúde, a questão da avaliação da qualidade de cuidados médicos passou a ser não apenas um motivo de interesse, mas também uma prioridade entre os responsáveis pela formulação de políticas sociais e de saúde. Enquanto que em vários países a avaliação da qualidade de serviços vem ocorrendo de forma sistemática, no Brasil isso não tem ocorrido, principalmente no que diz respeito à avaliação qualitativa. O estudo desenvolvido nesta tese se propõe a avaliar qualitativamente um serviço ambulatorial de saúde mental.

Os principais objetivos deste trabalho são: 1) avaliar o grau de satisfação dos pacientes com o tratamento recebido no serviço estudado; 2) analisar a interrelação entre o processo de prestação de serviços e os resultados finais do tratamento para se avaliar a qualidade da atenção prestada; e 3) determinar o peso que diferentes fatores, tais como processo de prestação de serviço, características individuais dos pacientes, e fatores relacionados à doença, podem ter na determinação de que o resultado final do tratamento possa ser considerado positivo ou negativo.

Foram sujeitos deste estudo os pacientes atendidos no Ambulatório de Saúde Mental da Faculdade de Medicina de Botucatu como "casos novos" ( $1^{\text {a }}$ consulta) de Psiquiatria durante os anos de 1989 e 1990, procedentes de Botucatu e São Manoel e portadores dos diagnósticos da “CID"-9 (1975) "Transtornos neuróticos", "Reações de ajustamento" e diagnósticos do "Código V" (V.61, V.62 e V.11). Os dados sobre o tratamento dos pacientes foram coletados das fichas de agendamento de consultas, dos prontuários médicos e de questionários 
aplicados aos pacientes em entrevistas domiciliares. Dos 1155 pacientes atendidos como "casos novos" foram incluídos nesta pesquisa 289 pacientes. Em função dos pacientes que não puderam responder às entrevistas domiciliares, contamos com um total de 211 pacientes dos quais obtivemos informações tanto dos prontuários médicos, como das entrevistas domiciliares. A análise estatística realizada pode ser dividida em duas fases: 1) onde foram obtidas informações através da distribuição de frequiências e associações entre variáveis, e 2), onde foram utilizados métodos de análise multivariada.

Em $66.5 \%$ dos casos os pacientes referiram sentir-se "melhor" como resultado do tratamento recebido, índice bastante similar ao da percepção do médico de "melhora com o tratamento" (65,7\%). Em 70,1\% dos casos os pacientes referiam estar satisfeitos com o tratamento. Neste estudo, as pessoas relacionadas com o tratamento como o médico e funcionários da recepção foram avaliados positivamente enquanto que alguns fatores organizativos foram avaliados mais negativamente.

Como em outros estudos, a satisfação geral esteve altamente associada com a percepção de melhora do paciente. Diferentemente de outros trabalhos, neste, a satisfação também esteve fortemente associada à percepção de melhora por parte do médico. São apresentados e discutidos vários aspectos do processo de assistência que estiveram associados aos resultados finais do tratamento. Analisando-se a interrelação de muitas das variáveis do processo com os resultados obtidos, podemos chegar à algumas conclusões "aproximadas" sobre a qualidade do serviço, que poderão servir para que se possam tomar decisões pragmáticas sobre a organização do serviço, ainda que em última instância não nos permitam responder de forma precisa à pergunta contida em um de nossos objetivos: "qual foi o nível de qualidade da assistência prestada?". Isso porque nos faltam critérios e "standards" explícitos aplicáveis a nosso meio. O desenvolvimento desses critérios e padrões explícitos de qualidade deveriam ser 
um objetivo prioritário de futuras pesquisas na área da avaliação qualitativa em Saúde Mental.

Com relação ao "peso que diferentes fatores podem ter na determinação do resultado final do tratamento", pode-se dizer que algumas características da doença tiveram pouco peso na determinação dos resultados, enquanto que certas características do paciente como sexo e renda per-cápita estiveram associadas de forma significante com os resultados do tratamento. Comentamos com detalhes esses dados, e salientamos que tais achados são válidos no contexto "deste" estudo. Além dessas duas características, também descrevemos outras variáveis ligadas ao processo, que estiveram altamente associadas à determinação dos resultados, através da análise multivariada. A "satisfação com o tratamento" foi a variável que mais fortemente esteve associada aos resultados finais. Do referido acima poderíamos concluir que atingimos o objetivo de verificarmos em que extensão, certos fatores podem interferir nos resultados finais.

Para finalizar, pudemos avaliar o grau de satisfação dos pacientes com o tratamento recebido. Tal avaliação foi de extrema importância nesta pesquisa, no sentido da complementaridade de informações que possibilitou, ao proporcionar a visão subjetiva do usuário que pôde ser somada aos dados obtidos do prontuário. Levando-se em consideração a situação atual das pesquisas qualitativas em nosso meio, sugere-se os estudos na linha da avaliação da satisfação com a assistência recebida sejam os que se mostrem mais factíveis de serem realizados, e em termos de resultados produzidos, poderiam ser tão bons quanto outros métodos para a avaliação da qualidade de serviços de saúde mental. 


\section{Abstract}

The interest in the quality of medical care and health services has been an issue that, in the last decades, has grown not only in the scientific and political arenas, but in the society as a whole. As the problems concerning the quality of health care delivery were known, the issue of their evaluation has been not only an issue of interest, but also a priority among the decision makers in the field of social and health policy. While in several countries the evaluation of health services is being sistematically developed, this has not been so in Brazil, and with special emphasis in qualitative evaluation. The aim of this thesis is to develop a qualitative evaluation of a mental health outpatient service.

The main objectives of this dissertation are: 1) to evaluate the patients satisfaction level with the treatment that they received in the service; 2) to analyze the relationship between the health care delivery process and the final treatment outcome in order to evaluate the health care delivery quality; and 3) to determine the weight that several factors, such as the health delivery process, the patients individual characteristics, and factors related to the illness, can have in the final positive or negative treatment outcome.

The subjects of this study were the patients treated in the outpatient mental health service of the Botucatu Medical School as "New Patients" (1st visit) during the years 1989 and 1990, coming from Botucatu and São Manoel Municipalities, and with the ICD-9 (1975) diagnosis "neurotic disorders", "adjustment reactions" and some "V Code" diagnosis (V.61, V.62, V.11). The patients" treatment data were collected from the scheduling records, medical records and home interviews applied to the patients. Among the 1155 patients that were examined as "new patients" 289 were included. From these, we obtained data from both, home interviews and the medical record with a final total of 211 patients. The statistical 
analysis can be divided into two phases: 1) when the information was obtained from the frequency distribution and correlations among variables, and 2) from multivariate analysis techniques.

From all the patients, $66.5 \%$ of them said to feel "better" after receiving treatment, a percentage quite similar to that of the physician's perception of "improvement with the treatment" $(65.7 \%)$. In $70,1 \%$ of the cases the patients said to be satisfied with the treatment. In our case, while people related with treatment such as the physicians and the reception employees were positively evaluated, some organizational factors related to the service were evaluated negatively.

As in other studies, the overall satisfaction was highly correlated to the patients' perception of improvement. Contrary to other studies, in this one, satisfaction was also highly correlated to the perception of improvement by the physician. Several aspects of the health delivery process related to treatment outcomes are presented and discussed. Analysing the relationship of several process variables with the outcomes, we obtained some conclusions about the service quality. These conclusions can be used to make decisions about the service organization, although these cannot be used to answer in a strict sense the question: "what was the quality level of health care achieved?'. This is due to the lack of explicit criteria and standards that can be used in our cultural context. The development of these explicit criteria should be a prioritary goal of further research in the area of quality evaluation in mental health care.

With regards to the "weight that different factors can have in the treatment outcome", while some illnesses' characteristics had a relatively low weight in the outcome, some patients characteristics such as sex and personal income were highly weighted. These results are extensively presented, and we stress that our conclusions are valid within the context of this study. Besides these two characteristics, we also describe other variables related to the process that we found to be highly related to the outcome using multivariate analysis. The 
"treatment satisfaction" was the most significant variable related to the final outcome. From these results we concluded that the objective of verifying that some factors can interfere in the final results has been achieved.

Finally, we were able to fully evaluate the patients' satisfaction level with the treatment received. Such evaluation was quite important for our research, because the subjective point of view of the patient provided complementary information to the data obtained from medical records. If we take into account the actual state of the art of the research on quality in our country, possibly the studies based on the evaluation of patients' satisfaction with the treatment received are the most feasible and, in terms of the results obtained, as good as other methods of mental health service quality valuation. 


\section{Introdução}

A qualidade da assistência médica e dos serviços de saúde é uma questão que, nas últimas décadas, passou a ser motivo de um crescente interesse tanto nos meios científicos e políticos, como na sociedade como um todo. Os serviços de saúde e a prática médica contaram por muitos anos com a confiança acrítica da sociedade, mas essa situação foi se modificando, à medida que a população e os responsáveis pelas políticas públicas foram tomando consciência da grande quantidade de problemas que afetam a prestação de serviços de saúde (32). Assim sendo, a questão da avaliação da qualidade de cuidados médicos passou a ser não apenas motivo de interesse, mas também uma prioridade entre aqueles responsáveis pela formulação de políticas sociais e de saúde.

Como citam Brook et al. (8), durante as duas últimas décadas nos Estados Unidos, o crescimento tanto do interesse, quanto do número de pesquisas no campo da avaliação da qualidade da assistência médica tem sido explosivo, e uma vasta bibliografia incluindo revisões da literatura sobre esse tópico tem sido publicada. ( $8,27,70,132,133)$.

Ainda que a preocupação com essa área seja algo atualmente disseminado em um grande número de países, foi nos Estados Unidos, a partir da década dos sessenta, que a avaliação da qualidade dos serviços médicos passou a ser desenvolvida de forma mais sistemática.

$\mathrm{O}$ alto custo dos cuidados médicos, bem como o crescimento do consumo e de movimentos enfatizando o direito à saúde, exerceram uma pressão crescente sobre o sistema de saúde, no sentido de que este respondesse com maior efetividade e responsabilidade às demandas assistenciais. Mas apesar das várias razões, o principal motivo do envolvimento do próprio governo americano, e de outras organizações, na questão da necessidade de avaliação da qualidade, foi a preocupação com a contenção dos custos, a utilização eficiente dos recursos, e a qualidade dos serviços assistências oferecidos em programas médicos financiados 
pelo governo federal (27). Porém, ao mesmo tempo que o governo, outros grupos econômicos com interesses assegurativos na esfera médico-sanitária, também estavam interessados na implementação de medidas avaliativas, com o objetivo principal de contenção de custos. Quando o controle de custos, passa a ser um objetivo importante no desenvolvimento sistemático de avaliações de serviços, a questão da qualidade em si mesma pode, em alguns casos, passar a ser posta em jogo, (além de interferir em várias outras questões éticas e de autonomia ligadas à prática médica), o que fez com que algumas organizações com fins não lucrativos, que participavam ativamente de programas de controle de qualidade em sua área de atuação (como por exemplo a Associação Americana de Psiquiatria), deixassem de ser executores das avaliações e passassem a atuar mais como organismos críticos no sentido de assegurar que certos princípios éticos não fossem deixados de lado no processo avaliativo. Apesar dessas peculiaridades, a necessidade de atividades avaliativas no sentido de garantir serviços médicos de boa qualidade, cada vez mais se tornam necessárias.

Como refere Pitta et. al. "as dimensões de custos, a acessibilidade e a qualidade do cuidado prestado nos serviços de saúde se encontram na ordem do dia das preocupações de países desenvolvidos, e mais ainda em países não tão desenvolvidos, que vêem crescer as demandas de saúde à medida que ultrapassam problemas de subsistência e os indivíduos começam a identificar o direito à saúde como conquista inerente à condição de cidadão" (87.a) . Esse último parágrafo expressa exatamente a situação em nosso meio.

Mas, enquanto que em vários países mais desenvolvidos, pelas mais diversas razões, a avaliação da qualidade de serviços vem ocorrendo de forma sistemática nas últimas décadas, no Brasil isso não tem ocorrido. Em nosso país, existe pouca tradição de avaliação de serviços de saúde, e, como refere Campos (14), a pouca experiência acumulada ao longo dos anos, refere-se à avaliação quantitativa, ao invés da avaliação qualitativa dos serviços públicos de saúde. Assim sendo, iniciativas na área de avaliação qualitativa, tornam-se cada vez mais necessárias, 
principalmente quando se observa a atual situação precária dos serviços responsáveis pela assistência médica no Brasil.

Se estudos de avaliação da qualidade de serviços de saúde de modo geral são raros em nosso país, mais ainda o são aqueles na área de saúde mental. Atualmente, encontra-se em fase inicial, um estudo multicêntrico sobre a avaliação da satisfação com as atividades desenvolvidas em serviços de saúde mental de quatro municípios brasileiros, em colaboração com a Organização Mundial de Saúde (87.a).

O estudo desenvolvido nesta tese, se propõe a avaliar qualitativamente um serviço ambulatorial de saúde mental. Mas antes de entrarmos na questão específica da avaliação de Serviços de Saúde Mental, pretendemos examinar o conceito de qualidade em medicina e discutir alguns aspectos do processo de avaliação da assistência médica em geral.

\subsection{Definição de Qualidade}

A palavra "qualidade" pode ter vários diferentes significados, mas no contexto em que será utilizada neste trabalho irá referir-se "ao mérito ou excelência de uma coisa ou atividade" (92).

Vários autores tem definido qualidade no que se refere à assistência médica. Para Lembcke (citado por Weiner, 117), qualidade de cuidados médicos tem a ver com "quão próximo os resultados da assistência aproximam-se do objetivo fundamental de prolongar a vida, aliviar o sofrimento, restaurar a função e prevenir incapacidade".

Donabedian $(21,22)$, por sua vez, refere-se à avaliação da qualidade como "um julgamento relativo ao processo de assistência, baseado na extensão em que essa assistência contribui para bons resultados. O processo de assistência à saúde pode ser, por sua vez, dividido em dois componentes principais: aspectos técnicos da assistência e o manejo das relações interpessoais entre o profissional e seus pacientes". 
Porém, como o próprio autor salienta, ainda que para fins de análise e compreensão do conceito de processo é importante que se faça essa distinção entre dois aspectos, ao mesmo tempo ressalta que esses dois componentes são interrelacionados, o que torna dificil, às vezes, sua separação. Menciona que assim como as relações interpessoais podem influenciar a qualidade técnica, por outro lado, também a natureza e o sucesso de certos procedimentos técnicos usados podem influenciar a relação interpessoal. Finalmente, cita o caso da aplicação de certas técnicas psicoterapêuticas, onde os elementos técnicos e interpessoais podem ser virtualmente inseparáveis.

Donabedian $(21,22)$ divide o processo de assistência em aspectos técnicos e interpessoais, e assinala que é portanto necessário definir o que constitui qualidade em cada uma dessas duas dimensões.

Com relação aos aspectos técnicos da assistência, ele afirma que a "qualidade dos cuidados técnicos consiste na aplicação da ciência e tecnologia médicas, de maneira a maximizar seus benefícios à saúde sem correspondentemente aumentar seus riscos".

O nível de qualidade técnica é definido portanto, em função da extensão na qual a assistência prestada atinge o melhor equilibrio entre riscos e beneficios.

Segundo o mesmo autor, o que constitui qualidade com respeito aos aspectos interpessoais do processo, já é mais dificil de resumir. O manejo das relações interpessoais deve ir de encontro à certos valores e normas definidos socialmente que governam a interação de indivíduos em geral, e em situações particulares. Essas normas são influenciadas em parte pela ética dos profissionais de saúde, e pelas expectativas e aspirações de cada paciente individualmente. Portanto, o grau de qualidade no manejo das relações interpessoais pode ser medido pela extensão em que se atinge uma conformidade com esses valores, normas, expectativas e aspirações.

Além dos aspectos técnicos e interpessoais, Donabedian inclui na avaliação da qualidade um terceiro elemento: as "amenidades" da assistência, referindo-se à 
certas características dos locais e ambientes onde os cuidados são prestados. Refere-se, por exemplo, à um consultório agradável e acolhedor, à uma cama confortável, à lençóis limpos...

Já Brook e Williams (12) definem qualidade de assistência da seguinte maneira:

$$
\left(\begin{array}{c}
\text { qualidade de } \\
\text { assistencia } \\
\text { à saude }
\end{array}\right)=\left(\begin{array}{c}
\text { Aspectos } \\
\text { tecnicos }
\end{array}\right)+\left(\begin{array}{c}
\text { "arte" } \\
\mathrm{da} \\
\text { assistencia }
\end{array}\right)+\left(\left(\begin{array}{l}
\text { aspectos } \\
\text { tecnicos }
\end{array}\right) \times\left(\begin{array}{c}
\text { "arte" } \\
\mathrm{da} \\
\text { assistencia }
\end{array}\right)\right]+\varepsilon
$$

onde aspectos técnicos da assistência incluem a adequação dos processos diagnósticos e terapêuticos. "Arte" refere-se ao meio, à maneira, e ao comportamento dos profissionais no momento da entrega dos serviços e na comunicação com o paciente. O sinal de multiplicação enfatiza a noção de que os dois termos não são apenas aditivos. Finalmente, um sinal de erro é incluído para ressaltar que a medida de qualquer constructo tal como qualidade, inclui um erro aleatório.

As três definições citadas acima, servem para que nos situemos com relação ao conceito de qualidade de assistência médica. Ainda que as duas últimas definições sejam bastante similares em sua essência, dentre as várias maneiras de se definir qualidade de cuidados, o ponto de vista de Donabedian $(21,22,23 . a)$ é o que prevalecerá como referencial neste trabalho. Essa opção foi feita pela simples razão de que esse é um tema desenvolvido por esse autor de forma extremamente minuciosa, especificando detalhadamente cada aspecto de sua definição (coloca especial ênfase no balanço entre beneficios e riscos à saúde), e com cuja visão estamos bastante de acordo.

Nesse sentido, nos estenderemos um pouco mais sobre alguns tópicos ligados à definição de qualidade segundo esse autor.

Ainda dentro da discussão sobre uma possível definição de qualidade, Donabedian $(21,22)$ discorre sobre a relação entre quantidade de cuidados e qualidade. 
Quando cita esse aspecto, obviamente faz menção à questão do acesso aos serviços e ao uso subsequente deles. Salienta tanto a possibilidade de uma baixa qualidade, caso se ofereça uma quantidade insuficiente de cuidados, o que os tornaria inefetivos por sua inadequação quantitativa, como os riscos que podem ser decorrentes do uso excessivo de cuidados. Além disso, quando se refere à quantidade excessiva de procedimentos, ele diz que mesmo nos casos que possam não oferecer riscos, isso pelo menos aumentará custos; dimensão que deve ser levada em consideração.

Neste sentido, Donabedian (21) propõe um modelo unificado para a definição de qualidade onde ele tenta integrar a questão dos beneficios, riscos e custos da assistência, discutindo esses conceitos primeiramente dentro do espectro dos aspectos técnicos da qualidade. Logo a seguir, trata de vincular a dimensão interpessoal ao seu modelo unificado.

Para esse autor, a qualidade também pode ser definida a partir de diferentes pontos de vista: dos profissionais de saúde, do indivíduo e da sociedade.

A qualidade dos cuidados médicos dentro da ótica dos profissionais de saúde poderia ser definida como "a aplicação de procedimentos por meio dos quais se espera atingir o melhor equilibrio entre beneficios e riscos à saúde". É uma responsabilidade do profissional recomendar e proceder a tal cuidado. Nesse sentido, todos os outros fatores, incluindo custos monetários, tanto quanto expectativas e valores dos pacientes, são vistos como obstáculos ou aspectos facilitadores para a implementação do padrão de qualidade.

Esse mesmo autor (21), também cita uma outra alternativa para esse ponto de vista: a que defende que a função primordial da assistência médica é melhorar (ou possibilitar) o bem estar do paciente.

Assim sendo, é inevitável que o paciente deva compartilhar com o profissional a responsabilidade de definir os objetivos da assistência e a avaliação dos benefícios e riscos que podem resultar de uma determinada opção. Quando o julgamento da 
qualidade leva em consideração os desejos e expectativas dos pacientes, Donabedian (21) a considera como uma definição "individualizada".

Os fatores que produzem a terceira definição, a social, são os mesmos usados para a definição de qualidade "individualizada", embora as quantidades sejam diferentes. Existe também um novo critério: em adição ao beneficio para toda a população, a distribuição social desses benefícios dentro da população torna-se muito importante. Além do mais, a sociedade pode fazer valorações diferentes com respeito à saúde e bem estar de diferentes segmentos da população, definidos em função de sexo, ocupação, ou outras características.

Em sua discussão relativa ao contexto onde se desenvolve a avaliação de qualidade, Donabedian (21) salienta que quando a atenção se desloca da relação entre a dupla paciente - provedor, para a assistência em saúde oferecida por grupos de profissionais para toda uma população, certos atributos da assistência tornam-se muito mais importantes como determinantes da qualidade. E é nesse marco que ele cita a importância da equidade, eficiência, acesso, continuidade e coordenação, como atributos da assistência que influenciam, de forma extremamente importante a qualidade dos cuidados.

Para finalizar, Donabedian (21) discorre sobre a satisfação tanto do profissional provedor de assistência, como sobre a satisfação do paciente, como elementos muito importantes na definição de qualidade. Segundo ele, a satisfação do usuário é fundamental como medida da qualidade da assistência, porque provê informações sobre o sucesso conseguido pelo provedor de serviços em atingir valores e expectativas dos pacientes, fatores estes sobre os quais o cliente é a autoridade principal.

Quando da discussão sobre a definição de qualidade, não se pode deixar de mencionar também, os conceitos de eficácia, efetividade e eficiência que, classicamente, sempre estiveram presentes nos mais variados processos de avaliação. 
Williamson (124), em um de seus inúmeros textos que versam sobre a utilização de resultados em avaliação de cuidados médicos, discorre sobre a evolução do significado e uso desses três termos dentro de um contexto histórico, revisando artigos prévios à 1900, e terminando por citar a definição proposta por White (WHO,1971) em um informe técnico da Organização Mundial de Saúde:

- Eficácia: $O$ beneficio ou utilidade que representa(m) para o indivíduo, o serviço, o tratamento, o regime, a medicação ou outras medidas preventivas ou de controle advogadas ou aplicadas à esse indivíduo.

- Efetividade: O efeito da atividade, e os resultados finais ou beneficios para a população, atingidos em relação aos objetivos estabelecidos.

- Eficiência: Os efeitos ou resultados finais atingidos, em relação ao esforço dispendido em termos financeiros, de recursos e tempo.

Williamson (124) crê que, apesar das definições acima servirem para esclarecer tais conceitos, estas ainda falham em fazer uma importante distinção funcional relacionada ao nível e às circunstâncias onde os benefícios da assistência podem ser demonstrados. Por exemplo: a eficácia deveria indicar o beneficio máximo possível sob condições "ideais", enquanto que a efetividade deveria estar relacionada ao grau em que tanto um indivíduo ou população podem se beneficiar de uma intervenção eficaz, em condições normais, ou usuais da prática clínica. Em função disso, tal autor propõe, para a finalidade de aplicação em avaliações de qualidade as seguintes definições:

- Eficácia: A extensão em que uma intervenção a nível de assistência à saúde pode demonstrar ser benéfica, sob ótimas condições de assistência.

- Efetividade: A extensão em que os possíveis beneficios atingíveis sob ótimas condições de assistência, são realmente atingidos na prática clínica.

- Eficiência: A proporção do custo total (por exemplo: dinheiro, recursos escassos e tempo), que pode ser associada aos beneficios realmente atingidos. 
Uma vez especificados tais conceitos, voltamos novamente a salientar, que neste trabalho a definição de qualidade proposta por Donabedian (21) é a que será usada como referência.

\subsection{Avaliação da Qualidade nos Serviços de Saúde}

A avaliação da qualidade foi, provavelmente, introduzida pela primeira vez na avaliação de assistência à saúde, através do trabalho de Codman logo nas primeiras décadas deste século $(89,129)$. Codman desenvolveu um método de avaliar hospitais pelos seus resultados e, em 1913, sua abordagem foi incorporada aos objetivos do recém-criado Colégio Americano de Cirurgiões. Este, sob influência do trabalho de Codman passa a se responsabilizar pela avaliação da qualidade dos serviços hospitalares nos E.U.A. Para tal atividade, o Colégio de Cirurgiões desenvolveu padrões de qualidade que, de certa forma, foram os embriões do "Programa de Credenciamento de Hospitais" sendo em 1951, substituído nessa função pela "Joint Comission on Accreditation of Hospitals" (J.C.A.H.), atualmente conhecida como "Joint Comission on Accreditation of Health Care Organizations" (J.C.A.H.O.).

Nos E.U.A., na década de setenta, preocupação com o crescente número de processos legais por mal-prática estimulou o interesse pela avaliação da qualidade de serviços. Partia-se do pressuposto de que esse aumento do número de processos era devido à assistência de baixa qualidade sendo, portanto, a avaliação dos cuidados uma forma de se prevenir tal situação.

Em 1972, ainda nos E.U.A, numa tentativa de controlar os custos massivos de programas federais de atenção à saúde (Medicare e Medicaid), o Congresso promulgou uma lei autorizando a criação de organizações de revisão de "standards" profissionais (Profissional Standards Review Organizations - PSROs) para que estas realizassem avaliações em programas financiados pelo governo federal. Essas organizações (PSROs) foram modificadas posteriormente e denominadas "Peer Review Organizations" (PROs), as quais passaram a ser as 
responsáveis em estabelecerem diretrizes e monitorarem os programas de revisão da utilização de hospitais (129).

$\mathrm{Na}$ Inglaterra, por sua vez, inúmeros estudos de avaliação da eficácia e eficiência dos procedimentos diagnósticos e terapêuticos foram conduzidos pelo "Medical Research Council", numa tentativa de se otimizar a aplicação desses procedimentos, uma vez que os recursos do "National Health Service" (N.H.S.) eram limitados, e a demanda por serviços bastante grande (14).

No campo da Saúde Mental, o desenvolvimento de programas de avaliação da qualidade ocorre de forma mais lenta do que em outras áreas médicas. Nos E.U.A., em 1951, a Associação Americana de Psiquiatria (A.P.A.) publica uma extensa lista de padrões para hospitais psiquiátricos, os quais representavam o consenso dos profissionais da área, sobre as caracteristicas consideradas necessárias para a prestação de serviços de alta qualidade (129). Em 1969, esses padrões foram revisados e atualizados seguindo as normas da "Joint Comission on Accreditation of Hospitals" (J.C.A.H.) e incluiam não só diretrizes para hospitais como também para outros serviços de Saúde Mental (2). Os sucessores desses primeiros padrões estão atualmente contidos no "Consolidated Standards Manual" (C.S.M.). Após um processo de revisão que se iniciou em 1981, alguns parâmetros referentes ao credenciamento de serviços psiquiátricos foram revisados, modificados, e postos em prática a partir de 1984. (121).

Na literatura sobre avaliação, somente em 1969, é que aparecerão as primeiras discussões efetuadas por Zusman e Ross (128), sobre a avaliação qualitativa de serviços de saúde mental.

Ainda nos E.U.A., progresso realmente rápido passa a ocorrer na área de avaliação em Saúde Mental, com as Leis Federais de 1975 (P.L. 94-63) e de 1980 (P.L. 96-398) que obrigavam os Centros Comunitários de Saúde Mental (C.M.H.C.) a conduzirem avaliações de seus serviços. Apesar de que a obrigatoriedade era de se desenvolver avaliação de programas e não só avaliação de qualidade, essa nova 
legislação fez com que inúmeras publicações sobre o tema surgissem na literatura $(40,70,88)$.

Em um interessante artigo, Hamilton (43), um antigo responsável pelo Comitê de "Peer Review" da Associação Americana de Psiquiatria (A.P.A.), fornece uma breve revisão do envolvimento da A.P.A. em atividades de avaliação da qualidade em saúde mental desde o final dos anos setenta até 1990. Descreve desde os motivos pelos quais a A.P.A. se envolvesse formalmente nesse tipo de atividades, até que, já no final dos anos oitenta, as tensões que naturalmente surgiram entre controle específico de qualidade e contenção de custos, fizeram com que tal Associação optasse por deixar de ser uma executora ativa de programas de avaliação.

Ainda assim, a A.P.A. continua exercendo uma influência importante nessa área, uma vez que a sua experiência, acumulada por mais de dez anos, lhe outorga a capacidade para que continuamente, possa estar desenvolvendo ou revisando diretrizes para a avaliação da prática clínica.

Tais diretrizes tentam refletir critérios ótimos de qualidade assistencial, e tem o objetivo, não só de servir como base em processos avaliativos, como também, de funcionar como um fator que possa influir na maneira como a prática em saúde mental está sendo conduzida.

Já no Brasil, como mencionado anteriormente, existe pouca tradição institucional de avaliação dos serviços de saúde (14), e a maior parte dos trabalhos existentes refere-se à avaliação quantitativa.

Em 1988, Panerai et al. (85) publicam os resultados de um projeto que desenvolveram sobre a avaliação de tecnologias perinatais, sendo que, alguns dos recursos usados na metodologia (por ex.: o painel de especialistas), poderiam ser utilizados em saúde mental, por exemplo, para a especificação de critérios e padrões de qualidade. Esse autor, também tem publicado sobre tópicos relacionados à avaliação de tecnologias em saúde e à possibilidade da aplicação de determinadas metodologias em países em desenvolvimento $(3,84)$. Coe e Banta 
(14.a), referindo-se à possibilidade de transferência de tecnologias em saúde para países latino americanos, ressaltam a necessidade de se estimular em nossos países a formação de pessoal habilitado, para o desenvolvimento de avaliações desse tipo de tecnologia. Também Banta (3.a), em artigo mais específico sobre a questão da utilização de tecnologia médica no Brasil, volta a salientar esse aspecto.

$\mathrm{Na}$ área de Saúde Mental, em 1973, a Secretaria de Assistência Médica do I.N.P.S. aprova o "Manual de Serviço para Assistência Psiquiátrica", onde se encontram diretrizes para a prática psiquiátrica numa tentativa de se dar "maior e melhor uso aos recursos extra-hospitalares, e consequentemente alcançar maior eficácia no atendimento psiquiátrico em geral" (78). Nesse Manual foram incluídas algumas diretrizes para controle e supervisão dos serviços mas, do ponto de vista avaliativo, o máximo que era solicitado dos serviços eram as estatísticas correspondentes às atividades dos membros das equipes.

Em um manual, elaborado pelo DINSAM em 1988, já se pode encontrar alguns critérios mais específicos sobre as caraterísticas necessárias para que os serviços possam prestar uma assistência de boa qualidade (77). Infelizmente, são critérios que, em sua grande maioria, referem-se apenas à componentes estruturais dos serviços.

Na literatura sobre avaliação, Frota (33) dá sua contribuição com uma extensa revisão sobre modalidades de avaliação de programas de serviços de Saúde Mental. Em sua dissertação, Frota chama a atenção para a ausência de estudos na área, e para a necessidade de que se iniciem, em nosso país, pelo menos estudos de avaliação de estrutura e funcionamento. Nos últimos anos, algumas iniciativas de avaliação em Saúde Mental tem sido publicadas, ainda que sejam estudos principalmente descritivos $(17,114,115)$.

Em 1995, se publica o protocolo de investigação de um estudo multicêntrico (OMS, CNPq, USP, UFRJ e UNICAMP) que se encontra em fase de andamento em 4 municípios brasileiros. Tal estudo tem como objetivo determinar a qualidade 
de serviços de saúde mental, através da avaliação da satisfação dos pacientes, familiares e trabalhadores de saúde. (87.a).

\subsection{Tipos de Abordagem para a Avaliação da Qualidade}

Donabedian define três abordagens básicas para a avaliação da qualidade de serviços: a avaliação da estrutura, do processo e dos resultados (21).

$\mathrm{Na}$ avaliação da Estrutura, estão incluídos os seguintes elementos: recursos humanos (número, tipo, qualificação, treinamento e motivação), características fisicas das instalações, equipamentos, formas de organização, sistemas de registro e informações, além de recursos financeiros. Os fatores estruturais tem sido o foco de grande quantidade de avaliações na área médica e, usualmente, tem servido de base para o estabelecimento de padrões de assistência, muitas vezes questionáveis em termos de sua validade (108). As avaliações de estrutura objetivam examinar se as instituições possuem os instrumentos necessários para a prestação de assistência de boa qualidade. Presume-se que a presença desses instrumentos esteja associada a boa qualidade dos cuidados, ou melhor dizendo, que sua ausência tornaria difícil a provisão de uma boa assistência (129).

A avaliação do processo tem a ver com o que fazem os profissionais envolvidos na prestação de serviço; como a assistência é prestada ao paciente. Essa área funcional da prática médica inclui reconhecimento de problemas, procedimentos diagnósticos e terapêuticos, manejo dos casos e reavaliações. Starfield (108) amplia os componentes pertencentes ao processo de assistência, incluindo, além do provedor de cuidados, também o paciente, receptor dessa assistência e que pode, com seu comportamento, sem dúvida influenciar a qualidade dos serviços.

A avaliação de resultados refere-se ao impacto provocado pelos cuidados médicos sobre o estado de saúde dos receptores dessa assistência. Em seu conceito original, Donabedian incluía em resultados, indicadores de saúde tais como sobrevivência, recuperação e restauração da função. Posteriormente, acrescentou a satisfação do paciente como um resultado final positivo (124). White, citado por 
Williamson (124), assinala como resultados negativos a mortalidade, a morbidade, a incapacidade, o desconforto, a insatisfação e a perturbação da vida produtiva e social.

Starfield (108) propõe sete categorias que descreveriam os resultados finais: longevidade, atividade, conforto, satisfação, morbidade, realizações e recuperação. Na visão de Starfield e de vários outros autores, satisfação é um item a ser incluído não apenas em resultados, mas também, em outras categorias, como por exemplo, em processo.

Dentro desse referencial, numerosas polêmicas tem surgido sobre a adequação maior ou menor de uma ou outra abordagem para a avaliação da qualidade de serviços. Alguns autores passaram a defender veementemente um ou outro tipo de estudos. Brook $(9,10)$ e Williamson $(124,125)$ se dedicaram ao desenvolvimento de métodos para a avaliação da qualidade através do estudo de resultados, apesar de também reconhecerem o valor de modelos integrativos de avaliação tais como o estudo da interrelação processo/resultado. McAuliffe $(72,73,74)$ faz uma brilhante análise crítica da validade dos vários métodos para avaliação de qualidade, e após argumentar contra o ponto de vista bastante disseminado de que estudos de resultados são superiores aos estudos de processo, conclui que não existe respaldo teórico que sustente a superioridade das medidas de resultado sobre as de processo. Além disso, considera que o estudo do processo seria um método que avaliaria mais diretamente a qualidade de serviços. Posteriormente, voltaremos à esse assunto para justificar a escolha da abordagem a ser desenvolvida neste estudo. A especificação das três abordagens acima descritas é importante na questão da avaliação qualitativa, pois a quase totalidade dos estudos pode ser classificada em algum desses três tipos. Com relação ao trabalho proposto neste projeto, é importante mencionar algumas dificuldades relativas à avaliação do processo e resultados em Saúde Mental:

Uma das dificuldades existentes é que para o estudo do processo de assistência o ideal seria podermos contar com critérios e padrões de qualidade já definidos 
especificamente para nosso meio, e para serviços similares ao avaliado nesta pesquisa. Segundo Donabedian (22), os critérios devem ser derivados de fundamentos cientificamente validados pelo conhecimento. Na ausência destes, devem expressar a opinião melhor informada ou com a maior autoridade disponível sobre $o$ assunto.

Critérios podem ser classificados como implícitos ou explícitos, baseados no fato de terem sido ou não pré-especificados.

Critério implícito refere-se à avaliação da qualidade, efetuada por um ou mais especialistas tomando-se por base sua experiência clínica. Não existe nenhuma diretriz detalhada, especificada antes de que seja iniciada a avaliação.

Critérios explícitos são aqueles claramente especificados antes de que qualquer processo de avaliação se inicie. Nesses casos, por exemplo, um grupo de especialistas desenvolvem cuidadosamente, critérios por escrito, que podem portanto, ser aplicados posteriormente por outros profissionais em atividades avaliativas (sem que, necessariamente, tenham que ter o mesmo nível de experiência que os especialistas que desenvolveram tais critérios).

Um exemplo do uso de critérios implícitos em psiquiatria é a supervisão clínica de um caso. O DSM-III-R ("Diagnostic and Statistical Manual of Mental DisordersThird Edition-Revised"), por outro lado, é um exemplo de um sistema de diagnósticos oficial que utiliza critérios explícitos, para aplicação em psiquiatria (27).

Donabedian, em publicação de 1981, discute as vantagens e limitações do uso de critérios explícitos para a avaliação da qualidade em serviços de saúde (20).

Os critérios podem ser categorizados de acordo com sua fonte: critérios derivados normativamente são aqueles estabelecidos pelo julgamento de um grupo de especialistas de uma determinada área. Critérios derivados empiricamente são aqueles desenvolvidos através de um levantamento do que está realmente sendo feito por um grupo de profissionais de uma determinada instituição de saúde. Donabedian discorre de forma extremamente detalhada sobre a definição de 
critérios e padrões de qualidade, discutindo desde a significação dada aos termos tais como normas, critérios e padrões até a especificação das diferentes técnicas passíveis de serem utilizadas para a obtenção de critérios e padrões (22).

Com relação ao estudo de resultados, uma das dificuldades encontradas nesse tipo de avaliação, principalmente em saúde mental, é que vários outros fatores, além daqueles relacionados à assistência prestada, podem contribuir para o resultado final. Assim sendo, um resultado negativo não necessariamente, significa que a assistência prestada foi de baixa qualidade, uma vez que a gravidade da doença, a idade do paciente e vários outros fatores podem influir de forma negativa nos resultados (27). A questão acima citada chama a atenção para o fato de que, em estudos de resultados e de processo/resultado, a utilização adequada de técnicas estatísticas defendida por McAuliffe, deve ocorrer na tentativa de se excluir o papel de fatores alheios, quando se tenta demonstrar a relação existente entre processo de prestação de serviços e resultados clínicos $(72,73,74)$.

A avaliação da qualidade de serviços de saúde mental apresenta caraterísticas peculiares quando comparadas à dos demais serviços de saúde. Os aspectos e procedimentos puramente técnicos, ainda que bem aplicados, por si só não necessariamente preenchem os critérios de boa qualidade. Como ressaltam Pitta et al. (87.a) "todos os aspectos objetivos e materiais, mais que em outras áreas, estão atravessados pela intersubjetividade das relações entre usuários, trabalhadores e instituições de saúde, aumentando as dificuldades já presumíveis nos processos de avaliar qualidade em serviços de saúde".

E é nesse sentido, de se levar em consideração a relação entre usuários e provedores da assistência, que nesta discussão sobre as possíveis abordagens para a avaliação da qualidade de serviços, vale a pena mencionarmos a questão da avaliação da satisfação do paciente com o tratamento oferecido. Estudos sobre satisfação com o tratamento são, algumas vezes, classificados como estudos de resultados, outras vezes, como estudos sobre o processo de assistência. De 
qualquer forma, o que nos interessa, é que sem dúvida, a satisfação do paciente é um importante componente da qualidade da assistência.

Ao mesmo tempo que a satisfação do paciente pode ser tomada como um indicador de resultados positivos, por outro lado, ela é muito importante como medida da qualidade, porque reflete diretamente o sucesso ou não da interação provedor/receptor durante o processo de prestação de serviços.

Mas a satisfação do paciente, além de ser um objetivo e um resultado da assistência, ainda pode ser vista como contribuinte para outros objetivos e resultados. Por exemplo: um cliente satisfeito é mais propenso a cooperar efetivamente com o médico e seguir corretamente suas recomendações. Além disso, a satisfação também pode influenciar no acesso à serviços, uma vez que um paciente satisfeito tem mais chance de procurar novamente assistência quando necessite (21).

Ware et al. (116) consideram a satisfação do paciente como uma avaliação pessoal, subjetiva, dos serviços sanitários e dos provedores. Desde esse ponto de vista, um determinado nível de satisfação pode fornecer informações tanto sobre a assistência recebida como sobre as preferências dos pacientes. E é nesse sentido, o das preferências /expectativas dos usuários que alguns autores como Scally et al. (98) ainda que ressaltando a importância de se prestar mais atenção às demandas expressadas pelos pacientes enquanto "consumidores" de serviços, chamam a atenção para o fato de que podem existir diferenças acentuadas entre o julgamento de um profissional (provedor) e a percepção do público (receptor) com respeito à qualidade da assistência prestada. Os pacientes também, podem ter muitas vezes, expectativas pouco reais sobre o potencial "curativo" de um serviço de saúde.

Essas diferenças acrescentam, portanto, mais problemas com respeito à avaliação da qualidade dos serviços.

Existe a questão da "qualidade objetiva" ou seja, a utilização de técnicas corretas aplicadas na solução de um determinado problema, e a questão de como o paciente "percebe" o seu tratamento. Muitas vezes, ainda que recebendo "um bom 
tratamento", o paciente pode sentir que suas expectativas com respeito à obtenção de certo serviço não estão sendo preenchidas e portanto, julgá-lo negativamente. Por exemplo: um paciente para cujo problema a indicação correta (do ponto de vista do provedor) seria psicoterapia, e ele o que deseja são medicamentos que rapidamente resolvem, ou um eletroencefalograma totalmente dispensável.

Com respeito a esses aspectos, é interessante o artigo de Ibern (50) onde ele analisa o conceito de satisfação tanto do ponto de vista da área de "marketing de serviços" como do ponto de vista das pesquisas sobre serviços sanitários. Segundo ele, o conceito de satisfação está estreitamente ligado ao conceito de preferências subjetivas ou expectativas depositadas. A satisfação com o serviço oferecido ou com o provedor fornece dados sobre uma valoração pessoal, que não pode ser conhecida a partir da observação externa. Em resumo, a medida da satisfação é um procedimento que pretende captar informação sobre a prestação de um serviço mais além da informação sobre a realidade objetiva que tem 0 provedor. De acordo com esse autor, supondo que se disponha de um instrumento de medida e se detecta a insatisfação, deveríamos nos perguntar: temos que modificar nossa estratégia de prestação de serviços ou temos que mudar as expectativas, preferências ou "standards" com a finalidade de aumentar o nivel de satisfação?

Essas últimas interrogações são importantes no momento de se interpretar os resultados de questionários de satisfação, e avaliar a contribuição desses estudos para a avaliação qualitativa de serviços. Esse mesmo autor, Ibern (50), citando trabalhos no campo do "marketing de serviços" realizados por Parasuraman et al., menciona a ênfase que esses autores dão ao que se denomina "qualidade de serviço percebida". Esta poderia ser definida como a "avaliação global da excelência de uma entidade ou provedor; se trata de uma atitude relacionada com a satisfação, mas que não é equivalente à ela e que implica a comparação entre as expectativas e a percepção dos resultados reais". 
A satisfação se relacionaria com uma transação ou prestação específica de um serviço, enquanto que a qualidade de serviço percebida é uma avaliação global do nível de concordância ou discrepância entre as percepções dos usuários e suas expectativas.

Em resumo, poder-se-ia dizer que de um conjunto de experiências de serviço satisfatórias, resulta uma percepção de qualidade de serviço elevada.

Esses aspectos citados acima, são relevantes no momento de medir e interpretar a satisfação com a assistência. É importante que o instrumento a ser utilizado contenha itens que levem em consideração a questão das expectativas do usuário.

Estas considerações demonstram que a satisfação dos pacientes pode estar relacionada à qualidade de cuidados de várias maneiras. Assim sendo, é uma dimensão que deve ser levada em consideração quando nos propomos a avaliar a qualidade de um determinado serviço.

Uma vez que foi mencionado anteriormente, que na avaliação da qualidade em saúde mental, muitos aspectos vinculados aos usuários, provedores e ao contexto da atenção se mesclam aos procedimentos puramente técnicos e objetivos a serem medidos, vale a pena citar Guba e Lincoln (36.a), autores que definem uma nova abordagem de avaliação, "emergente, mas madura" segundo eles, que vai além dos enfoques puramente científicos que comumente são utilizados no campo das avaliações. Esses autores denominam sua abordagem "avaliação de quarta geração", e através dela tentam ir além dos métodos pré-existentes, basicamente orientados para medidas, julgamentos ou descrições (o que apresentamos até este ponto), para incluir no processo avaliativo, a grande variedade de elementos humanos, políticos, sociais, culturais e contextuais que envolvem as avaliações.

É um enfoque muito interessante, e que mesmo partindo de pressupostos completamente distintos, poderia enriquecer substancialmente, com as idéias nele contidas, a interpretação e discussão de achados obtidos através de avaliações mais convencionais. 


\subsection{A Avaliação da Qualidade em Saúde Mental}

Um grande número de autores tem publicado sobre sistemas de avaliação aplicáveis à serviços de saúde mental. Edelstien (24) descreve um modelo de avaliação psiquiátrica desenvolvido por uma equipe de saúde mental de um hospital geral. O principal elemento dessa forma de avaliação é um formulário desenvolvido para a verificação do cumprimento ou não de certos procedimentos considerados necessários para uma boa assistência. Dentro dessa mesma linha, Roy-Birne et al. (94) desenvolvem uma bateria de instrumentos baseados em dados já disponíveis, para ser utilizada por psiquiatras como um meio para a obtenção de medidas padronizadas referentes ao estado clínico (incluindo diagnósticos e nível de psicopatologia) de pacientes psiquiátricos internados. Eles crêem que essa padronização de medidas facilitaria a avaliação de resultados, poderia ser útil para fins didáticos com estudantes e residentes de psiquiatria e contribuiria para a melhora da qualidade dos serviços.

Diamond et al. (18) instituíram um sistema para monitorar a prescrição de psicofármacos por psiquiatras em Centros Comunitários de Saúde Mental. Michel e Kolakowska (76) nos apresentam resultados de um estudo sobre os padrões de prescrição de fármacos em dois hospitais psiquiátricos. Tyrer (134) faz uma análise das prescrições de todos os pacientes que passam a ser seguidos num ambulatório de psiquiatria ao longo de dois anos, depois de terem sido encaminhados por clínicos gerais. Ainda que seu artigo trate mais especificamente do comportamento do médico geral na hora de medicar o paciente com transtorno mental, seus resultados e conclusões são bastante úteis pois podem ser extrapolados ao padrão de consumo e prescrição de psicofármacos existentes em ambulatórios de saúde mental.

Mattson (70) faz uma interessante revisão sobre a avaliação da qualidade de programas em saúde mental, salientando as várias modificações ocorridas na área em resposta à preocupação com o crescente aumento dos custos no setor. Wilson (132) também, em publicação de 1992, situa num contexto histórico a evolução 
das várias abordagens e metodologias para controlar custos e assegurar qualidade e continuidade de assistência. Embora nesta tese não sejam avaliados aspectos econômicos ligados à assistência, dois outros artigos são citados, pois análises de custo-beneficio e custo-efetividade sempre estiveram presentes na origem dos programas de avaliação de qualidade. May (71), no início da década dos setenta, faz uma revisão da literatura daquele período sobre o custo-efetividade na prestação de serviços de saúde mental. Seu artigo se centra mais na assistência psiquiátrica hospitalar. $O$ interessante desta publicação é observar o estado das investigações nessa área em seus primórdios; no final dos anos cinqüenta e na década dos sessenta. Goldberg e Glass (34) apresentam um método para avaliar modificações em serviços psiquiátricos, dentro de um contexto de análise de custobeneficio.

No início dos anos 70, alguns Comitês foram criados para a avaliação de práticas psicoterápicas individuais e de grupo. Allen (1) descreve as atividades de avaliação de psicoterapias efetuadas na região de Washington D.C., no período de 1972 à 1977. Schulberg (100) discorre criticamente à respeito dos efeitos das avaliações de qualidade sobre a prática psiquiátrica (principalmente sobre as psicoterapias), observando os prós e contras desses estudos. Shwed et al. (104) descrevem sua experiência quando submetidos à uma auditoria de rotina pela entidade asseguradora (no caso "Medicaid") com respeito às psicoterapias que efetuavam, e fazem uma crítica bastante grande sobre os danos que esses procedimentos podem fazer com respeito à relação médico-paciente, à confidencialidade e inclusive sua possível interferência nociva no próprio processo terapêutico. Luft et al. (64) também escrevem sobre os efeitos das avaliações de práticas psicoterápicas em ambulatórios. Apresentam os resultados de entrevistas feitas à terapeutas e pacientes e suas conclusões não foram tão negativas quanto de início se pensava sobre o efeito de um "intruso" em meio ao processo terapêutico. Ainda assim, uma certa porcentagem tanto de médicos quanto de pacientes expressaram que a 
avaliação de seu tratamento tinha interferido na aliança terapêutica, e no processo psicoterápico.

Hine et al. (47), ainda na questão da avaliação da efetividade de psicoterapiàs, cita diversos problemas metodológicos na investigação desse tema, sugerindo que apenas os métodos usualmente utilizados nas ciências naturais por si só não são suficientes para avaliar a eficácia de psicoterapias. Nessa mesma linha, Weiss et al. (118), sugerem uma metodologia para medir mudanças após psicoterapia, que vai além da simples medida de sintomas. Horowitz et al. (49) que pertencem ao mesmo grupo de Weiss, apresentam os resultados de um trabalho que avalia de forma mais abrangente o efeito da psicoterapia breve de orientação dinâmica. Cohen e Holstein (15), ainda nesse tópico da avaliação de psicoterapias estudam caracteristicas biográficas, padrões de prática clínica e atitudes com respeito ao processo de revisão ("peer review"), de avaliadores ("peer reviewers") e provedores de psicoterapia. Hamilton et al. (42) em publicação de 1993, descrevem o desenvolvimento de indicadores para monitorar e avaliar terapias de grupo em um serviço de psiquiatria de um hospital geral, utilizando recursos já existentes. É interessante observar a diferença de posição dos psicoterapeutas em relação à avaliação de psicoterapias, quando comparamos as publicações mais antigas e as mais atuais.

Finalmente, Gray (135), em artigo mais recente, quando aparentemente a prática rotineira de avaliações de psicoterapia já está mais assimilada pelos médicos, discorre de forma mais ampla sobre a possivel avaliação dos vários tipos de psicoterapia individual. Conclui que inclusive na área psicoanalítica, as pesquisas levadas a termo nesse campo, permitiram o desenvolvimento de diretrizes que podem ser utilizadas por qualquer psiquiatra que se veja envolvido em processos avaliativos. Esses protocolos, além de facilitarem o processo de revisão, ao mesmo tempo protegem o paciente, a relação terapêutica, e o resultado do tratamento.

Em se tratando de serviços de emergência psiquiátrica, Gustafson et al. (37) descrevem a construção e a avaliação de um índice específico que permitiria a 
medida da qualidade da assistência em emergências psiquiátricas. Segal et al. (101) publicam um estudo bastante interessante que leva em consideração a qualidade técnica, a "arte" implicada na assistência e o investimento de tempo, para analisar os fatores que interferem na qualidade das avaliações de pacientes em serviços de emergência psiquiátrica de hospitais gerais.

Lebow e Newman (56) sugerem a utilização de medidas simples para a avaliação de programas de saúde mental. Dentro desse contexto, Smith (107) e Sherrman (103) descrevem vários indicadores de performance aplicáveis à centros comunitários de saúde mental. Schinnar et al. (99) relatam vários outros índices de performance utilizados para a avaliação de programas parciais de saúde mental.

Hafner e Heiden (38), avaliando os efeitos de um programa ambulatorial para tratamento de esquizofrênicos, enfatizam a necessidade de se monitorar resultados de tratamento e de se avaliar a efetividade de estratégias alternativas no tratamento de pacientes crônicos.

Taube et al (111), por sua vez, fazem uma análise crítica de estudos de avaliação de programas comunitários assertivos e sugerem o aprimoramento de outros aspectos metodológicos, que possibilitariam melhores conclusões acerca da efetividade dos programas. Nesse sentido, em 1995, McGrew et al. (75) publicam um estudo multicêntrico de avaliação de resultados de tratamento em pacientes vinculados a seis programas comunitários assertivos de um estado americano. Concluem que esse tipo de tratamento pode ser uma forma efetiva de atenção comunitária para pessoas com enfermidades mentais graves. Neale e Rosenheck (79), em outra pesquisa efetuada nesse mesmo tipo de programa (assertivo), tentam analisar a correlação entre a aliança terapêutica existente entre o paciente e o profissional que maneja seu caso ("case manager"), e o resultado do tratamento. Quanto mais forte o vínculo entre paciente e terapeuta, mais resultados positivos foram encontrados. Tal vínculo aparenta ser um componente significativo da efetividade terapêutica. 
Thompson et al. (112), tentam avaliar a qualidade de programas "controlados" de assistência ("managed care programs") em saúde mental, com dados de admissão de 9.055 pacientes sendo utilizados como medidas indiretas de qualidade. Ainda que tenham obtido resultados que esclarecem aspectos desse tipo de atenção, concluem que a qualidade desses serviços só pode ser avaliada com dados especificamente coletados para uso em avaliações.

Wilkinson et al. (122), descrevem sua experiência e o resultado da avaliação de um serviço comunitário de saúde mental, com equipe multidisciplinar, em uma área semi-rural da Inglaterra. Eles sugerem que sua experiência na assistência à pacientes que vem sendo tratados à longo prazo por transtornos mentais, pode servir de referência para outros serviços com esse tipo de demanda. Norquist et al. (81), através de um estudo retrospectivo, onde utilizam a revisão de prontuários médicos como principal fonte de dados, descrevem as diferenças encontradas na avaliação da qualidade da assistência prestada à pacientes idosos deprimidos internados em unidades de psiquiatria ou em emfermarias de medicina geral de hospitais gerais.

Zusman (129) por sua vez, é o responsável por um artigo que objetiva apresentar à profissionais de Saúde Mental os métodos e a terminologia utilizada em avaliações qualitativas. Salgado (97) trata de revisar alguns modelos de avaliação de qualidade visando utilizá-los no campo da saúde mental em um país em desenvolvimento como o México. Morlino et al. (69), analisando o abandono de tratamento por parte dos pacientes em um ambulatório universitário de psiquiatria na Itália, tentam determinar as variáveis que podem estar associadas à esse fato.

Fauman (27) realiza uma extensa revisão sobre avaliação de qualidade em psiquiatria, apresentando desde aspectos históricos até sugestões técnicas sobre a implementação de estudos avaliativos em Saúde Mental.

Finalmente, Evans et al. (25), descrevem o desenvolvimento de um sistema que tem por objetivo o aprimoramento do processo de qualidade em saúde mental à nível estadual. Tais autores salientam que sistemas estaduais que administram 
vários hospitais e centros de saúde dispersos por todo o estado, podem perder a possibilidade de utilizar adequadamente os dados que cada um desses centros produzem em seus próprios programas de controle de qualidade, caso não haja um esforço centrado na integração e unificação dos mesmos. Em resumo, eles advogam que os esforços para a melhoria da qualidade assistencial não devem ficar isolados, mas sim, serem coordenados e integrados para alcançarem o objetivo principal de implementar a qualidade dos serviços.

Com relação à avaliação da satisfação com o tratamento, inúmeros autores tem se dedicado ao estudo desse tema como uma alternativa a mais para a avaliação da qualidade da assistência. Lebow tem publicado extensivamente sobre o tema, ressaltando a possibilidade de utilização da avaliação da satisfação como uma medida simples para avaliação da qualidade de serviços de saúde mental $(56,58)$. Em seus vários artigos $(57,58,59)$, ele sugere diretrizes metodológicas bastante precisas a serem seguidas em estudos de satisfação com o tratamento. Em outra publicação, Lebow (60) faz uma extensa revisão de estudos sobre satisfação e conclui com alguns comentários bastante úteis para quem se interessa pelo tema. Também Tanner (110) nos apresenta uma revisão de literatura que tenta explicar os fatores e variáveis que podem influenciar nos resultados de satisfação de pacientes com serviços de saúde mental. Pickett et al. (87) descrevem os resultados de uma pesquisa que também pretendia identificar os fatores que poderiam ser relevantes na predição de satisfação com a assistência em um programa "administrado" de saúde mental ("managed care").

Hall e Dornan (41) publicam os achados de uma meta-análise da literatura sobre a satisfação com a assistência sanitária, ainda que esse estudo não seja específico para saúde mental. Ibern (50) faz uma revisão de instrumentos e conceitos aplicáveis à medidas de satisfação, mas dá uma ênfase especial à serviços hospitalares. Um dos aspectos mais interessantes de seu artigo é a exposição do conceito de satisfação desde o ponto de vista da área de "marketing". 
Greenley e Schoenherr (36), por sua vez, discorrem sobre os efeitos que aspectos organizacionais podem ter sobre a satisfação de pacientes com a humanidade de serviços. Flynn et al. (30), Tillman (113), e Slater et al. (106) nos oferecem exemplos de escalas de satisfação passiveis de serem utilizadas para avaliação em saúde mental, além de fornecerem importantes subsídios metodológicos aos interessados na utilização dessa técnica.

Kelstrup et al. (51), avaliam a satisfação de pacientes psiquiátricos internados e tentam verificar a correlação entre este aspecto e outras variáveis como diagnóstico e tratamento recebido.

Estudos de satisfação com a assistência prestada em centros de saúde mental comunitários são apresentados por Flynn et al. (30), Lorefice et al. (63), MacDonald et al. (65), e Eppel et al. (26). Estes últimos autores utilizaram o questionário de satisfação como uma medida à mais, além da revisão do prontuário, e de questionários aplicados aos médicos que lhes enviaram os pacientes, para avaliar a qualidade assistencial de um centro de saúde mental comunitário canadense.

Ruggeri e Dall'Agnola (95), descrevem o desenvolvimento e o uso de uma escala elaborada pelos autores, para a aplicação em um serviço de psiquiatria comunitária (Verona/Itália) para medir expectativas e satisfação com os serviços de saúde mental. $O$ interessante desse trabalho é o fato de medirem paralelamente satisfação e expectativas com a assistência em pacientes, familiares e profissionais.

No Brasil, Pitta et al. (87.a), desenvolvem atualmente uma pesquisa de avaliação de qualidade de serviços de saúde mental em quatro municípios. Como no artigo citado anteriormente, também dèsejam estudar a satisfação com o tratamento do ponto de vista não só do paciente, como também dos familiares e trabalhadores de saúde mental.

Através dessa revisão da literatura foram obtidos subsídios sobre o tema a ser desenvolvido neste projeto. A implementação de qualquer projeto de avaliação implica diversas dificuldades que englobam desde a escolha adequada das 
prioridades a serem estudadas $(123,126)$, até a questão de se definir um desenho de pesquisa apropriado às fontes de dados disponíveis.

Sabe-se que grande parte dos dados utilizados em estudos de avaliação provém de anotações em prontuários médicos, e a boa ou má qualidade das informações contidas nesses prontuários já é um problema em si dentro desse tipo de estudos $(29,61,66)$.

Isso se deve ao fato de que por um lado o prontuário médico é um meio através do qual se pode obter dados para avaliar o processo de tratamento, e por outro lado, a quantidade e qualidade das anotações pode ser uma das dimensões que denotam qualidade de atenção. Embora esse seja um tema controverso, Lyons e Payne (66) defendem que prontuários médicos de boa qualidade estão relacionados com boa qualidade no desempenho assistencial. Fessel e Van Brunt (29) por sua vez, discordam desse ponto de vista, uma vez que em seus achados não encontram correlação entre a quantidade e qualidade das anotações médicas e os resultados do tratamento. Observam que ótimos profissionais podem ter anotações inadequadas e de baixa qualidade, enquanto que outros profissionais menos competentes podem escrever profusamente e fornecer muitos dados. Sem dúvida podem estar corretos nesta observação, mas o trabalho desses dois últimos autores é avaliado criticamente por McAuliffe (74), que encontra várias falhas em sua metodologia que faz com que seus resultados e conclusões sejam questionáveis.

Mas, com respeito à adequação das fontes de dados, o trabalho de Lewis (61) questionando as anotações médicas em prontuários podem ser utilizadas em avaliações de qualidade em países em desenvolvimento contribui para esclarecer esse tema, além de ajudar na defesa de uma possível utilização dessa fonte como um meio para medir qualidade em países como o Brasil.

Como salienta Lewis (61) referindo-se aos inúmeros obstáculos ligados à utilização de registros médicos em países latinoamericanos, "nem todos os problemas estão necessariamente presentes em todos os hospitais, e especialmente em aspectos tais como anotações nos prontuários, grandes diferenças podem existir de um serviço 
para outro dentro de um mesmo hospital". Também admite que "alguns desses problemas poderiam ser considerados universais; problemas que afetam todos os hospitais e outros serviços sanitários, em maior ou menor intensidade".

Essas observações são bastante procedentes, e no que diz respeito à este trabalho, através da experiência empírica de observação de registros de vários serviços, pode-se dizer que apesar de todas as possíveis deficiências existentes nas anotações dos prontuários, estes contém informações bastante importantes para o cumprimento dos objetivos a serem propostos. Além do mais, neste projeto o prontuário não foi a única fonte de dados. O paciente, através das entrevistas domiciliares, foi um fator importante e complementar na prestação de informações. Apesar de que qualquer fonte de dados possa ser falível e susceptível à criticas, o uso concomitante e complementar das duas fontes citadas acima, pode minimizar seus respectivos pontos fracos.

Caso não se pense dessa maneira, se poderia chegar à conclusão de que em nossos países não se pode fazer qualquer tipo de pesquisa utilizando prontuários, porque os registros médicos estão muito longe de serem "perfeitos". O importante é levar em consideração esses aspectos, e tentar melhorar e contornar as possíveis deficiências.

Citamos abaixo, em sua versão original, um parágrafo do artigo de Lewis (61) "Can medical records in developing countries be used to measure quality?" pois ele resume nosso ponto de vista:

"Are the problems so formidable, the causes so complex, and priority for quality assurance so low that greater attempts should not be made to use medical records to measure quality? I think not. If studies using existing records were initiated on topics that the medical staff perceived as addressing problems of interest to them, I believe that this would offer an incentive to improve medical record documentation and management, leading to improved evaluations of 
quality of care in the future and, more important, improved patient care".

Neste projeto, tivemos como objetivo, o desenvolvimento de uma avaliação da qualidade de um serviço de saúde mental, através do estudo das interrelações entre o processo de prestação de serviços e os resultados do tratamento. Optamos por esse modelo integrativo de estudo do processo e de resultados, pois acreditamos na validação recíproca desses dois elementos. Assim como medidas de resultados são utilizadas para validar critérios estruturais e de processo, o reverso também é verdadeiro (72).

Donabedian (23.a), em um artigo que praticamente resume seu ponto de vista sobre a questão da avaliação de qualidade, assinala que como regra geral, o mais adequado em qualquer sistema avaliativo seria incluir elementos de estrutura, processo e resultados. Isso permitiria a correção de debilidades em qualquer dos enfoques e facilitaria a interpretação dos achados além de várias outras razões especificadas por ele.

Dentro do contexto das investigações sobre avaliações qualitativas de serviços, durante certo período houve muita polêmica sobre a maior ou menor adequação de uma determinada abordagem metodológica para se medir qualidade. Havia os defensores das medidas de processo, e posteriormente detratores destas, favoráveis às medidas de resultado. Depois de. uma extensa revisão de questões metodológicas, e de discussões conceituais, McAuliffe (72) chega à conclusão de que não se pode considerar que medidas de resultado sejam superiores às de processo. Numa de suas considerações ele afirma: "o objetivo da avaliação de qualidade não é produzir saúde, pelo menos não diretamente; seu objetivo é determinar se a assistência adequada foi prestada. Pode-se presumir que se o cuidado adequado foi prestado, o melhor resultado será atingido sob determinadas circunstâncias". Nesse sentido, num primeiro momento, a maneira mais direta de avaliação seria observar o processo de assistência; a seguir, uma abordagem menos direta seria observar se o paciente apresentou bons resultados "como 
conseqüência do tratamento recebido". O problema é que nem sempre se pode saber claramente se o resultado é primariamente uma conseqüência do processo. Problemas relacionados à qualidade e tipo de coleta de dados atingem tanto à medidas de processo quanto de resultado.

Uma vez que nenhum dos métodos é claramente superior ao outro, esse autor defende que se queremos saber como a qualidade pode ser medida de forma mais prática e válida, passada a fase de discussões conceituais, o que se necessita é maior número de investigações empíricas na área, utilizando metodologia mais aprimorada que possibilite medidas cada vez mais válidas.

Em função disso, através da análise das interrelações entre o processo de prestação de serviços e os resultados do tratamento, utilizando um modelo integrativo de estudo do processo/resultados (pois acreditamos que esses dois elementos se validam mutuamente), pretendemos avaliar a qualidade da assistência de um ambulatório de saúde mental.

Tomando-se por base todas as considerações efetuadas até este ponto, especificamos à continuação as hipóteses e objetivos que direcionarão este trabalho. 


\section{Definição de Hipóteses e Objetivos}

\subsection{Hipóteses}

1. Dentro da avaliação da qualidade da assistência em saúde mental, não apenas o estudo do processo de prestação de serviços, nem apenas a avaliação dos resultados finais do tratamento seriam as melhores formas de avaliação da qualidade. Nesse sentido, o estudo da interrelação entre processo e resultados finais seria a forma mais adequada de avaliação nesse tipo de serviços.

2. Em saúde, e em particular saúde mental, fatores outros que não os diretamente ligados ao processo de prestação de serviços podem interferir nos resultados finais. Contudo, pode-se presumir que numa proporção significativa, um processo de prestação de serviços que atinja padrões determinantes de boa qualidade, deverá estar correlacionado com um bom resultado de tratamento.

\subsection{Objetivos}

1. Analisar a interrelação entre o processo de prestação de serviços e os resultados finais de tratamento para se avaliar a qualidade da atenção num serviço ambulatorial de saúde mental.

2. Determinar o peso que diferentes fatores, tais como, processo de prestação de serviço, características individuais de pacientes (sexo, idade, escolaridade, situação ocupacional), e fatores relacionados à doença, podem ter na determinação de que o resultado final do tratamento possa ser considerado positivo ou negativo.

3. Avaliar o grau de satisfação dos pacientes com o tratamento recebido no serviço estudado. 


\section{Definição de Hipóteses e Objetivos}

\subsection{Hipóteses}

1. Dentro da avaliação da qualidade da assistência em saúde mental, não apenas o estudo do processo de prestação de serviços, nem apenas a avaliação dos resultados finais do tratamento seriam as melhores formas de avaliação da qualidade. Nesse sentido, o estudo da interrelação entre processo e resultados finais seria a forma mais adequada de avaliação nesse tipo de serviços.

2. Em saúde, e em particular saúde mental, fatores outros que não os diretamente ligados ao processo de prestação de serviços podem interferir nos resultados finais. Contudo, pode-se presumir que numa proporção significativa, um processo de prestação de serviços que atinja padrões determinantes de boa qualidade, deverá estar correlacionado com um bom resultado de tratamento.

\subsection{Objetivos}

1. Analisar a interrelação entre o processo de prestação de serviços e os resultados finais de tratamento para se avaliar a qualidade da atenção num serviço ambulatorial de saúde mental.

2. Determinar o peso que diferentes fatores, tais como, processo de prestação de serviço, características individuais de pacientes (sexo, idade, escolaridade, situação ocupacional), e fatores relacionados à doença, podem ter na determinação de que o resultado final do tratamento possa ser considerado positivo ou negativo.

3. Avaliar o grau de satisfação dos pacientes com o tratamento recebido no serviço estudado. 


\section{Sujeitos e Métodos}

Este estudo foi desenvolvido no Ambulatório de Saúde Mental da Faculdade de Medicina de Botucatu - UNESP, cujas características serão abaixo descritas.

\subsection{Descrição do Serviço}

O Ambulatório de Saúde Mental da Faculdade de Medicina de Botucatu - UNESP existe há aproximadamente 23 anos, sendo que suas atividades foram consolidadas a partir de 1975 quando, com a assinatura do Convênio de Saúde Mental entre a Secretaria de Estado da Saúde e a UNESP, um número maior de profissionais pôde ser contratado para a prestação de serviços em Saúde Mental. O Hospital das Clínicas da Faculdade de Medicina de Botucatu não tem uma área delimitada de captação populacional, sendo que em realidade é a referência terciária para uma região bastante extensa do Centro-Sul e Centro-Oeste de São Paulo. No ambulatório de Saúde Mental da UNESP são atendidos pacientes não só do município de Botucatu e região, mas também de outros locais mais distantes, inclusive do Norte do Paraná. Apesar de ser um ambulatório de retaguarda, nele são prestados serviços de nível secundário, e também de nível primário de atenção. A composição da equipe multidisciplinar desse ambulatório na época deste estudo era a seguinte:

- Profissionais docentes: 3 médicos psiquiatras e 4 psicólogos em regime de trabalho integral e dedicação exclusiva (40 horas semanais).

- Profissionais não-docentes: 2 médicos psiquiatras, 2 psicólogas, 1 enfermeira, 3 assistentes sociais, 2 terapeutas ocupacionais e 1 orientadora educacional (todos 40 horas semanais).

- Pessoal auxiliar: 2 atendentes de enfermagem e 1 auxiliar de enfermagem (40 horas semanais) 
- Residentes de Psiquiatria ${ }^{2}$ e Estagiários: 2 médicos residentes de $1^{\circ}$ ano, 3 médicos residentes de $2^{\circ}$ ano, 3 estagiários de Psicologia e 1 estagiário de Serviço Social.

São desenvolvidas nesse ambulatório atividades de ensino, assistência e pesquisa. No aspecto assistencial são desenvolvidas atividades de triagem e emergência, além de atendimentos de rotina de psiquiatria, psicologia, serviço social, terapia ocupacional, enfermagem e orientação educacional. Além dos atendimentos clínicos individuais, também são desenvolvidas atividades psicoterápicas individuais e grupais, sendo estas últimas as formas mais freqüentes. Para especificação mais detalhada de todas as atividades desenvolvidas com as respectivas cargas horárias vide Anexo 1.

Além dessas atividades de assistência, o ambulatório desenvolve um grande número de atividades de ensino tanto a nível de graduação em Medicina como a nível de residência em Psiquiatria e estágio.

Alunos do $5^{\circ}$ ano médico no internato de Psiquiatria, residentes de $1^{\circ}$ e $2^{\circ}$ anos (eventualmente $3^{\circ}$ ano) bem como estagiários de Psicologia e Serviço Social tem a maior parte de suas atividades centradas nesse Serviço.

O horário, local e maneira de como são realizadas as atividades ambulatoriais são as seguintes: os horários de atendimento são das 8:00 as 12:00 hrs e das 14:00 as 18:00 hrs. A triagem de Psiquiatria e o posto de enfermagem estão abertos ao público no período da tarde desde as $12: 30 \mathrm{hrs}$. No horário noturno e aos fins de semana existe atendimento psiquiátrico de emergência (plantões) na triagem geral do Hospital das Clínicas.

O local de atendimento é o Bloco I dos ambulatórios da Faculdade de Medicina, localizada no Campus de Rubião Júnior. Distante $8 \mathrm{kms}$ do centro da cidade de

2 de modo geral, os residentes ficam em torno a quatro meses em cada estágio, rodiziando entre ambulatório, hospital dia, hospital psiquiátrico, triagem e emergência, interconsulta, centro de saúde, além das atividades teóricas que desenvolvem. Quando estão no ambulatório, excluindo-se atividades teóricas, e reuniões clínicas e administrativas, estão presentes no ambulatório ao redor de 28 horas semanais (incluindo-se supervisão de casos) 
Botucatu, tem vários horários regulares de ônibus facilitando o acesso ao serviço. $\mathrm{O}$ ambulatório conta com 12 salas adequadamente mobiliadas para os diversos tipos de atendimento. Além disso existem as instalações do Hospital-Dia que eventualmente são utilizadas para alguns dos grupos.

Não existe um critério de definição da população a ser atendida. Com relação à admissão no serviço, qualquer individuo de qualquer procedência pode ser atendido. A porta de entrada, via de regra, é a triagem geral do Hospital das Clínicas (também pode vir derivado de outras clínicas do H.C.). Depois do paciente ser avaliado pelo médico geral da triagem, e ser ou não atendido como emergência psiquiátrica, o paciente é encaminhado ao Bloco I. Lá chegando, os pacientes passam por uma triagem psiquiátrica/psicológica feita por auxiliar de enfermagem especialmente treinada para isso (e com pelo menos 18 anos de experiência nessa função), que decide para qual programa o paciente dever ser encaminhado para uma consulta tipo "caso novo". De modo geral, todos os pacientes passam por uma consulta tipo "caso novo" independentemente de ser atendido pela Psiquiatria, Psicologia, Serviço Social ou outra especialidade. A única exceção é para alcoolistas que são encaminhados diretamente para o grupo de alcoolistas. Uma vez no grupo, além de serem atendidos pela assistente social, sempre são entrevistados pelo médico psiquiatra que os avalia e se encarrega do seguimento clínico desses pacientes. Após o "caso novo" é que se decide se o indivíduo deve receber apenas tratamento medicamentoso, psicoterápico individual, grupal, ou outro tipo qualquer de intervenção. O mais freqüente é que ele receba indicação de algum tipo de abordagem psicoterápica além de tratamento com psicofármacos.

Os "casos novos" da Psiquiatria podem ser feitos por profissionais da equipe fixa, ou por residentes ou internos sob supervisão de docentes, que revisam todos os casos atendidos, encarregando se de aclarar aspectos da anamnese psiquiátrica, do exame psíquico, e finalmente efetuar os diagnósticos e prescrições. No que se refere à freqüência das consultas, esta pode ser bastante variável. Os atendimentos 
psicoterápicos são, em geral, semanais ou quinzenais. Já os retornos medicamentosos variam de caso para caso. Casos agudos podem ser vistos no início, com intervalo de 1 semana (ou menos) a 15 dias. Em média a freqüência é de 1 e meio a 2 meses, mas do $2^{\circ}$ semestre do ano em diante, esse espaço aumenta para quase 3 meses por não haver mais vagas para suprir toda a demanda.

Pode-se observar como aqui vai se caraterizando que o serviço está conformado muito mais em função de sua estrutura (ou falta dela) do que por critérios de qualidade. $\mathrm{O}$ número total de atendimentos ambulatoriais do $1^{\circ}$ semestre de 1989 foi de 2.997 casos. Vale lembrar que vários membros da equipe também atendem fora do ambulatório e na comunidade (Hospital dia e Centro de Saúde-Escola), e os residentes tem estágios em outros serviços, e isto não está incluído no número acima.

Com relação ao prontuário e ao registro médico, não existe um prontuário específico da Saúde Mental. O paciente tem um número único de registro do Hospital das Clínicas e seu prontuário tem registros de todas as clínicas do Hospital das Clinicas por onde o paciente já passou. Existem, sim, formulários específicos para "casos novos" de Psiquiatria, Psicologia e Serviço Social. As cores das folhas dos prontuários são também diferentes de clínica para clínica. Além dos prontuários, a Saúde Mental conta também com um arquivo próprio com ficha com os dados de identificação e procedência de todos os pacientes que já passaram pelo serviço.

Quanto às anotações médicas, pode-se dizer que os "casos novos" contém grande quantidade de dados, em geral de qualidade confiável. Já os retornos tem anotações mais sumárias, mas pelo menos contém dados breves de evolução, exame psíquico, hipótese diagnóstica e conduta.

Existem problemas com os registros de atendimentos psicoterápicos: na maior parte desses casos, no prontuário é anotado apenas que o paciente encontra-se em psicoterapia, algum dado sobre sua evolução e pouco mais. Muitos terapeutas tem arquivos paralelos com seus registros sobre psicoterapias, uma vez que a questão 
da confidencialidade é um problema sério num ambulatório onde tantos funcionários, médicos e estudantes tem acesso aos arquivos.

Com relação ao trabalho desenvolvido, creio ser importante ressaltar alguns pontos nesta descrição: dado que fizemos a seleção da amostra a partir dos "casos novos" de Psiquiatria, cumpre ressaltar que a maioria das histórias clínicas (na primeira visita) terá sido feita por pessoal em treinamento (residentes e internos) sob supervisão de docentes, por encontrar-se nosso ambulatório dentro de um serviço ligado à Universidade. Como já foi mencionado anteriormente, os docentes encarregam-se durante a supervisão, e na presença do paciente, de esclarecer dúvidas referentes à história clínica e exame psíquico, faz os diagnóstico e as prescrições. Após ter se submetido ao "caso novo" da Psiquiatria, o paciente poderá ter seguido caminhos bastante diversos dentro do serviço, em função da variabilidade de programas/profissionais para os quais ele tenha sido encaminhado. Isso propiciou que no desenrolar do estudo, profissionais da equipe fixa e não só indivíduos em treinamento, tenham sido avaliados no processo de atendimento aos usuários desse ambulatório. Esse é um aspecto que é necessário que fique bem claro: esta avaliação não se restringe apenas à primeira visita, e como avalia o processo de tratamento como um todo, também avalia o desempenho dos diversos profissionais da equipe fixa.

\subsection{Procedimentos Metodológicos}

Para que cumpríssemos com os objetivos propostos na seção anterior, este estudo foi desenvolvido em pelo menos dois tempos (vide a Figura I, onde estão esquematizados os procedimentos descritos abaixo): Num primeiro momento, fizemos o levantamento de dados sobre o tratamento oferecido/recebido à um determinado grupo de pacientes, no intuito de obtermos informações sobre o processo de prestação dos serviços oferecidos e sobre os resultados do tratamento. Utilizamos para isso as informações contidas nos prontuários médicos e obtidas de questionários aplicados à pacientes em entrevistas domiciliares. As informações 


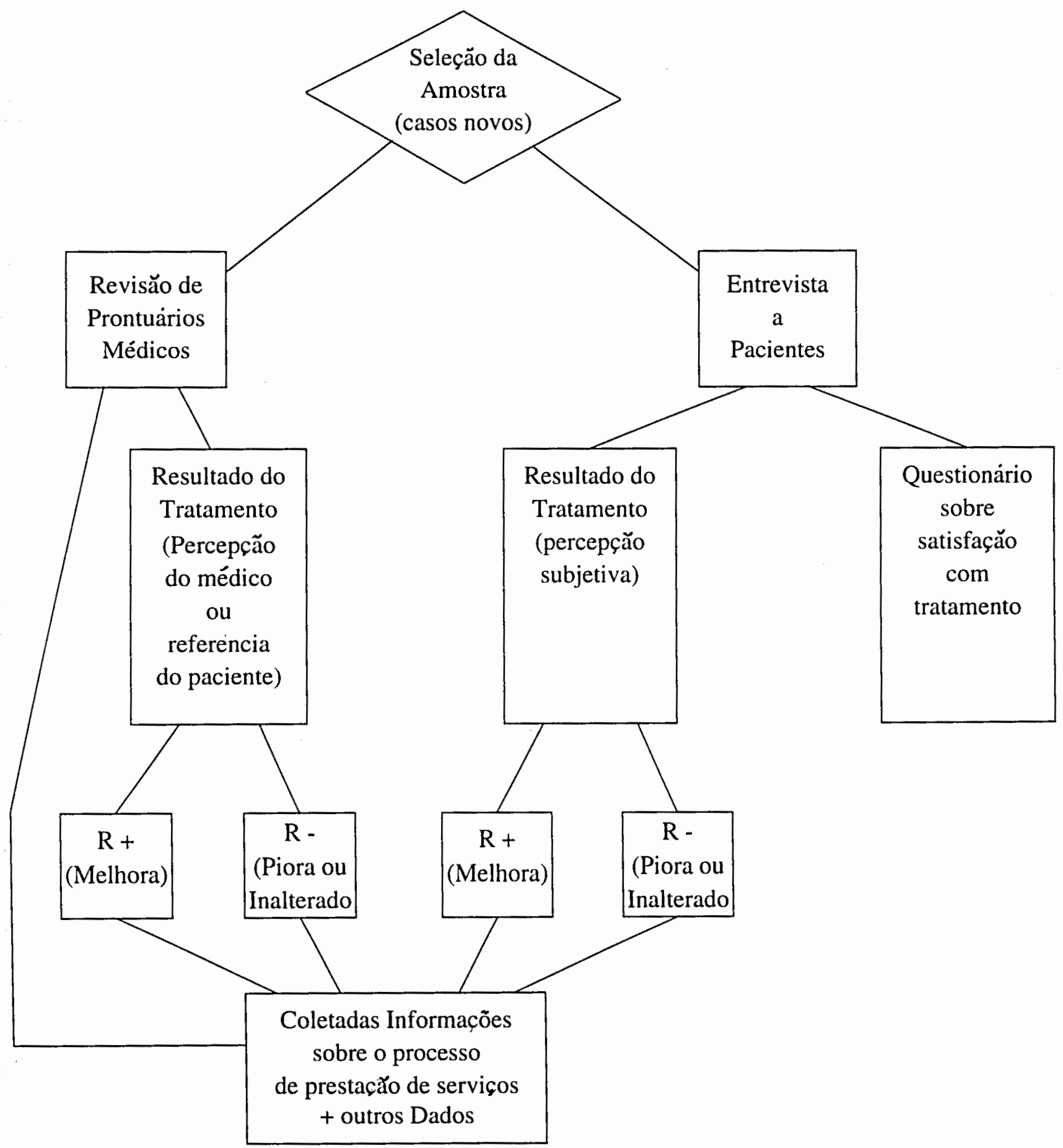


sobre os resultados do tratamento permitiram que fossem diferenciados dois grupos de pacientes, os quais foram comparados entre si no tocante à diferenças ou similaridades de procedimentos recebidos durante o processo de prestação de serviços. Um grupo foi o que apresentou resultados positivos (melhora dos sintomas com o tratamento) e outro, o de resultados negativos (estado inalterado ou piora dos sintomas ao término do tratamento). Como os resultados foram obtidos dos prontuários e da entrevista aos pacientes, esperávamos contar com a percepção de melhora ou piora com o tratamento tanto por parte do médico como do paciente. Com respeito a essa expectativa tivemos que nos defrontar com um problema surgido na análise dos dados: numa porcentagem razoável, principalmente naqueles casos que vieram apenas na primeira consulta, deixamos de obter a percepção do médico. Assim sendo, consideramos a percepção do paciente de melhora ou piora dos sintomas, para classificarmos a estes em grupos de resultados positivos (GR+), ou negativos (GR-). Num segundo momento, com os dados coletados, iniciamos a análise estatística dos dados, realizando de início um estudo descritivo das características dos pacientes e do serviço, através da distribuição de freqüências, e associações entre variáveis.

Já para o cumprimento do objetivo de se estimar o peso que diferentes fatores (tais como a qualidade dos serviços oferecidos, características próprias dos indivíduos ou da doença) podem ter na determinação de um resultado positivo ou negativo; utilizamos métodos estatísticos de análise multivariada $(96,52,35)$.

A seguir, serão descritos com detalhes os critérios utilizados para a seleção dos sujeitos estudados; quais foram as fontes de dados, os métodos para a coleta de informações, etc.. Na Figura I estão esquematizados os procedimentos que foram desenvolvidos com informações sumárias do que será descrito subseqüentemente nas próximas seções. 


\subsection{Sujeitos}

Foram sujeitos deste estudo os pacientes atendidos no Ambulatório de Saúde Mental da Faculdade de Medicina de Botucatu como "casos novos" ( $1^{\text {a }}$ consulta) de Psiquiatria durante o período de janeiro de 1989 a dezembro de 1990, e que fossem portadores dos diagnósticos abaixo especificados nos seguintes critérios para inclusão no estudo:

1. Ser "caso novo" ( $1^{\mathrm{a}}$ consulta) de psiquiatria.

2. Ter sido atendido no período de janeiro de 1989 a dezembro de 1990.

3. Ser procedente dos municípios de Botucatu e São Manoel.

4. Ser portador dos seguintes diagnósticos da "Classificação Internacional de Doenças" - 9a Revisão - 1975 - "C.I.D. - 9" (incluindo o Código V): "Transtornos Neuróticos" - C.I.D. 300.0 - 300.9 (exceto 300.3³). Inclui: 300.0 -Estados de ansiedade 300.1 - Histeria 300.2 - Estado fóbico 300.4 - Depressão neurótica 300.5 - Neurastenia 300.6 - Síndrome de despersonalização

300.7 - Hipocondria

300.8 - Outros transtornos neuróticos 300.9 - Não especificados

"Reação de Ajustamento" - C.I.D. 309.0 - 309.9 inclui:

309.0 -Reação depressiva breve

309.1 - Reação depressiva prolongada

309.2 - Com distúrbios predominantes de outras emoç̃os

309.3 - Com distúrbios predominantes de conduta

309.4 - Com distúrbios mistos das emoções e da conduta

${ }^{3}$ Transtornos obsessivo-compulsivos 
309.8 - Outra

309.9 - Não especificada

Código V - "Classificação suplementar de fatores que exercem influência sobre o estado de saúde e de oportunidades de contato com serviços de saúde". Inclui:

V.61 - Circunstâncias familiares

V.61.0 - Dissolução familiar

V.61.1 - Problemas conjugais

V.61.2 - Problemas entre pais e filhos

V.61.3 - Problemas com pais ou sogros idosos

V.61.4 -Problemas de saúde na família

V.61.5 -Multiparidade

V.61.6 - Ilegitimidade ou gravidez ilegítima

V.61.7 - Outras formas de gravidez não desejada

V.61.8 - Outras

V.61.9 - Não especificadas.

V.62 - Outras circunstâncias psicossociais:

V.62.0 - Desemprego

V.62.1 - Efeitos adversos do ambiente de trabalho

V.62.2 -Outras circunstâncias ou desajustes ocupacionais

V.62.3 - Circunstâncias educacionais

V.62.4 - Desajustamento social

V.62.5 - Circunstâncias legais

V.62.6 -Recusa de tratamento por razões religiosas ou de consciência V.62.8 - Outras tensões psicológicas ou físicas não classificadas em outra parte

V.62.9 - Não especificadas.

V.11 - Antecedentes de história pessoal de transtorno mental 
A definição segundo o CID-9 dos diagnósticos incluídos no estudo podem ser encontrados no Anexo II. A razão para a escolha desses diagnósticos deveu-se basicamente à sua alta freqüência nos serviços de saúde mental; ao fato de que são condições habitualmente tratadas com os métodos terapêuticos empregados em saúde mental e também por questões metodológicas tais como tentativa de se trabalhar com grupos diagnósticos com alguma similaridade entre si e não díspares como poderia ocorrer caso fossem escolhidos outros diagnósticos dentro da grande diversidade dos transtornos mentais.

Esse último aspecto, a questão metodológica, merece ser explicada um pouco mais detalhadamente: caso se pretenda estudar a interrelação de processo de tratamento com os resultados finais decorrentes do tratamento, é importante que os diagnósticos escolhidos tenham alguma similaridade entre si tanto com respeito ao possível tratamento a ser oferecido, como com respeito ao curso e prognóstico do transtorno. É obvio que teríamos muitos problemas na hora da avaliação dos resultados, com certeza problemas com respeito às conclusões a partir dos dados coletados, caso avaliássemos grupos diagnósticos muito distintos. Por exemplo: existe muito mais probabilidade que o tipo de tratamento, a evolução e o prognóstico de um paciente esquizofrênico seja diferente do tratamento e prognóstico para um paciente com transtorno de ansiedade, ou um alcoolista, do que se estudarmos pacientes com diagnósticos mais parecidos como poderia ser um quadro depressivo reativo ou um transtorno de ansiedade, onde o tipo de tratamento e o possível prognóstico podem ser mais similares. Para evitar esse tipo de problema metodológico, decidimos trabalhar com grupos diagnósticos com alguma similaridade entre eles. Pacientes com transtornos obsessivos-compulsivos foram excluídos pelo fato de que nesse mesmo periodo outra pesquisa incluindo esse tipo de diagnóstico estava começando a ser conduzida.

Fauman (27), dentro de uma revisão que faz sobre avaliação de Serviços de Saúde Mental, chama a atenção para o fato de que na hora da escolha de uma 
determinada área a ser avaliada devem ser levadas em consideração, como prioridades, áreas que representam dentro de um serviço, grande volume de atendimentos, alto risco ou áreas problemáticas na prática clínica. Mattson (70) complementa esse ponto de vista, observando que também devem ser levadas em consideração as áreas que apresentam maior potencial de mudança em termos de melhora das condições de saúde; seriedade do problema, número de pacientes envolvidos e possibilidades de contenção de custo. Donabedian (23.a), quando discorre sobre os métodos para escolher o tipo de casos que possam proporcionar uma visão ilustrativa da qualidade de um serviço, cita o princípio de Williamson do "máximo beneficio atingivel". Quer dizer com isso, que se pode selecionar certas categorias diagnósticas por serem estas bastante frequentes, por poder ocorrer deficiências na atenção desse tipo de problemas, e por serem estas deficiências passíveis de correção.

Em nosso caso, a escolha deveu-se principalmente à alta freqüência (129) em nosso serviço, dos diagnósticos de neuroses e reações (115) e ao fato de que são condições com grande probabilidade de que uma vez tratadas, podem representar melhora significativa no estado de saúde da população em estudo. Williamson $(123,126)$ enfatiza esse aspecto quando da formulação de prioridades para avaliação. Neste trabalho também, por questões metodológicas (principalmente para a análise estatística multivariada), era necessário contar com um número suficientemente grande de casos, coisa possível com as categorias diagnósticas escolhidas, e que não seria viável em caso de se haver optado por um diagnóstico menos frequente.

Através das fichas de agendamento pudemos realizar um levantamento dos "casos novos" atendidos entre Janeiro de 1989 e Dezembro de 1990 (1155 pacientes), e a partir dai selecionarmos aqueles que preenchiam os requisitos para inclusão no estudo. Foram escolhidos os anos de 1989 e 1990 por se tratar de um período relativamente recente com respeito ao momento da realização das entrevistas 
domiciliares (Setembro e Outubro de 1991), numa tentativa de se minorar, no momento da aplicação dos questionários, "erros" de lembrança ("recall bias"). Além disso, tivemos nesses dois anos um período de tempo suficiente para podermos verificar o "caminho natural" do paciente dentro do serviço, podendo observar início e término de certos tratamentos, diferentes encaminhamentos feitos, altas a pedido, altas médicas, abandono de tratamento etc...

Com respeito aos "erros" de lembrança ("recall bias"), esse tipo de problema é inerente a qualquer pesquisa que tenha que utilizar a memória do paciente para recordar fatos ou situações passadas, com o objetivo de obter determinadas informações. Nesse sentido, quanto mais próximo do evento, ou procedimento que se pretenda avaliar, se aplica o questionário, maior a chance de se obter respostas mais precisas, diminuindo portanto as possibilidades de erros de lembrança. Assim, é importante que ao aplicar os instrumentos de avaliação o entrevistador especifique muito bem o assunto em questão, e utilize uma linguagem clara que facilite ao paciente a compreensão do que se pretende investigar. No caso deste estudo, como problemas de saúde mental são problemas que em geral são bastante significativos na vida do paciente, isso pode ser um fato que favoreça que o paciente se recorde bem de certos eventos relativos ao seu tratamento, principalmente a pergunta principal: se "melhorou ou não com o tratamento".

\subsection{Fontes de Dados}

Para fins deste estudo, os dados sobre o tratamento dos pacientes foram coletados das fichas de agendamento de consultas; dos prontuários médicos e de questionários aplicados aos pacientes em entrevistas domiciliares.

As fichas de agendamento possibilitaram que se fizesse a seleção de todos os "casos novos" de Psiquiatria atendidos nos anos de 1989 e 1990, e a partir da localização dos respectivos prontuários, complementar a seleção da amostra escolhendo os casos procedentes de Botucatu e São Manoel, e portadores dos diagnósticos propostos. Foram identificados como "casos novos" (primeiras 
consultas) nesses anos, 1155 pacientes. Como os dados de registro e identificação dos pacientes ainda não estavam informatizados, foi necessário revisar manualmente o prontuário individual de cada paciente, para que se pudesse escolher aqueles que preenchiam os critérios diagnósticos e de procedência para inclusão no trabalho. Após essa primeira revisão, do total de 1155 pacientes atendidos, preencheram os critérios para inclusão nesta pesquisa 297 pacientes. Destes, excluídas algumas perdas, definitivamente foram selecionados 289 pacientes. Por meio de uma nova revisão dos prontuários foram obtidos dados sobre o processo de prestação de serviços e sobre resultados do tratamento. Quanto aos questionários aplicados aos pacientes em entrevista domiciliar, estes forneceram dados demográficos atualizados, dados sobre satisfação com o tratamento e percepção subjetiva de melhora ou piora de sintomas com o tratamento. Maiores especificações serão feitas mais adiante quando serão descritos os procedimentos realizados durante a coleta de dados.

No Quadro I estão apresentadas de forma sumária as fontes de dados utilizadas e as informações obtidas através delas.

\subsection{Método para a Coleta de Dados.}

Como já foi citado anteriormente, os dados foram coletados através das fichas de agendamento; dos prontuários médicos e dos questionários aplicados aos pacientes. Estes últimos foram aplicados nos domicílios dos pacientes por auxiliares de pesquisa devidamente treinados. Estes auxiliares, além de treinados especificamente para a aplicação dos questionários deste estudo, já tinham bastante experiência prévia nesse tipo de atividade, tendo participado em inúmeros outros estudos sócio-epidemiológicos desenvolvidos pela Faculdade de Medicina.

\subsubsection{Revisão de Prontuários}

Para a revisão dos prontuários foi elaborado um formulário específico (Formulário I) para anotação dos dados sócio-demográficos e do processo de prestação de serviços (anexo IV). 
Quadro I: Fonte de Dados

\begin{tabular}{|c|c|c|}
\hline $\begin{array}{c}\text { FICHAS DE } \\
\text { AGENDAMENTO }\end{array}$ & $\begin{array}{l}\text { PRONTUÁRIOS } \\
\text { MÉDICOS }\end{array}$ & $\begin{array}{c}\text { QUESTIONÁRIOS } \\
\text { APLICADOS } \\
\text { A PACIENTES }\end{array}$ \\
\hline \multicolumn{3}{|c|}{ ProcedIMENTOS } \\
\hline $\begin{array}{l}\text { Início da seleção } \\
\text { da amostra }\left({ }^{*}\right)\end{array}$ & $\begin{array}{l}\text { Revisão de } \\
\text { prontuários médicos } \\
\text { para: } \\
\text { - Completar seleção } \\
\text { da amostra } \\
\text { - Determinação de } \\
\text { resultados + ou - }\left({ }^{* *}\right) \\
\text { - Coleta de informa- } \\
\text { ções sobre o } \\
\text { processo de prestação } \\
\text { de serviços }\end{array}$ & $\begin{array}{l}\text { - Avaliação da percepção } \\
\text { subjetiva de melhora ou piora } \\
\text { com o tratamento } \\
\text { - Avaliação da satisfação } \\
\text { com o tratamento } \\
\text { - Coleta de dados } \\
\text { sócio-demográficos }\end{array}$ \\
\hline
\end{tabular}

$\left({ }^{*}\right)$ "Casos novos" procedentes de Botucatu e São Manuel com diagnósticos CID-9, CID300, 309 e alguns diagnósticos do Código V relacionados à Saúde Mental.

Exceção: 300.3 transtornos obsessivos compulsivos.

(**) Resultado positivo: Melhora com o tratamento (percepção do médico e/ou do paciente). Resultado negativo: Piora com o tratamento ou estado inalterado. 
Através do prontuário médico pode-se obter informações sobre identificação do paciente; sobre a anamnese psiquiátrica inicial; sobre a evolução do caso e diferentes procedimentos aos quais o paciente foi submetido, além de informações sobre a passagem do paciente por outras clínicas que não o Ambulatório de Saúde Mental.

Na descrição do serviço estudado já foi descrito de forma sucinta o conteúdo e forma dos prontuários.

Com relação ao formulário do caso novo, cito a seguir seus principais itens, ainda que um exemplar dele possa ser observado em sua totalidade no Anexo III.

Os principais itens do formulário do caso novo são: Dados de identificação e sócio-demográficos, Queixa e duração, História da moléstia atual, Antecedentes familiares e pessoais, Antecedentes mórbidos, Antecedentes psíquicos, Uso e abuso de substâncias, Comportamento antisocial, Condições de vida atuais, Exame fisico, Exame psíquico, Exames subsidiários, Súmula, Hipótese Diagnóstica, Conduta, Identificação de quem atendeu, e qual foi o docente responsável, além de um espaço para observações.

Este formulário com itens de uma anamnese psiquiátrica completa é padronizado e seu preenchimento é rotina em toda primeira consulta feita por um paciente no ambulatório de Psiquiatria. $O$ fato de ser padronizado nos permite a comparabilidade da qualidade das anamneses efetuadas pelos diferentes profissionais.

Cito abaixo alguns dados que puderam ser extraídos do formulário do "caso novo":

1. Preenchimento da anamnese psiquiátrica na primeira consulta Preenchimento completo ou incompleto da anamnese- Anotação do exame psíquico (completo ou incompleto)- Anotação de dados do exame físicoPresença de um diagnóstico psiquiátrico na primeira consulta.

2. Pedido de exames complementares ou interconsultas quando da presença de diagnósticos diferenciais ou diagnósticos secundários não psiquiátricos. 
3. Anotação do tratamento prescrito (ex.: farmacológico, psicoterápico ou combinação de ambos)- Caso o tratamento fosse medicamentoso; que tipo de fármacos? que dosagem? quantas vezes ao dia? Tipos de encaminhamentos.

4. Dados indiretos sobre a relação médico-paciente.

5. Dados sobre a evolução:

- Tipo e freqüência de retornos

- Tempo de duração do tratamento

- Continuidade de tratamento com o mesmo profissional

- Tipo de profissionais envolvidos no tratamento

- Qualidade das anotações

- Percepção do médico de melhora ou piora dos sintomas com o tratamento, etc...

Os itens que foram incluídos no formulário para revisão foram definidos pela pesquisadora com o auxílio de outros profissionais da área e testados previamente na revisão de um grupo de 10 prontuários com as mesmas características para inclusão na amostra, mas de procedência diferente; portanto não pertencentes à amostra estudada.

Essa fase do trabalho foi a mais dificil já que implicava em uma revisão minuciosa de prontuários "caóticos" em sua organização. Além de serem liberados pelo arquivo médico parcelada e lentamente, ainda nos encontramos com prontuários que continham informações e registros de todas as clínicas da Faculdade, e que nem sempre estavam ordenados de uma forma racional. Apesar disso, o mais importante, que era encontrar os dados do tratamento devidamente registrados, isso foi obtido.

\subsubsection{Entrevistas Domiciliares}

O questionário que foi utilizado nas entrevistas domiciliares (Formulário II/Anexo V) continha três seções: uma sobre questões sócio-demográficas (dados atualizados), outra para a avaliação da percepção subjetiva de melhora ou piora 
com o tratamento, além de perguntas sobre a razão para a interrupção do tratamento (quando procedente) e utilização de outros serviços, e outra contendo o questionário específico para a avaliação da satisfação com o tratamento. As entrevistas domiciliares foram realizadas em setembro e outubro de 1991.

Uma vez que diversos modelos de questionários sobre satisfação com tratamento de transtornos mentais utilizados e testados em outros países $(30,59,58,57,106)$ não tinham sido validados e aplicados no Brasil, decidimos pela elaboração de um instrumento específico para este estudo, baseando-nos na literatura acima citada e noutros questionários sobre satisfação desenvolvidos e utilizados em nosso país (109).

Obviamente teríamos preferido contar com um instrumento já bem validado e utilizado em diversos serviços, pois como ressalta Lebow $(57,59)$ isso permitiria maior comparabilidade entre diferentes estudos e maior confiabilidade, além de requerer menos esforços. Foram incluídos no questionário sobre satisfação questões que abordavam as seguintes dimensões:

- Satisfação geral

- Acessibilidade (incluindo localização, facilidade para agendamento, adequação de horários, etc.)

- Tempo de espera para atendimento

- Ambiente fisico (incluindo higiene, conforto, limpeza)

- Preenchimento de expectativas prévias

- Cordialidade do pessoal burocrático

- Competência (percepção subjetiva) do médico e/ou outro profissional

- Disponibilidade do médico e/ou outro profissional de ouvir

- Quantidade de esclarecimentos fornecidos pelo médico (sobre o problema, tratamento, etc.)

- Continuidade do tratamento

Dentre os diferentes conteúdos de questionários citados na literatura (41), a maioria das áreas referidas foi abordada no questionário elaborado, com exceção 
de aspectos financeiros e de custos, por não ser especialmente relevante para o presente estudo. Lebow (59) fazendo considerações sobre aspectos metodológicos da avaliação de satisfação na área de saúde mental sugere várias diretrizes bastante úteis para quem pretende utilizar satisfação do paciente na avaliação global da qualidade de tratamento. Em suas diretrizes ele fornece esclarecimentos bastante detalhados sobre instrumentos já padronizados; sobre a construção de novas escalas quando instrumentos já padronizados não são passíveis de utilização e sobre o desenho e modo de aplicação do questionário.

No presente instrumento utilizamos perguntas fechadas, com alternativas de resposta escalar com número ímpar (cinco itens) mas deixando espaço para comentários que o entrevistado desejasse fazer.

Antes da confecção do questionário, um levantamento preliminar foi feito com uma pequena amostra $(n=9)$ representativa de pacientes que foi ouvida, para que pudéssemos conhecer melhor as críticas mais comuns e alguns aspectos de interesse mais locais, que facilitariam a escolha dos itens que constariam da versão definitiva do questionário. Pretendeu-se, como sugere Frota (33) que fossem formuladas perguntas bem claras e diretas, numa linguagem simples, acessível a todos os entrevistados.

Antes da aplicação do questionário em sua forma definitiva, este foi testado em um grupo de pacientes $(n=12)$ do mesmo serviço, mas que não pertenciam ao grupo estudado.

Também previamente à aplicação dos questionários nos domicilios, foi necessário um período de treinamento dos auxiliares de pesquisa. Estes, apesar de serem bastante experiente, por já haverem participado em inúmeros outros estudos epidemiológicos, tiveram que receber treinamento específico pelas particularidades do instrumento, e por estarem entrevistando "pacientes psiquiátricos". Apesar de estarmos trabalhando apenas com diagnósticos tais como "neuroses e reações", ainda assim o rótulo "psiquiátrico" pode criar certas dificuldades para um entrevistador que não esteja acostumado a interagir com pacientes com problemas 
psicológicos/psiquiátricos. Isso fez com que fosse necessário um treinamento mais específico sobre esse aspecto.

No momento da aplicação do questionário certos cuidados foram seguidos:

1. os entrevistadores eram externos ao serviço;

2. foi explicado cuidadosamente ao entrevistado, a razão de se estar conduzindo tal inquérito e,

3. foi garantida confidencialidade.

A solicitação de um consentimento prévio à aplicação do instrumento não foi feita, mas isso ocorreu apenas após recebermos um parecer favorável a esse respeito por parte da Comissão de Ética da Faculdade de Medicina. Acreditamos que nesse tipo de entrevista a solicitação de consentimento prévio é provavelmente mais "perturbadora" (e geradora de desconfiança?) que o próprio procedimento de coleta de dados (59). Além do mais; sendo entrevistado em seu domicílio o indivíduo sempre teria maior liberdade para se recusar a responder certas questões, do que quando entrevistado no próprio local de tratamento.

Finalmente, deve-se lembrar que o questionário utilizado nas entrevistas domiciliares (Formulário II) continha além da seção sobre satisfação com o tratamento, duas outras seções sobre dados sócio-demográficos e sobre percepção subjetiva de melhora ou piora com o tratamento. Para que as questões sobre satisfação não interferissem com a percepção do paciente sobre o resultado do tratamento, foi importante que na ordem de apresentação, o questionário sobre satisfação tenha sido aplicado posteriormente à pergunta sobre percepção de melhora ou piora sobre o tratamento.

Apesar das dificuldades inerentes à aplicação de entrevistas domiciliares, de modo geral, as atividades se desenvolveram à contento. $\mathrm{O}$ mais dificil foi a localização dos endereços, pois a maioria dos pacientes sendo provenientes de famílias de baixa renda, viviam em bairros periféricos onde a locomoção e a localização de residências, é mais dificil que nas regiões centrais das cidades. 
Do total de 289 pacientes elegíveis para o estudo, 74 entrevistas domiciliares não puderam ser realizadas. Com exceção de um óbito e de uma pessoa que por questões médicas não estava em condições de responder, a causa mais comum da não execução das entrevistas foi a não localização de pacientes por mudança de domicílio, muitas vezes para outros municípios. Não houve recusas quanto à participação neste estudo. Quatro dos prontuários que previamente haviam sido selecionados quando da definição da amostra (e cujos pacientes responderam à entrevista domiciliar), não foram localizados no momento da revisão definitiva dos prontuários. Assim sendo, contamos com 211 pacientes dos quais obtivemos informação tanto dos prontuários, como das entrevistas domiciliares.

Ao término desses procedimentos de coleta de informações foi elaborado um manual de codificação bastante detalhado, e realizada a codificação dos dados obtidos para a subsequente análise estatística.

\subsection{Análise Estatística dos Dados}

Poderíamos dividir a análise estatística realizada em duas fases: 1) onde obtivemos informações através da distribuição de freqüências e associações entre variáveis, e 2), onde foram utilizados métodos de análise multivariada.

Para a distribuição de freqüências, e associações entre variáveis, utilizamos o programa estatístico SAS (130), e para a análise estatística multivariada utilizamos o programa TSP (Time Series Package ) Versão 4.2.

De início trabalhamos com dados do total de pacientes elegiveis para o estudo $(n=289)$, e dos 211 casos dos quais obtivemos informações dos prontuários e dos pacientes. Ao compararmos os dados desses dois grupos, estes eram tão similares que terminamos por apresentar os resultados em tabelas onde podiam ser comparados paralelamente. Fizemos uma descrição das características gerais e do processo de tratamento que lhes foi oferecido, para o grupo de 211 pacientes, apontando, quando existentes, algumas diferenças deste com o grupo $(n=289)$. Já para a análise multivariada e para os cruzamentos através dos quais pudemos 
verificar as associações entre variáveis, somente utilizamos aqueles 211 casos dos quais contínhamos informações obtidas tanto através da revisão dos prontuários como das entrevistas domiciliares. Nos cruzamentos, utilizamos o teste do $\chi^{2}$ para verificação da significância estatística (105).

A Análise Estatística Multivariada (AEM) oferece um conjunto de métodos apropriados para responder à perguntas num contexto complexo. Em geral, a AEM estuda as relações entre conjuntos de variáveis dependentes e os indivíduos para os quais essas variáveis foram medidas $(35,52)$.

Podemos diferenciar quatro tipos de AEM em função dos objetivos a serem atingidos:

- Simplificação Estrutural: a procura da simplificação da complexidade do problema através da condensação das $p$ variáveis em questão num número menor de novas variáveis. Esses tipos de técnicas são denominadas Técnicas de redução da dimensão (ex., Análise de Componentes Principais, Análise Fatorial).

- Classificação ou Agrupação: este objetivo tem como finalidade formar grupos homogêneos quanto a uma característica determinada. Em geral, todas as variáveis tem um papel similar. Todas atuam como um critério multivariante para definir a homogeneidade entre objetos (ex., análise "cluster" ou de segmentação)

- Análise de Interdependência: o objetivo é procurar a interdependência entre grupos de variáveis, sem que a priori se suponha uma relação de causalidade unidirecional entre elas. A metodologia mais conhecida é a análise de correlações canônicas, generalização da análise de correlação bivariante.

- Análise de Dependência: essa técnica explica as relações entre grupos de variáveis, onde o suposto reside em que umas podem ser as causas das outras. A metodologia mais conhecida é a análise de regressão múltipla. Este tipo de análise tem uma possibilidade de derivação de várias técnicas em função do tipo de variáveis do modelo. A análise discriminante, a análise de regressão e 
os modelos logísticos são métodos que procuram explicar o resultado de um acontecimento em função de variáveis qualitativas e/ou quantitativas explicativas.

Neste estudo estamos interessados no último item da classificação. Se trata de explicar, através de uma série de variáveis qualitativas e quantitativas, a percepção da melhora (ou não) de um paciente dentro de um serviço de atenção ambulatorial em saúde mental. Para isso utilizamos os dados obtidos através dos instrumentos descritos anteriormente. A variável "dependente", que vem explicada pelas variáveis "independentes", é de tipo binário; a variável toma o valor 1 se o resultado do tratamento é positivo, e 0 se o resultado (a percepção da melhora ou não do paciente depois do atendimento no serviço) é negativo. As variáveis independentes incluem características sócio-demográficas dos pacientes, características da prestação dos serviços, tipos de diagnósticos e satisfação com o tipo de atendimento recebido. Este tipo de análise se situa nos modelos denominados "Probit" ou "Logit", nos quais aparece uma variável dependente discreta binária ou multivariada, mas sempre de tipo categórico, que depende de variáveis contínuas ou discretas independentes.

Os modelos de regressão de variável dependente qualitativa formam parte da metodologia de regressão: são modelos de regressão, com a peculiaridade de que a variável a explicar não é contínua. O modelo de regressão múltipla, também chamado de modelo de probabilidade linear, vem especificado pela seguinte equação:

$$
Y_{i}=\beta_{0}+\beta_{1} X_{1 i}+\beta_{2} X_{2 i}+\ldots+\beta_{p} X_{p i}+\varepsilon \quad(i=1, \ldots, n)
$$

onde $Y i$ é a variável dependente, $\beta_{j}$ é o coeficiente associado à variável independente $X_{i j}$, $\varepsilon$ é o erro e $p$ o número de variáveis explicativas. A característica peculiar deste tipo de modelo é que a variável categórica $Y i$ depende 
linearmente das $p$ variáveis e de fatores aleatórios, referidos às particularidades de cada um dos pacientes, e que vem recolhidos no termo de erro $\varepsilon$. Esta especificação vem denotada pela variável $Y$, binária que tem dois valores, 1 se a percepção da melhora é positiva e 0 se é negativa, com probabilidades $P_{i}$ e $1-P_{i}$ (desconhecidas) respectivamente, condicionadas pelos valores das $X . P_{i}$ é a probabilidade de que a percepção do indivíduo $i$ seja positiva, dadas as características próprias e do serviço recebido. Pode-se demonstrar facilmente que $P_{i}$ é a esperança matemática da variável independente, condicionada aos valores de $X$. Temos que a equação (1) pode se rescrever da seguinte forma:

$$
\mathrm{E}\left(Y_{i} / X\right)=P_{i}=\beta_{1} X_{1 i}+\beta_{2} X_{2 i}+\ldots+\beta_{p} X_{p i}(i=1 \ldots n)
$$

Esta equação ajuda a interpretar as estimações obtidas com o modelo de probabilidade linear. Se, por exemplo, $X_{\mathrm{j}}$ representa o sexo do paciente (0 masculino e 1 feminino) e o coeficiente $\beta_{\mathrm{j}}$ associado é igual a 0,08 na regressão, isso significa que uma mulher tem um $8 \%$ mais de probabilidade de ter uma percepção de melhora $(\mathrm{R}+)$ que um homem com traços similares. Apesar da simplicidade da interpretação, o modelo de probabilidade linear tem dois problemas sérios neste tipo de modelo:

- Devido a que a variável $Y_{i}$ é dicotômica, o erro $\varepsilon$ também é dicotômico. Isso implica que não segue uma distribuição normal, hipótese fundamental na análise de regressão múltipla, para poder realizar contrastes de hipóteses e poder validar o modelo. A variância de $\varepsilon$ não é constante $P_{i}$ e não se obtém estimadores $\beta$ eficientes.

- A interpretação do modelo é em função da probabilidade $\beta$. Mas ninguém garante que o valor de $P$ obtido através do método de regressão dos mínimos quadrados esteja no intervalo $(0,1)$. 
Os modelos Probit e Logit, derivados do modelo básico de probabilidade linear, estão desenhados para evitar esses problemas de estimação. Se parte da hipótese de que cada um dos indivíduos tem um "score" ou índice de propensão a dar um resultado positivo $Z_{i}$, não observável, que pode ter qualquer valor positivo ou negativo, e que é função das variáveis independentes $X$. 0 modelo pode ser expressado da seguinte forma:

$$
Z_{i}=\beta_{o}+\beta_{1} X_{1 i}+\beta_{2} X_{2 i}+\ldots+\beta_{p} X_{p i}+\varepsilon \quad i=1, \ldots, n
$$

ou de forma vetorial:

$$
Z_{i}=X_{i}{ }^{\prime} \beta+\varepsilon_{i} \quad i=1,2, \ldots n
$$

onde $\mathrm{X}_{\mathrm{i}}^{\prime}$ é o vetor fila de dados correspondentes às variáveis explicativas do i-ésimo paciente, e é $\beta_{1 i}$ o vetor coluna dos $p=1$ coeficientes $\beta_{i}$ a estimar.

$O$ "índice de propensão da melhora" $Z_{i}$ da $i$-ésima pessoa é uma variável não observável. Somente temos conhecimento de que o paciente tem melhorado $\left(Y_{i}=\right.$ 1) ou não $\left(Y_{i}=0\right)$. Como se deu o resultado? Se supõe que existe um valor crítico $Z^{*}$ do índice $Z_{i}$ que tem levado o paciente da seguinte forma:

- $Z_{\mathrm{i}} \geq Z^{*}$ Se o paciente percebe uma melhora, $Y_{i}=1$

- $Z_{i}<Z^{*}$ Se o paciente não percebe uma melhora, $Y_{i}=0$

Como regra de normalização e sem perda de generalização, pode-se fixar o valor crítico em $Z^{*}=0$. A regra de decisão da pessoa i-ésima pode-se escrever da seguinte maneira:

$$
\begin{aligned}
& \text { - } \quad \operatorname{Se} Z_{i}=X_{i}^{\prime} \beta_{i}+\varepsilon_{i}>0, Y_{i}=1 \\
& \text { - } \quad \operatorname{Se} Z_{i}=X_{i}^{\prime} \beta_{i}+\varepsilon_{i} \leq 0, Y_{i}=0
\end{aligned}
$$


A equação de regressão vai expressar a probabilidade $P_{\mathbf{i}}$ de melhora do paciente $i$ em função das características $\mathrm{X}_{\mathrm{i}}$. Isso implica que:

- $\quad P\left(Y_{i}=1\right)=P\left(Z_{i}>0\right)=\varepsilon_{i}>-X_{i} \beta_{i}=1-F\left(-X_{i}^{\prime} \beta_{i}\right)$

- $\quad \mathrm{P}\left(\mathrm{Y}_{\mathrm{i}}=0\right)=\mathrm{P}\left(\mathrm{Z}_{\mathrm{i}} \leq 0=\mathrm{P}\left(\varepsilon_{\mathrm{i}} \leq-\mathrm{X}_{\mathrm{i}} \beta_{\mathrm{i}}\right)=\mathrm{F}\left(\mathrm{X}_{\mathrm{i}}^{\prime} \beta_{\mathrm{i}}\right)\right.$

As expressões (6) e (7) mostram que as probabilidades de ambas opções são função dos coeficientes $\beta$ e das características $X$ do paciente. A função é linear em $\mathrm{X}$ se a distribuição de $\varepsilon$ é uniforme. Se a distribuição é Normal de média 0 e desviação típica $\sigma$ o modelo se denomina Probit. Se a distribuição dos erros segue uma distribuição logística, o modelo se denomina Logit. No caso binomial, o resultado de ambos modelos é muito similar. Tanto a distribuição normal como a logística tem a sua máxima inclinação em torno do valor médio da distribuição, quando a probabilidade é de 0.5. Esse fator faz com que a variação da probabilidade do resultado seja muito maior quando está perto de 0.5 que para valores extremos da probabilidade. No caso extremo, o fato de que dois pacientes com idênticas características exceto na idade, um com 64 anos e um com 65 anos, faz com que se a probabilidade de satisfação for muito alta, esta não difira muito entre os dois pacientes. Se ao contrário, a probabilidade está perto de 0.5 pode ser que o resultado seja diferente na percepção: o primeiro poderia dar a um $Y_{i}=0$ e o segundo um $\mathrm{Y}_{\mathrm{i}}=1$.

Neste estudo optamos por utilizar um modelo Probit binomial, já que se considera que a distribuição dos erros é de tipo Normal. Para obter os valores dos coeficientes $\beta$ foi aplicado o método da máxima verossimilhança devido à existência de variáveis contínuas independentes. A sua filosofia consiste na obtenção dos valores dos coeficientes $\beta$ que maximizem a probabilidade conjunta de se obter os melhores parâmetros da distribuição.

Para poder explicar o resultado da percepção dos pacientes de melhora (ou piora) depois do tratamento, foram consideradas diversas variáveis explicativas obtidas através do questionário e dos prontuários dos pacientes. As variáveis são 
apresentadas no Quadro II. Para poder incorporar e interpretar as variáveis categóricas com mais de dois itens no modelo de regressão Probit, foi criado, para cada um dos itens da variável, uma nova variável "dummy" o fictícia. Por exemplo, a variável Diagnóstico Principal tem 3 itens: 1) Neurose, 2) Reações, e 3) Código V. Para cada um desses itens se cria uma variável fictícia que toma o valor 1 se o item é "positivo" para os pacientes da amostra e 0 no caso contrário (ex., se o paciente tem uma Neurose, a variável fictícia associada à Neuroses toma o valor 1,e as outras variáveis fictícias correspondentes a Reações e Código V o valor 0 ). Na hora de efetuar a regressão se substituem as variáveis categóricas pelas suas variáveis fictícias correspondentes, mas, para evitar problemas de multicolinearidade, se tem que eliminar uma das variáveis fictícias correspondente a cada uma das variáveis categóricas do modelo. No resultado final, a interpretação destas variáveis fictícias se efetua em relação à variável fictícia eliminada. No exemplo anterior, se eliminamos a variável fictícia associada à Neuroses, e o coeficiente da variável fictícia Código V é significante $(\mathrm{P}<0.05)$ e com valor 0.8 , significa que um paciente com Código V soma 0.8 no "score" de dar um resultado positivo, mais que um paciente com Neurose e com as outras características similares. 
Quadro II: Variáveis explicativas utilizadas na análise multivariada

\begin{tabular}{|c|c|c|}
\hline Variáveis & Codificação & Descrição \\
\hline Sexo & $\begin{array}{l}0 \\
1\end{array}$ & $\begin{array}{l}\text { Masculino } \\
\text { Feminino }\end{array}$ \\
\hline Escolaridade & $\begin{array}{l}0 \\
1 \\
2 \\
\end{array}$ & $\begin{array}{l}0 \leq x<4 \text { anos } \\
4 \leq x \leq 8 \text { anos } \\
x>8 \text { anos }\end{array}$ \\
\hline Renda per cápita & variável & contínua \\
\hline $\begin{array}{l}\text { Diagnóstico principal } \\
\text { agrupado }\end{array}$ & $\begin{array}{l}1 \\
2 \\
3 \\
\end{array}$ & $\begin{array}{l}\text { Neuroses } \\
\text { Reaçōes } \\
\text { Código V }\end{array}$ \\
\hline Duração do problema & variável & contínua \\
\hline $\begin{array}{l}\text { Sentimentos do entrevistador } \\
\text { (no caso novo) }\end{array}$ & $\begin{array}{l}0 \\
1 \\
9 \\
\end{array}$ & $\begin{array}{l}\text { positivos controlados } \\
\text { negativos controlados } \\
\text { não anotado }\end{array}$ \\
\hline $\begin{array}{l}\text { Razāo para interrupção } \\
\text { (Situação no tratamento) }\end{array}$ & $\begin{array}{l}0 \\
1 \\
3 \\
4 \\
\end{array}$ & $\begin{array}{l}\text { em tratamento } \\
\text { alta ou estava melhor } \\
\text { Dif. acesso/encaminh/perda cont. } \\
\text { Crítica ao serviço }\end{array}$ \\
\hline Duração do tratamento & v.contínua & \\
\hline Média de visitas & contínua & \\
\hline Tipo de Profissional & $\begin{array}{l}0 \\
1 \\
\end{array}$ & $\begin{array}{l}\text { Psiquiatra } \\
\text { Psiq. e outros profiss. }\end{array}$ \\
\hline $\begin{array}{l}\text { Tipo de tratamento } \\
\text { recebido }\end{array}$ & $\begin{array}{l}1 \\
2 \\
3 \\
4 \\
5\end{array}$ & $\begin{array}{l}\text { Só farmacol. } \\
\text { PI (só ou com fármaco) } \\
\text { PG (só ou com fármaco) } \\
\text { H.dia + outros procedimentos } \\
\text { Orient/encaminh./alta }\end{array}$ \\
\hline
\end{tabular}


Quadro II (segue): Variáveis explicativas utilizadas na análise multivariada

\begin{tabular}{||l|cl||}
\hline \hline Variáveis & Codificação & Descrição \\
\hline \hline \multirow{2}{*}{ Satisfação com } & 1 & $\begin{array}{l}\text { insatisfeito } \\
\text { (+ ou -) satisfeito } \\
\text { o tratamento }\end{array}$ \\
& 2 & \\
& 3 & satisfeito \\
\hline Continuidade com o & 0 & $x<3$ visitas \\
mesmo médico & 1 & $3 \leq x<7$ visitas \\
& 2 & $x \geq T$ visitas \\
\hline Tipo de medicação & 0 & não utilizou \\
durante o tratamento & 1 & Benzodiazepínicos \\
& 2 & outras drogas psiquiátricas \\
& 3 & Antidepressivos \\
\hline \hline
\end{tabular}




\section{RESULTADOS}

Como já foi citado anteriormente, dos 1155 pacientes atendidos como "casos novos" (primeiras consultas) nos anos de 1989 e 1990, definitivamente foram selecionados 289 casos que preenchiam os critérios para inclusão nesta pesquisa.

Destes, 74 pacientes não puderam responder às entrevistas domiciliares. Com exceção de um óbito (por razões não psiquiátricas), e de uma pessoa que por motivos médicos não estava em condições de responder, a razão principal da não execução das entrevistas foi a impossibilidade de localização de pacientes por mudança de domicílio, freqüentemente para outros municípios. Não houve recusas quanto à participação neste estudo.

Quatro dos prontuários que previamente haviam sido selecionados quando da definição da amostra (e cujos pacientes responderam à entrevista domiciliar), não foram localizados no momento da realização definitiva da revisão de prontuários.

Contamos portanto com um total de 211 pacientes dos quais obtivemos informação tanto dos prontuários médicos como das entrevistas realizadas nos domicílios.

Apesar de ter sido realizada uma primeira análise descritiva mais genérica com dados do total de 289 pacientes, ao encontrarmos que eram mínimas as diferenças entre os resultados desse grupo, e os do grupo de 211 pacientes citados acima, decidimos apresentar tais achados em tabelas onde estes podem ser comparados paralelamente.

Em função disso, e para que não se tornasse enfadonha a leitura repetitiva de resultados muito similares, apresentaremos a seguir somente a análise descritiva dos dados do grupo de 211 pacientes. Em caso de existência de alguma diferença importante, esta será mencionada. Também quando da apresentação dos resultados das associações entre variáveis, da análise por separado dos grupos com diferentes resultados de tratamento, e para a análise multivariada, utilizaremos apenas os 211 
casos de pacientes dos quais obtivemos informação tanto dos prontuários, quanto das entrevistas domiciliares.

Algumas das características sóciodemográficas dos sujeitos $(n=211)$ estudados serão descritas a seguir (Vide Tabela R1):

Houve um predominio do sexo feminino (77.7\%) sobre o masculino $(22.3 \%)$. Era um grupo constituído principalmente por adultos jovens (40.5\% com menos de 35 anos) ou de meia idade (33.3\% entre 35 e 49 anos), em sua maioria casados $(63.6 \%)$ e procedentes de zonas urbanas de Botucatu (80.1\%) e São Manoel $(18.5 \%)$. Com respeito a este último item, é interessante mencionar que neste grupo $(n=211)$ a população era quase exclusivamente urbana $(98.6 \%)$ e apenas $1.4 \%$ dos casos procediam da zona rural, enquanto que no outro grupo $(n=289)$, $6.9 \%$ dos pacientes eram da área rural. Provavelmente esse fato se explica em função de ser a zona rural de mais dificil acesso e de maior dificuldade de localização de endereços... Assim sendo, parte da "perda de casos" para a entrevista domiciliar saiu desse grupo.

De modo geral o grau de escolaridade era baixo, com $43.6 \%$ dos indivíduos tendo estudado no máximo até a $4^{\mathrm{a}}$ série do $1^{\circ}$ grau (6.2\% eram analfabetos). Estudaram de 5 a 8 anos $22.3 \%$, e conseguiram cursar o colegial (completo ou incompleto) $19 \%$ dos pacientes. Somente uma minoria (9\%) estudou mais de 11 anos (superior completo ou incompleto).

A ocupação mais freqüente (41.4\%) foi a de "prendas domésticas", logo seguida (30\%) pelas ocupações manuais (18.1\% manuais especializadas e $11.9 \%$ manuais semi ou não especializadas), e não manuais (21\%). A renda per cápita (obtida pela entrevista domiciliar) de forma geral (77.5\%) se encontrava abaixo de 2 salários mínimos ( $35.4 \%$ com menos de 1 salário). Apenas $1.9 \%$ dos pacientes provinha de famílias com uma renda per cápita acima de 5 salários mínimos.

Com relação aos achados acima descritos, o predomínio do sexo feminino entre os usuários é um dado que está de acordo com a maioria de trabalhos que apontam 
Tabela R.1: Características Sóciodemográficas dos sujeitos

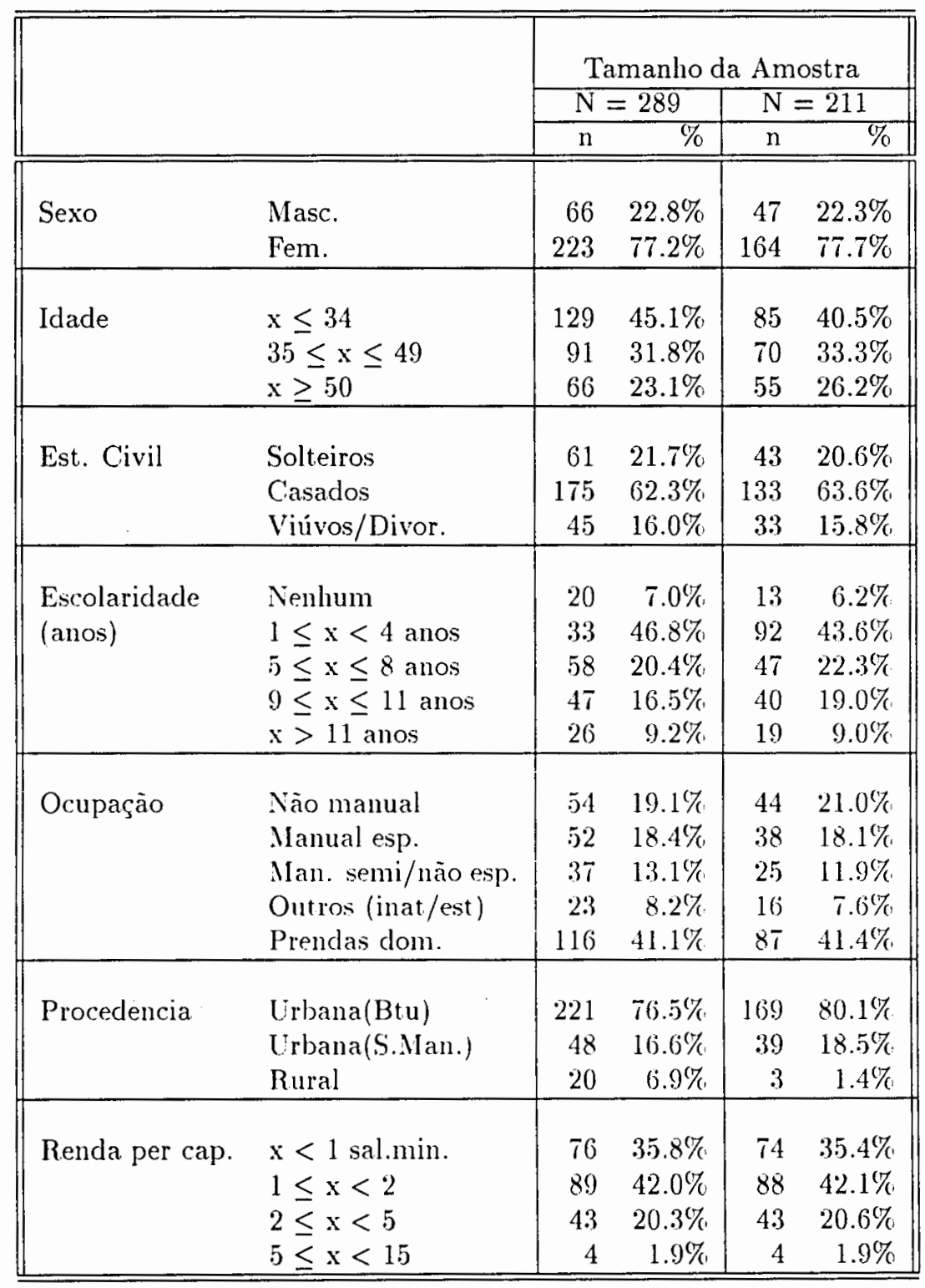


Tabela R.1 (segue): Características Sóciodemográficas dos sujeitos

\begin{tabular}{|c|c|c|c|c|c|}
\hline & & \multicolumn{4}{|c|}{ Tamanho da Amostra } \\
\hline & & \multicolumn{2}{|c|}{$\mathrm{N}=289$} & \multicolumn{2}{|c|}{$N=211$} \\
\hline & & $\mathrm{n}$ & $\%$ & $n$ & $\%$ \\
\hline \multirow[t]{5}{*}{ Ocupação do "chefe" de fam } & manual espec & 61 & $29.0 \%$ & 60 & $20.1 \%$ \\
\hline & manual nào espec & 27 & $12.9 \%$ & 25 & $12.1 \%$ \\
\hline & não manual & 60 & $28.6 \%$ & 60 & $29.1 \%$ \\
\hline & inativos & 59 & $28.1 \%$ & 58 & $28.2 \%$ \\
\hline & p.domésticas & 3 & $1.4 \%$ & 3 & $1.5 \%$ \\
\hline \multirow{5}{*}{$\begin{array}{l}\text { Escolaridade do chefe } \\
\text { de família } \\
\text { (anos) }\end{array}$} & nenhum & 9 & $4.2 \%$ & 9 & $4.3 \%$ \\
\hline & $1 \leq \mathrm{x} \leq 4$ & 99 & $46.3 \%$ & 96 & $45.7 \%$ \\
\hline & $5 \leq x \leq 8$ & 59 & $27.6 \%$ & 58 & $27.6 \%$ \\
\hline & $9 \leq x \leq 11$ & 30 & $14.0 \%$ & 30 & $14.3 \%$ \\
\hline & $x>11$ & 17 & $7.9 \%$ & 17 & $8.1 \%$ \\
\hline \multirow[t]{3}{*}{ no. pessoas no domicílio } & 1 a 2 & 44 & $20.6 \%$ & 44 & $20.9 \%$ \\
\hline & 3 a 4 & 91 & $42.5 \%$ & 89 & $42.2 \%$ \\
\hline & 5 a 8 & 79 & $36.9 \%$ & 78 & $37.0 \%$ \\
\hline
\end{tabular}


para uma predominância marcante da procura de serviços pelas mulheres $(102$, $114,48,82,53,54,120,7)$.

Além disso, o fato de haver uma maioria de mulheres casadas e com atividades domésticas também é um dado compatível com a literatura que ressalta o predominio de pessoas com essas características, principalmente quando os diagnósticos são de linha neurótica ou reativa, como neste caso ( $44,102,68$, 114).

A maior porcentagem de adultos jovens também é algo em conformidade com diversos trabalhos, que apontam para uma tendência decrescente de procura de serviços à medida que aumenta a faixa etária $(6,102,19,48,82,114)$.

Com relação ao processo de tratamento recebido pelos 211 pacientes pudemos observar os seguintes dados referentes ao "Caso Novo" e evolução dos pacientes: (Tabelas R2 e R3)

- Neste início os dados referem-se aos procedimentos ocorridos durante a primeira consulta (Caso Novo) e foram obtidos da revisão dos prontuários (Vide Tabela R2). Mais adiante serão mencionados os dados referentes ao processo de atendimento ao longo do tratamento.

No que diz respeito às anotações da anamnese psiquiátrica, em $85.8 \%$ dos casos a história clínica e antecedentes foi preenchida de forma completa. Já o exame fisico apenas em $43.1 \%$ dos casos estava completo, sendo que em $23.2 \%$ das vezes não foi preenchido (não sabemos portanto se foi realizado ou não). Quanto ao exame psíquico este foi preenchido em $91.9 \%$ dos casos ( $76.3 \%$ de forma completa).

Com relação ao processo de tratamento, observando-se os achados apresentados acima, o fato de aproximadamente $86 \%$ das anamneses psiquiátricas iniciais terem sido preenchidas de forma completa com respeito à história clínica e antecedentes (e os restantes 14\% preenchidos, ainda que não completamente), isso é um dado em favor da qualidade do serviço (66). Porém, pensando-se que o ambulatório avaliado é um serviço universitário, poderiam ser melhoradas as anotações no 
Tabela R.2: Dados do Caso Novo

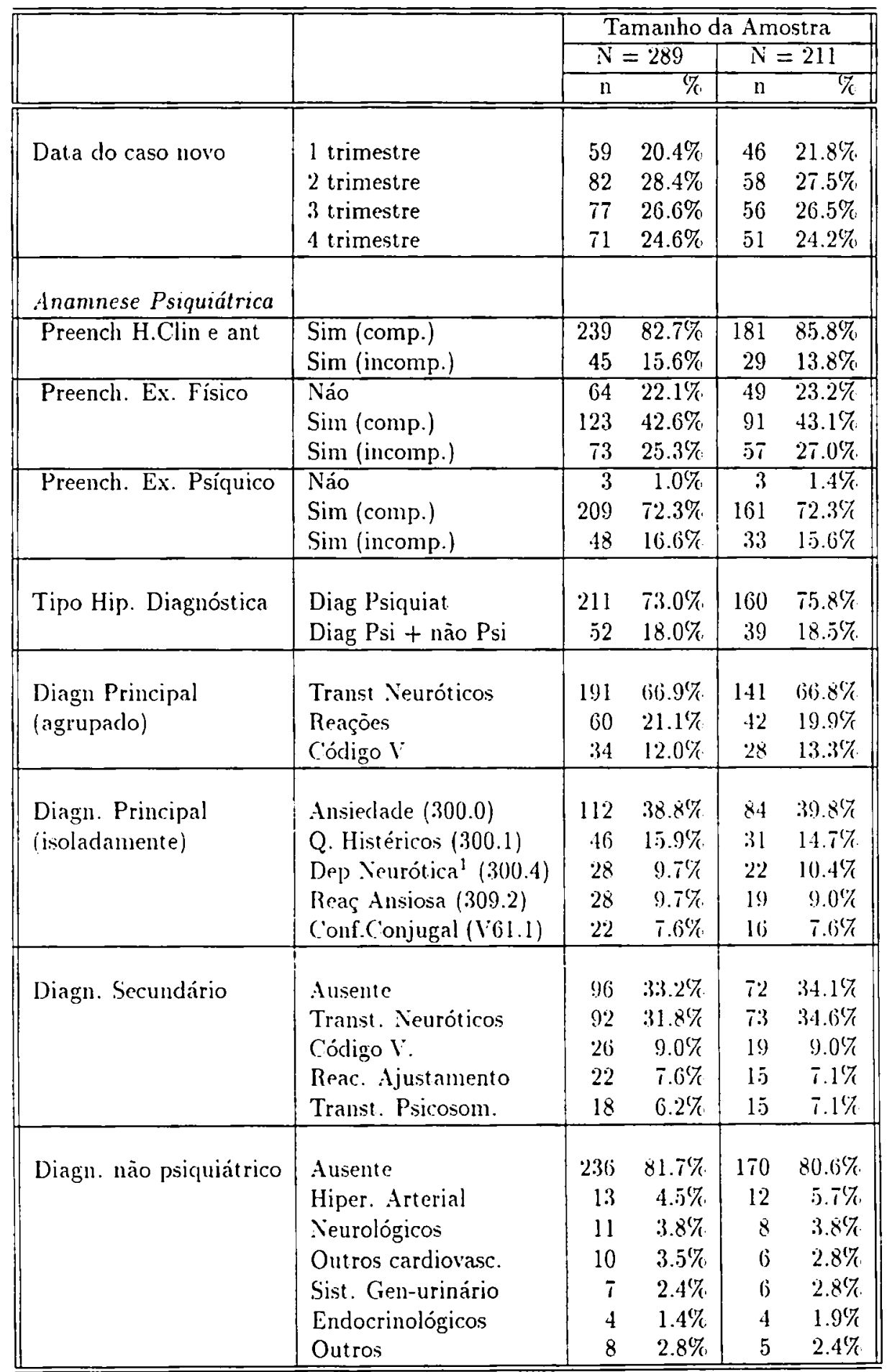


Tabela R.2 (segue): Dados do Caso Novo

\begin{tabular}{|c|c|c|c|c|c|}
\hline & & \multicolumn{4}{|c|}{ Tamanho da Amostra } \\
\hline & & \multicolumn{2}{|c|}{$N=289$} & \multicolumn{2}{|c|}{$N^{\prime}=211$} \\
\hline & & $n$ & $\%$ & $\mathrm{n}$ & 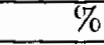 \\
\hline Conduta no caso novo & $\begin{array}{l}\text { Farmacológica } \\
\text { Psicoterapia (PI/PG) } \\
\text { Far+Pster(PI/PG/Rlx) } \\
\text { H.Dia+Outros proced. } \\
\text { Orient+encam+alt }\end{array}$ & $\begin{array}{r}106 \\
39 \\
81 \\
15 \\
26 \\
\end{array}$ & $\begin{array}{r}36.7 \% \\
13.5 \% \\
28.0 \% \\
5.2 \% \\
9.0 \%\end{array}$ & $\begin{array}{l}7 i \\
30 \\
63 \\
11 \\
19\end{array}$ & $\begin{array}{r}36.5 \% \\
14.2 \% \\
29.9 \% \\
5.2 \% \\
9.0 \%\end{array}$ \\
\hline Tipo de Medic. & $\begin{array}{l}\text { Nào prescrita } \\
\text { Benzodiazepínicos } \\
\text { Antidepressivos } \\
\text { Benz+ antidep } \\
\text { Comb de Psicof } \\
\text { Pstrop+nào Pstrop } \\
\text { Nào psicotrópico }\end{array}$ & $\begin{array}{r}56 \\
158 \\
13 \\
12 \\
11 \\
9 \\
6 \\
\end{array}$ & $\begin{array}{l}19.4 \% \\
54.7 \% \\
4.5 \% \\
4.2 \% \\
3.7 \% \\
3.1 \% \\
2.1 \% \\
\end{array}$ & $\begin{array}{r}42 \\
117 \\
9 \\
12 \\
9 \\
4 \\
5 \\
\end{array}$ & $\begin{array}{r}19.9 \% \\
55.5 \% \\
4.3 \% \\
5.7 \% \\
4.3 \% \\
1.9 \% \\
2.4 \% \\
\end{array}$ \\
\hline Freq. admin. droga & $\begin{array}{l}1 \text { vez ao dia } \\
2 \text { vezes } \\
3 \text { vezes } \\
\end{array}$ & $\begin{array}{r}117 \\
71 \\
12 \\
\end{array}$ & $\begin{array}{r}40.5 \% \\
24.6 \% \\
4.2 \% \\
\end{array}$ & $\begin{array}{l}8.5 \\
5.5 \\
10 \\
\end{array}$ & $\begin{array}{r}40.3 \% \\
26.1 \% \\
4.7 \% \\
\end{array}$ \\
\hline Ind.Psicoterapia & $\begin{array}{l}\text { Não } \\
\text { Sim }\end{array}$ & $\begin{array}{l}129 \\
132 \\
\end{array}$ & $\begin{array}{l}44.6 \% \\
45.7 \% \\
\end{array}$ & $\begin{array}{l}96 \\
99\end{array}$ & $\begin{array}{l}45.5 \% \\
46.9 \%\end{array}$ \\
\hline Duraçào transtorno & $\begin{array}{l}x<6 \text { meses } \\
0 \leq x<12 \text { meses } \\
1 \leq x<5 \text { anos } \\
+ \text { de } 5 \text { anos } \\
\end{array}$ & $\begin{array}{l}82 \\
48 \\
70 \\
71 \\
\end{array}$ & $\begin{array}{l}29.6 \% \\
17.3 \% \\
25.3 \% \\
27.8 \% \\
\end{array}$ & $\begin{array}{l}60 \\
34 \\
55 \\
55 \\
\end{array}$ & $\begin{array}{l}29.4 \% \\
16.7 \% \\
27.0 \% \\
27.0 \% \\
\end{array}$ \\
\hline Profiss. caso novo & $\begin{array}{l}\text { Prof. Equipe fixa } \\
\text { Resid/internos/Psiq }\end{array}$ & $\begin{array}{r}16 \\
250 \\
\end{array}$ & $\begin{array}{r}5.5 \% \\
86.5 \% \\
\end{array}$ & $\begin{array}{r}8 \\
192 \\
\end{array}$ & $\begin{array}{r}3.8 \% \\
91.0 \% \\
\end{array}$ \\
\hline $\begin{array}{l}\text { Sentim. do entrevistador } \\
\text { (Caso Novo) }\end{array}$ & $\begin{array}{l}\text { Pos. Control } \\
\text { Neg. Control } \\
\text { Infor. não anot }\end{array}$ & $\begin{array}{r}205 \\
32 \\
52 \\
\end{array}$ & $\begin{array}{l}70.9 \% \\
11.1 \% \\
18.0 \%\end{array}$ & $\begin{array}{r}157 \\
23 \\
31 \\
\end{array}$ & $\begin{array}{l}74.4 \% \\
10.9 \% \\
14.7 \%\end{array}$ \\
\hline
\end{tabular}


referente ao exame psíquico e fisico; principalmente neste último, apesar de não termos parâmetros objetivos para comparar o nível de preenchimento atingido, com o de outros serviços de saúde mental brasileiros com características similares. Em 75.8\% dos casos foram realizadas hipóteses diagnósticas apenas com diagnósticos psiquiátricos ( 1 ou + ), enquanto que em $18.5 \%$ dos casos houve uma combinação de diagnósticos psiquiátricos e não psiquiátricos.

O grupo mais freqüente de diagnósticos psiquiátricos (diagnóstico principal na "hipótese diagnóstica") foi o de "Transtornos Neuróticos" (66.8\%), seguido pelas "Reações de Ajustamento" (19.9\%) e por diagnósticos contidos no "Código V" da C.I.D.(13.3\%).

Dentre estes diagnósticos principais ( $1^{\circ}$ diagnóstico), os mais comuns foram os "Estados de Ansiedade" (CID 300.0) em 39.8\% dos casos, seguidos pelos "Quadros Histéricos" (CID 300.1) em 14.7\% e pelas "Depressões Neuróticas" (CID 300.4), em 10.4\% dos casos.

Se analisamos separadamente cada agrupamento diagnóstico; nos quadros neuróticos a ordem de maior freqüência foi "Estados de Ansiedade", seguidos por "Neurose Histérica" e "Depressão". Os quadros fóbicos e hipocondríacos apareceram em uma frequêencia muito pequena ( $1.9 \%$ dos casos) nos diagnósticos principais. Como diagnóstico secundário apareceram em $4.8 \%$ dos casos.

Nos quadros reativos, os diagnósticos mais comuns foram as "reações de ansiedade" (9\%), seguidos pelas "reações depressivas breves $(5.7 \%) \mathrm{e}$ prolongadas" $(3.8 \%)$.

Quanto aos diagnósticos do Código $\mathrm{V}$, o diagnóstico mais freqüente foi o de "Problemas Conjugais" (V61.1) com 7.6\% dos casos, seguido por "Problemas entre Pais e Filhos"(2.8\%) e "Outras circunstâncias familiares não especificadas" (2.4\%). "Problemas de saúde na família" (V61.4) foi o único dos outros diagnósticos do Código $\mathrm{V}$ que esteve presente nos diagnósticos psiquiátricos principais. Podemos dizer que do total dos diagnósticos do Código $\mathrm{V}$ passíveis de serem utilizados neste estudo, somente os citados acima (V.61) referentes à 
circunstâncias familiares, e o V.11 "Antecedentes de história pessoal de transtorno mental" (como diagnóstico secundário) foram os que apareceram em algum momento desta pesquisa.

Com relação a um segundo diagnóstico psiquiátrico (chamado por nós "diagnóstico psiquiátrico secundário") que esteve presente em $65.9 \%$ dos casos, o grupo de diagnósticos mais freqüente foi novamente o de "Neuroses" (34.6\%), seguidos por diagnósticos do Código V (9\%), "Quadros Reativos" (7.1\%) e "Transtornos fisiológicos decorrentes de fatores emocionais" (7.1\%).

Se analisamos os diagnósticos psiquiátricos secundários de forma não agrupada, os mais comuns foram: "Quadros depressivos neuróticos"(12.3\%), seguidos por "Estados de ansiedade"(9\%) e "Transtornos fisiológicos decorrentes de fatores emocionais"(onde foram classificados os quadros de somatização) em $7.1 \%$ dos casos.

Em resumo; neste grupo $(n=211)$, ocorreu o mesmo que no grupo $(n=289)$ : houve um predomínio de quadros ansiosos (neuróticos ou reativos) nos diagnósticos psiquiátricos principais, enquanto que nos diagnósticos psiquiátricos secundários predominaram os quadros depressivos neuróticos ou reativos.

Pudemos observar que em $26.5 \%$ dos casos houve um $3^{\circ}$ diagnóstico psiquiátrico, sendo que nesses casos "Conflito conjugal" foi o diagnóstico mais freqüente $(4.7 \%)$.

Quanto a diagnósticos não psiquiátricos, houve um 19.4\% de casos em que estes estiveram presentes. Os diagnósticos mais freqüentes foram: Hipertensão arterial $(5.7 \%)$ seguida por "problemas neurológicos" (por ex. epilepsia), em $3.8 \%$ dos casos e "outros problemas cardiovasculares" (2.8\%), em freqüência similar ao de "problemas do trato gênito-urinário" (2.8\%)

.Apesar desses diagnósticos, em apenas 3.3\% dos casos foram pedidos exames subsidiários, e para $9 \%$ dos pacientes foram pedidas interconsultas ou feitos encaminhamentos para outras clínicas da Faculdade (7.6\%) ou serviços da região $(1.4 \%)$. 
Observando-se os dados acima, nos parece um pouco baixo o índice de pedidos de exames/ interconsultas, a menos que isso se explique pelo fato de que num Hospital Universitário uma parcela dos pacientes com diagnósticos não psiquiátricos já poderiam estar sendo seguidos noutra especialidade, não precisando portanto serem encaminhados para outra clínica por primeira vez, ou que se solicitasse exames laboratoriais para controle.

Nessa primeira consulta (caso novo), as condutas mais indicadas foram: Tratamento apenas farmacológico (36.5\%), Psicoterapia (P.Grupal, Individual ou Relaxamento) associada a tratamento farmacológico (29.9\%) e apenas psicoterapia (P.I. ou P.G.) em $14.2 \%$ dos casos. Houve encaminhamentos para o Hospital Dia em $5.2 \%$ das vezes, e ao redor de $9 \%$ dos casos receberam apenas Orientação, e muitas vezes foram encaminhados para outros serviços da região, outras clínicas da Faculdade ou receberam alta médica.

De modo geral, $74.1 \%$ dos casos receberam algum tipo de tratamento farmacológico. Destes, $2.4 \%$ receberam medicação não psicotrópica, e $1.9 \%$ uma combinação de psicotrópicos e não psicotrópicos.

Entre os psicofármacos, os mais prescritos foram: benzodiazepínicos (55.5\%), antidepressivos em associação com benzodiazepínicos (5.7\%) e somente antidepressivos (4.3\%). Os restantes $4.3 \%$ referiam-se a outras drogas ou combinações. No que diz respeito à freqüência de administração, estas drogas na grande maioria das vezes $(40.3 \%)$ eram prescritas para serem tomadas uma vez ao dia. Duas vezes (26.1\%), e três vezes em $4.7 \%$ dos casos.

Nessa primeira consulta, foi feita a indicação de psicoterapia para $46.9 \%$ dos pacientes, o que não necessariamente ocorreu de forma efetiva ao longo do tratamento.

No referente às condutas no caso novo, apesar de que alguma abordagem psicoterápica tenha sido oferecida aos pacientes (com ou sem medicação associada) na frequêencia citada acima, nos parece que esse índice haveria de ser maior se pensarmos que para os diagnósticos mais freqüentes neste estudo, 
provavelmente psicoterapia ou associação de terapia mais fármacos, seriam de melhor valia do que apenas tratamento farmacológico (que ocorreu em porcentagem relativamente alta).

O fato de se observar uma frequiência alta apenas de tratamento farmacológico poderia ser explicado pela possibilidade de que em muitos casos, ainda que o profissional que esteja atendendo pudesse indicar psicoterapia em certas situações, muitas vezes já não o faz por saber que nesse momento o serviço já não pode oferecer tal opção de tratamento. Às vezes também não indica, pelas próprias condições do paciente (por exemplo: alguém que recentemente foi contratado em um novo emprego, e que desde o início manifesta que não poderia ser dispensado do trabalho para vir ao serviço com a freqüência necessária para a psicoterapia). $\mathrm{Na}$ primeira suposição, observamos fatores organizacionais do serviço condicionando decisões técnicas, ao invés destas irem obrigando o serviço a se reestruturar para uma melhor qualidade.

Por outro lado, o tipo de medicação mais freqüentemente utilizado (benzodiazepínicos e antidepressivos em porcentagem bastante menor) e sua forma de administração, são coerentes com os diagnósticos, além de que uma freqüência baixa de administração ( número de vezes ao longo do dia) facilita o cumprimento das prescrições $(76,18)$.

O tempo de evolução dos transtornos, entre início dos sintomas e a vinda para uma primeira consulta foi de menos de 6 meses em $29.4 \%$ dos casos. De mais de 5 anos em $27 \%$ dos pacientes; de 1 a 5 anos (27\%) e de 6 meses a 1 ano em $16.7 \%$ dos casos. Com exceção desta última faixa, as porcentagens encontradas não são muito diferentes entre si. Entretanto, pode-se observar um ligeiro predomínio (54\%) de casos tendendo à cronificação (de um a cinco anos de evolução), ou de casos crônicos (mais de 5 anos), em comparação com casos com menos de 1 ano de evolução (46.1\%).

Neste grupo de 211 pacientes, $91 \%$ dos casos novos foram realizados por residentes ou internos sob a supervisão de um psiquiatra $(86.5 \%$ no grupo $n=289)$. 
Foram poucos os primeiros atendimentos feitos exclusivamente por um profissional da equipe fixa. Isso pode ser explicado pelas características do serviço (Hospital Universitário) onde a assistência é diretamente associada ao ensino, bem como a forma pela qual foram selecionados os casos para este estudo. Como a seleção dos casos foi feita a partir das primeiras visitas constantes nas folhas de agendamento da rotina normal do serviço, aqueles primeiros atendimentos feitos diretamente por docentes (ou por outros profissionais da equipe fixa) e que na maioria das vezes não estavam agendados na forma usual (não constavam da folha de agendamento do ambulatório) não fizeram parte deste trabalho. Um certo esforço foi feito no sentido de se localizar esses casos, mas ainda assim, seguramente esse grupo foi "sub representado". Mas, se comparamos com o número total de atendimentos do ambulatório, esses casos que seguiam uma "via paralela" dentro da rotina do serviço, atendidos em primeira consulta por docentes sem constarem do agendamento formal, podem ser considerados uma minoria.

É importante porém salientar (para que não fiquem dúvidas a respeito de que a avaliação abrangia atendimentos feitos tanto pela equipe fixa quanto por pessoal em formação), que apesar de grande parte dos pacientes estudados terem sido casos didáticos em alguma fase de seu tratamento, isto era praticamente no que se referia ao momento do caso novo. Após essa primeira consulta, aqueles pacientes que seguiam o tratamento podiam ser derivados para os mais diversos programas do serviço, podendo ser portanto atendidos por psiquiatras, psicólogos, terapeutas ocupacionais, assistentes sociais ou enfermeira, em atendimentos psicoterápicos ou apenas farmacológicos.

Isso significa portanto, que ao avaliar o processo de prestação de serviço ao longo do tratamento, não estamos avaliando apenas os primeiros atendimentos feitos por residentes ou internos sob supervisão, mas também o trabalho dos diversos profissionais de todo o ambulatório.

Em $74.4 \%$ dos casos, quem realizou o caso novo manifestou sentimentos positivos controlados em relação ao paciente. Sentimentos negativos controlados 
(10.9\%) também foram mencionados. Em $14.7 \%$ dos atendimentos esse item não foi anotado, o que nos faz perguntar se foi apenas uma lacuna casual no preenchimento dos dados da anamnese, ou se isso significou sentimentos negativos em relação ao paciente, não anotados de forma objetiva. As associações desses dados com outras variáveis estudadas serão discutidas mais adiante.

- A partir deste momento, a descrição se refere aos achados relativos à evolução ao longo do tratamento deste grupo de pacientes $(n=211)$. Vide Tabela $R 3$.

No momento da revisão dos prontuários, e através das informações contidas nestes, $20.5 \%$ dos pacientes encontravam-se em tratamento. Receberam alta $16.7 \%$ dos casos, e em $62.9 \%$ dos prontuários observamos uma interrupção do tratamento sem que pelas anotações pudéssemos esclarecer as causas (não sabemos se foi abandono, altas, ou simplesmente falta de anotações).

Essa grande quantidade de interrupções sem causas esclarecidas nos surpreende, frente ao número de altas ou de pessoas em tratamento, porém, quando da entrevista domiciliar, com a explicação do paciente, se observa que esse número diminui, elevando-se a porcentagem de altas ou interrupções por "encontrar-se melhor".

Com relação à duração do tratamento , $41.7 \%$ dos pacientes utilizou o serviço por 1 mês ou menos (25.6\% esteve apenas na $1^{a}$ consulta). De 2 meses a 1 ano (33\%), e um $25.1 \%$ esteve em tratamento por mais de 12 meses.

Nos parece bastante alta a porcentagem de pacientes que utilizou o serviço por um mês ou menos, apesar de que comparando-se esse dado com outro trabalho (69) onde se descrevem os índices de interrupção de tratamento num ambulatório universitário (63\% depois da primeira visita, e um total de $82 \%$ de pacientes que abandonaram o tratamento nos primeiros 3 meses), nossos índices não são tão elevados. Também, no momento das entrevistas domiciliares, os pacientes desse grupo (menos de 1 mês de tratamento) nos forneceram algum material para reflexão quando disseram nas "razões para interrupção", que deixaram de se tratar 
Tabela R.3: Dados da Evoluçào

\begin{tabular}{|c|c|c|c|c|c|}
\hline & & \multicolumn{4}{|c|}{ Tamanho da Amostra } \\
\hline & & \multirow{2}{*}{\multicolumn{2}{|c|}{$\frac{N=289}{n} \%$}} & \multicolumn{2}{|c|}{$N=211$} \\
\hline & & & & $\mathrm{n}$ & $\%$ \\
\hline $\begin{array}{l}\text { Situação Tratam. } \\
\text { Razão p/ interr. }\end{array}$ & $\begin{array}{l}\text { em tratamento } \\
\text { Alta } \\
\text { Interrup. não escl. }\end{array}$ & $\begin{array}{r}53 \\
48 \\
183 \\
\end{array}$ & $\begin{array}{l}18.7 \% \\
16.9 \% \\
64.4 \%\end{array}$ & $\begin{array}{r}43 \\
35 \\
132 \\
\end{array}$ & $\begin{array}{l}20.5 \% \\
16.7 \% \\
62.9 \%\end{array}$ \\
\hline Duraçào tratamento & $\begin{array}{l}x \leq 1 \text { mes } \\
2 \leq x \leq 12 \\
x>12 \text { meses }\end{array}$ & $\begin{array}{r}122 \\
96 \\
67 \\
\end{array}$ & $\begin{array}{l}42.8 \% \\
33.7 \% \\
23.5 \% \\
\end{array}$ & $\begin{array}{l}88 \\
70 \\
\mathbf{5 3} \\
\end{array}$ & $\begin{array}{l}41.7 \% \\
33.2 \% \\
25.1 \% \\
\end{array}$ \\
\hline no. total de visitas & $\begin{array}{l}1 \\
2 \leq x \leq 5 \\
6 \leq x \leq 30 \\
x>30\end{array}$ & $\begin{array}{r}55 \\
141 \\
69 \\
19 \\
\end{array}$ & $\begin{array}{r}19.4 \% \\
49.6 \% \\
24.3 \% \\
6.7 \% \\
\end{array}$ & $\begin{array}{r}43 \\
102 \\
51 \\
15 \\
\end{array}$ & $\begin{array}{r}20.4 \% \\
48.3 \% \\
24.2 \% \\
\quad .1 \% \\
\end{array}$ \\
\hline total de faltas & $\begin{array}{l}0 \\
1 \leq x \leq 2 \\
x>3\end{array}$ & $\begin{array}{r}134 \\
100 \\
45 \\
\end{array}$ & $\begin{array}{l}48.0 \% \\
35.8 \% \\
16.1 \% \\
\end{array}$ & $\begin{array}{r}105 \\
70 \\
33 \\
\end{array}$ & $\begin{array}{l}50.5 \% \\
33.7 \% \\
1.5 \% \\
\end{array}$ \\
\hline Tipo trat. recebido & $\begin{array}{l}\text { Farmacológico } \\
\text { Psicoterápico } \\
\text { Farmactpsicoter } \\
\text { HD+(fárm/Psicot) } \\
\text { Orient/alta/encaninlt }\end{array}$ & $\begin{array}{r}137 \\
17 \\
70 \\
25 \\
34 \\
\end{array}$ & $\begin{array}{r}48.6 \% \\
6.0 \% \\
2.1 .8 \% \\
8.5 \% \\
12.1 \% \\
\end{array}$ & $\begin{array}{r}102 \\
12 \\
52 \\
16 \\
27 \\
\end{array}$ & $\begin{array}{r}48.8 \% \\
5.7 \% \\
24.9 \% \\
7.7 \% \\
12.9 \% \\
\end{array}$ \\
\hline Tempo Medicaçào & $\begin{array}{l}\text { nào utilizou } \\
1 \leq x<12 \text { meses } \\
x \geq 12 \text { meses }\end{array}$ & $\begin{array}{r}56 \\
122 \\
41 \\
\end{array}$ & $\begin{array}{l}25.6 \% \\
5.7 \% \\
18.7 \%\end{array}$ & $\begin{array}{l}41 \\
87 \\
33 \\
\end{array}$ & $\begin{array}{l}25.5 \% \\
54.0 \% \\
20.5 \% \\
\end{array}$ \\
\hline P Individual & Sim & 44 & $15.4 \%$ & 32 & $15.2 \%$ \\
\hline$P$ grupal & $\operatorname{Sim}$ & 76 & $26.6 \%$ & $5 \pi$ & $2 \pi .0 \%$ \\
\hline Int parcial Hosp Dia & $\operatorname{Sim}$ & 25 & $8.8 \%$ & 17 & $8.1 \%$ \\
\hline Int tot hosp psiq & Nào houve & 0 & & - & - \\
\hline
\end{tabular}


Tabela R.3 (segue): Dados da Evolução

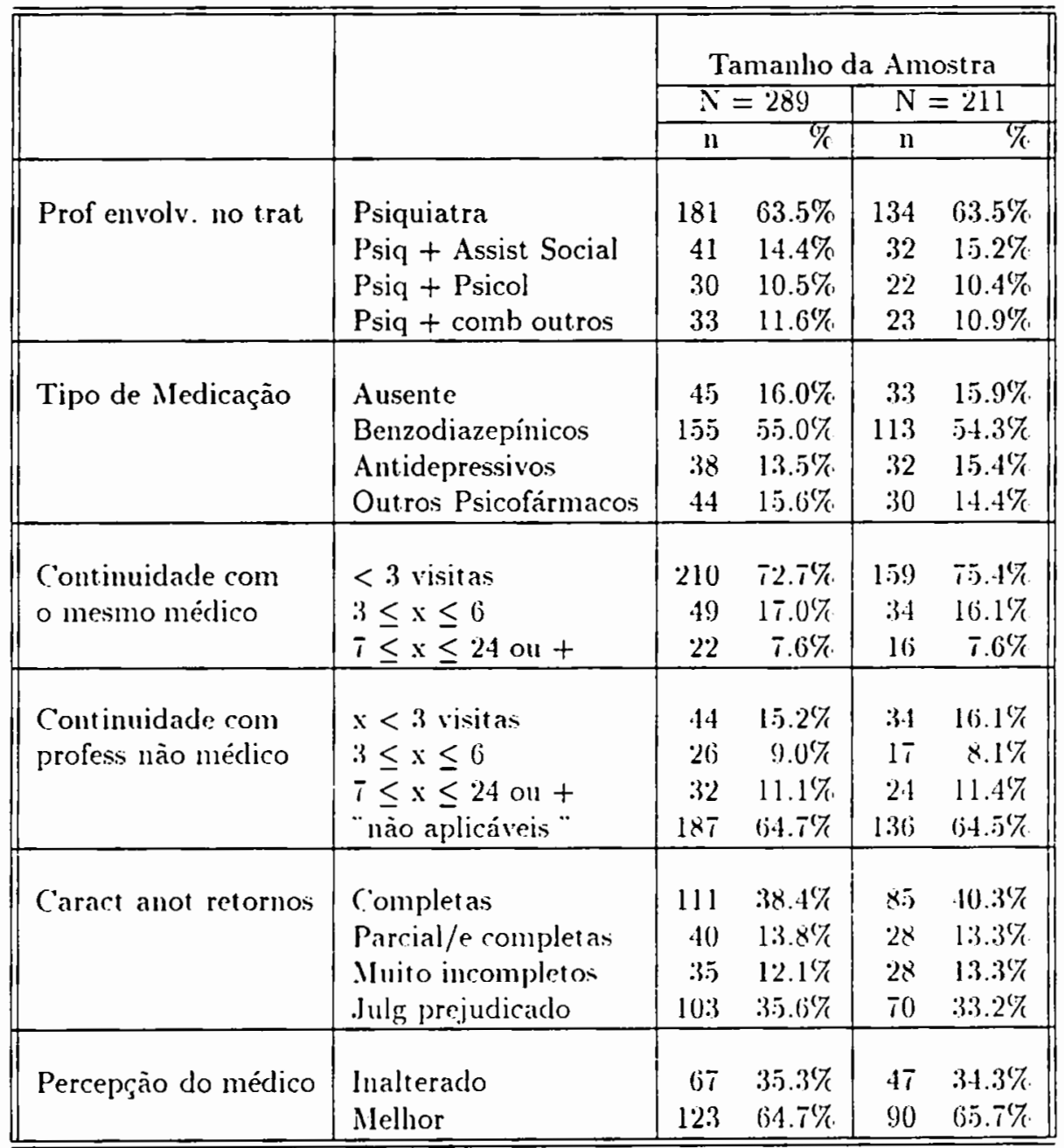


por terem recebido alta ou por encontrarem-se melhor (43\%), por dificuldades de acesso $(23 \%)$, por críticas ao serviço $(20 \%)$, ou por terem sido encaminhados ou perdido contato com o serviço por razões diversas (10\%). Cerca de $4 \%$ referia ainda seguir em tratamento.

Poderíamos também especular se esses tratamentos breves não podem ser explicados em parte por terem sido os quadros reativos os que mais freqüentemente estiveram relacionados à essa curta duração. Não queremos dizer que quadros reativos necessitem apenas uma consulta, ou tratamentos de menos de um mês, mas, como os pacientes já numa primeira visita recebem algum apoio psicológico, além de serem muitas vezes medicados, ao terem alguma dificuldade de acesso, ou se apresentarem logo de início alguma melhora, podem por essas duas razões associadas deixar o tratamento.

Aproximadamente metade dos pacientes (48.3\%) visitou o serviço de 2 a 5 vezes, enquanto que $24.2 \%$ freqüentou-o de 6 a 30 vezes. Uma minoria de $7.1 \%$ fez mais de 30 visitas. Provavelmente eram pacientes submetidos à psicoterapia.

Com relação ao número total de visitas ao serviço nossos dados são relativamente similares à outros trabalhos $(48,114)$ no tocante à porcentagem de pacientes com 5 visitas ou menos. A partir daí, nossos dados apresentam uma proporção um pouco maior que a dos trabalhos citados, de usuários com mais de 10 consultas.

No que diz respeito à média de visitas (total de visitas/ duração do tratamento), a maioria dos pacientes (48.9\%) visitava o serviço uma vez à cada 2 meses (ou em menor freqüência). Ao redor de 1 vez ao mês em 16.6\% dos casos. De mais de uma, até 2 visitas/mês em $17.1 \%$ das vezes e mais de 2 a 4 visitas/mês em $11.8 \%$ dos casos. Uma minoria de pacientes $(5.7 \%)$ poder-se-ia considerar de grandes usuários, pois vinham mais de 4 vezes ao mês.

Não foram anotadas faltas em $50.5 \%$ dos casos, sendo que $33.7 \%$ dos pacientes tiveram de 1 a 2 faltas.

Comparando-se a média de visitas de aproximadamente $50 \%$ de nossos pacientes, com o índice de freqüência de visitas do total de pacientes de ambulatórios 
psiquiátricos de uma cidade do interior de São Paulo, nossa média de visitas é menor que a do ambulatório universitário (cerca de 1 retorno/mês) estudado, e quase similar à freqüência de retornos do ambulatório do hospital psiquiátrico regional (17). De qualquer forma, os dados desse trabalho eram do início da década dos oitenta, e como no próprio trabalho se observava uma tendência decrescente da freqüência de retorno em ambos serviços, pode ser que 10 anos depois os índices não sejam muito diferentes dos nossos (17).

Receberam tratamento apenas farmacológico $48.8 \%$ dos casos; apenas psicoterapia (5.7\%); uma combinação de psicoterapia e fármacos $(24.9 \%)$, e em $7.7 \%$ das vezes houve internação em Hospital-dia associada à tratamento farmacológico e/ou psicoterápico. Receberam apenas orientação e alta, ou encaminhamento para outras clínicas da Faculdade ou serviços da região $12.9 \%$ dos pacientes.

Comparando-se o tratamento efetivamente recebido com as indicações feitas no caso novo, se nota que aumentaram os índices de tratamento apenas medicamentoso (de $36.5 \%$ para $48.8 \%$ ), diminuíram os índices de psicoterapia exclusivamente (de $14.2 \%$ para $5.7 \%$ ) e de psicoterapia combinada com fármacos (de $29.9 \%$ para $24.9 \%$ ). Também ocorreram mais internações no hospital-dia e mais encaminhamentos para outros serviços, apesar de que esses dois últimos dados são passíveis de se esperar ao longo do tratamento.

Com relação à esses dados, apesar de que quase a metade dos pacientes recebeu alguma abordagem psicoterápica, maior porcentagem que essa recebeu medicação (ainda que em parte associada à terapia), e portanto voltamos a assinalar que em função dos diagnósticos com os quais estamos trabalhando, essa relação deveria ser inversa. Existem dados que demonstram que mesmo num serviço de saúde mental em Centro de Saúde, e com equipe mínima, se pode oferecer à pacientes com esses diagnósticos mais psicoterapia que fármacos (114).

Em termos de tempo de duração do uso de medicamentos, 54\% dos pacientes utilizaram a medicação por um período de 1 ano ou menos, enquanto que $20.5 \%$ 
ultrapassaram esse periodo. É interessante notar que $25.5 \%$ dos pacientes não utilizou medicação alguma ao longo do tratamento.

Observando-se o tempo de uso de medicamentos, e a não utilização deles por uma boa parcela de pacientes, esses dados fazem com que o serviço avaliado se diferencie parcialmente do padrão de atendimento ambulatorial muito rápido, centrado apenas em medicamentos e com retornos muito esparsos citado por Bezerra (5).

Analisando-se os tipos de psicoterapia que realmente foram recebidos, psicoterapia grupal $(27 \%)$ prevaleceu sobre a psicoterapia individual (15.2\%). Utilizaram-se técnicas de relaxamento em $1.4 \%$ dos pacientes. Houve $8.1 \%$ de internações parciais (Hospital Dia) e nenhuma internação em Hospital Psiquiátrico.

Esses dados são um pouco distintos dos apresentados por Contel (17), em uma avaliação de um ambulatório universitário, onde predominava a psicoterapia individual sobre a grupal. $O$ fato de que não houve nenhuma internação em hospital psiquiátrico (internação total), é coerente com os diagnósticos estudados, apesar de $7.7 \%$ dos casos terem sido encaminhados para internação no hospital-dia pertencente ao serviço. Não dispomos de dados para comparar esse índice de internações parciais (para pacientes com os diagnósticos aqui estudados), com o de outros serviços em nosso país. Mas de qualquer forma, que nenhum paciente tenha sido internado em hospitais psiquiátricos, isso demonstra uma postura do serviço contrária ao uso desse recurso, a não ser em casos estritamente necessários.

Não encontramos diferenças importantes entre os que receberam terapia com frequêencia semanal $(10.4 \%)$, ou quinzenal (12.3\%). Em menor proporção (8.5\%), houve quem recebeu psicoterapia numa freqüência variável.

Apesar de na maioria das vezes não ter sido possível obter a informação sobre o tempo ocorrido entre o encaminhamento para terapia e o início desta, em $35 \%$ dos casos onde isso foi possível de ser verificado, $78.1 \%$ dos pacientes tardavam 1 mês ou menos para iniciar o processo terapêutico. Porém, $21.9 \%$ dos pacientes esperaram de 2 a 19 meses para serem chamados para psicoterapia. 
Os achados acima citados nos fazem pensar se essa perda de informações (em apenas $35 \%$ dos casos pudemos saber o tempo entre encaminhamento e início) não se deve ao fato de que grande parte dos pacientes que receberam indicação de psicoterapia no Caso Novo nunca chegaram a recebê-la a partir desse encaminhamento, e que os que se submeteram à terapia chegaram à ela por vias diversas ao longo do tratamento. Existe uma fila de espera para psicoterapia, onde todos os pacientes que recebem essa indicação preenchem uma ficha. $\mathrm{O}$ que se observa é que muitas vezes quem está na fila nem sempre é chamado, enquanto outros iniciam a terapia por vias "paralelas". Assim, ainda que exista uma proporção bastante parecida (ainda que um pouco menor) entre psicoterapias "indicadas" na primeira consulta, e "recebidas", não sabemos se estes são os mesmos casos da primeira indicação.

Quanto ao profissional que esteve envolvido no tratamento, a grande maioria dos casos $(63.5 \%)$ foi vista apenas por psiquiatras. Foram atendidos por assistentes sociais conjuntamente com psiquiatra $15.2 \%$ dos pacientes; $10.4 \%$ por psicólogos e psiquiatras e em $10.9 \%$ das vezes houve uma combinação de mais de um profissional juntamente com um psiquiatra (por exemplo: assistente social + terapeuta ocupacional + psiquiatra).

$\mathrm{O}$ fato do psiquiatra na maioria das vezes ser o único profissional envolvido no tratamento, nos faz pensar se esse tipo de divisão de serviços não poderia "facilitar" que um tipo de tratamento mais centrado em fármacos prevalecesse, e portanto, se quiséssemos que outras alternativas de tratamento predominassem, haveria que ocorrer um maior envolvimento de profissionais não médicos nos cuidados à pacientes com os diagnósticos estudados. Isso não quer dizer que os médicos não possam oferecer terapia (a maioria dos psiquiatras desse serviço atendem pacientes em psicoterapia), mas o que ocorre no modelo de serviço que estamos avaliando é que muitas vezes, na divisão de tarefas, ao psiquiatra lhe é deixada a função de cuidar dos aspectos psicofarmacológicos, ou dar supervisão 
aos residentes em suas prescrições, e em menor parcela encarregar-se diretamente das psicoterapias.

Os psicofármacos mais utilizados foram benzodiazepínicos (54.3\%), seguidos por antidepressivos, que sozinhos, ou em combinação com outras drogas (principalmente benzodiazepínicos), foram utilizados em $15.4 \%$ dos casos.

Quando se avalia a continuidade do tratamento com um mesmo médico, se observa que de forma geral $(75.4 \%)$ os pacientes eram vistos poucas vezes (menos de 3 vezes) por um mesmo médico. De 3 a 6 vezes (16.1\%) e de 7 até mais de 24 vezes em $7.6 \%$ dos casos.

A continuidade foi razoavelmente maior quando os envolvidos no tratamento eram profissionais não médicos. Quando nos foi possível verificar esse aspecto, apesar de predominar um baixo número de visitas (45.3\% era visto menos de 3 vezes), $22.7 \%$ dos casos foi seguido de 3 a 6 vezes, e ao redor de $32 \%$ foi visto de 7 a mais de 24 vezes pelo mesmo profissional. Este último dado difere acentuadamente do observado com os médicos.

De qualquer forma, para se falar de continuidade maior ou menor, há de se valorar os achados acima em relação à duração do tratamento. Mas ainda assim, o fato dos pacientes serem vistos poucas vezes pelo mesmo médico tem a ver com aspectos organizativos do serviço como por exemplo, o rodízio dos residentes. Se houver interesse na melhora de qualidade do serviço, algumas modificações nesses aspectos organizativos terão que ser feitas para reverter tal situação. A continuidade com profissionais não médicos foi um pouco maior provavelmente pelo fato de que a maior parte das psicoterapias (principalmente a grupal) ser oferecida por esses profissionais. Como o aspecto da continuidade pode estar vinculado à resultados positivos ou negativos, mais adiante, ao discutirmos as associações voltaremos a esse tema

Quanto às anotações nos retornos, em $40.3 \%$ dos casos poderíamos considerá-las completas. Cerca de 13\% continham um mínimo de informações, e $13.3 \%$ delas 
eram muito incompletas. Com referência à questão da qualidade/quantidade das anotações, os números acima deixam muito a desejar.

Um dos aspectos importantes na revisão dos prontuários foi a obtenção da percepção do médico com relação à melhora ou piora do paciente com o tratamento. Deixamos de obter esse dado em muitos casos, principalmente naqueles que vieram em apenas 1 consulta, ou quando pelas anotações não ficava claro qual a opinião do médico. Nesses casos, sempre que havia pouca precisão, deixávamos de anotar a posição do médico.

Em função disso, obtivemos a percepção do médico de melhora ou piora com o tratamento, em um total de 137 prontuários.

Em $65.7 \%$ dos pacientes o médico considerou que houve melhora dos sintomas (90 casos, 80 dos quais foram considerados que estavam "melhor" e 10, "muito melhor"); portanto, um resultado positivo. Em 34.3\% observou-se um resultado negativo, já que o médico opinava que o caso na grande maioria das vezes estava inalterado ou pior (47 casos, 46 dos quais "inalterados" e apenas 1 "pior").

- Mais adiante compararemos esses resultados com os obtidos do próprio paciente através da entrevista domiciliar, cujos dados passamos agora a descrever (Vide Tabela R.4):

Através da entrevista domiciliar $66.5 \%$ dos pacientes ( 139 casos, 123 dos quais referiam sentir-se "melhor" e 16 "muito melhor") referiam sentir-se melhor dos sintomas em função do tratamento. Um resultado negativo foi observado em $33.5 \%$ dos pacientes (70 casos, 63 dos quais referiam encontrar-se "na mesma", 5 "piores" e 2 "muito piores") que referiam estar na mesma ou piores em relação ao início do tratamento.

É interessante notar que houve uma correlação entre a percepção do médico e do paciente com relação aos resultados do tratamento. Como pode-se observar, as cifras acima, não diferem em muito da percepção do médico, apesar do número de sujeitos avaliados nessas duas situaçōes ser diferente. 
Tabela R.4: Entrevista Domiciliar

\begin{tabular}{|c|c|c|c|c|c|}
\hline & & \multicolumn{4}{|c|}{ Tamanho da Amostra } \\
\hline & & \multicolumn{2}{|c|}{$\mathrm{N}=289$} & \multicolumn{2}{|c|}{$N=211$} \\
\hline & & $\mathrm{n}$ & $\%$ & $\mathrm{n}$ & $\%$ \\
\hline Percepção paciente & $\begin{array}{l}\text { (R-) Inalt/pior } \\
\text { (R+) Melhor } \\
\text { Inf.ausente }\end{array}$ & $\begin{array}{r}73 \\
140 \\
76 \\
\end{array}$ & $\begin{array}{r}34.3 \% \\
65.7 \% \\
-\end{array}$ & $\begin{array}{r}70 \\
139 \\
2 \\
\end{array}$ & $\begin{array}{r}33.5 \% \\
66.5 \% \\
-\end{array}$ \\
\hline Razōes Int. Trat. & $\begin{array}{l}\text { Nào interr/segue trat. } \\
\text { Alta/Int por sentir-se ben } \\
\text { Insat/críticas/ineficácia } \\
\text { Dificuldades de acesso } \\
\text { Enc.p/ outro serviço }\end{array}$ & $\begin{array}{l}43 \\
65 \\
38 \\
38 \\
27 \\
\end{array}$ & $\begin{array}{l}20.4 \% \\
30.8 \% \\
18.0 \% \\
18.0 \% \\
12.8 \% \\
\end{array}$ & $\begin{array}{l}43 \\
65 \\
37 \\
37 \\
25\end{array}$ & $\begin{array}{l}20.8 \% \\
31.4 \% \\
17.9 \% \\
17.9 \% \\
12.1 \% \\
\end{array}$ \\
\hline Util, outros serv. & $\begin{array}{l}\text { Não } \\
\text { Serv Púb S.mental } \\
\text { Médico particular } \\
\text { Outros serv nào psiq. } \\
\text { Fora do sist tradicional } \\
2 \text { oll mais serv. }\end{array}$ & $\begin{array}{r}152 \\
26 \\
14 \\
9 \\
6 \\
6 \\
\end{array}$ & $\begin{array}{l}71.4 \% \\
12.2 \% \\
6.6 \% \\
4.2 \% \\
2.8 \% \\
2.8 \% \\
\end{array}$ & $\begin{array}{r}149 \\
26 \\
14 \\
9 \\
6 \\
5\end{array}$ & $\begin{array}{l}71.3 \% \\
12.4 \% \\
6.7 \% \\
4.3 \% \\
2.9 \% \\
2.4 \% \\
\end{array}$ \\
\hline Satisf. geral c/ trat. & $\begin{array}{l}\text { Insatisfeitos } \\
"+/-" \text { satisfeitos } \\
\text { Satisfeitos }\end{array}$ & $\begin{array}{r}22 \\
43 \\
150 \\
\end{array}$ & $\begin{array}{l}10.2 \% \\
20.0 \% \\
69.8 \% \\
\end{array}$ & $\begin{array}{r}22 \\
41 \\
148 \\
\end{array}$ & $\begin{array}{l}10.4 \% \\
19.4 \% \\
70.1 \%\end{array}$ \\
\hline
\end{tabular}


No momento da entrevista, $20.8 \%$ dos pacientes seguiam em tratamento e $31.4 \%$ referiam haver recebido alta médica ou interrompido o tratamento por sentirem-se melhor. O restante dos pacientes $(47.9 \%)$ que interromperam o tratamento atribuíram esse fato à dificuldades de "acesso" em $17.9 \%$ dos casos; à "insatisfação, inadaptação ao tratamento, ou críticas objetivas ao serviço ou à profissionais" (17.9\%), e finalmente $12.1 \%$ dos pacientes perderam contato com o serviço por "razões diversas" (faltou e não remarcou, o serviço ficou de chamar para terapia e nunca o fez) ou por "ter sido encaminhado para outros serviços da região".

Em $71.3 \%$ dos casos os pacientes referiram não terem feito uso de outros serviços de saúde mental simultaneamente ao tratamento. Entre os $28.7 \%$ restantes que em algum período utilizaram outro tipo de recurso durante o tratamento, a maioria (12.4\%) utilizou serviços públicos de saúde mental, $6.7 \%$ das pessoas visitaram médicos particulares, $4.3 \%$ utilizaram serviços fora dos municípios estudados, ou serviços não psiquiátricos. Recursos fora do sistema tradicional de saúde (benzedeiras, espiritismo, terreiros de umbanda...) foram utilizados por $2.9 \%$ dos pacientes, e $2.4 \%$ dos casos utilizaram mais de um tipo de serviço ao mesmo tempo em que se tratavam.

Para finalizar, apresentamos mais alguns dados sócio demográficos provenientes da entrevista domiciliar: um maior número de pacientes $(42.2 \%)$ vivia em domicílios constituídos por 3 a 4 pessoas. Cerca de $37 \%$ viviam em famílias de 5 a 8 pessoas. Ao redor de $21 \%$ dos pacientes viviam sozinhos, ou com apenas mais uma pessoa. O grau de escolaridade do "chefe" da família, de forma similar ao observado entre os pacientes, seguia sendo baixo, com $50 \%$ das pessoas tendo recebido 4 anos ou menos de educação regular. Já o índice de não alfabetização era um pouco menor $(4.3 \%)$.

As ocupações mais freqüentemente desenvolvidas pelos "chefes" de família eram ocupações manuais $(41.2 \%)$, com predominância das ocupações manuais especializadas (29.1\%). Exerciam ocupações não manuais $29.1 \%$ das pessoas, e 
28.2\% se encontravam no grupo de "inativos" (aposentados, pensionistas, desempregados...). Diferentemente do que ocorreu com os pacientes em tratamento, apenas $1.5 \%$ das pessoas consideradas como "chefes" de família, tinham "prendas domésticas" como sua ocupação primordial.

- Dados sobre os resultados do questionário de "satisfação com o tratamento":

No que diz respeito à satisfação com o tratamento, utilizaremos a Tabela R5 para simplificar a exposição dos resultados; mas se pode dizer que de modo geral, a maioria dos pacientes $(70.1 \%)$, manifestou-se satisfeita com o tratamento.

Razoavelmente ("mais ou menos") satisfeitos estiveram em 19.4\% dos casos, e $10.4 \%$ referiu insatisfação em relação ao tratamento recebido.

Analisando-se isoladamente, os itens do questionário que receberam uma maior freqüência de avaliação positiva foram: "limpeza do consultório"(99.1\%); "bom atendimento (cordialidade, atenção) por parte dos funcionários da recepção"(96.7\%); "atenção às queixas por parte do médico/ profissional que atendia"(92.4\%), e "recomendação para amigos" (92.4\%).

Os que mais freqüentemente receberam uma avaliação negativa foram: "tempo de espera nos dias de consulta" (36\%), "tempo de espera para obtenção da primeira consulta" (25.1\%), logo seguido por "dificuldade/facilidade de acesso e localização" (21.4\%).

$\mathrm{Na}$ escala de 5 pontos existente em cada pergunta, a questão com maior "score positivo" foi a que se referia ao "bom atendimento recebido por parte dos funcionários da recepção"(46.5\%), e o maior "score negativo" foi para a questão "tempo de espera nos dias de consulta" (9.8\%).

Podemos dizer que 0 índice de satisfação geral encontrado neste estudo encontrase próximo aos valores apresentados em inúmeros outros trabalhos sobre satisfação $(59,60,41,30,13,26,67)$.

É interessante notar que os tópicos mais freqüentemente avaliados de forma negativa dizem respeito mais à aspectos da organização do serviço que à aspectos 
Tabela R.5: Questionário de Satisfação c/ o Tratamento

\begin{tabular}{|c|c|c|c|c|c|c|c|}
\hline & \multirow{3}{*}{ Questão } & \multicolumn{6}{|c|}{ Grau de Satisfação } \\
\hline & & \multicolumn{2}{|c|}{ Insat. } & \multicolumn{2}{|c|}{$(+/-)$} & \multicolumn{2}{|c|}{ Satisf. } \\
\hline & & $\mathrm{n}$ & & $\mathrm{n}$ & $\%$ & $\mathrm{n}$ & $\%$ \\
\hline 1 & Acesso/Localização & 45 & $21.4 \%$ & 30 & $14.3 \%$ & 135 & $64.3 \%$ \\
\hline 2 & Tempo marc. $1^{a}$ consulta & 52 & $25.1 \%$ & 39 & $18.8 \%$ & 116 & $56.0 \%$ \\
\hline 3 & Cordialidade (Recepção) & 2 & $0.9 \%$ & 5 & $2.4 \%$ & 204 & $96.7 \%$ \\
\hline 4 & Adequaçào Horários & 11 & $5.2 \%$ & 19 & $9.0 \%$ & 181 & $85.8 \%$ \\
\hline 5 & Sala espera/conforto & 11 & $5.2 \%$ & 33 & $15.6 \%$ & 167 & $79.1 \%$ \\
\hline 6 & Sala espera/limpeza & 3 & $1.4 \%$ & 25 & $11.8 \%$ & 183 & $86.7 \%$ \\
\hline 7 & Tempo espera consulta & 76 & $36.0 \%$ & 78 & $37.0 \%$ & 5 & $27.0 \%$ \\
\hline 8 & Consultório/conforto & 2 & $0.9 \%$ & 32 & $15.2 \%$ & $17 T$ & $83.7 \%$ \\
\hline 9 & Consultório/limpeza & & & 2 & $0.9 \%$ & 209 & $99.1 \%$ \\
\hline 10 & Atenção Profissional & 5 & $2.4 \%$ & 11 & $5.2 \%$ & 195 & $92.4 \%$ \\
\hline 11 & Inform rec.(Qtidade) & 28 & $13.5 \%$ & 71 & $34.1 \%$ & 109 & $52.4 \%$ \\
\hline 12 & Inf.receb. (Facil.ent.) & 15 & $7.5 \%$ & 38 & $19.0 \%$ & 147 & $73.5 \%$ \\
\hline 13 & Facilidade remarcaçào* & 9 & $4.3 \%$ & 7 & $3.3 \%$ & 37 & $17.5 \%$ \\
\hline 14 & Acesso à emergência* & 4 & $1.9 \%$ & 5 & $2.1 \%$ & 21 & $10.0 \%$ \\
\hline 15 & Acerto no trat. & 16 & $8.1 \%$ & 53 & $26.8 \%$ & 129 & $6.5 .2 \%$ \\
\hline 16 & Expect. com o trat. & 18 & $8.7 \%$ & 70 & $33.8 \%$ & 119 & $57.5 \%$ \\
\hline 17 & Melhora/piora trat. & $T$ & $3.4 \%$ & 54 & $26.1 \%$ & 146 & $70.5 \%$ \\
\hline 18 & Recomend. amigos & 13 & $6.2 \%$ & 3 & $1.4 \%$ & 194 & $92.4 \%$ \\
\hline 19 & Voltaria ao trat. & 11 & $5.3 \%$ & 6 & $2.9 \%$ & 189 & $91.7 \%$ \\
\hline 20 & Satisf. Geral & 22 & $10.4 \%$ & 41 & $19.4 \%$ & 148 & $70.1 \%$ \\
\hline
\end{tabular}


interpessoais ou técnicos. Vários dos aspectos insatisfatórios revelados pelo questionário poderiam ser modificados apenas com alterações não muito complexas na organização do serviço tais como alterações no horário de marcação dos atendimentos, modificações no modo de agendamento, possível criação de um serviço de "pré-consultas" que desse prioridade a casos mais urgentes, etc...Também se poderia pensar em modificações no número de casos novos a serem agendados. Se poderia aumentar o número de primeiras visitas, se fossem modificadas certas técnicas de seguimento... De qualquer forma, aspectos bastante importantes do tratamento, tanto técnicos, quanto da interrelação pessoal, foram avaliados positivamente.

Também vale a pena notar que houve uma aproximação numérica acentuada (70.1\% e 66.5\%) entre os itens "satisfação geral" e "percepção por parte do paciente de melhora ou piora com o tratamento".

- Apresentação dos dados resultantes da comparação entre os grupos de resultados positivos (GR+), e resultados negativos (GR-).

A definição de positivo ou negativo foi baseada na percepção por parte do paciente, de melhora ou piora com o tratamento, expressada através das entrevistas domiciliares.

Com relação às variáveis sócio demográficas (Vide Tabela R.1.2), segue havendo predomínio do sexo feminino nos dois grupos, mas no GR- existe uma porcentagem maior de homens (32.9\%); quase o dobro, quando comparado ao $\mathrm{GR}+(16.5 \%$ de homens $)$.

Quase não se observam diferenças entre os grupos com relação à idade. Uma pequena diferença de porcentagem (2.3\%) de pessoas na faixa acima dos 50 anos se encontra no GR-, mais que no GR+.

Segue havendo um predomínio de casados/união livre, mas no GR- existe uma porcentagem maior $(67.1 \%)$ de casados que no GR+ (61.3\%). 
Tabela R.1.2: Características Sóciodemográficas dos sujeitos Grupos $(\mathrm{R}+) \times(\mathrm{R}-)$

\begin{tabular}{|c|c|c|c|c|c|}
\hline & \multicolumn{4}{|c|}{ Tamanho da Amostra } \\
\hline & & \multicolumn{2}{|c|}{$\mathrm{N}=70(\mathrm{R}-)$} & \multicolumn{2}{|c|}{$\mathrm{N}=139(\mathrm{R}+)$} \\
\hline & & $\mathrm{n}$ & $\%$ & $\mathrm{n}$ & $\%$ \\
\hline Sexo & $\begin{array}{l}\text { Masc. } \\
\text { Fem. }\end{array}$ & $\begin{array}{l}23 \\
47\end{array}$ & $\begin{array}{l}32.9 \% \\
67.1 \%\end{array}$ & $\begin{array}{r}23 \\
116\end{array}$ & $\begin{array}{l}16.5 \% \\
83.5 \%\end{array}$ \\
\hline Idade & $\begin{array}{l}x \leq 34 \\
35 \leq x \leq 49 \\
x \geq 50\end{array}$ & $\begin{array}{l}28 \\
22 \\
19\end{array}$ & $\begin{array}{l}40.6 \% \\
31.9 \% \\
27.5 \%\end{array}$ & $\begin{array}{l}56 \\
48 \\
35\end{array}$ & $\begin{array}{l}40.3 \% \\
34.5 \% \\
25.2 \%\end{array}$ \\
\hline Est. Civil & $\begin{array}{l}\text { Solteiros } \\
\text { Casados } \\
\text { Viúvos/Divor. }\end{array}$ & $\begin{array}{l}13 \\
47 \\
10\end{array}$ & $\begin{array}{l}18.6 \% \\
67.1 \% \\
14.3 \%\end{array}$ & $\begin{array}{l}30 \\
84 \\
23\end{array}$ & $\begin{array}{l}21.9 \% \\
61.3 \% \\
16.8 \%\end{array}$ \\
\hline $\begin{array}{l}\text { Escolaridade } \\
\text { (anos) }\end{array}$ & $\begin{array}{l}\text { Nenhum } \\
1 \leq x \leq 4 \text { anos } \\
5 \leq x \leq 8 \text { anos } \\
9 \leq x \leq 11 \text { anos } \\
x>11 \text { anos }\end{array}$ & $\begin{array}{r}4 \\
34 \\
14 \\
10 \\
8 \\
\end{array}$ & $\begin{array}{r}5.7 \% \\
48.6 \% \\
20.0 \% \\
14.3 \% \\
11.4 \% \\
\end{array}$ & $\begin{array}{r}9 \\
58 \\
33 \\
29 \\
10 \\
\end{array}$ & $\begin{array}{r}6.5 \% \\
41.7 \% \\
23.7 \% \\
20.9 \% \\
7.2 \% \\
\end{array}$ \\
\hline Ocupação & $\begin{array}{l}\text { Nào manual } \\
\text { Manual esp. } \\
\text { Man. semi/nào esp. } \\
\text { Outros (inat/est) } \\
\text { Prendas dom. } \\
\end{array}$ & $\begin{array}{r}17 \\
13 \\
13 \\
4 \\
23 \\
\end{array}$ & $\begin{array}{r}24.3 \% \\
18.6 \% \\
18.6 \% \\
5.7 \% \\
32.9 \% \\
\end{array}$ & $\begin{array}{l}25 \\
25 \\
12 \\
12 \\
64 \\
\end{array}$ & $\begin{array}{l}18.1 \% \\
18.1 \% \\
8.7 \% \\
8.7 \% \\
46.4 \% \\
\end{array}$ \\
\hline Procedencia & $\begin{array}{l}\text { Urbana(Botucatu) } \\
\text { Erbana(S.Manoel) } \\
\text { Rural }\end{array}$ & $\begin{array}{r}57 \\
13 \\
0\end{array}$ & $\begin{array}{r}81.4 \% \\
18.6 \% \\
0.0 \%\end{array}$ & $\begin{array}{r}110 \\
26 \\
3 \\
\end{array}$ & $\begin{array}{r}79.1 \% \\
18.7 \% \\
2.2 \% \\
\end{array}$ \\
\hline Renda per cap. & $\begin{array}{l}x<1 \text { sal.min } \\
1 \leq x<2 \\
2 \leq x<5 \\
5 \leq x<15\end{array}$ & $\begin{array}{r}25 \\
32 \\
12 \\
1\end{array}$ & $\begin{array}{l}35.7 \% \\
45.7 \% \\
17.1 \% \\
1.4 \%\end{array}$ & $\begin{array}{r}49 \\
56 \\
30 \\
2\end{array}$ & $\begin{array}{l}35.8 \% \\
40.9 \% \\
21.9 \% \\
1.5 \%\end{array}$ \\
\hline
\end{tabular}


Tabela R.1.2 (segue): Caracteristicas Sóciodemográficas dos sujeitos Grupos $(R+) \times(R-)$

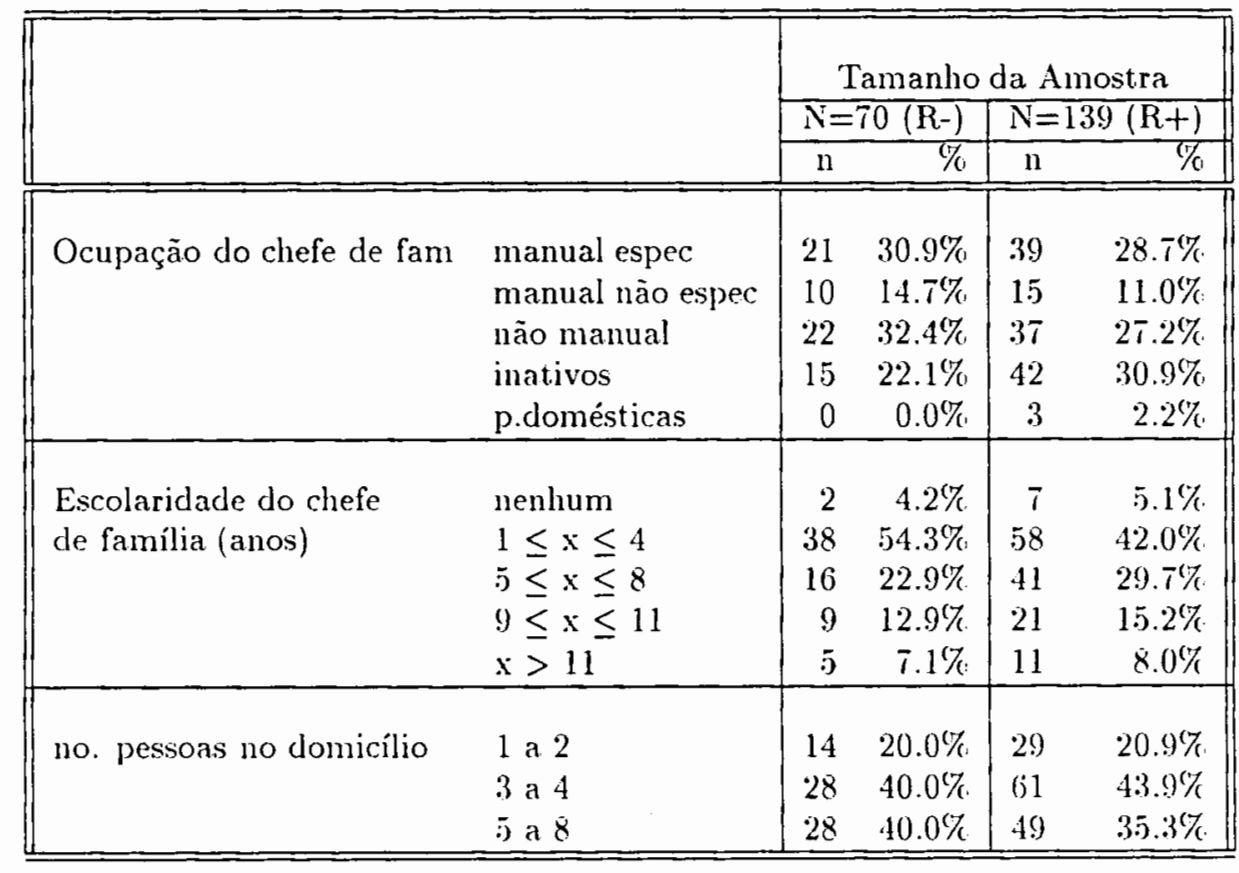


$\mathrm{O}$ GR + tem uma porcentagem maior de escolaridade na faixa intermediária de 5 a 11 anos (44.6\%) quando comparado ao GR- (34.3\%). Por outro lado, o GR- tem mais indivíduos com escolaridade acima de 11 anos (11.4\%), que o GR+ (7.2\%). Com relação à ocupação, a grande diferença entre grupos é que apesar de haver predomínio de "prendas domésticas", o GR+ tem maior porcentagem de "prendas domésticas" (46.4\%), que o GR- (32.9\%). O GR+ tem menor porcentagem de ocupações manuais semi ou não especializadas (8.75), quando comparado com o GR- (18.6\%). Porém, também existe uma maior porcentagem (24.3\%), de ocupações não manuais no GR- que no GR+ (18.1\%).

Não existiram diferenças importantes com relação a procedência, mas vale lembrar que no GR- não houve pacientes do meio rural.

Não ocorreram grandes diferenças com relação à renda per cápita, mas no GR+ houve uma porcentagem um pouco maior $(21.9 \%)$ de pessoas com renda entre 2 a 5 salários mínimos, quando comparado ao GR- (17.1\%). No GR- havia maior porcentagem de renda na faixa inferior de 1 a 2 salários (45.7\%), que no GR+ $(40.9 \%)$.

Com relação ao nível de escolaridade do "chefe" da família, o GR+ tinha uma maior porcentagem de indivíduos na faixa de 5 a 11 anos de escolaridade (44.9\%) que o GR- (35.8\%). No GR- era maior a porcentagem $(54.3 \%)$ de pessoas na faixa entre 1 e 4 anos, que no $\mathrm{GR}+(42 \%)$.

Encontramos também no GR-porcentagem um pouco maior (40\%) de famílias constituídas por 5 ou mais pessoas que no $\mathrm{GR}+(35.3 \%)$.

Em resumo, se poderia dizer que no GR-proporcionalmente havia mais homens (em termos relativos), mais casados/união livre, escolaridade intermediária (5-11 anos) menor (apesar de haver maior proporção de pessoas com nível superior), menor porcentagem de "prendas domésticas" (ainda que esta fosse a ocupação predominante), renda per cápita levemente inferior, famílias com maior número de pessoas, e "chefes" de família com escolaridade inferior, quando comparado ao GR+. 
Com exceção do sexo, estado civil e tipo de ocupação, as outras variáveis sócio demográficas mostram um grupo de pessoas com maiores "desvantagens" do ponto de vista sócio econômico, o que nos faz pensar se isso em si já não é um fator que predisporia (ou facilitaria) a um pior prognóstico no tratamento.

$O$ fato de que proporcionalmente havia mais homens no GR- (ainda que em termos absolutos predominassem as mulheres nos dois grupos), nos faz pensar se isso poderia estar correlacionado com maior grau de gravidade de sintomas (entre os homens) dentre os diagnósticos estudados. Uma vez que normalmente são as mulheres as maiores usuárias de serviços de saúde, poderíamos nos indagar se quando os homens procuram tratamento psiquiátrico não é porque já podem estar apresentando problemas de um maior nível de gravidade? Isso poderia parcialmente explicar um possivel prognóstico pior quanto ao resultado do tratamento. De qualquer forma, com os dados disponíveis, não foi possível quantificar a gravidade dos quadros estudados.

- Dados relativos ao Caso Novo - Comparação entre os grupos de resultado positivo (GR+), e negativos (GR-) (Vide Tabela R2.2).

No tocante à elaboração da anamnese psiquiátrica no Caso Novo, é interessante notar que houve pequena diferença entre os grupos com relação ao preenchimento da história clínica e antecedentes, tendo o GR+ apresentado uma porcentagem levemente maior $(86.3 \%)$ de preenchimento completo que o GR- $(84.3 \%)$. Entretanto, existe uma porcentagem bastante maior de casos onde não foram anotados os dados do exame fisico (e talvez não realizado) no GR- (30\%), quando comparamos com o GR+ (19.4\%). Também encontramos o exame psíquico preenchido de forma incompleta em maior proporção no GR- (20\%), que no GR+ $(13.7 \%)$.

No que diz respeito ao diagnóstico psiquiátrico principal praticamente não houve diferenças entre os grupos na porcentagem de "transtornos neuróticos". Houve um pequeno predomínio de "quadros reativos" no GR+ (20.9\%), em relação ao GR- 
Tabela R.2.2: Dados do Caso Novo

Grupos (R+) x (R-)

\begin{tabular}{|c|c|c|c|c|c|}
\hline & & \multicolumn{4}{|c|}{ Tamanho da Amostra } \\
\hline & & \multicolumn{2}{|c|}{$\mathrm{N}=70(\mathrm{R}-)$} & \multicolumn{2}{|c|}{$\mathrm{N}=139(\mathrm{R}+)$} \\
\hline & & & & $\mathrm{n}$ & $\%$ \\
\hline \multirow[t]{4}{*}{ Data do caso novo } & 1 & 15 & $21.4 \%$ & 30 & $21.6 \%$ \\
\hline & 2 & 21 & $30.0 \%$ & 37 & $26.6 \%$ \\
\hline & 3 & 17 & $24.3 \%$ & 38 & $27.3 \%$ \\
\hline & 4 & 17 & $24.3 \%$ & 34 & $24.5 \%$ \\
\hline \multicolumn{6}{|l|}{ Anamnese Psiquiátrica } \\
\hline \multirow[t]{2}{*}{ Preench H.Clín e ant } & Sim (comp.) & 59 & $84.3 \%$ & 120 & $86.3 \%$ \\
\hline & Sim (incomp.) & 11 & $15.7 \%$ & 18 & $13.0 \%$ \\
\hline \multirow[t]{3}{*}{ Preench. Ex. Físico } & Nào & 21 & $30.0 \%$ & 27 & $19.4 \%$ \\
\hline & Sim (comp.) & 32 & $45.7 \%$ & 58 & $41.7 \%$ \\
\hline & Sim (incomp.) & 14 & $20.0 \%$ & 43 & $30.9 \%$ \\
\hline \multirow[t]{3}{*}{ Preench. Ex. Psíquico } & Nào & 1 & $1.4 \%$ & 2 & $1.4 \%$ \\
\hline & Sim (comp.) & 52 & $74.3 \%$ & 107 & $7 \pi .0 \%$ \\
\hline & Sim (incomp.) & 14 & $20.0 \%$ & 19 & $13.7 \%$ \\
\hline \multirow[t]{2}{*}{ Tipo Hip. Diagnóstica } & Diag Psiquiát & 55 & $78.6 \%$ & 103 & $74.1 \%$ \\
\hline & Diag Psiq + não Psiq & 12 & $17.1 \%$ & 27 & $19.4 \%$ \\
\hline \multirow{3}{*}{$\begin{array}{l}\text { Diagn Principal } \\
\text { (agrupado) }\end{array}$} & Transt Neurót & 47 & $6 \pi .1 \%$ & 93 & $66.9 \%$ \\
\hline & Reaçōes & 12 & $17.1 \%$ & 29 & $20.9 \%$ \\
\hline & Código V & 11 & $15.7 \%$ & 17 & $12.2 \%$ \\
\hline \multirow{6}{*}{$\begin{array}{l}\text { Diagn Principal } \\
\text { (isoladamente) }\end{array}$} & Ansiedade $(300.0)$ & $2 \pi$ & $38.6 \%$ & $\bar{T}$ & $41.0 \%$ \\
\hline & Q. Histéricos (300.1) & $\bar{i}$ & $10.0 \%$ & $2: 3$ & $16.5 \%$ \\
\hline & Dep Neurótica² (300.4) & 10) & $14.3 \%$ & 12 & $8.6 \%$ \\
\hline & Reaç Ansiosa (309.2) & 5 & $7.1 \%$ & 13 & $9.4 \%$ \\
\hline & Reaç dep breve (309.0) & 5 & $7.1 \%$ & $i$ & $5.0 \%$ \\
\hline & Conf Conjugal (V61.1) & $i$ & $10.0 \%$ & 9 & $0.5 \%$ \\
\hline \multirow[t]{5}{*}{ Diagn. Secundário } & Ausente & 17 & $24.3 \%$ & 53 & $38.1 \%$ \\
\hline & Transt. Neuróticos & 31 & $44.3 \%$ & 42 & $30.2 \%$ \\
\hline & Código $V$. & 4 & $5.7 \%$ & 15 & $10.8 \%$ \\
\hline & Reaç. Ajustamento & i & $10.0 \%$ & 8 & $5.8 \%$ \\
\hline & Transt. Psicosom. & 4 & $5.7 \%$ & 11 & $7.9 \%$ \\
\hline \multirow[t]{7}{*}{ Diagn. nāo psiquiátrico } & Ausente & 54 & $77.1 \%$ & 102 & $73.4 \%$ \\
\hline & Hiper. Arterial & 8 & $11.4 \%$ & 4 & $2.9 \%$ \\
\hline & Neurológicos & 0 & $0.0 \%$ & 8 & $5.8 \%$ \\
\hline & Outros cardiovasc. & 1 & $1.4 \%$ & 5 & $3.6 \%$ \\
\hline & Sist. Gen-urinário & 1 & $1.4 \%$ & 5 & $3.6 \%$ \\
\hline & Endocrinológicos & 1 & $1.4 \%$ & 3 & $2.2 \%$ \\
\hline & Outros & 2 & $2.9 \%$ & 3 & $2.2 \%$ \\
\hline
\end{tabular}


Tabela R.2.2 (segue): Dados do Caso Novo Grupos $(\mathrm{R}+) \times(\mathrm{R}-)$

\begin{tabular}{|c|c|c|c|c|c|}
\hline & & \multicolumn{4}{|c|}{ Tamanho da Amostra } \\
\hline & & \multicolumn{2}{|c|}{$\mathrm{N}=70(\mathrm{R}-)$} & \multicolumn{2}{|c|}{$\mathrm{N}=139(\mathrm{R}+)$} \\
\hline & & $n$ & $\%$ & $\bar{n}$ & $\%$ \\
\hline C'onduta no caso novo & $\begin{array}{l}\text { Farmacológica } \\
\text { Psicoterapia (PI/PG) } \\
\text { Far+Pster(PI/PG/Rlx) } \\
\text { H.Dia+Outros proced. } \\
\text { Orient+encam+alt } \\
\end{array}$ & $\begin{array}{r}24 \\
6 \\
23 \\
4 \\
9\end{array}$ & $\begin{array}{r}34.3 \% \\
8.6 \% \\
32.9 \% \\
5.7 \% \\
12.9 \% \\
\end{array}$ & $\begin{array}{r}53 \\
24 \\
39 \\
7 \\
9 \\
\end{array}$ & $\begin{array}{r}38.1 \% \\
17.3 \% \\
28.1 \% \\
5.0 \% \\
6.5 \% \\
\end{array}$ \\
\hline Tipo de Medic. & $\begin{array}{l}\text { Não prescrita } \\
\text { Benzodiazepínicos } \\
\text { Antidepressivos } \\
\text { Benz+ antidep } \\
\text { Comb de Psicof } \\
\text { Pstrop+não Pstrop } \\
\text { Não psicotrópico }\end{array}$ & $\begin{array}{r}14 \\
39 \\
3 \\
5 \\
3 \\
1 \\
1 \\
\end{array}$ & $\begin{array}{r}20.0 \% \\
55.7 \% \\
4.3 \% \\
7.1 \% \\
4.3 \% \\
1.4 \% \\
1.4 \% \\
\end{array}$ & $\begin{array}{r}27 \\
78 \\
5 \\
7 \\
6 \\
3 \\
4\end{array}$ & $\begin{array}{l}19.4 \% \\
56.1 \% \\
3.6 \% \\
5.0 \% \\
4.3 \% \\
2.2 \% \\
2.9 \% \\
\end{array}$ \\
\hline Freq. admin. droga & $\begin{array}{l}1 \text { vez ao dia } \\
2 \text { vezes } \\
3 \text { vezes } \\
4 \text { vezes } \\
\end{array}$ & $\begin{array}{r}29 \\
20 \\
2 \\
1 \\
\end{array}$ & $\begin{array}{c}41.4 \% \\
28.6 \% \\
2.9 \% \\
1.4 \% \\
\end{array}$ & $\begin{array}{r}56 \\
35 \\
8 \\
0 \\
\end{array}$ & $\begin{array}{r}40.3 \% \\
25.2 \% \\
5.8 \% \\
0.0 \%\end{array}$ \\
\hline Ind.Psicoterapia & $\begin{array}{l}\text { Não } \\
\text { Sim }\end{array}$ & $\begin{array}{l}33 \\
33 \\
\end{array}$ & $\begin{array}{l}47.1 \% \\
47.1 \% \\
\end{array}$ & $\begin{array}{l}62 \\
655 \\
\end{array}$ & $\begin{array}{l}44.6 \% \\
46.8 \%\end{array}$ \\
\hline Duração transtorno & $\begin{array}{l}x<6 \text { meses } \\
6 \leq x<12 \text { meses } \\
1 \leq x<5 \text { anos } \\
+ \text { de } 5 \text { anos } \\
\end{array}$ & $\begin{array}{r}22 \\
9 \\
15 \\
21 \\
\end{array}$ & $\begin{array}{l}32.8 \% \\
13.4 \% \\
22.4 \% \\
31.3 \% \\
\end{array}$ & $\begin{array}{l}37 \\
24 \\
40 \\
34 \\
\end{array}$ & $\begin{array}{l}27.4 \% \\
17.8 \% \\
29.6 \% \\
25.2 \%\end{array}$ \\
\hline $\begin{array}{l}\text { Sentim. do entrevistador } \\
\text { (caso novo) }\end{array}$ & $\begin{array}{l}\text { Pos. Control } \\
\text { Neg. Control } \\
\text { Infor. não anot }\end{array}$ & $\begin{array}{l}47 \\
10 \\
13\end{array}$ & $\begin{array}{l}67.1 \% \\
14.3 \% \\
18.6 \%\end{array}$ & $\begin{array}{r}108 \\
13 \\
18\end{array}$ & $\begin{array}{r}-i .7 \% \\
9.4 \% \\
12.9 \%\end{array}$ \\
\hline
\end{tabular}


(17.1\%). Entretanto houve maior quantidade de diagnósticos do "Código V" no GR- (15.7\%), que no GR+ (12.2\%).

Essa diferença poderia ser explicada pelo fato de que um quadro reativo dentre os diagnósticos em estudo, poderia ser considerado em alguns casos (pela evolução possivelmente mais curta de seus sintomas), como um quadro de "menor gravidade", que muitas vezes pode ser "auto limitado", e que portanto seria mais fácil de estar associado a um resultado positivo.

Já os diagnósticos do Código $\mathrm{V}$ podem ser problemas mais localizados numa esfera "social", algumas vezes mais "crônicos" e portanto de mais dificil solução (por ex: conflito conjugal). Isso explicaria parcialmente sua ocorrência em maior número no GR-.

Quando analisamos o diagnóstico psiquiátrico principal isoladamente, nos chama a atenção um maior predomínio de "depressão neurótica" (14.3\%) e de "conflito conjugal" (10\%) no GR-. No GR+ esses diagnósticos apareceram em menor quantidade; $8.6 \%$ e $6.5 \%$ respectivamente. $\mathrm{O}$ que predominou no $\mathrm{GR}+$ em relação ao GR-, foram os "quadros histéricos".

De qualquer forma, numa forma resumida, se poderia dizer que no GR- houve maior proporção de diagnósticos de "depressão" (neurótica ou reativa) e de "problemas conjugais" comparado ao GR+, enquanto que neste ocorreu maior porcentagem de quadros de "ansiedade"(neuróticos ou reativos) e "quadros histéricos" que no GR-.

Este último achado; um maior número de quadros histéricos ligados a um resultado positivo já é mais difícil de se explicar, em função de ser muitas vezes um problema de dificil resolução, que nem sempre evolui bem dentro do padrão de atendimento ambulatorial convencional.

Observamos também que existe uma ausência maior de diagnósticos psiquiátricos secundários no GR+ (38.1\%), que no GR- (24.3\%). Neste grupo, onde proporcionalmente existem mais diagnósticos psiquiátricos secundários, os "transtornos neuróticos" (44.3\%) e as "reações de ajustamento" (10\%) foram os 
diagnósticos secundários encontrados de forma mais freqüente que no $\mathrm{GR}+$ ( $30.2 \%$ e $5.8 \%$, respectivamente).

Com relação aos diagnósticos não psiquiátricos é interessante ressaltar que houve uma maior porcentagem de pacientes com hipertensão arterial no GR- (11.4\%) que no GR+ $(2.9 \%)$. Neste grupo GR+, foram mais comuns os diagnósticos neurológicos (5.8\%) que no GR- onde esses diagnósticos não foram encontrados. Também vale assinalar que com relação ao número total de diagnósticos não psiquiátricos no caso novo, havia maior proporção de casos com "mais de um diagnóstico não psiquiátrico" no GR- (8.6\%) que no GR+ $(4.3 \%)$.

Em função desses últimos dados, poderíamos nos perguntar se a associação de doença orgânica (não psiquiátrica) ao problema emocional, não poderia estar funcionando como algo que favoreceria uma má evolução dos pacientes. Também o fato de haver maior número de pacientes com hipertensão arterial no GR- nos faz pensar em doentes com enfermidades "crônicas". Além disso, se observamos que no GR- havia maior número de diagnósticos de depressão, e também uma maior proporção relativa (se comparamos com o $\mathrm{GR}+$ ) de homens, esses dois últimos dados associados à hipertensão arterial, nos chama a atenção para algo que até o momento não havíamos percebido: é muito freqüente que a tríade "sexo masculino, depressão e hipertensão arterial" esteja associada a alcoolismo $(4,119,86,93)$. Como no GR- essa triade estava presente, poderíamos indagar se no que diz respeito ao transtorno psiquiátrico, parte dos pacientes pertencentes à esse grupo não eram portadores do diagnóstico de alcoolismo, ainda que não manifestassem tal problema de forma verbal. Uma vez que o diagnóstico não era feito (casos de alcoolismo ou outros problemas orgânicos eram excluídos da seleção para este estudo), e que o tratamento adequado não era oferecido, esse poderia ser um fator a mais para explicar uma parcela de resultados negativos. Assim sendo, maior atenção deveria ser prestada para detectar casos que poderiam estar passando despercebidos mesmo num ambulatório de psiquiatria. 
Nas condutas tomadas no caso novo, o que mais se faz notar é que houve maior freqüência de indicação de psicoterapia (como único recurso) no $\mathrm{GR}+(17.3 \%)$ que no GR- (8.6\%). Porém, psicoterapia associada à medicação era um pouco mais freqüente $(32.9 \%)$ no GR- que no GR+ $(28.1 \%)$. No GR- haviam mais casos de "orientação e/ou encaminhamentos/alta" (12.9\%) que no GR+ (6.5\%). Esse último dado nos faz pensar se o simples fato de alguém que procura tratamento ser orientado e encaminhado para outro serviço, ou receber orientação sobre seu problema e receber alta, não poderia "frustrar" o paciente, e portanto elicitar respostas negativas?

Poucas diferenças entre os dois grupos existiam com respeito ao tipo de medicação prescrita no caso novo, e quase nenhuma diferença se observou com relação ao tempo de evolução dos transtornos, se os dividimos em transtornos com evolução maior ou menor que 1 ano.

Foram mencionados sentimentos positivos controlados por parte de quem realizou a primeira consulta, em maior número no $\mathrm{GR}+(77.7 \%)$ que no $\mathrm{GR}-(67.1 \%)$. $\mathrm{O}$ oposto também ocorreu; maior menção de sentimentos negativos controlados no GR- (14.3\%) que no GR+ (9.4\%). Além disso, no GR- houve também uma menor anotação dessa informação que no GR+, o que nos faz pensar se esse item não foi anotado por uma lacuna casual no preenchimento do C.N., ou se isso indiretamente significava sentimentos negativos não reconhecidos objetivamente. As possiveis implicações disso discutiremos mais adiante ao comentarmos os resultados das associações.

- Dados de evolução: comparação entre GR+ e GR-(Vide Tabela R.3.2).

Praticamente não encontramos diferenças entre os dois grupos com respeito a encontrar-se em tratamento ou haver recebido alta ou interrompido o tratamento.

Por outro lado encontramos tratamentos com duração mais curta (1 mês ou menos) no GR+ (43.2\%) que no GR- (37.1\%), enquanto que essa relação se inverte para os tratamentos na faixa entre 2 e 12 meses de duração, mais 
freqüentes no GR- (37.1\%) que no GR+ (31.7\%). Acima de 12 meses não existem diferenças entre os grupos.

Também encontramos uma maior porcentagem de visitas (na faixa de 6-30 visitas) no GR+ $(27.3 \%)$, que no GR- (18.6\%).O GR- apresentava maior porcentagem na faixa de $2-5$ visitas (54.3\%), comparado ao $\mathrm{GR}+(46 \%)$.

Em termos de média de visitas, o GR- apresentou uma porcentagem um pouco maior (51.4\%) na faixa de 1 visita a cada 2 meses (ou freqüência de visita ainda menor), comparado ao $\mathrm{GR}+(46.7 \%)$. Os pacientes do $\mathrm{GR}+$ por sua vez estavam em um número um pouco maior (35.3\%) na faixa de 1 a 2 visitas/mês, que o GR(31.4\%). A partir de 2 a 4 visitas/mês, não havia diferenças entre os grupos.

Com respeito à duração do tratamento ter sido mais curta no GR+, e mais longa no GR-, isso nos remete novamente à questão de que possivelmente boa parte desses tratamentos mais curtos eram de quadros reativos, diagnósticos que poderiam responder ao tratamento de forma mais rápida, e também estar correlacionados à melhores resultados. Poderíamos nos perguntar se o GR- não tinha quadros de maior gravidade e que necessitariam tratamentos um pouco mais prolongados.

Também o número de visitas e sua freqüência, foi um pouco superior no GR+; ou seja que aparentemente havia uma "maior exposição" ao tratamento no GR+.

É importante acentuar que com relação ao tipo de tratamento recebido, praticamente não houve diferenças entre os dois grupos.

Analisando-se o tempo de uso de medicação, observa-se que entre os que não utilizaram drogas durante o tratamento, houve uma proporção um pouco maior (26\%) para o GR+ que entre os pacientes do GR- (23.3\%). Já uma maior porcentagem (23.3\%) de pessoas do GR-utilizou drogas por mais de 12 meses, comparado ao GR+ (19\%). Isso aparentemente poderia ter correlação com a duração do tratamento.

Quase não houve diferenças em relação à proporção de pacientes que foram internados no H.Dia, ou receberam psicoterapia individual. No tocante à psicoterapia grupal, os pacientes do GR- receberam psicoterapia grupal numa 
Tabela R.3.2: Dados da Evolução

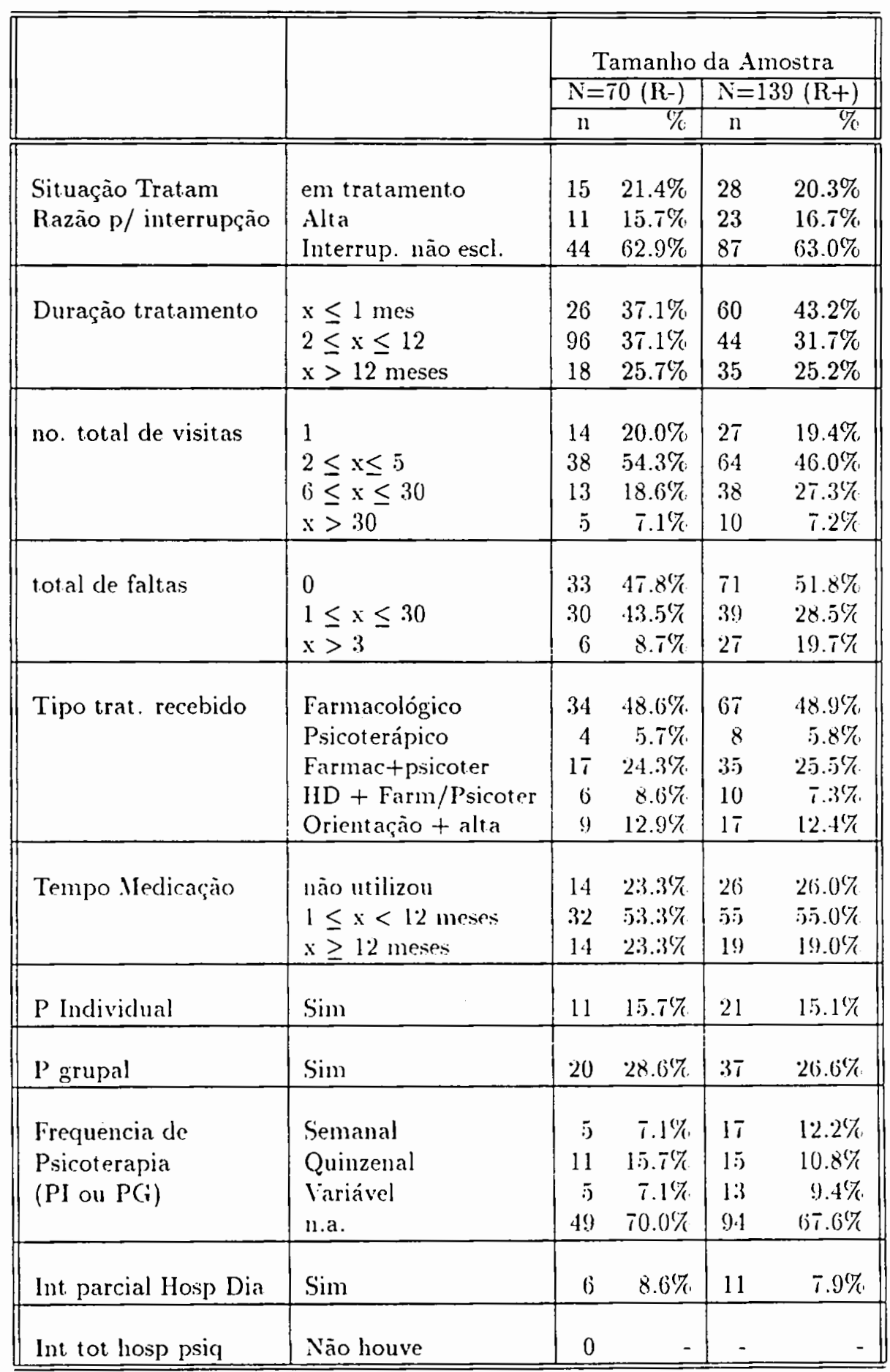


Tabela R.3.2 (segue): Dados da Evolução

\begin{tabular}{|c|c|c|c|c|c|}
\hline & & \multicolumn{4}{|c|}{ Tamanho da Amostra } \\
\hline & & \multicolumn{2}{|c|}{$N=70(\mathrm{R}-)$} & \multicolumn{2}{|c|}{$N=139(\mathrm{R}+)$} \\
\hline & & n & & II & $\%$ \\
\hline Prof envolv. no trat & $\begin{array}{l}\text { Psiquiatra } \\
\text { Psiq + Assist Social } \\
\text { Psiq + Psicol } \\
\text { Psiq + comb outros }\end{array}$ & $\begin{array}{r}44 \\
11 \\
7 \\
8 \\
\end{array}$ & $\begin{array}{l}62.9 \% \\
15.7 \% \\
10.0 \% \\
11.4 \% \\
\end{array}$ & $\begin{array}{l}88 \\
21 \\
15 \\
15\end{array}$ & $\begin{array}{l}63.3 \% \\
15.1 \% \\
10.8 \% \\
10.8 \% \\
\end{array}$ \\
\hline Tipo de Medicação & $\begin{array}{l}\text { Ausente } \\
\text { Benzodiazepínicos } \\
\text { Antidepressivos } \\
\text { Outros Psicofármacos }\end{array}$ & $\begin{array}{l}11 \\
35 \\
13 \\
11 \\
\end{array}$ & $\begin{array}{l}15.7 \% \\
50.0 \% \\
18.6 \% \\
15.7 \%\end{array}$ & $\begin{array}{l}21 \\
78 \\
18 \\
19\end{array}$ & $\begin{array}{l}15.4 \% \\
57.4 \% \\
13.2 \% \\
14.0 \% \\
\end{array}$ \\
\hline $\begin{array}{l}\text { Continuidade com } \\
\text { o mesmo médico }\end{array}$ & $\begin{array}{l}<3 \text { visitas } \\
3 \leq x \leq 6 \\
i \leq x \leq 24 \text { ou }+\end{array}$ & $\begin{array}{r}54 \\
10 \\
5\end{array}$ & $\begin{array}{l}7.1 \% \\
14.3 \% \\
7.1 \%\end{array}$ & $\begin{array}{r}103 \\
24 \\
11\end{array}$ & $\begin{array}{r}7.4 .1 \% \\
17.3 \% \\
7.9 \%\end{array}$ \\
\hline $\begin{array}{l}\text { Continuidade com } \\
\text { profiss nào médico }\end{array}$ & $\begin{array}{l}x<3 \text { visitas } \\
3 \leq x \leq 6 \\
7 \leq x \leq 24 \text { ou }+ \\
\text { "não aplicáveis " }\end{array}$ & $\begin{array}{r}16 \\
4 \\
6 \\
44 \\
\end{array}$ & $\begin{array}{r}22.9 \% \\
5.7 \% \\
8.6 \% \\
62.0 \% \\
\end{array}$ & $\begin{array}{l}18 \\
13 \\
18 \\
90\end{array}$ & $\begin{array}{r}12.9 \% \\
0.4 \% \\
12.9 \% \\
6.1 .7 \% \\
\end{array}$ \\
\hline Caract anot retornos & $\begin{array}{l}\text { Completas } \\
\text { Parcial/e completas } \\
\text { Muito incompletas } \\
\text { Julg prejuclicado }\end{array}$ & $\begin{array}{r}31 \\
12 \\
9 \\
18\end{array}$ & $\begin{array}{l}-14.3 \% \\
17.1 \% \\
12.9 \% \\
25.7 \%\end{array}$ & $\begin{array}{l}54 \\
16 \\
19 \\
50\end{array}$ & $\begin{array}{l}38.8 \% \\
11.5 \% \\
13.7 \% \\
36.0 \%\end{array}$ \\
\hline Percepção do médico & $\begin{array}{l}\text { Inalterado } \\
\text { Melhor } \\
\text { Inf ausente } \\
\end{array}$ & $\begin{array}{l}31 \\
17 \\
22 \\
\end{array}$ & $\begin{array}{l}64.6 \% \\
35.4 \%\end{array}$ & $\begin{array}{l}16 \\
73 \\
50 \\
\end{array}$ & $\begin{array}{l}18.0 \% \\
82.0 \%\end{array}$ \\
\hline Medvist & $\begin{array}{l}x \leq 0.5 \\
0.5<x \leq 2 \\
2<x \leq 4 \\
x \geq 4\end{array}$ & $\begin{array}{r}36 \\
22 \\
9 \\
3 \\
\end{array}$ & $\begin{array}{r}.31 .4 \% \\
31.4 \% \\
12.9 \% \\
4.3 \%\end{array}$ & $\begin{array}{r}65 \\
49 \\
16 \\
9 \\
\end{array}$ & $\begin{array}{r}46.5 \% \\
35.3 \% \\
11.5 \% \\
6.5 \% \\
\end{array}$ \\
\hline
\end{tabular}


proporção um pouco maior (28.6\%) que o $\mathrm{GR}+(26.6 \%)$. Isso poderia estar associado ao fato de que problemas conjugais (que foi um diagnóstico mais freqüente no GR-) eram usualmente tratados em terapia grupal.

Onde encontramos diferença um pouco maior foi na freqüência da psicoterapia. Entre os que receberam psicoterapia se observa que no $\mathrm{GR}+$ houve maior proporção de pacientes em terapia semanal (12.2\%) que no GR- (7.1\%). No GRpredominou a frequêencia quinzenal na terapia $(15.7 \%)$ em comparação ao GR+ $(10.8 \%)$.

Esse fato nos faz perguntar se o que realmente importa em termos de um bom resultado não é tanto o tipo de terapia (grupal ou individual), mas sim a freqüência com que ela ocorre.

Como já foi citado anteriormente, não houve internações psiquiátricas (de forma completa) em nenhum dos grupos. Também quase não houve diferenças com relação ao tipo de profissional envolvido no tratamento.

Com relação ao tipo de medicação prescrita/utilizada, o GR+ utilizou mais benzodiazepínicos (57.4\%) que o GR- (50\%). Em compensação, os antidepressivos foram mais utilizados pelo GR- (18.6\%), que pelo GR+ (13.2\%). Esses dados são coerentes com os tipos de diagnósticos mais freqüentes nos dois grupos.

Apesar da diferença entre os grupos seguir sendo pequena, houve maior porcentagem de individuos com baixa continuidade de tratamento com mesmo médico no GR- (77.1\% com menos de 3 visitas), comparado ao GR+ (74.1\%). O mesmo ocorre com a continuidade de tratamento por profissionais não médicos, ainda que para se falar em continuidade maior ou menor, tem-se que comparar com a duração do tratamento. O GR- apresentou baixa "continuidade" (menos de 3 visitas) em maior proporção que o GR+. A relação inversa também foi válida com o GR+ tendo apresentado "continuidade" (maior número de visitas com mesmo profissional) mais alta que o GR-. 
Deixaremos para discutir as implicações desses achados quando mais adiante analisarmos as associações entre a variável duração do tratamento e continuidade com mesmo médico/profissional.

É interessante notar, com relação à qualidade das anotações, que apesar da diferença não ter sido muito grande, existiu uma maior porcentagem de anotações de retorno completas, ou parcialmente completas (61.4\%) no GR-, que no GR+ $(50.3 \%)$.

Esse é um fato curioso, pois assim como se observa que no GR- houve menor preenchimento do exame fisico e maior quantidade de exames psíquicos anotados de forma incompleta no caso novo, no que se refere às anotações nos retornos, se verifica o inverso; preenchimentos mais completos de dados da evolução no GR-, que no GR+. Isso demonstra que a relação entre qualidade de anotações e qualidade de serviços (talvez melhor dizendo: associação com resultados positivos) pode continuar sendo objeto de controvérsias $(66,29,61)$.

Com relação à percepção do médico de melhora ou piora com o tratamento ocorreu o esperado, ou seja: maior porcentagem de resultados negativos (64.6\%) no GR-, que no GR+ (18\%), e maior porcentagem de resultados positivos (82\%) no GR+ que no GR- (35.4\%). Este último número no entanto, nos mostra algo interessante: entre aqueles pacientes que se auto percebiam como não tendo melhorado (GR-) o médico em $35.4 \%$ dos casos tinha percepção contrária à dos próprios pacientes e os avaliava positivamente.

- Dados referentes ao tratamento, obtidos da entrevista domiciliar (Vide Tabela $\mathbf{R}$ 4.2).

São nos tópicos descritos a seguir onde encontramos diferenças maiores entre os grupos. Inicialmente, havia mais pacientes no $\mathrm{GR}+(22.8 \%)$ que referiam seguir em tratamento, que no GR- (17.4\%). 
Em relação às razões para interrupção do tratamento os pacientes do GR+ referiam ter interrompido o tratamento por alta médica ou por sentirem-se bem em $39.7 \%$ dos casos, enquanto que isso ocorreu em número menor (14.5\%) no GR-. Em compensação, os pacientes do GR- em maior proporção deixaram o tratamento por apresentarem críticas ou insatisfação com o tratamento (39.1\%) ou por terem sido encaminhados para outro serviço, ou perdido contato com o serviço por razões diversas $(17.4 \%)$. No GR+ as interrupções por críticas ou insatisfação ocorreram em número bem menor $(6.6 \%)$, o mesmo ocorrendo para os encaminhamentos ou perdas de contato com o serviço $(9.6 \%)$. O que houve em maior quantidade no GR+ foram internupções por dificuldade de acesso (21.3\%). No GR- isso ocorreu em $11.6 \%$ dos casos.

No que se refere à utilização de outros serviços concomitantemente com o tratamento, observa-se maior utilização de serviços por parte do GR- (41.4\%) que por parte do GR+ $(21.9 \%)$. Os pacientes do GR- utilizaram outros serviços de saúde mental da região em número maior $(20 \%)$, que o GR+ $(8 \%)$. Também buscaram mais ajuda em recursos fora do sistema tradicional (5.7\%), ou utilizaram 2 ou mais serviços ao mesmo tempo em que se tratavam $(4.3 \%)$, que o $\mathrm{GR}+(1.5 \%$ e $1.5 \%$ respectivamente).

Isso nos faz perguntar se esta diferença de padrão de utilização de serviços está relacionada à diferenças reais ou percebidas da gravidade do problema tratado; à características individuais dos pacientes, ou à qualidade objetiva do tratamento prestado. Na questão da qualidade do serviço, ainda existe a questão da qualidade "objetiva" ou seja, a aplicação de técnicas corretas aplicadas na solução de determinado problema, e a questão de como o paciente "percebe" o seu tratamento. Muitas vezes, ainda que recebendo um "bom" tratamento, o paciente sente que seu problema não se está resolvendo e isso o faz buscar soluções onde quer que seja. Muitos fatores estão em meio à esse problema; desde características do paciente, do serviço, e da doença em si. Um dos problemas neste estudo é que não nos foi possivel com os dados disponíveis quantificar o parâmetro "gravidade 
Tabela R.4.2: Entrevista Domiciliar

Grupos (R+) x (R-)

\begin{tabular}{|c|c|c|c|c|c|}
\hline & \multicolumn{4}{|c|}{ Tamanho da Amostra } \\
\hline & & \multicolumn{2}{|c|}{$\mathrm{N}=70(\mathrm{R}-)$} & \multicolumn{2}{|c|}{$\mathrm{N}=139(\mathrm{R}+)$} \\
\hline & & $n$ & $\%$ & n & $\%$ \\
\hline Percep̧̧ão paciente & $\begin{array}{l}\text { (R-) Inalt/pior } \\
(\mathrm{R}+) \text { Melhor }\end{array}$ & $\begin{array}{r}70 \\
0\end{array}$ & $\begin{array}{r}100.0 \% \\
0.0 \%\end{array}$ & & $\begin{array}{r}0.0 \% \\
100.0 \%\end{array}$ \\
\hline Razões Int Trat & $\begin{array}{l}\text { Nào interr/segue trat. } \\
\text { Alta/Int por sentir-se bem } \\
\text { Insat/criticas ineficácia } \\
\text { Dificuldades de acesso } \\
\text { Enc.p/ outro serviço }\end{array}$ & $\begin{array}{r}12 \\
10 \\
27 \\
8 \\
12 \\
\end{array}$ & $\begin{array}{l}17.4 \% \\
14.5 \% \\
39.1 \% \\
11.6 \% \\
17.4 \%\end{array}$ & $\begin{array}{r}31 \\
54 \\
9 \\
29 \\
13 \\
\end{array}$ & $\begin{array}{r}22.8 \% \\
39.7 \% \\
6.6 \% \\
21.3 \% \\
9.6 \% \\
\end{array}$ \\
\hline Litil. outros serv. & $\begin{array}{l}\text { Não } \\
\text { Serv Púb S.mental } \\
\text { Médico particular } \\
\text { Outros serv não psiq. } \\
\text { Fora do sist. tradicional } \\
2 \text { ou mais serv. }\end{array}$ & $\begin{array}{r}41 \\
14 \\
5 \\
3 \\
4 \\
3 \\
\end{array}$ & $\begin{array}{l}58.6 \% \\
20.0 \% \\
7.1 \% \\
4.3 \% \\
5.7 \% \\
4.3 \% \\
\end{array}$ & $\begin{array}{r}107 \\
11 \\
9 \\
6 \\
2 \\
2 \\
\end{array}$ & $\begin{array}{r}78.1 \% \\
8.0 \% \\
6.6 \% \\
4.4 \% \\
1.5 \% \\
1.5 \% \\
\end{array}$ \\
\hline $\begin{array}{l}\text { Satisf. geral com } \\
\text { tratamento }\end{array}$ & $\begin{array}{l}\text { Insatisfeitos } \\
"+/-" \text { satisf. } \\
\text { Satisfeitos }\end{array}$ & $\begin{array}{l}18 \\
31 \\
21\end{array}$ & $\begin{array}{l}25.7 \% \\
44.3 \% \\
30.0 \%\end{array}$ & $\begin{array}{r}4 \\
10 \\
125\end{array}$ & $\begin{array}{r}2.9 \% \\
7.2 \% \\
80.9 \%\end{array}$ \\
\hline
\end{tabular}


do quadro clínico" e isso fez com que tenhamos perdido uma dimensão importante no que diz respeito aos quadros clínicos.

De qualquer forma, as repercussões econômicas dessa múltipla utilização de serviços são importantes, e apesar de que a avaliação disso não é um dos objetivos deste estudo, cumpre chamar a atenção dos administradores em saúde em nosso país, para a necessidade de maior número de estudos ligando a questão da qualidade à fatores econômicos $(90,16,34,71)$.

Também com respeito ao fato de que pacientes do GR- tenham utilizado outros serviços ao mesmo tempo que o tratamento, nos faz pensar se ao final terminavam por seguir "realmente" algum dos tratamentos aos que se submetiam...

- Dados sobre satisfação com o tratamento. Comparação entre os grupos de resultado positivo (GR+), e negativo (GR-) .Vide Tabela $R$ 5.2.

Em termos de satisfação com o tratamento, como se poderia esperar, ocorreu um maior número de insatisfeitos $(25.7 \%)$ ou "mais ou menos satisfeitos" (44.3\%) no GR-, comparado ao GR+ $(2.9 \%$ e $7.2 \%$ respectivamente). O oposto também ocorreu, ou seja: $89.9 \%$ dos pacientes do GR+ revelaram-se "satisfeitos" comparados ao GR- (30\%). Ainda assim, é bastante interessante observar que ainda que reconhecendo que seu problema não havia melhorado com o tratamento, $30 \%$ dos pacientes do GR- se manifestou "satisfeito" com o tipo de atenção recebida.

Quando são analisados de forma isolada, os itens do questionário de satisfação que apresentaram uma maior freqüência de avaliação positiva foram: Para o GR+; "limpeza do consultório" (98.6\%), "bom atendimento por parte dos funcionários da recepção" (97.8\%) e "recomendação para amigos (97.8\%). "Atenção do médico/profissional" e "volta ao tratamento" (ambos com 97.1\%) foram os seguintes itens com melhor avaliação. Já para o GR-, os itens melhores avaliados foram: "limpeza do consultório" (100\%), "bom atendimento por parte dos funcionários da recepção" (94.3\%) e "limpeza da sala de espera" (92.9\%). 
Tabela R.5.2: Questionário de Satisfação com o Tratamento Grupos (R+) e (R-)

\begin{tabular}{|c|c|c|c|c|c|c|c|c|c|c|c|c|c|}
\hline & \multirow{4}{*}{ Questão } & \multicolumn{12}{|c|}{ Grau de Satisfação } \\
\hline & & \multicolumn{4}{|c|}{ Insat. } & \multicolumn{4}{|c|}{$(+/-)$} & \multicolumn{4}{|c|}{ Satisf. } \\
\hline & & \multicolumn{2}{|c|}{$(\mathrm{R}-)$} & \multicolumn{2}{|c|}{$(\mathrm{R}+)$} & \multicolumn{2}{|c|}{$(\mathrm{R}-)$} & \multicolumn{2}{|c|}{$(\mathrm{R}+)$} & \multicolumn{2}{|c|}{$(\mathrm{R}-)$} & \multicolumn{2}{|c|}{$(\mathrm{R}+)$} \\
\hline & & $n$ & $\%$ & $n$ & $\%$ & $\mathrm{n}$ & $\%$ & $\mathrm{n}$ & $\%$ & $\mathrm{n}$ & $\%$ & $\mathrm{n}$ & $\%$ \\
\hline 1 & Acesso/Loc & 16 & $22.9 \%$ & 28 & $23.3 \%$ & 10 & $14.3 \%$ & 20 & $14.5 \%$ & 44 & $62.9 \%$ & 90 & $65.2 \%$ \\
\hline 2 & Tempo marc. $1^{a}$ consulta & 25 & $36.8 \%$ & $2 \pi$ & $19.6 \%$ & 11 & $16.2 \%$ & 28 & $20.3 \%$ & 32 & $47.1 \%$ & 83 & $60.1 \%$ \\
\hline 3 & Cordialidade & 2 & $2.9 \%$ & 0 & $0.0 \%$ & 2 & $2.9 \%$ & 3 & $2.2 \%$ & 66 & $94.3 \%$ & 136 & $97.8 \%$ \\
\hline 4 & Adequação Horários & 5 & $7.1 \%$ & 6 & $4.3 \%$ & $\tau$ & $10.0 \%$ & 11 & $7.9 \%$ & 58 & $82.9 \%$ & 122 & $87.9 \%$ \\
\hline 5 & Sala espera/conforto & 6 & $8.6 \%$ & 4 & $2.9 \%$ & 7 & $10.0 \%$ & 25 & $18.0 \%$ & 57 & $81.4 \%$ & 110 & $79.1 \%$ \\
\hline 6 & Sala espera/limpeza & 1 & $1.4 \%$ & 2 & $1.4 \%$ & 4 & $5.7 \%$ & 20 & $14.4 \%$ & 65 & $92.9 \%$ & 117 & $84.2 \%$ \\
\hline 7 & Tempo espera consulta & 28 & $40.0 \%$ & 47 & $33.8 \%$ & 29 & $41.4 \%$ & 48 & $34.5 \%$ & 13 & $18.6 \%$ & 44 & $31.7 \%$ \\
\hline 8 & Consultório/conforto & 2 & $2.9 \%$ & 0 & $0.0 \%$ & 12 & 17.1 & 19 & $13.7 \%$ & 56 & $80.0 \%$ & 120 & $86.3 \%$ \\
\hline 9 & Consultório/limpeza & 0 & $0.0 \%$ & 0 & $0.0 \%$ & 0 & $0.0 \%$ & 2 & $1.4 \%$ & 70 & $100.0 \%$ & 137 & $98.6 \%$ \\
\hline 10 & Atenção Profissional & 5 & $7.1 \%$ & 0 & $0.0 \%$ & 7 & $10.0 \%$ & 4 & $2.9 \%$ & 58 & $82.9 \%$ & 135 & $97.1 \%$ \\
\hline 11 & Inform rec.(Qtidade) & 17 & $24.3 \%$ & 11 & $8.1 \%$ & 26 & $37.1 \%$ & 44 & $32.4 \%$ & 27 & $38.6 \%$ & 81 & $59.6 \%$ \\
\hline 12 & Inf.recebidas & 11 & $16.7 \%$ & 4 & $3.0 \%$ & 12 & $18.2 \%$ & 26 & $19.7 \%$ & 43 & $65.2 \%$ & 102 & $77.3 \%$ \\
\hline 13 & Facilidade remarcação* & 4 & $5.7 \%$ & 5 & $3.6 \%$ & 2 & $2.9 \%$ & 5 & $3.6 \%$ & 12 & $17.1 \%$ & 25 & $18.0 \%$ \\
\hline 14 & Acesso ã emergencia* & 2 & $2.9 \%$ & 2 & $1.4 \%$ & 1 & $1.4 \%$ & 4 & $2.9 \%$ & 6 & $8.6 \%$ & 15 & $10.8 \%$ \\
\hline 15 & Acerto no trat. & 13 & $20.6 \%$ & 3 & $2.2 \%$ & 37 & $58.7 \%$ & 16 & $11.9 \%$ & 13 & $20.6 \%$ & 116 & $85.9 \%$ \\
\hline 16 & Expect. com o trat. & 14 & $20.9 \%$ & 4 & $2.9 \%$ & 37 & $55.2 \%$ & 33 & $23 . i \%$ & 16 & $23.9 \%$ & 102 & $73.4 \%$ \\
\hline 17 & Melhora/piora trat. & 6 & $8.7 \%$ & 1 & $0.7 \%$ & 46 & $66.7 \%$ & 8 & $5.8 \%$ & 17 & $24.6 \%$ & 129 & $93.5 \%$ \\
\hline 18 & Recomend. amigos & 11 & $15.9 \%$ & 2 & $1.4 \%$ & 2 & $2.9 \%$ & l. & $0.7 \%$ & 56 & $81.2 \%$ & 136 & $97.8 \%$ \\
\hline 19 & Voltaria ao trat. & 9 & $13.4 \%$ & 2 & $1.5 \%$ & 4 & $6.0 \%$ & 2 & $1.5 \%$ & 54 & $80.6 \%$ & 133 & $97.1 \%$ \\
\hline 20 & Satisf. Geral & 18 & $25.7 \%$ & 4 & $2.9 \%$ & 31 & $44.3 \%$ & 10 & $7.2 \%$ & 21 & $30.0 \%$ & 125 & $89.9 \%$ \\
\hline
\end{tabular}


"Atenção do médico/profissional" (82.9\%) e "adequação de horários" (82.9\%) foram os próximos itens melhor avaliados.

Os que mais freqüentemente receberam uma avaliação negativa foram : Para o GR+ ; "tempo de espera em dias de consulta" (33.8\%), "dificuldade/facilidade de acesso e localização" (23.3\%) e "tempo de espera para obtenção da primeira consulta" (19.6\%). Para o GR- os piores avaliados foram: "tempo de espera em dias de consulta" (40\%), "tempo de espera para obtenção da primeira consulta" (36.8\%), e "quantidade de informações recebidas" (24.3\%).

$\mathrm{Na}$ escala de 5 pontos existente em cada pergunta, a questão com maior "score positivo" tanto para o GR+, quanto para o GR-, foi a referente ao "bom atendimento por parte dos funcionários da recepção". O maior "score negativo" para o GR+ foi "tempo de espera em dias de consulta", enquanto que para o GRfoi "tempo de espera para obtenção da primeira consulta". O item "tempo de espera em dias de consulta" foi o segundo pior avaliado no GR-.

Como já foi assinalado anteriormente, os itens que com maior freqüência foram avaliados negativamente diziam mais respeito à aspectos de organização do serviço.

De modo geral também se pode dizer que com exceção do item "satisfação geral", houve concordância relativamente grande entre os dois grupos, com relação aos itens avaliados positiva e negativamente. A quase unanimidade foi atingida no referente aos aspectos negativos.

- Resultados das associações entre algumas das variáveis estudadas (utilizamos o teste do $\chi^{2}$ para verificação de significâncias estatísticas).

Antes de iniciar a descrição das associações significantes entre variáveis, explicaremos qual foi o critério de seleção para as variáveis que serão mencionadas.

De início citaremos as variáveis que estiveram associadas de forma significante tanto com "percepção do paciente de melhora ou piora" (que foi o que determinou 
a classificação entre resultados positivos e negativos do tratamento), como com a "percepção do médico de melhora ou piora com o tratamento".

Como na análise estatística foi realizado um número bastante grande de cruzamentos, e como inúmeras associações significantes foram encontradas se tornaria dificil e tedioso fazer referência a todas elas. Citaremos portanto num segundo momento aquelas que estiveram associadas às variáveis que acima foram citadas, e que por sua vez, estavam relacionadas com resultados positivos ou negativos do tratamento (do ponto de vista do paciente ou do médico).

Também mencionaremos algumas associações encontradas com a variável "sentimento do entrevistador no caso novo", que diz respeito às impressões sentidas pelo indivíduo que efetuou a anamnese psiquiátrica no caso novo. Escolhemos essa variável por ser praticamente a única variável obtida através do prontuário que nos dá (de forma objetiva) uma informação indireta da relação interpessoal entre o médico e o paciente (desde o ponto de vista do médico).

Levando em consideração as informações do paciente, descreveremos as relações ocorridas entre variáveis do "questionário de satisfação", com variáveis relativas ao tratamento ou aos pacientes. As correlações com as "razões para interrupção do tratamento" também serão citadas.

Inicialmente nos pareceu haver encontrado um baixo número de variáveis (principalmente referentes ao processo de tratamento), que se associaram diretamente à percepção de melhora ou piora desde o ponto de vista do paciente. Aumenta o número de variáveis referentes ao processo de prestação de serviços quando avaliamos os resultados pela percepção do médico.

- Do estudo das associações significantes entre "percepção por parte do paciente de melhora ou piora com o tratamento" (que para simplificar chamaremos "percepção do paciente") e diversas outras variáveis destacam-se:

$\mathrm{Na}$ associação com a variável sexo $(\mathrm{p}<0.007)$, se pode observar que as mulheres predominaram nos dois grupos, mas estavam presentes em proporção bastante 
maior ( mais de duas vezes) no GR+. Em compensação, os homens se dividiam (em termos absolutos) eqüitativamente (50\%) entre resultados positivos e negativos. Havia entretanto no GR- uma proporção relativa duas vezes maior de homens que no GR+.

Com relação ao número de faltas $(\mathrm{p}<0.035)$, ainda que tenha havido uma proporção bastante maior de pacientes sem nenhuma falta no GR+ comparado ao GR-, o que também se observa é que foi no grupo GR+ onde a proporção de pacientes com 3 ou mais faltas era bastante maior. Isto poderia talvez ser explicado pelo tipo de tratamento que esses pacientes pudessem haver recebido (por ex: psicoterapia implica em maior número de visitas, maior duração de tratamento e favoreceria portanto maior possibilidade de faltas).

Foi também significante a associação da "percepção do paciente", com a "percepção do médico de melhora ou piora com o tratamento", onde pudemos observar uma boa concordância de percepções $(p<0.001)$. (Vide Tabela 6).

Houve concordância de percepções em $76 \%$ dos casos, sendo que a concordância entre resultados positivos foi de $53.3 \%$ e de resultados negativos em $22.7 \%$ dos casos.

Houve discordância de percepções em $24 \%$ dos casos, sendo que $11.7 \%$ dos casos vistos pelos pacientes como resultado positivo $(\mathrm{R}+)$, o médico os considerava resultado negativo (R-). Em $12.4 \%$ das vezes o paciente considerava um resultado negativo e o médico os via como casos que haviam melhorado $(\mathrm{R}+)$. $\mathrm{Na}$ associação com a variável "utilização de serviços simultaneamente ao tratamento" ( $\mathrm{p}<0.03$ ), pode-se observar que enquanto a maior parte dos pacientes do GR+ (78\%), não utilizou outros serviços durante o tratamento, os pacientes pertencentes ao GR- utilizaram outros serviços em proporção bastante maior (41\%). Os serviços mais utilizados por estes foram: outros serviços públicos de saúde mental da região, médico particular e recursos fora do sistema tradicional de saúde (curandeiros, macumba ...) 
Tabela R.6: Percepção do paciente X Percepção do médico

\begin{tabular}{||l|l|r|r|r||}
\hline & $\begin{array}{l}\text { Percep. do } \\
\text { médico }\end{array}$ & \multicolumn{3}{|c||}{ Percepcaào do paciente } \\
\hline & & $\mathrm{R}(-)$ & $\mathrm{R}(+)$ & Total \\
\hline & & & & \\
Frequência & $\mathrm{R}(-)$ & 31 & 16 & 47 \\
Percent. & & $22.63 \%$ & $11.68 \%$ & $34.31 \%$ \\
Percent. linha & & $65.96 \%$ & $34.04 \%$ & \\
Percent. Coluna & & $64.58 \%$ & $17.98 \%$ & \\
\hline & & & & \\
Frequência & $\mathrm{R}(+)$ & 17 & 73 & 90 \\
Percent. & & $12.41 \%$ & $53.28 \%$ & $65.69 \%$ \\
Percent. linha & & $18.89 \%$ & $81.11 \%$ & \\
Percent. Coluna & & $35.42 \%$ & $82.02 \%$ & \\
\hline & & & & \\
Total & & 48 & 89 & 137 \\
& & $35.04 \%$ & $64.96 \%$ & $100.00 \%$ \\
\hline \hline
\end{tabular}


Da associação com variáveis pertencentes ao questionário de satisfação com o tratamento destacam-se: associação com a variável "satisfação geral" ( $p<0.001$ ), onde se observa que como se poderia esperar, a grande maioria dos pacientes satisfeitos encontrava-se no GR+, e a grande maioria dos insatisfeitos pertencia ao GR-, É importante ressaltar que apesar de acharem que não melhoraram com o tratamento, $30 \%$ dos pacientes do GR- diziam-se satisfeitos com o tratamento recebido. Entre os pacientes que referiam sentir-se "mais ou menos" satisfeitos, predominaram os resultados negativos.

Essa alta correlação entre percepção de melhora do paciente e satisfação geral é um dado encontrado em vários trabalhos, alguns deles que incluem revisões extensas de estudos sobre o tema $(59,60,110)$.

Na associação com a variável "percepção de acerto no tratamento" ( $p<0.001$ ), como esperado, entre os que opinavam que o médico havia "acertado no tratamento", houve predomínio quase total $(90 \%)$ de pacientes do GR+. O oposto também foi verdadeiro. Entre os que consideravam que o médico "errou" no tratamento, predominavam $(81 \%)$ resultados negativos. $\dot{E}$ interessante notar que $20 \%$ dos pacientes que não haviam melhorado (GR-) ainda assim achavam que o médico havia acertado no seu tratamento, e que a maior parte desses pacientes acreditava que o médico havia "acertado parcialmente" no tratamento.

Na relação com "expectativa com o tratamento" ( $p<0.001$ ), a maior parte dos pacientes do GR+ referia que o tratamento havia sido melhor que o esperado. Mas, o interessante foi notar que entre os pacientes do GR- houve mais pessoas que referiam que o tratamento "havia sido melhor que esperava" (24\%), que "pior" $(20 \%)$. De qualquer forma, a maior parte dos pacientes do GR- emitiram um juízo intermediário a respeito, referindo que suas expectativas haviam se cumprido "razoavelmente".

- A partir deste ponto, da análise das associações entre a variável "percepção do médico de melhora ou piora com o tratamento" (que também nos dá a "versão 
médica" de resultados positivos ou negativos), e diversas outras variáveis, citaremos abaixo aquelas que consideramos significantes $(p<0.05)$.

Foi também significante $(\mathrm{p}<0.022)$ a associação entre "percepção do médico" e o "tipo de profissional envolvido em todo o tratamento". Se avaliamos este cruzamento a partir do tipo de profissional que esteve ligado à prestação de serviços, o que se observa é que enquanto os atendimentos feitos apenas por psiquiatras, por psiquiatras e psicólogos ou por psiquiatras juntamente com 2 ou mais profissionais, estiveram associados à resultados positivos em maior proporção que com resultados negativos; quando o tratamento foi feito por psiquiatras e por assistentes sociais, essa relação se inverteu e essa combinação de profissionais esteve associada em maior proporção à resultados negativos (pacientes que não melhoraram desde o ponto de vista do médico).

Discutiremos este achado mais adiante, quando outras associações com "tipo de profissional" forem mencionadas.

Observamos que quando a "continuidade de tratamento com um mesmo médico" era maior (de 3 a 6, e 7 ou mais visitas), a proporção de resultados positivos era muito maior que a de resultados negativos $(\mathrm{p}<0.022)$. Em compensação, quando o paciente era visto menos que 3 vezes seguidas pelo mesmo médico, a proporção de resultados positivos diminuía bastante e se aproximava mais aos índices do GR-. A associação de "percepção do paciente" com "percepção do médico" já foi descrita anteriormente (Vide Tabela 6).

Da associação da "percepção do médico", com variáveis do questionário de satisfação, as associações significantes foram as mesmas que ocorreram no cruzamento entre essas variáveis e a "percepção do paciente": associação com "percepção de acerto no tratamento"( $\mathrm{p}<0.003)$, com "expectativa com o tratamento" ( $p<0.016)$ e com "satisfação geral" $(\mathrm{p}<0.001)$.

Com relação à "satisfação geral" ( $p<0.001)$, como ocorreu anteriormente, a maior porcentagem de satisfeitos encontrava-se no $\mathrm{GR}+$, e os insatisfeitos encontravam-se em maior proporção no GR-. No entanto, $47 \%$ dos pacientes que 
não haviam melhorado na opinião do médico (R-), referiam estar satisfeitos com o tratamento que receberam.

Neste estudo, o índice de satisfação geral esteve fortemente associado à percepção de melhora por parte do médico, diferentemente de outros trabalhos $(59,60,110)$ que não encontram esta correlação (de modo diferente do que ocorre com a percepção do paciente).

$\mathrm{Na}$ associação com "expectativa com o tratamento" ( $\mathrm{p}<0.016)$, a maioria dos pacientes do GR+ acharam que o tratamento recebido havia sido melhor que o esperado. É importante ressaltar que entre os que não haviam melhorado (GR-), ainda $\operatorname{assim} 41 \% *$ deles referiam que o tratamento havia sido melhor que em suas expectativas, e apenas $15 \%$ referiam que foi pior do que esperavam. Também no GR+ houve $5.6 \%$ de pacientes que expressaram que o tratamento havia sido pior do que esperavam. *Este índice é maior que o encontrado na associação com percepção do paciente, e é possivelmente explicado pelas discordâncias entre a percepção do médico e a do paciente.

$\mathrm{Na}$ associação com "acerto no tratamento" ( $\mathrm{p}<0.003)$ também houve uma concordância grande entre os pacientes que referiam melhora $(\mathrm{R}+)$ e que achavam que o médico "acertou" no tratamento. Porém, o que é mais interessante de destacar é que entre aqueles casos considerados pelo médico como resultados negativos, ainda assim, a maior parte deles (44\%) achava que o médico "havia acertado no seu tratamento", $40 \%$ diziam que o médico havia acertado parcialmente, e apenas $16 \%$ desses pacientes opinava que o médico havia "errado no seu tratamento". Esses achados talvez se expliquem pela porcentagem de percepções discordantes (ainda que não tenha sido grande) entre a percepção do médico e a percepção do paciente de melhora ou piora com o tratamento. Outra possível explicação é que os próprios pacientes em seu julgamento sobre melhora ou piora também pudessem haver levado em consideração o fato de que outros fatores que não só o tratamento médico recebido pudessem haver contribuído para seu estado de saúde. 
- A variável "satisfação geral com o tratamento", além de haver estado associada de forma importante com a "percepção do paciente", e com a "percepção do médico" (dados já citados acima), também esteve associada com "utilização de serviços simultaneamente ao tratamento" ( $\mathrm{p}<0.001)$, e "razões para interrupção do tratamento" $(\mathrm{p}<0.001)$.

$\mathrm{Da}$ relação entre "satisfação geral" e "utilização de serviços simultaneamente ao tratamento" ( $p<0.001)$, o que vale ressaltar é que a maior parte dos satisfeitos, bem como dos insatisfeitos não utilizou outros serviços. A maior proporção de pessoas que utilizaram outros recursos ao mesmo tempo que se tratavam estava entre os que se referiam "mais ou menos" satisfeitos com o tratamento. Nesse grupo de "parcialmente satisfeitos" se encontrava a maior porcentagem dos que utilizaram "mais de 1 recurso além do tratamento" ou que buscaram ajuda em "recursos fora do sistema tradicional de saúde".

Pode se observar, pelo cruzamento da variável "satisfação geral" com "razões para interrupção do tratamento" ( $\mathrm{p}<0.001$ ), que a maioria dos que receberam alta médica ou que seguiam o tratamento estava entre os pacientes satisfeitos. Também as interrupções por dificuldade de acesso ou por encaminhamentos, ocorreram em maior proporção entre os pacientes satisfeitos.

Já as interrupções por críticas ao serviço ou por acharem que o tratamento não estava sendo eficaz, ocorreram na maioria das vezes entre os que se manifestaram insatisfeitos ou "mais ou menos" satisfeitos.

Esses achados são compatíveis com estudos $(59,60,110)$ que relacionam a forma de interrupção do tratamento com satisfação. Esta estaria associada de forma similar ao que encontramos, ou seja: pacientes mais satisfeitos seguiriam em tratamento ou receberiam alta, enquanto que os insatisfeitos interromperiam antes do término formal.

Além do mais, em função das duas associações mencionadas acima, podemos mais uma vez constatar que a satisfação com o tratamento além de poder ser 
categorizada como mais um "resultado" e objetivo como opinam vários autores $(108,124)$, também pode ser classificada como parte do processo $(21,108)$, uma vez que reflete aspectos dele e ao mesmo tempo interfere nele (por exemplo: um individuo satisfeito interromperia menos o tratamento, seguiria melhor as prescrições, retornaria ao serviço...).

- A variável sexo que estava relacionada com "percepção do paciente de melhora", esteve associada de forma significante $(\mathrm{p}<0.031)$ com "renda per cápita".

Apesar de que a maioria (77\%) de homens e mulheres se encontrava em faixas de salário entre menos de 1 até 2 salários ( $20 \%$ de 2 até 5 ), o que chama a atenção é que a grande maioria dos pacientes que viviam com menos de 1 salário mínimo eram mulheres, e entre aqueles poucos que viviam com 5 ou mais salários per cápita, $75 \%$ deles eram homens.

- Da associação entre "total de faltas", com as variáveis "tipo de tratamento", "tipo de profissional durante o tratamento" e "continuidade com profissional não médico", ressaltamos o seguinte:

Entre os pacientes que tiveram 3 ou mais faltas, o que se pode observar quando se analisa a associação com "tipo de tratamento" $(\mathrm{p}<0.001)$ é que a maior parte desses pacientes (64\%) receberam tratamento psicoterápico associado a fármacos. Também dessa associação ("total de faltas") com "tipo de profissional durante o tratamento" ( $p<0.001$ ), se observa que os pacientes com menor número de faltas foram tratados apenas por psiquiatras (tratamentos mais breves?), enquanto que os pacientes com 3 ou mais faltas eram tratados por psiquiatras juntamente com assistentes sociais. Deveriam estar portanto seguindo tratamento psicoterápico (dado que está de acordo com o que mencionamos anteriormente), o que possibilita tratamentos com maior número de visitas, que pode estar relacionado a um resultado positivo, mas que favorece talvez um maior índice de faltas. 
Da relação entre "total de faltas" e "continuidade com profissional não médico" ( $p$ $<0.001)$ o que se observa é que o aumento do número de faltas está diretamente relacionado ao aumento da continuidade do tratamento, mas isso poderia ser o esperado, uma vez que a continuidade com profissional não médico está correlacionada com psicoterapia (psicoterapia individual, $\mathrm{p}<0.001$ ), e portanto com tratamentos de maior duração ( $\mathrm{p}<0.001$ ); o que favorece que ocorra um maior número de faltas.

- A partir de agora, mencionarei as associações significantes que ocorreram com as variáveis "tipo de profissional durante o tratamento" e "continuidade de tratamento com mesmo médico", já que estas variáveis se relacionaram significantemente com a "percepção do médico de melhora ou piora com o tratamento" ou seja, com resultados positivos ou negativos.

A variável "tipo do profissional durante todo o tratamento", se associou significantemente com as seguintes variáveis: "diagnóstico principal", "situação no tratamento", "duração do tratamento", "total de visitas", "psicoterapia individual", "psicoterapia grupal" e "renda per cápita". Abaixo citaremos o que encontramos de mais interessante nesses cruzamentos:

Do cruzamento da variável "tipo de profissional...", com "diagnóstico principal" ( p $<0.001)$ o que se observa é que apesar de que neuroses era o diagnóstico mais freqüente para todos os profissionais, a maior proporção de neuroses e de reações era tratada apenas pelo psiquiatra, enquanto que os diagnósticos do Código $\mathrm{V}$ eram tratados em porcentagem similar apenas pelo psiquiatra, ou por assistentes sociais em conjunto com o psiquiatra.

Da associação "tipo de profissional..." com "situação no tratamento" $(p<0.001)$ se observa que ainda que os psiquiatras tivessem maior número de pacientes nas três condições (em tratamento, alta ou interrupção), os tratamentos feitos pelas assistentes sociais e psiquiatras, ou apenas por psiquiatras, eram os que apresentavam maior proporção de interrupções por razões não esclarecidas (pelas 
informações do prontuário), enquanto que a associação de psicólogas com psiquiatra era a que apresentava maior proporção de pacientes que ainda continuavam em tratamento.

Quando analisamos a relação entre "tipo de profissional..." e "duração do tratamento" ( $\mathrm{p}<0.001)$, também aqui o psiquiatra é o profissional mais envolvido nas várias faixas de duração do tratamento, mas o mais interessante é observar que quando o psiquiatra é o único profissional envolvido no tratamento, a tendência é haver predomínio de tratamentos bastante breves (1 mês ou menos). Quando o atendimento é feito por psicólogo e psiquiatra, a duração é mais longa (mais de 12 meses), e no caso das assistentes sociais a duração é intermediária (de 2 a 12 meses).

Achado coerente com esse é o que encontramos com o cruzamento do "tipo de profissional..." com "total de visitas" $(\mathrm{p}<0.001)$. Quando o atendimento é realizado apenas por psiquiatra ou por psiquiatra e assistente social, o total de visitas (2-5) é menor que quando quem esteve envolvido no tratamento foi psicólogo e psiquiatra (6-30 visitas).

Esses achados tem a ver com caracteristicas estruturais do ambulatório estudado. Uma grande parte dos casos que recebem psicoterapia de modo geral são atendidos por assistentes sociais, psicólogos, ou outros profissionais não médicos, ainda que o psiquiatra faça o seguimento farmacológico do paciente. Dessa maneira, a duração mais longa encontrada com esses profissionais, com boa probabilidade se deve ao fato de estar relacionada à psicoterapia. Por outro lado, o significado de tratamentos mais breves associados ao psiquiatra pode ter a ver com o fato de que uma parte desses "tratamentos de curta duração" poderem ser apenas a primeira visita (caso novo), que sempre é feita apenas por psiquiatras. Outra explicação é que muitas vezes o "psiquiatra" é um residente de psiquiatria que na maioria das vezes não pode oferecer tratamento psicoterápico e portanto se encarrega de casos que podem ser tratados mais brevemente, principalmente com 
fármacos e com alguma abordagem de apoio. Esse último aspecto também poderia facilitar interrupções, e portanto tratamentos mais "breves".

Quando os pacientes receberam "psicoterapia individual" $(\mathrm{p}<0.001)$, os profissionais envolvidos ao longo de todo o tratamento em maior proporção foram psiquiatras em associação com "mais de um dos profissionais não médicos".

Nos casos de "psicoterapia de grupo" $(p<0.001)$ no ambulatório (excluídos os grupos do H.Dia), os profissionais mais envolvidos ao longo do tratamento foram assistentes sociais juntamente com psiquiatra.

Na associação com "renda per cápita" $(\mathrm{p}<0.01)$, se pode dizer que no tratamento a pacientes com menor renda (menos de 2 salários) os profissionais mais envolvidos no tratamento foram assistentes sociais e psiquiatras, enquanto que os psicólogos juntamente com psiquiatras atenderam pacientes com rendas um pouco maiores.

Já que mencionamos a relação de pacientes de menor renda com tratamento com assistentes sociais e psiquiatras, antes de seguirmos adiante é importante discutirmos os resultados da associação encontrada entre "percepção do médico" com "tipo de profissional" onde se verificava que a associação de psiquiatra com assistente social era a combinação de profissionais que mais estava relacionada com resultados negativos do ponto de vista do médico. Frente aos dados até aqui apresentados, vale lembrar que os casos atendidos por assistentes sociais em geral são pacientes com diagnósticos do Código $\mathrm{V}$, muitas vezes problemas crônicos, ligados à esfera social, de dificil resolução, como por exemplo os problemas conjugais. Também para esses problemas, a terapia mais comumente oferecida tem freqüência quinzenal, que já observamos estar associada com menor número de resultados positivos. Os pacientes tratados por esses profissionais são os que tem menor renda (o que também facilita interrupção por dificuldades de acesso), além de que os diagnósticos do Código $\mathrm{V}$ são os que mais freqüentemente despertam sentimentos negativos no entrevistador (fato que pode repercutir indiretamente no tratamento). 
Toda essa conjunção de fatores talvez ajude a explicar o porquê dessa associação com resultados negativos, mas não nos impede de sugerir que frente a tantas circunstâncias adversas talvez devessem ser revisadas certas características da assistência prestada pela combinação médico-assistente social, a esse grupo de pacientes (talvez aumentar a freqüência de atendimentos, repensar os tipos de grupos terapêuticos, etc.).

- A variável "continuidade com mesmo médico" (que esteve relacionada à "percepção do médico de melhora..."), esteve associada significantemente com as seguintes variáveis: "sentimentos do entrevistador", "situação no tratamento", "duração do tratamento", "total de visitas", "tipo de tratamento recebido", "tempo de medicação", "psicoterapia individual", "psicoterapia grupal", "anotações nos retornos" e "renda per cápita".

Abaixo descreveremos os achados mais interessantes dessas associações:

Analisando os "sentimentos do entrevistador no caso novo" $(p<0.009)$, em relação à "continuidade com médico", se observa que apesar da continuidade com mesmo médico ser baixa de modo geral, nos casos em que o indivíduo que fez a anamnese psiquiátrica manifestou "sentimentos negativos controlados", ela foi mais baixa que entre os que revelaram "sentimentos positivos".

Do cruzamento com a variável "situação no tratamento/razões para interrupção" ( $p<0.001$ ), observamos que tanto os pacientes que tiveram alta, como os que interromperam o tratamento sem razões esclarecidas tiveram continuidade mais baixa que os que ainda estavam em tratamento. De qualquer forma, entre os que tiveram menos de 3 visitas com mesmo médico houve predominância de pacientes que interromperam tratamento sem esclarecer.

No tocante à "duração do tratamento" ( $\mathrm{p}<0.001)$ como seria de se esperar, $50 \%$ dos pacientes que haviam sido vistos pelo mesmo médico menos de 3 vezes seguidas, também haviam recebido tratamentos breves ( 1 mês ou menos), o que faz com que não possamos usar o termo "continuidade" nesses casos. Ainda que a "continuidade" aumentasse um pouco quando se aumentava a duração do 
tratamento, mesmo assim predominava um baixo número de visitas nas outras faixas de duração ( de 2 a 12 , e mais que 12 meses). Por ex: $49 \%$ das pessoas que se tratavam por mais de 1 ano eram vistas pelo mesmo médico menos de 3 vezes seguidas.

Com relação ao "número total de visitas" ( $\mathrm{p}<0.001$ ), pode-se observar que o maior número de visitas favoreceu a possibilidade de uma maior "continuidade". Porém, também se pode ressaitar que no grupo de pacientes que tiveram de 6 a 30 visitas, 53\% deles apresentaram baixa continuidade (menos de 3 visitas seguidas com um mesmo médico).

Quando se analisa o "tipo de tratamento recebido" ( $\mathrm{p}<0.001)$, se observa que por razões lógicas, os pacientes que estiveram internados no H.Dia, e que além da internação também receberam outros tipos de terapia, foram os que apresentaram maior continuidade com mesmo médico. A "continuidade" mais baixa esteve relacionada com aqueles casos que receberam tratamento apenas farmacológico.

Neste ponto, é necessário fazer uma pausa para analisar a questão da "continuidade com mesmo médico", que esteve associada significantemente à resultados do tratamento desde o ponto de vista do médico. A "continuidade de tratamento com mesmo médico" foi de modo geral bastante baixa. Os pacientes eram seguidos poucas vezes (menos de 3 visitas) por um mesmo médico. Isso demonstrou estar vinculado à resultados negativos e se queremos melhorar a qualidade do serviço haveria de se modificar aspectos organizativos para se reverter essa situação. Não há dúvida que o fato de um paciente ser (ou não) atendido sempre pelo mesmo profissional, que o conhece bem a ele e a seus problemas, sem dúvida incita maior confiança, maior adesão ao tratamento, maior seguimento de orientações e prescrições e consequentemente possibilita melhores resultados. No caso deste estudo, pela somatória dos vários dados até aqui mencionados, se pode deduzir que esse problema ("baixa continuidade"), entre outras razões ocorre por questões organizativas do serviço, e principalmente no que se refere ao rodízio dos residentes (estes mudam de estágio mais ou menos a 
cada 3 e $1 / 2$ - 4 meses). Uma vez que se pode saber onde se localiza o problema, atitudes deveriam ser tomadas com o objetivo de se reestruturar certos tipos de práticas desse ambulatório (por exemplo: o sub-programa "retorno geral") e melhorar substancialmente a qualidade dos serviços e o resultado das intervenções. Ainda que neste caso este seja um fato determinado por características deste serviço em particular, a baixa continuidade não é um problema específico só deste ambulatório. É bastante comum em muitos serviços públicos.

É como se os serviços estivessem ativamente "rechaçando" os pacientes usando a tática de negar continuidade com o mesmo profissional. Isso faria com que os pacientes não ficassem ligados ao serviço por longo tempo possibilitando uma maior vazão à demanda por pronto atendimento.

A "continuidade com mesmo médico" também se associou com "tempo de medicação" $(p<0.001)$. A maior proporção de pessoas que tomou medicação até 1 ano tinha "baixa continuidade" (< de 3 visitas). O mesmo ocorreu com 45\% dos pacientes que utilizaram fármacos acima de 1 ano. Por outro lado, cerca de metade das pessoas vistas pelo mesmo médico mais de 7 vezes seguidas também utilizaram medicações por mais de um ano.

Da relação "continuidade ..." com haver recebido "terapia individual" ( $<<0.001)$ se observa que entre os que receberam terapia individual existem mais pacientes $(47 \%)$ com baixa continuidade com mesmo médico $(<3$ vezes) que com continuidade maior (32\%), ainda que a minoria que foi vista por mais de 7 vezes pelo mesmo médico recebia terapia individual. Isso significa que provavelmente boa parte dos pacientes que se submeteu à terapia individual não a realizou com profissionais médicos, e estes faziam principalmente o seguimento farmacológico destes pacientes.

Pacientes que participaram de "psicoterapia grupal" ( $\mathrm{p}<0.001)$ no ambulatório, apresentavam baixa continuidade com médico. No entanto, a participação em grupos do Hospital Dia se correlacionou com uma alta continuidade com mesmo 
médico, por razões bastante óbvias de organização do serviço (havia médicos "fixos" no H.D.).

Com relação às "características das anotações nos retornos" $(p<0.001)$ se pode observar que de forma global, as anotações completas estiveram associadas com baixa "continuidade" ( menos de 3 visitas).

Este é um dado curioso, mas uma possivel explicação poderia ser que ao não ser um paciente conhecido, e que possivelmente seria atendido por outro médico num próximo retorno, o profissional se preocuparia em anotar corretamente (e melhor) sua percepção e procedimentos efetuados, diferentemente talvez do que faria se o paciente fosse seu conhecido por ser seguido com uma freqüência adequada.

A baixa continuidade foi o que predominou em todas as faixas de renda, mas se pode observar que a "renda per cápita" ( $p<0.001)$ abaixo de 2 salários foi a que em maior proporção se associou à baixa continuidade ( $<3$ vezes). Por outro lado, entre os pacientes que receberam tratamento com maior continuidade (poucos), a maior porcentagem deles também pertencia às faixas mais baixas de renda.

Outros cruzamentos que achamos que deveriam ser mencionados foram aqueles que se associaram significantemente com a variável "razões para interrupção do tratamento", já que nos ajuda a entender um ponto importante do processo de tratamento.

A "procedência" ( $p<0.033$ ) esteve associada à "razão para interrupção" de uma forma relativamente esperada: apesar de que proporcionalmente entre os procedentes das zonas urbanas tanto de Botucatu, quanto de São Manoel havia uma porcentagem similar de pessoas que seguiam em tratamento, entre os que interromperam o tratamento, a porcentagem maior de interrupção foi devido à dificuldades de acesso entre aqueles que provinham ou da zona rural, ou de São Manoel. A maior porcentagem de interrupções devida à alta médica, ou porque os pacientes referiam sentir-se melhor e não necessitavam seguir em tratamento ocorreu entre os pacientes de Botucatu. 
O mais interessante da relação entre "razões para interrupção do tratamento" mencionada pelo paciente na entrevista domiciliar, e a variável "situação no tratamento/razões para interrupção" ( $\mathrm{p}<0.001$ ) obtida através do prontuário, é que essa associação nos explica através da referência dos pacientes, aqueles casos que pela revisão eram classificados como "interrupção por razões não esclarecidas". Destes, 5.4\% ainda seguiam em tratamento apesar de não haver dados no prontuário; $34 \%$ haviam recebido alta, ou interrompido por sentirem-se melhor, 23\% deles haviam alegado dificuldades de acesso, $23 \%$ pararam por críticas ao tratamento, e finalmente, $14.6 \%$ foi encaminhado para outros serviços ou perdeu contato por razões diversas. Também $9 \%$ daqueles que haviam recebido alta (pelo prontuário) referiam ainda estar em tratamento.

A variável "razões para interrupção", também esteve relacionada à "renda per cápita" ( $p<0.001)$. A maior porcentagem dos que receberam alta se encontrava na faixa de 2 a 5 salários. A grande maioria dos que ainda seguiam em tratamento estava na faixa abaixo de 2 salários. A maior porcentagem dos que alegaram dificuldades de acesso ( onde se inclui falta de dinheiro para a passagem, por ex.) ocorreu na faixa de menos de 1 salário. $\mathrm{O}$ maior número dos que interromperam por críticas ou por acharem que o tratamento não era eficaz, estava na faixa de 1 a 2 salários.

Outra associação significante $(p<0.025)$ foi a que ocorreu entre "razões para interrupção" e "utilização de serviços simultaneamente ao tratamento". O mais interessante nessa relação foi observar que a grande maioria dos que receberam alta ou que seguiam em tratamento não haviam utilizado outros serviços. Quando uma pequena minoria do grupo que seguia em tratamento utilizou outro recurso, foi médico particular o mais procurado. Entre os que interromperam o tratamento por críticas ao serviço ou por achar que o tratamento estava sendo ineficaz, utilizaram com mais freqüência outros serviços públicos de saúde mental da região e médicos particulares. Este foi o grupo que mais utilizou psiquiatras particulares. 
Para finalizar, "razões para interrupção" também esteve associada com as variáveis do questionário sobre satisfação "localização/acesso" $(\mathrm{p}<0.001)$, "adequação de horários" $(p<0.007)$ e "percepção de acerto no tratamento" $(p<0.001)$.

Com respeito à relação com a "percepção de acerto no tratamento" $(p<0.001)$, os que seguiam em tratamento, os que haviam recebido alta, sido encaminhados, ou interrompido por dificuldades de acesso, na maioria das vezes opinava que o médico havia "acertado" no tratamento. Já os que deixaram o tratamento por críticas a ele, em $22 \%$ dos casos acharam que o médico havia "errado", ainda que a maior parte dos pacientes desse grupo (58\%) achavam que o médico havia "acertado parcialmente" no seu tratamento. Isso talvez demonstre que ao deixar o tratamento por insatisfação ou críticas à ele, o paciente possa estar fazendo um julgamento mais amplo, de vários componentes do tratamento e não só da percepção da competência do profissional em oferecer o procedimento mais efetivo para o seu caso.

Com relação à opinião sobre dificuldade ou facilidade de acesso ao ambulatório ( $p$ $<0.001$ ), com exceção do grupo que referiu interrupção por dificuldade de acesso, predominou a percep̧ão de que era fácil chegar ao ambulatório em todos os grupos, mas principalmente entre os que receberam alta ou seguiam em tratamento. O mais interessante foi que entre os que citaram como razão para interrupção "dificuldades de acesso", estes se dividiram eqüitativamente entre achar que era fácil ou difícil chegar ao ambulatório. Talvez isso se explique porque em "dificuldades de acesso" se podem incluir aspectos que não dizem respeito somente à questão da localização geográfica do serviço.

Apesar de que na grande maioria das vezes os pacientes referiam que os horários marcados para consulta eram bons, aqueles que interromperam o tratamento por críticas foram os que apresentavam menor proporção de respostas positivas sobre a adequação dos horários. 
- Algumas das variáveis do questionário sobre satisfação com o tratamento que estiveram relacionadas com a "percep̧̧ão do paciente", e com a "percepção do médico", já foram citadas anteriormente ("acerto no tratamento", "expectativas com o tratamento" e "satisfação geral"), bem como outras relacionadas à variável "razões para interrupção do tratamento".

Além dessas, várias outras se relacionaram de forma significante com algumas variáveis sócio demográficas. A seguir, citaremos os achados mais interessantes:

A variável "dificuldade/facilidade de acesso e localização", esteve associada com "escolaridade", "procedência" e "ocupação", além de "razões para internupção" já citada anteriormente.

Quanto maior a escolaridade, maior proporção de pessoas achava que chegar ao ambulatório para tratamento era fácil $(p<0.04)$. Como seria de se esperar, os procedentes da zona rural foram os que mais manifestaram dificuldades de acesso em função da localização do ambulatório, logo seguidos nessa opinião pelos pacientes procedentes de São Manoel, apesar de uma porcentagem bastante razoável destes $(36 \%)$, achar que era fácil chegar ao ambulatório $(p<0.001)$.

No referente à ocupação; entre as pessoas que referiram ser dificil chegar ao ambulatório, quem tinha como ocupação "prendas domésticas", foi quem referiu maior proporção de opiniões a esse respeito $(p<0.05)$.

- "Renda per cápita" se relacionou com as variáveis "conforto da sala de espera" $(p<0.02)$, "conforto do consultório" $(p<0.002)$, com "tempo de espera nos dias de consulta" $(\mathrm{p}<0.02)$, e com "dificuldade de entendimento das explicações do médico" $(\mathrm{p}<0.03)$.

Apesar de que na maioria das vezes as pessoas consideraram boas as "condições da sala de espera" ( $p<0.02$ ), quem em maior proporção considerou "ruim ou razoável" a sala de espera, foram pacientes na faixa de 2 a 5 salários per cápita.

A opinião a respeito do "conforto do consultório" $(p<0.002)$ se associou com "renda per cápita" de forma similar à opinião expressada sobre o conforto da sala 
de espera. Foram os pacientes na faixa de 2 a 5 salários quem em maior proporção expressaram que os consultórios eram razoavelmente confortáveis. Ainda assim, as condições de conforto do consultório foram avaliadas de forma mais positiva que as condições da sala de espera.

Também com relação ao "conforto no consultório", as opiniões menos favoráveis (razoavelmente confortável) foram manifestadas pelos pacientes que desenvolviam ocupações não manuais $(\mathrm{p}<0.001)$.

Os dados acima, demonstram o que pode ser relativamente esperado: provavelmente pessoas que provinham de faixas mais altas de renda manifestavam expectativas mais altas de conforto que pessoas de renda mais baixa. Ainda assim, de modo geral, levando-se em consideração que as instalações apesar de limpas são bastante austeras, os julgamentos foram relativamente positivos.

Foram os pacientes com menor renda (menos que 1 salário), seguidos pelos da faixa de 1 a 2 salários, que manifestaram maior porcentagem de opiniões intermediárias ou negativas à respeito do "tempo de espera em dias de consulta" (p $<0.02)$.

A pergunta que se faz é: existe algum tratamento diferencial com respeito à pacientes com maior ou menor renda, em termos de se esperar mais ou menos nos dias de consulta? A possível resposta é que de forma direta não, mas indiretamente sim. Isto porque, quase com certeza, os de renda mais baixa que mais se queixavam eram os que participavam do sub-programa "retorno geral" onde o tratamento era basicamente medicamentoso, e os pacientes tinham que chegar todos à mesma hora pela manha, e portanto os últimos a serem atendidos tinham razões de sobra para se queixarem. Em compensação, os que vinham para psicoterapia tinham horários mais específicos e não esperavam tanto.

Ainda que a maioria dos pacientes tenha considerado fácil o entendimento das explicações, a "dificuldade para entender as explicações médicas" $(p<0.03)$ foi inversamente proporcional à renda per cápita. Os que tinham maior "renda" achavam mais fácil entender as explicações. 
O mesmo ocorreu com grau de "escolaridade" $(p<0.03)$. Quanto maior a escolaridade, mais fácil o entendimento das explicações.

A "escolaridade", também esteve associada à "atenção do médico/profissional" ( $p$ $<0.002)$. Na quase totalidade dos casos, os pacientes de zero a 11 anos de escolaridade (colegial completo), foram unânimes em achar que os profissionais (médicos ou não) que os atendia eram atentos. Apenas uma minoria $(2.8 \%) \mathrm{com}$ mais de 12 anos de escolaridade manifestou opiniões negativas (1.4\%), ou parcialmente negativas (1.4\%) a esse respeito.

- Para finalizar, descreveremos as associações significantes ocorridas com a variável "sentimentos do entrevistador durante o caso novo", que expressa as impressões sentidas por quem efetuou a anamnese psiquiátrica na primeira consulta.

Como acreditamos que isso possa interferir no processo de tratamento, e por ser a única variável obtida do prontuário que nos fornece dados indiretos da relação médico paciente durante a primeira entrevista, descreveremos a seguir os achados mais interessantes relacionados à essa variável:

$\mathrm{Na}$ relação com "diagnóstico principal" ( $\mathrm{p}<0.03$ ), ainda que em números absolutos ocorra uma maior associação de sentimentos positivos com neuroses (por ser o diagnóstico mais comum) o que de mais interessante se observa é que "reações de ajustamento" é o diagnóstico com maior proporção de sentimentos positivos associados, enquanto que "diagnósticos do Código V", são os que apresentam maior proporção de sentimentos negativos. Com o diagnóstico "transtornos neuróticos", é onde ocorre a maior porcentagem de "não anotação" desse dado.

Da relação "sentimentos do entrevistador", com "conduta no caso novo" ( $\mathrm{p}<$ $0.001)$ se pode observar que são os pacientes que receberam tratamento apenas farmacológico $(30 \%)$, seguidos por indicação de psicoterapia associada à fármacos $(22.3 \%)$, os que despertaram maior proporção de sentimentos positivos. 
Por outro lado, os pacientes que com maior freqüência provocaram sentimentos negativos (11\%), receberam primeiramente indicação de tratamento farmacológico associado ao psicoterápico, seguidos pelos que receberam tratamento apenas farmacológico.

Ainda que a "indicação de psicoterapia" tenha sido associada mais freqüentemente (em números absolutos e relativos) com sentimentos positivos, diferentemente do que era esperado, nos casos em que sentimentos negativos foram manifestados (11\%), houve maior proporção de "indicação de psicoterapia no caso novo" ( $p<$ 0.001).

Com relação ao "tipo de tratamento efetivamente recebido durante o tratamento" $(p<0.04)$, encontramos a mesma relação observada na associação com "conduta no caso novo". Os pacientes que receberam tratamento apenas farmacológico, logo seguidos pelos que receberam psicoterapia associada a tratamento farmacológico, foram os que em maior proporção haviam causado sentimentos positivos.

Também, os que mais sentimentos negativos despertaram em quem realizou o caso novo $(11 \%)$, foram os pacientes que com maior freqüência receberam efetivamente tratamento psicoterápico associado ao farmacológico, seguidos por aqueles que só receberam medicação.

Destes achados se pode concluir que diferentemente do que se poderia esperar, os sentimentos do entrevistador não influenciaram negativamente no tipo de conduta tomada ou no tratamento oferecido/ recebido. Inclusive, diferentemente do que se poderia esperar, quem despertou sentimentos negativos até recebeu maior indicação de psicoterapia no caso novo.

A associação de "sentimentos do entrevistador" com a variável "continuidade com médico", já foi mencionada anteriormente, mas observamos que sentimentos negativos estiveram correlacionados com continuidade com mesmo médico mais baixa que entre os que suscitaram sentimentos positivos $(p<0.009)$, ainda que $o$ número de visitas seguidas com o mesmo médico tenha sido baixo de modo geral. 
Com relação à "quantidade de informações fornecidas pelo médico a respeito do problema" $(p<0.05)$, pela referência dos pacientes no questionário de satisfação, se observa que aqueles que despertaram sentimentos positivos receberam proporcionalmente maior quantidade de informações que os que suscitaram sentimentos negativos. Também, os resultados numéricos dos casos onde houve manifestação de sentimentos negativos, foram bastante similares aos casos onde o dado sobre os sentimentos do entrevistador não foi anotado, somente que uma proporção um pouco maior destes receberam "algumas informações" em maior. número que os que despertaram sentimentos negativos.

Esse paralelismo de achados entre não anotação e sentimentos negativos, reforça a impressão de que o fato de não se anotar tal dado pode significar sentimentos negativos não manifestados de forma objetiva.

Dessas últimas associações descritas, o que se pode deduzir é que ainda que os sentimentos que o paciente despertou no entrevistador não tenham interferido no tipo de "procedimento técnico" indicado pelo médico, com muita probabilidade na hora de oferecer o tratamento, sim, pode ter havido diferenças, tanto pelo que vemos acima com respeito a maior quantidade de informações fornecidas pelo profissional, como pelo maior número de visitas seguidas, feitas pelo mesmo médico.

Esses achados são similares aos encontrados no estudo de Segal et al. (101) onde os autores observam que os preconceitos dos médicos com respeito à seus pacientes e os sentimentos positivos sentidos em relação a eles estavam associados à qualidade da atenção. Sentimentos positivos em relação ao paciente (ter "gostado" do paciente), esteve associado positivamente com o lado mais "afetivo" do processo de atenção; esteve mais ligado à "arte da assistência", enquanto que os preconceitos estiveram associados negativamente com a qualidade "técnica".

De tudo o que acabamos de mencionar, e que como vimos pode ter muita influência na determinação de qualidade da atenção, o que é importante salientar é que muitos dos aspectos associados à relação médico-paciente nem sempre podem 
ser medidos de uma forma objetiva, pois muitas vezes são aspectos intersubjetivos vivenciados pelo provedor/ receptor de serviços, mas que ainda que sejam dificeis de medir não perdem em importância como fatores que podem influenciar nos resultados finais. Empatia, cordialidade, respeito, atenção, são aspectos que sem dúvida podem fazer com que um paciente siga mais corretamente as prescrições, não interrompa o tratamento, retorne a ele se necessário...Enfim, aspectos que possibilitam (ou facilitam) um resultado positivo. É na avaliação desses tipos de indicadores que os questionários de satisfação são bastante importantes como instrumento de avaliação.

\subsection{Resultados da Análise Multivariada}

Como foi apresentado na seção sobre a metodologia da análise multivariada, o modelo Probit foi utilizado para obter a relação entre o resultado da percepção da melhora (ou não) dos pacientes e as correspondentes variáveis explicativas descritas no Quadro II. O método da máxima verossimilhança foi utilizado para obter os coeficientes associados às variáveis explicativas. Os resultados obtidos são apresentados na tabela seguinte (Tabela M.1). Na segunda coluna se apresenta o coeficiente estimado para cada um dos itens das variáveis utilizadas. Na terceira coluna figura o "erro estandard" e na quarta o "teste $t$ de student", para examinar a significância dos parâmetros estimados. Para as variáveis categóricas se indica com um asterisco o item de referência.

Numa primeira estimação foi introduzida, além das variáveis da Tabeia M.1, a variável satisfação no tratamento. A inclusão desta variável, altamente correlacionada com a variável dependente, provocou que quase todo o poder explicativo do modelo se concentrara no "score" associado (problema de endogeneidade), deixando as outras variáveis com um poder explicativo muito reduzido. Se optou por exclui-la do modelo para poder observar o comportamento das outras variáveis escolhidas. 
Quadro II: Variáveis explicativas utilizadas na análise multivariada

\begin{tabular}{|c|c|c|}
\hline Variáveis & Codificação & Descrição \\
\hline Sexo & $\begin{array}{l}0 \\
1\end{array}$ & $\begin{array}{l}\text { Masculino } \\
\text { Feminino }\end{array}$ \\
\hline Escolaridade & $\begin{array}{l}0 \\
1 \\
2\end{array}$ & $\begin{array}{l}0 \leq x<4 \text { anos } \\
4 \leq x \leq 8 \text { anos } \\
x>8 \text { anos }\end{array}$ \\
\hline Renda per cápita & variável & contínua \\
\hline $\begin{array}{l}\text { Diagnóstico principal } \\
\text { agrupado }\end{array}$ & $\begin{array}{l}1 \\
2 \\
3 \\
\end{array}$ & $\begin{array}{l}\text { Neuroses } \\
\text { Reações } \\
\text { Código V } \\
\end{array}$ \\
\hline Duração do problema & variável & contínua \\
\hline $\begin{array}{l}\text { Sentimentos do entrevistador } \\
\text { (no caso novo) }\end{array}$ & $\begin{array}{l}0 \\
1 \\
9 \\
\end{array}$ & $\begin{array}{l}\text { positivos controlados } \\
\text { negativos controlados } \\
\text { não anotado } \\
\end{array}$ \\
\hline $\begin{array}{l}\text { Razão para interrupção } \\
\text { (Situação no tratamento) }\end{array}$ & $\begin{array}{l}0 \\
1 \\
3 \\
4\end{array}$ & $\begin{array}{l}\text { em tratamento } \\
\text { alta ou estava melhor } \\
\text { Dif. acesso/encaminh/perda cont. } \\
\text { Crítica ao serviço }\end{array}$ \\
\hline Duração do tratamento & v.contínua & \\
\hline Média de visitas & contínua & \\
\hline Tipo de Profissional & $\begin{array}{l}0 \\
1 \\
\end{array}$ & $\begin{array}{l}\text { Psiquiatra } \\
\text { Psiq. e outros profiss. }\end{array}$ \\
\hline $\begin{array}{l}\text { Tipo de tratamento } \\
\text { recebido }\end{array}$ & $\begin{array}{l}1 \\
2 \\
3 \\
4 \\
5\end{array}$ & $\begin{array}{l}\text { Só farmacol. } \\
\text { PI (só ou com fármaco) } \\
\text { PG (só ou com fármaco) } \\
\text { H.dia + outros procedimentos } \\
\text { Orient/encaminh./alta }\end{array}$ \\
\hline
\end{tabular}


Quadro II (segue): Variáveis explicativas utilizadas na análise multivariada

\begin{tabular}{||l|cl||}
\hline \hline Variáveis & Codificação & Descrição \\
\hline \hline Satisfação com & 1 & $\begin{array}{l}\text { insatisfeito } \\
\text { o trau -) satisfeito }\end{array}$ \\
\hline & 2 & satisfeito \\
\hline Continuidade com o & 0 & $\mathrm{x}<3$ visitas \\
mesmo médico & 1 & $3 \leq \mathrm{x}<7$ visitas \\
& 2 & $\mathrm{x} \geq 7$ visitas \\
\hline Tipo de medicação & 0 & não utilizou \\
durante o tratamento & 1 & Benzodiazepínicos \\
& 2 & outras drogas psiquiátricas \\
& 3 & Antidepressivos \\
\hline \hline
\end{tabular}


A proporção na variação da variável dependente explicada pela variação das variáveis independentes é de $50 \%$, dado pelo coeficiente de determinação $\mathrm{R}^{2}$. Se ajustamos o coeficiente em função das variáveis independentes, este se reduz até $42.2 \%$. Ainda assim, o modelo explica bastante o resultado obtido. Outro parâmetro importante para analisar e avaliar o modelo é o percentual das predições corretas. O modelo consegue predizer corretamente $77.0 \%$ dos resultados da variável dependente.

Se o poder explicativo do modelo é bastante satisfatório, examinando cada um dos regressores associados a cada uma das variáveis independentes pode-se observar que só alguns deles são significantes com o teste $t$ de student $>1.96$. Assim, o coeficiente relacionado com a variável Sexo deu significante com valor 0.78 . A interpretação desse coeficiente é a seguinte: uma mulher aumenta o "score" final em 0.78 em comparação ao homem. Os outros valores da regressão que foram significantes são a renda per cápita, $(\beta=0.06)$, a "não anotação" do sentimento do entrevistador na comparação entre positivos controlados e dados não anotados ( $\beta$ $=-0.73$ ), a média de visitas $(\beta=0.11)$, o tipo de medicação na comparação entre "outras drogas" e sem medicação $(\beta=-0.81)$ e todas variáveis "dummies" das razões para a interrupção comparadas à crítica ao serviço ("segue em tratamento" $\beta=0.78$, "Alta ou melhoria" $\beta=1.54$, "dificuldade de acesso/outras" $\beta=0.81$ ). A pouca significância das restantes variáveis, certamente é devida à alta correlação entre algumas delas, o que faz com que o erro "standard" dos regressores seja bastante elevado, afetando assim o teste "t de Student".

Dado que o poder de explicação global do modelo tem um bom nível, este pode ser utilizado para examinar o resultado de perfis diferentes de pacientes que utilizam o ambulatório em distintas combinações de tratamento. Na tabela M.2 apresentamos sete perfis diferentes de pacientes em cinco situações distintas de tratamento que criamos a partir da observação empírica da demanda do ambulatório estudado. 
O primeiro caso ilustra relativamente um paciente "padrão" do programa "retorno geral". Mulher, baixa renda, quadro neurótico, atendida por psiquiatra, com baixa continuidade com o mesmo médico. Recebeu apenas tratamento farmacológico (benzodiazepínicos) com freqüência de 1 visita ao ambulatório a cada dois meses. Através do que referiu na entrevista domiciliar, interrompeu o tratamento por dificuldades de acesso.

O segundo caso tenta refletir um paciente que participa do "grupo de problemas conjugais": mulher, baixa renda, $1^{\circ}$ grau completo, com problemas conjugais, que despertou sentimentos positivos em quem realizou o Caso Novo. Seguida em tratamento psicoterápico grupal, com freqüência quinzenal, atendida por assistente social e psiquiatra. Além da terapia utilizou benzodiazepínicos. Segue atualmente em tratamento.

O terceiro caso ilustra o paciente um pouco mais "diferenciado" que recebe terapia individual: mulher, com escolaridade acima de oito anos, melhor renda per cápita (quatro salários) que os outros casos, com diagnóstico de neurose, atualmente em tratamento psicoterápico individual com freqüência semanal. $\dot{E}$ tratada por psiquiatra (com boa continuidade) e outro profissional (ex.: psicólogo), utilizando também benzodiazepínicos.

O quarto caso é uma variação do terceiro: a paciente não tem um nível de escolaridade tão bom (escolaridade entre 4 e 8 anos), com uma renda muito inferior (1 salário mínimo) e seguida pelo mesmo médico por menos de 3 visitas.

A quinta simulação é um caso idêntico ao terceiro caso com a única variação de que o paciente é um homem e não uma mulher.

O sexto paciente é muito similar ao quarto; a única mudança corresponde ao diagnóstico principal. Ao invés de neurose seu diagnóstico é problemas conjugais (Código V).

Finalmente, se desenha o perfil do caso "ideal": aquele que daria o melhor resultado dadas as estimações do modelo 
Tabela M.1: Resultados da Estimação

\begin{tabular}{|c|c|c|c|c|}
\hline & $\begin{array}{r}\text { Number of Observations } \\
\text { Log of Likelihood Function } \\
\text { N. of positive observations } \\
\text { Sum of squared residuals } \\
\text { R-Squared } \\
\text { Adjusted R-Squared } \\
\text { Percent Correct Predictions } \\
\end{array}$ & $\begin{array}{l}195 \\
-102.453 \\
128 \\
35.0243 \\
0.50 \\
0.42 \\
0.77 \\
\end{array}$ & & \\
\hline Variável & item & $\beta$ & $\sigma$ & $t$ student \\
\hline Constante & & -0.44 & 0.50 & -0.87 \\
\hline Sexo & $\begin{array}{l}\text { Masculino } \\
\text { Femenino } \\
\end{array}$ & $\begin{array}{r}* \\
0.78 \\
\end{array}$ & 0.27 & 2.90 \\
\hline Duração do Problema & $\mathrm{v}$. continua & 0.00 & 0.00 & 0.86 \\
\hline Tipo de Profissional & $\begin{array}{l}\text { Psiquiatra } \\
\text { Psiq + outros } \\
\end{array}$ & $\begin{array}{r}* \\
0.12 \\
\end{array}$ & 0.60 & 0.20 \\
\hline Média visitas & v. contínua & 0.11 & 0.06 & 1.79 \\
\hline Renda per cápita & v. contínua & 0.06 & 0.03 & 1.97 \\
\hline Escolaridade & $\begin{array}{l}\text { menor ou igual a } 4 \text { anos } \\
\text { de } 5 \text { a } 8 \text { anos } \\
\text { mais de } 8\end{array}$ & $\begin{array}{r}* \\
-0.01 \\
-0.23 \\
\end{array}$ & $\begin{array}{l}0.27 \\
0.28 \\
\end{array}$ & $\begin{array}{l}-0.04 \\
-0.81 \\
\end{array}$ \\
\hline $\begin{array}{l}\text { Sent do } \\
\text { entrevistador }\end{array}$ & $\begin{array}{l}\text { posit. contr. } \\
\text { negat. contr. } \\
\text { não anotado }\end{array}$ & $\begin{array}{r}* \\
-0.11 \\
-0.73\end{array}$ & $\begin{array}{l}0.36 \\
0.36\end{array}$ & $\begin{array}{l}-0.30 \\
-2.01\end{array}$ \\
\hline
\end{tabular}


Tabela M.1 (segue): Resultados da Estimação

\begin{tabular}{|c|c|c|c|c|}
\hline Variável & item & $\beta$ & $\sigma$ & $t$ student \\
\hline Tipo medicação & $\begin{array}{l}\text { Sem Medic. } \\
\text { Benzodiazep. } \\
\text { Outras drogas } \\
\text { Antidepressivos }\end{array}$ & $\begin{array}{r}* \\
-0.12 \\
-0.81 \\
-0.59\end{array}$ & $\begin{array}{l}0.38 \\
0.45 \\
0.46\end{array}$ & $\begin{array}{l}-0.31 \\
-1.82 \\
-1.28\end{array}$ \\
\hline Tipo de Tratamento & $\begin{array}{l}\text { Só fármaco } \\
\mathrm{PI}+\text { fármaco } \\
\mathrm{PG}+\text { fármaco } \\
\mathrm{HD}+\text { outros } \\
\text { Orient + alta/enc }\end{array}$ & $\begin{array}{r}* \\
-0.13 \\
-0.45 \\
-0.87 \\
0.04\end{array}$ & $\begin{array}{l}0.60 \\
0.66 \\
0.86 \\
0.43 \\
\end{array}$ & $\begin{array}{r}-0.21 \\
-0.69 \\
-1.02 \\
0.08 \\
\end{array}$ \\
\hline $\begin{array}{l}\text { Continuidade com } \\
\text { o mesmo médico }\end{array}$ & $\begin{array}{l}\text { - de } 3 \text { vezes } \\
3-6 \text { vezes } \\
\text { mais de } 6 \text { vezes }\end{array}$ & $\begin{array}{r}* \\
0.18 \\
0.46\end{array}$ & $\begin{array}{l}0.32 \\
0.50\end{array}$ & $\begin{array}{l}0.56 \\
0.92\end{array}$ \\
\hline $\begin{array}{l}\text { Diagnóstico } \\
\text { principal }\end{array}$ & $\begin{array}{l}\text { Neurose } \\
\text { Reaçōes } \\
\text { Código V }\end{array}$ & $\begin{array}{r}* \\
-0.09 \\
-0.14 \\
\end{array}$ & $\begin{array}{l}0.30 \\
0.34 \\
\end{array}$ & $\begin{array}{r}-0.29 \\
-0.42 \\
\end{array}$ \\
\hline $\begin{array}{l}\text { Razòes para } \\
\text { interrupção }\end{array}$ & $\begin{array}{l}\text { Críticas } \\
\text { Segue em tratamento } \\
\text { Alta ou melhoria } \\
\text { Dif. Acesso / outros }\end{array}$ & $\begin{array}{r}* \\
0.78 \\
1.54 \\
0.81\end{array}$ & $\begin{array}{l}0.29 \\
0.42 \\
0.32\end{array}$ & $\begin{array}{l}2.67 \\
3.65 \\
2.56\end{array}$ \\
\hline
\end{tabular}


Na tabela M.2 figuram o "score" final e a probabilidade de que se apresente um resultado positivo desde o ponto de vista do paciente (que o paciente apresente percepção de melhora dos sintomas com o tratamento). A paciente 3 é a que tem as maiores chances de apresentar um resultado positivo (prob $=95 \%$ ) logo seguida pelo caso 1 e pelo caso 2 com chances menores de resultados positivos ( $88 \% \mathrm{e}$ $79 \%$ respetivamente)..

É interessante notar que se simulamos outras situações, podemos verificar uma infinidade de probabilidades de que nas condições deste ambulatório possamos obter resultados positivos em maior ou menor intensidade. Isso é interessante para avaliar por exemplo o papel do sexo, da renda e da escolaridade de um paciente na determinação de um resultado.

Por exemplo, simulamos o caso do paciente número 4: é mulher, está recebendo as mesmas condições de tratamento que a paciente do caso 3 e também se manifesta satisfeita com o tratamento. Apenas diminuímos a renda per cápita de 4 para 1 salário, a continuidade com o médico (menor que três visitas) e a escolaridade entre 5 e 8 anos. O "score" obtido nesse caso foi de 1.50 e a probabilidade de apresentar um resultado positivo é igual à $93 \%$. Se observa que de $95 \%$ da paciente 3, a probabilidade baixou para $93 \%$.

Noutro exemplo (paciente 5), mantemos as mesmas condições da paciente 3 e apenas modificamos o sexo da paciente. Passa a ser um homem, nas mesmas condições anteriores. Como em nosso estudo o sexo masculino facilitou a associação com Resultados negativos, o "score" obtido pelo paciente 5 foi 0.85 e a probabilidade $80 \%$ de obtenção de resultado positivo. Observamos um decréscimo de $95 \%$ para $80 \%$ na probabilidade de $\mathrm{R}+$, apenas pela diferença do sexo. Lembrar que isto ocorre dentro do contexto deste estudo.

O sexto paciente é uma variação do quarto no que diz respeito ao diagnóstico principal (Código V). Se observa uma ligeira redução no score final (de 1.50 a 1.36), e em conseqüência, na probabilidade de melhora (de $93 \%$ a $91 \%$ ). 
Finalmente, se simulou $\circ$ paciente que poderia dar o melhor resultado (a probabilidade maior). É uma mulher de baixa escolaridade, mas com um nível salarial alto para a população em estudo (4 salários), com um diagnóstico principal de neurose. A média de visitas foi de 4 vezes ao mês, atendida por psiquiatras e outros profissionais. A continuidade com o mesmo médico foi elevada (mais de 6 vezes) e o tipo de medicação foi de benzodiazepínicos. Recebeu alta e o sentimento do entrevistador foi + controlado. A probabilidade final de melhora $\mathrm{e}$ quase perfeita (99\%).

O que foi interessante de observar através dos casos citados acima, é que apesar de que certas influências do paciente (sexo e renda) tem papel importante no resultado final, ainda assim pudemos verificar que certos procedimentos relativos à prestação de serviços também podem estar em maior ou menor grau relacionados à uma melhora de sintomas por parte do paciente. 
Tabela M.2:

Características dos pacientes e resultados em sete situações distintas.

\begin{tabular}{|c|c|c|c|}
\hline Variáveis & Paciente 1 & Paciente 2 & Paciente 3 \\
\hline Sexo & Feminino & Feminino & Feminino \\
\hline Escolaridade & até 4 anos & de 5 a 8 anos & mais de 8 anos \\
\hline Renda & 1 salário & 1 salário & 4 salários \\
\hline Diag. principal & Neurose & Código V & Neurose \\
\hline Duração Probl. & 2 anos & 2 anos & 2 anos \\
\hline Sent. Entrevistador & + controlado & + controlado & + controlado \\
\hline Razōes interrup. & interr/dif acesso a & em tratamento & em tratamento \\
\hline Média visitas & 0.5 ao mês & 2 ao mês & 4 ao mês \\
\hline Tipo de Profissional & Psiquiatra & Psiq. + outros & Psic. + outros \\
\hline Tipo tratamento & Só Fármaco & $\mathrm{PG}+$ Fármaco & $\mathrm{PI}+$ Fármaco \\
\hline Cont. c/ mesmo Med. & menos de 3 & menos de 3 & entre 3 e 6 \\
\hline Tipo medicação & $\mathrm{BZD}$ & $\mathrm{BZD}$ & $\mathrm{BZD}$ \\
\hline Score & $1.1 \tau$ & 0.82 & 1.63 \\
\hline Prob. de melhora & $88 \%$ & $79 \%$ & $95 \%$ \\
\hline
\end{tabular}


Tabela M.2 (segue): Características dos pacientes e resultados em sete situações distintas.

\begin{tabular}{|c|c|c|c|c|}
\hline Variáveis & Paciente 4 & Paciente 5 & Paciente 6 & Paciente 7 \\
\hline Sexo & Feminino & Masculino & Feminino & Feminino \\
\hline Escolaridade & de 5 a 8 anos & mais de 8 anos & de 5 a 8 anos & até 4 anos \\
\hline Renda & 1 salário & 4 salários & 1 salário & 4 salários \\
\hline Diag. principal & Neurose & Neurose & Código V & Neurose \\
\hline Duração Probl. & 2 anos & 2 anos & 2 anos & 2 anos \\
\hline Sent. Entrevistador & + controlado & + controlado & + controlado & + controlado \\
\hline Razòes interrup. & em tratament & em tratamento & em tratamento & Alta o Melho \\
\hline Média visitas & 4 ao mês & 4 ao mês & + ao mês & 4 ao mês \\
\hline Tipo de Profissional & Psiq. + outr & Psiquiatra & Psiq. + outros & Psiq. + outros \\
\hline Tipo tratamento & $\mathrm{PI}+$ Fármaco & $\mathrm{PI}+$ Fármaco & $\mathrm{PI}+$ Fármaco & Só Fármaco(1) \\
\hline Cont. c/ mesmo Méd. & menos de 3 & entre 3 e 6 & menos de 3 & Mais de 6 vezes \\
\hline Tipo medicação & BZD & $\mathrm{BZD}$ & $\mathrm{BZD}$ & $\mathrm{BZD}$ \\
\hline Score & 1.50 & 0.85 & 1.36 & $3.0 \tau$ \\
\hline Prob de melhora & $93 \%$ & $80 \%$ & $91 \%$ & $99.9 \%$ \\
\hline
\end{tabular}

(1) Obs.: Depois de Só Fármaco o melhor resultado é PI+ Fármaco. Se PI+ Fármaco é utilizado, a probabilidade queda quase inalterada 


\section{Comentários finais e Conclusões}

Antes de tentarmos formular qualquer conclusão, é importante fazermos alguns comentários finais complementares sobre alguns dos aspectos observados no decorrer deste estudo.

De início, apesar da profusão de achados obtidos da análise dos dados, ao verificarmos as associações significantes entre variáveis, nos pareceu haver encontrado um baixo número de variáveis (principalmente referentes ao processo de tratamento) que se associaram diretamente à percepção de melhora ou piora desde o ponto de vista do paciente. O número de variáveis relacionadas ao processo de prestação de serviços, diretamente associadas à resultados finais aumentou, quando avaliamos os resultados através da percepção do médico. Também pudemos ampliar nossos achados, para que nos permitisse um maior entendimento do que significavam os números encontrados, quando decidimos analisar as associações significantes relacionadas às variáveis que haviam se relacionado diretamente com os resultados finais tanto pela ótica do paciente quanto do médico.

Os comentários sobre os aspectos mais interessantes do que pudemos observar ao longo da análise dos dados, já foram sendo incluídos quando da descrição dos resultados.

Esperamos ter sido capazes de salientar tanto os pontos positivos, quanto os negativos do serviço estudado, ainda que nesta seção ainda possamos ressaltar algum tópico que possa não ter sido discutido mais profundamente.

Com respeito à questões metodológicas, neste trabalho as informações obtidas dos pacientes através da entrevista domiciliar (onde se inclui o questionário de satisfação), foram muito importantes e complementares, por suprirem lacunas dos prontuários fornecendo-nos dados não só dos resultados, como também do processo, vistos desde o ponto de vista do paciente (informações qualitativamente diferentes das do "provedor de serviços"). Foram dados que nos mostraram uma 
dimensão bastante subjetiva, mas que foi essencial, principalmente por se tratar de um estudo sobre saúde mental.

Nesse sentido, vale a pena nos estendermos um pouco mais sobre os dados obtidos do questionário de satisfação, já que a avaliação do grau de satisfação dos pacientes com o tratamento recebido foi um dos objetivos deste projeto.

É importante ressaltar a grande correlação entre satisfação geral com o tratamento e resultados finais vistos tanto pelo ângulo do paciente quanto pelo do médico. Além dessa associação bastante relevante, também inúmeras outras variáveis obtidas do paciente e do questionário de satisfação nos forneceram dados bastante interessantes e fundamentais para entender aspectos do processo de tratamento. Tanto os que funcionam bem como os que apontam para deficiências que necessitam ser sanadas caso exista a preocupação em se fornecer uma assistência que se possa dizer de "qualidade".

Vários de nossos achados com relação aos índices de satisfação estão de acordo com resultados de vários estudos e alguns apresentam algumas diferenças. Entre os achados que estão de acordo com resultados de diversos estudos estão: nosso índice de satisfação geral (70.1\%), que como na maioria das vezes é alto, encontra-se em um nível muito próximo ao da maioria dos estudos $(30,41,59,60$, 13, ,26); o mesmo ocorrendo com a porcentagem de insatisfeitos que de modo geral, encontra-se ao redor de $10 \%$ na maioria dos trabalhos citados anteriormente. Em nosso caso, como em alguns estudos $(59,60)$, as pessoas relacionadas com o tratamento como o médico e funcionários da recepção foram avaliados bastante positivamente, enquanto que fatores organizativos tais como tempo de espera em dias de consulta e dificuldades para a obtenção da $1^{\text {a }}$ consulta foram avaliados mais negativamente. A quantidade de informações fornecidas pelo médico, que na maioria dos estudos é um item avaliado negativamente $(59,60)$, em nosso caso, apesar de não ter sido dos itens pior avaliados, tampouco recebeu uma pontuação muito boa. Mas se a quantidade de informações fornecidas não foi muito grande, pelo menos foi feita de modo a ser facilmente compreendida. 
Similar ao que ocorreu nas pesquisas mencionadas, em nosso caso, satisfação geral esteve altamente associada com a percepção de melhora do paciente. Já, diferentemente de outros trabalhos $(59,60$ e 110), o índice de satisfação geral neste estudo esteve fortemente associado à percepção de melhora por parte do médico.

Obtivemos também melhores índices de "possibilidade de volta ao tratamento caso necessário", e de "recomendação do serviço para amigos" (30). Com relação à percepção de melhora devida ao tratamento, os nossos índices foram similares em alguns casos $(30,26)$ e algumas vezes melhores do que em outras publicações (41).

De qualquer forma, quando no desenvolver deste estudo percebemos que existem múltiplas facetas do paciente, da doença e do tratamento que interferem diretamente com o resultado final, e quando verificamos que a satisfação com o tratamento além de ser categorizada como mais um "resultado" e objetivo, também pode ser classificada como parte do processo, uma vez que reflete aspectos dele e ao mesmo tempo interfere nele, mais que nunca ficamos convencidos da importância dela em avaliações como a do presente estudo.

Uma vez que ao discutirmos satisfação estamos nos referindo à percepções subjetivas desde o ponto de vista do paciente, seria interessante mencionarmos a variável "sentimentos do entrevistador durante o caso novo", por ser a única variável obtida do prontuário que se refere à relação médico-paciente e que denota aspectos interpessoais que pudemos observar indiretamente desde o ângulo do provedor (profissional que atendeu o paciente na primeira visita).

Pudemos observar que esses aspectos intersubjetivos podem influir em certos procedimentos do processo, e portanto podem estar conectados com resultados positivos ou negativos. Como já foi mencionado anteriormente os sentimentos do entrevistador não interferiram no tipo de tratamento oferecido, ou seja, não influenciaram diretamente em procedimentos "técnicos" (um sentimento negativo 
despertado pelo paciente não levou à que este recebesse um tipo de tratamento que pudesse ser considerado de "menor valor". Em realidade ocorreu o contrário.).

Porém, sentimentos negativos estiveram associados à menor quantidade de informações fornecidas pelo médico, e também a um menor número de visitas seguidas por um mesmo médico. Como já foi referido anteriormente, e de acordo com certos autores (101), sentimentos positivos despertados no profissional que atende se relacionam positivamente com o lado mais "afetivo" do processo de atenção. Estão mais relacionados à "arte" da assistência.

Um dado que deve ser mencionado, é que numa certa proporção os "sentimentos do entrevistador" não foram anotados no Caso Novo. Nossa impressão, que depois foi reforçada pelos resultados da análise multivariada (que encontrou uma associação negativa desse item com probabilidade de melhora), é que a não anotação pode significar sentimentos negativos não expressados objetivamente.

Neste estudo pudemos observar a associação de vários aspectos do processo de assistência (por exemplo: tipo de tratamento, duração, continuidade, freqüência de atendimento, tempo de medicação, quantidade de anotações, satisfação...) com resultados positivos ou negativos. De forma muito resumida, poderíamos enumerar alguns dos achados:

Dentro dos aspectos positivos, o nosso índice de melhora com o tratamento foi similar ao de alguns estudos $(30,26)$, ainda que isso não nos permita dizer que atingimos padrões de boa qualidade.

Houve uma boa concordância entre a percepção de melhora com o tratamento por parte do médico e do paciente.

Também a satisfação geral esteve relacionada com a percep̧̧ão de melhora por parte do médico, fato que de modo geral não ocorre em grande parte dos trabalhos sobre o tema.

O nosso índice de satisfação geral foi bom, e também similar a muitos estudos, mas o que vale salientar é que as pessoas relacionadas com o tratamento como médicos/ outros profissionais e funcionários da recepção foram avaliados bastante 
positivamente, enquanto que alguns fatores organizativos (que são mais fáceis de corrigir que pessoas) foram os avaliados mais negativamente.

Ainda relacionando tópicos positivos relativos ao processo de tratamento, pode-se dizer que tanto os pacientes do GR+ como os do GR- tiveram igualdade de condições no que diz respeito ao tipo de tratamento (psicoterápico/ farmacológico) que receberam. Já a freqüência foi diferente.

Também positivo quanto ao processo de assistência foi o fato de que a história clínica, antecedentes e exame psíquico, na maioria das vezes estavam preenchidos de forma completa, apesar de que isto deva ser o esperado num serviço universitário podendo inclusive ser melhorado. Quanto ao fato da quantidade/ qualidade das anotações não ser muito conclusiva no que diz respeito à sua relação com resultados positivos ou negativos, esse foi outro tema citado durante a apresentação dos resultados.

Outro fator positivo que se há de observar é que tanto o tipo como a duração e modo de administração dos medicamentos foram adequados ao diagnóstico, e de forma a facilitar o cumprimento das prescrições. Além do tempo de uso de medicação não ser muito longo, $26 \%$ dos pacientes não utilizaram fármaco algum ao longo do tratamento. Isso diferencia parcialmente este ambulatório de um padrão de atendimento bastante comum em nosso país. Também a grande maioria dos pacientes referia não haver utilizado outros serviços simultaneamente ao tratamento.

Como aspectos negativos do processo de assistência poderíamos mencionar: de modo geral a continuidade de tratamento com o mesmo médico foi baixa nos dois grupos, mas foi ainda menor no GR-. Também esteve associada ao recebimento de tratamento apenas farmacológico e à pacientes de baixa renda, que eram vistos basicamente pelo médico. Isso é decorrente de vários problemas organizativos, mas pelas características citadas anteriormente mostra principalmente a falha de um subprograma do ambulatório conhecido como "retorno geral", o qual, para o bem da melhoria da qualidade, já estava sendo substancialmente modificado à época do 
término da coleta de dados para este estudo. Maiores observações sobre essa questão já as expressamos durante a exposição dos resultados.

Houve também um grande número de interrupções do tratamento sem que pelas anotações do prontuário se pudesse saber quais foram as causas. Esse número diminui e passa a ser melhor compreendido, quando os pacientes referem suas razões para interrupção do tratamento no momento da entrevista domiciliar. De qualquer forma ainda que nossos indices não sejam tão importantes quanto comparados a outros trabalhos (69), devem ser levados em consideração. Também a qualidade das anotações nos retornos tem que ser bastante melhoradas.

Referindo-nos à profissionais envolvidos no tratamento, algo que chamou a atenção foi que a associação psiquiatra mais assistente social foi a que menos resultados positivos apresentou. Já comentamos anteriormente nossa interpretação com respeito a esse fato, mas aqui repetimos que possiveis causas podem ser o fato das terapias oferecidas por esses profissionais serem de freqüência quinzenal, para pessoas com problemas conjugais e de baixa renda. Existiriam portanto aspectos externos ao processo de tratamento que aí interfeririam, mas quanto à questão das terapias esse é outro ponto a salientar.

Anteriormente já opinamos que em função dos diagnósticos e dentro das limitações do serviço, poderia ser maior a oferta de tratamentos psicoterápicos ao invés de observarmos uma proporção relativamente alta de tratamentos puramente farmacológicos. Também nas terapias, a freqüência semanal esteve associada ao $\mathrm{GR}+$ enquanto que uma menor freqüência (quinzenal) esteve associada ao GR-. Como observamos que profissionais não médicos estiveram envolvidos no tratamento em $35 \%$ dos casos, havendo predomínio de tratamento médico, salientamos que haveria que ocorrer um maior envolvimento de profissionais não médicos caso quiséssemos modificar o padrão de atendimento atual, e poder oferecer uma assistência com maior número de alternativas psicoterápicas. Fato que também comentamos, e que deve ser modificado, é que grande parte das indicações de psicoterapia feitas pelas vias "normais" não chega a se efetivar, 
recebendo psicoterapia pessoas que chegam a ela por vias paralelas ao longo do tratamento. Isso depende basicamente da modificação do comportamento da equipe como um todo, e da extinção de uma "tradição" que como o próprio nome já diz, já é tomada como natural, mas que prejudica aos pacientes da fila de espera (uma pequena parte da interrupção de tratamentos foi devida à que pacientes ficaram esperando para serem chamados para terapia e isso nunca ocorreu).

Os aspectos citados acima são em nossa opinião os mais criticáveis, e que necessitam modificações com o objetivo de melhorar a qualidade do serviço.

Através das várias associações mencionadas anteriormente (ainda que existam muitas outras), pudemos ver que várias características do processo estiveram correlacionadas a resultados negativos e positivos de tratamento. Analisando-se a interrelação de muitas das variáveis do processo de assistência com os resultados finais obtidos, podemos tirar algumas conclusões "aproximadas" sobre a qualidade maior ou menor do serviço, que em última instância servem para que se possam tomar decisões pragmáticas como por exemplo: modificar certas práticas, manter outras, fazer alterações estruturais e organizativas, etc. Isso porque podemos nos basear na observação empírica para chegar a essas conclusões "aproximadas" sobre o nivel de qualidade. Mas seria uma aproximação pouco precisa, onde poderíamos utilizar por exemplo: os índices de melhora com o tratamento (resultados finais positivos), índices de satisfação e talvez outros indicadores presentes na literatura, para podermos comparar nossos resultados finais com o desses outros estudos e através da interrelação de fatores do processo com os resultados chegarmos a alguma conclusão sobre o nível de qualidade do serviço avaliado.

Porém, dentro do objetivo 1 (referido no capítulo 2 - "Definição de hipóteses e objetivos") desta tese, na frase "para se avaliar a qualidade da atenção..." existe uma pergunta que diretamente emerge dessa frase: Qual foi o nível de qualidade da assistência prestada?

Não creio que possamos responder a essa pergunta de uma forma bastante precisa, pois para dizer se o serviço estudado realmente preenche ou não critérios de 
qualidade, sempre nos ficam faltando elementos de comparação. Portanto nos faltam exatamente critérios e "standards" mais explícitos, aplicáveis a nosso meio para podermos compará-los com as características do processo de assistência do ambulatório avaliado, para realmente podermos dizer se foram atingidos níveis aceitáveis de qualidade.

O desenvolvimento de critérios e padrões de qualidade definidos especificamente para o nosso meio, levando-se em consideração características culturais e tipo de serviços que se tem por objetivo avaliar, ainda que uma tarefa complexa, deveria ser um dos objetivos prioritários de futuras pesquisas na área da avaliação qualitativa em Saúde Mental.

Isso porque para a avaliação do processo de atenção, a existência de critérios explícitos facilitaria em muito o trabalho do avaliador, além de possibilitar conclusões mais objetivas.

Enquanto esses critérios explícitos não existem, como no momento em que se realiza este estudo, é necessária a utilização de dados baseados em critérios empíricos e a realização de julgamentos implícitos para se definir níveis melhores ou piores de qualidade.

Tomando-se por base os comentários anteriores, se poderia dizer que quanto ao objetivo (1) "analisar a interrelação entre processo de prestação de serviços e os resultados finais de tratamento para se avaliar a qualidade de atenção num serviço ambulatorial de saúde mental", através dos dados encontrados nesta tese, poderíamos dizer que tal objetivo foi atingido parcialmente, faltando-nos critérios mais explícitos que permitissem um melhor julgamento dos atributos do processo de assistência para emitirmos uma conclusão final sobre a qualidade do serviço. Com relação ao objetivo (2), sobre o "peso que diferentes fatores podem ter na determinação de que o resultado final do tratamento possa ser considerado positivo ou negativo", poderíamos fazer alguns comentários: um dos achados que nos chamou a atenção foi o pouco peso que certas características da doença (como 
tempo de evolução do problema e tipo de diagnóstico) tiveram na determinação dos resultados.

Ainda que tenhamos encontrado algumas associações como uma maior proporção de diagnósticos do "Código V" relacionados à resultados negativos, e o inverso para "quadros reativos", ainda assim essas associações não foram reforçadas pelos achados da análise multivariada. O mesmo ocorreu com o "tempo de evolução do problema" que não foi significativo com respeito à determinação de resultados. Uma possivel explicação poderia estar na metodologia, pois ao agruparmos diagnósticos com alguma similaridade entre eles, já aumentamos o grau de homogeneidade, e reduzimos portanto a possibilidade de diferenças significantes.

Em compensação, certas características do paciente como sexo e renda per-cápita, desde o início (e ao longo das várias fases da análise estatística) demonstraram ter uma associação significante com resultados de tratamento. Assim como renda percápita é uma variável cuja associação com resultados não é dificil de ser compreendida, já a associação com sexo nem sempre é tão clara. É importante salientar que esses achados são válidos no contexto "deste" estudo. Na discussão dos resultados já comentamos qual a possível explicação para a relação de sexo masculino com piores resultados, mas voltamos a mencioná-la: acreditamos que os homens quando utilizam serviços de saúde mental podem ir buscá-lo mais tardiamente que as mulheres, quando seus problemas já atingem um grau de gravidade maior. Isso facilitaria um pior prognóstico. Não podemos testar essa hipótese por não termos medidas que nos indiquem o nível de gravidade inicial dos quadros atendidos.

Outra explicação seria a possível presença de diagnósticos de alcoolismo ocultos debaixo de outros rótulos, e que ao não serem diagnosticados não seriam tratados adequadamente. Pensamos nessa possibilidade ao verificarmos a presença (ainda que em pequena porcentagem) no GR- da tríade depressão, hipertensão arterial e sexo masculino, que poderia estar relacionada à alcoolismo. 
Através da análise multivariada encontramos que esses dois fatores "sexo" e "renda" realmente estiveram relacionados significantemente com a determinação dos resultados finais.

Além de todas as associações significantes que observamos através dos resultados das associações entre variáveis do processo e resultados finais, as variáveis ligadas ao processo que encontramos estarem mais fortemente associadas à determinação dos resultados através da análise estatística multivariada foram: "satisfação com o tratamento", "situação no tratamento/razões para interrupção" e "não anotação dos sentimentos do entrevistador no caso novo". Além dessas, "média de visitas", e "tipo de medicação" também se relacionaram com o resultado final. No caso da média de visitas, quanto maior a freqüência ao tratamento, mais probabilidade de melhora existia. Com respeito à medicação, os pacientes que utilizavam outros fármacos que não benzodiazepínicos ou antidepressivos, tinham menos probabilidades de melhora. No caso da situação no tratamento, em comparação aos pacientes que haviam interrompido o tratamento por críticas, tanto os que receberam alta, seguidos pelos que continuavam em tratamento, e pelos que deixaram de se tratar por dificuldades de acesso, todos esses pacientes apresentavam uma correlação positiva com resultado de tratamento. Ou seja, tinham nessa ordem decrescente, probabilidades maiores ou menores de se associarem com resultados positivos. Finalmente, a "não anotação dos sentimentos do entrevistador" estiveram associados negativamente com resultados positivos. Como já discutimos anteriormente, se "não anotação" significar sentimentos negativos despertados em quem fez o caso novo, já vimos que estes poderiam se associar a certas características do processo como menor continuidade com mesmo médico, e menor quantidade de informações fornecidas aos pacientes. Como sabemos que os sentimentos do entrevistador podem estar associados à "arte" da assistência, e uma vez que esse aspecto está diretamente ligado à qualidade de serviços, é importante levar em consideração essa dimensão interpessoal quando da análise e interpretação de dados do processo de tratamento. 
Com relação à satisfação geral, creio que já discutimos o suficiente a esse respeito, e já está mais do que clara sua associação com percepção de melhora com o tratamento. Sempre é válido recordar que satisfação tanto pode ser vista como um resultado, como um objetivo a se atingir, mas também como um componente importante do processo de assistência.

Dos achados acima, poderiamos concluir que conseguimos atingir o objetivo (2), de verificarmos o quanto certos fatores podem interferir nos resultados finais. As características da doença demonstraram pouco peso, enquanto que algumas características do processo e dos pacientes mostraram ser importantes na determinação de certos resultados. Uma vez mais, vale salientar que esses achados são específicos "deste" trabalho, ainda que em saúde, mas principalmente em saúde mental sempre se soube que outros fatores que não apenas os relacionados ao transtorno ou ào tratamento, podem ter um papel de importância com respeito a influenciar os resultados finais. Levando-se em consideração que grande parte dos usuários de serviços públicos de saúde mental de nosso país pertencem à estratos de baixa renda, muitas vezes com vários problemas sociais associados, a dimensão das características sócio demográficas dos pacientes devem sempre ser levadas em consideração em estudos de avaliação.

Com respeito ao objetivo (3), "avaliar o grau de satisfação dos pacientes com o tratamento recebido", esse foi um objetivo plenamente atingido, já discutido anteriormente, mas que vale a pena novamente salientar, que tal avaliação foi de extrema importância nesta pesquisa, no sentido da complementaridade de informações que possibilitou, ao proporcionar a visão subjetiva do usuário que pode ser somada aos dados do processo obtidos do prontuário.

Com certeza, se avaliássemos apenas a satisfação com tratamento, deixando de lado o estudo do processo, ou vice-versa, não obteríamos informações muito amplas. Quando por outro lado utilizamos a dimensão do paciente para verificação de resultados (entre eles o estudo da satisfação com o tratamento) associada à avaliação de alguns dados objetivos do processo de assistência, isso sem dúvida 
nos provê informações bastante mais amplas, que em última instância servem para fornecer informações e favorecer modificações na organização dos serviços no intuito final de se atingir melhores níveis de qualidade.

O que acabamos de referir acima, vai de encontro à uma de nossas hipóteses iniciais, onde expressávamos a nossa crença de que "o estudo da interrelação entre o processo de prestação de serviços, e os resultados finais do tratamento seria a forma mais adequada na avaliação de serviços de saúde mental". Não sabemos se "adequada" é a palavra mais correta neste caso, mas sim, podemos dizer que o estudo da interrelação entre o processo e resultados do tratamento é a forma de avaliação que nos oferece dados mais amplos e úteis, se pensamos em utilizar esse tipo de pesquisa para promover e facilitar alterações no processo de prestação de serviço que favoreça a obtenção de um alto nível de qualidade.

Em conclusão, não sei se poderíamos dizer que nossa hipótese foi provada, uma vez que já desde o momento em que ela foi formulada, ela já expressava uma "opção" por um modelo de procedimento avaliativo, por nos parecer que esse modelo integrativo de estudo do processo e de resultados era o mais completo, pois proporcionava a validação recíproca desses dois elementos. Assim como medidas de resultados são utilizadas para validar critérios estruturais e de processo, o reverso também é verdadeiro.

Em nosso caso, os resultados serviram para validar e ajudar na interpretação de certas características do processo de assistência, assim como a avaliação dos procedimentos do processo (e inclusive alguns aspectos estruturais) serviram para validar e dar sentido aos resultados encontrados. Assim sendo, sem entrarmos em discussões mais profundas sobre o mérito maior ou menor de certo tipo de abordagem para avaliação de serviços (uma vez que já existe uma literatura extensa defendendo um tipo ou outro, e mesmo preconizando o estudo integrado), podemos concluir que dentro do contexto desta pesquisa, esse tipo de modelo integrativo funcionou muito bem para a avaliação qualitativa do serviço de saúde mental estudado, proporcionando-nos muitos dados, muita informação, e material 
passível de ser utilizado para futuras modificações de certas práticas e fatores organizativos, no sentido de se aprimorar o nível de qualidade da assistência.

Com referência à segunda hipótese "...em saúde mental, fatores outros que não os diretamente ligados ao processo de prestação de serviços, podem interferir nos resultados finais. Contudo, pode-se presumir que numa proporção significativa, um processo de prestação de serviços que atinja padrões determinantes de boa qualidade, deverá estar correlacionado com um bom resultado final", poderíamos dizer que ela foi parcialmente comprovada, uma vez que pudemos observar em nosso estudo, que certos fatores não diretamente ligados ao tratamento, principalmente certas características do paciente, estiveram associados significantemente aos resultados finais.

Também pudemos verificar que quando eram alinhados diversos fatores do tratamento que empiricamente poderiam ser definidos como procedimentos que denotavam qualidade, ainda existindo as influências das características do paciente, pudemos verificar a parcela de correlação entre essas características do processo de prestação de serviços e resultados positivos de tratamento.

O que nos fica faltando portanto, para comprovar totalmente a hipótese (a segunda afirmação contida nela), são critérios e "standards" explícitos, que pudessem proporcionar parâmetros de comparação, que nos possibilitasse definir objetivamente se o processo de assistência avaliado atingia padrões determinantes de boa qualidade.

Para finalizar, podemos concluir, que conseguimos atingir quase totalmente os objetivos definidos no início desta tese, faltando-nos apenas os critérios e "standards" acima mencionados, para podermos definir objetivamente o que seria um serviço de bom nível de qualidade.

Nesse sentido, sugerimos que o desenvolvimento de critérios aplicáveis à avaliação de serviços de saúde mental adequados ao nosso contexto cultural, deveria ser um objetivo prioritário de futuras pesquisas na área da avaliação qualitativa em Saúde 
Mental. É uma tarefa bastante complexa, mas que facilitaria em muito o trabalho de futuros investigadores, além de facilitar conclusões mais objetivas.

Enquanto isso, em nossas atuais circunstâncias, talvez os estudos na linha da avaliação da satisfação com a assistência recebida, sejam os que se mostrem mais factíveis, de mais fácil aplicação (o que não implica em menor rigor metodológico), e em termos de resultados produzidos, tão bons quanto outros métodos para a avaliação da qualidade de serviços de saúde mental. 


\section{Bibliografia}

(1). Allen, M.G.: "Peer Review of Group Therapy: Washington D.C., 1972-77". Am. J. Psychiatry $136\left(4^{\mathrm{a}}\right)$, 444-447, 1979.

(2). American Psychiatric Association: Standards for Psychiatric Facilities - A Revision of the Standards for Hospitals and Clinics. A.P.A., Washington D.C., 1969.

(3). Attinger, E.O e Panerai, R.: "Transferability of Health Technology Assessment with Particular Emphasis on Developing Countries". Intl. J. of Technology Assessment in Health Care 4, 1988.

(3.a) Banta H.D.: "Medical Technology and Developing Countries: The Case of Brazil”. Intl. J. of Health Serv. 16(3), 363-373, 1986.

(4). Berner, P. et al.: "Alcohol and Depression". Psychopathology 19(2), 1986.

(5). Bezerra B.: "Considerações sobre terapêuticas ambulatoriais em saúde mental", Em: Cidadania e Loucura: Políticas de Saúde Mental no Brasil, Ed. Vozes, 1987.

(6). Borus, J.F.: "Neigborhood Health Centers as Providers of Primary Mental Health Care". The New England Journal of Medicine 295: 140-145, 1976.

(7). Botega, N.J. et al.: "Ambulatório de Psiquiatria em Hospital geral - Alguns dados do HC/Unicamp". Revista ABP-APAL 10:2, 1988. 
(8). Brook R.H. et al.: "Quality Assessment in Mental Health". Professional Psycology 13:1, 1982.

(9). Brook, R.H. et al.: Quality of Medical Care Assessment Using Outcome Measures: Vol.I. An Overview of the Method. The Rand Corporation, Santa Monica, CA, 1976.

(10). Brook, R.H. et al.: Quality of Medical Care Assessment Using Outcome Measures: NCHSR Research Summary Series. The Rand Corporation, Santa Monica, CA, 1977.

(11). Brook, R.H. e Appel, F.A.: "Quality of Care Assessment: Choosing a Method for Peer Review". N. Engl. J. Med. 288 (25), 1323 - 1329, 1973.

(12). Brook, R.H. e Williams, K.N.: "Quality of Health Care for the Disadvantaged", Journal of Community Health 1, 132-156, 1975.

(13). Bugge I., Hendel D. e Moen, R.: "Client evaluations of therapeutic processes and outcomes in a University mental health center", Journal of the American College Health Association 33, 141-151, 1985.

(14). Campos, F.E.: Resolutividade: Uma Aproximação à Avaliação Qualitativa dos Serviços de Saúde. Tese de Doutoramento apresentada a Escola Nacional de Saúde Pública, FIOCRUZ, Rio De Janeiro, 1988.

(14.a) Coe, G.A. e Banta, D.: "Health Care Technology Transfer in Latin America and the Caribbean", Intl. J. of Tech. Assmnt. in Health Care 8(2), 255-267, 1992. 
(15). Cohen L.H. e Holstein, C. M.: "Characeristics and Attitudes of Peer - Reviewers and Providers in Psychology". Professional Psychology 13(1), 1982.

(16). Cohen L.H.: "Research on Mental Health Quality Assurance", em G. Stricker and A. Rodriguez (eds): Handbook of Quality Assurance in Mental Health. New York: Plenum Press, 1988.

(17). Contel, J.O.: "Contribuição ao Estudo Comparativo da Assitência Ambulatorial Psiquátrica Pública em Ribeirão Preto (SP)". J. Bras. Psiq. 43(3), 1994.

(18). Diamond, H. et al.: "Peer Review of Prescribing Patterns in a C.M.H.C." em Evaluation in Practice D.H.H.S. Publication (ADM) 80-763, 1980.

(19). Diehr, P., Williams S.J., Martin D.P. e Price, K. : "Ambulatory Mental Health Utilization in Three Provider Plans". Medical Care 22: 1-13, 1984.

(20). Donabedian A.: "Advantages and Limitations of Explicit Criteria for Assessing the Quality of Health Care". Milbank Memorial Fund Quarterly: Health and Society 59:1, 1981.

(21). Donabedian, A.: Explorations in Quality Assessment and Monitoring - Vol.I: The Definition of Quality and Approaches to its Assessment. Ann Arbor, MI: Health Administration Press, 1980

(22). Donabedian, A.: Explorations in Quality Assessment and Monitoring Vol.II: The Criteria and Standards of Quality. Ann Ar bor, MI: Health Administration Press, 1982 
(23). Donabedian, A.: Explorations in Quality Assessment and Monitoring Vol.III: An Illustrated Analysis. Ann Arbor, MI: Health Administration Press, 1985

(23.a) Donabedian, A.: The Quality of Care. How Can it Be Assessed? . JAMA 260(12), 1743-1748, 1988.

(24). Edelstien, M.G.: "Psychiatric Peer Review: A Working Model". Hosp Community Psychiatry 27(9), 656-659, 1976.

(25). Evans, O.N. et al.: “A Quality Improvement Process for State Mental Health Systems”. Hospital and Community Pshychiatry 43(5), 1992.

(26). Eppel A., Fuyarchuk C., Phelps D. e Tersigni, A.: " A comprehensive and practical quality assurance program for community mental health services". Canadian Journal of Psychiatry 36, 102-106, 1991.

(27). Fauman M.A.: "Quality Assurance Monitoring in Psychiatry." Am. J. Psychiatry 146:9, 1989.

(28). Fernandes Pitta, A.M. et al.: "Determinantes da Qualidade de Serviços de Saúde Mental em Municípios Brasileiros - Estudo da Satisfação com os Resultados das Atividades Desenvolvidas por Pacientes, Familiares e Trabalhadores dos Serviços". J. Bras. Psiq. 44:9, 1995.

(29). Fessel, W.J.e Van Brunt, E.E.: "Assessing Quality of Care from the Medical Record". N. Eng. J. Med. 286(3), 134-138, 1972. 
(30). Flynn, T.C. et al.: "Predicting Client Improvement from and Satisfaction with Community Mental Health Center Services". Am. J. Community Psychology 9(3), 339-346, 1981.

(31). Freeman H.: "Evaluation in Mental Health Care". British J. Psychiatry 161, 1992.

(32). Frenk, J.e Mohr, J.P.: Evaluación de Tecnologia y Calidad de la Atención en Salud. Washington D.C.: O.P.A.S., O.M.S., 1985

(33). Frota, L.H.: Modalidades de Avaliação de Programas e Serviços de Saúde Mental. Dissertação de Mestrado, apresentada ao Instituto de Psiquiatria da Universidade Federal de Rio de Janeiro, Rio de Janeiro, 1979.

(34). Glass, N.S. e Goldberg, D.: "Cost-benefit Analysis and the Evaluation of Psyquiatric Services". Psichological Medicine 7, 1977.

(35). Gonzalez, B.: Análisis Multivariante: Aplicación al Ámbito Sanitario. SG. Editores, 1993.

(36). Greenley, J.R. e Schoenherr, R.A.: "Organization Efects on Client Satisfaction with Humaneness of Service" Journal of Health and Social Behavior 22(3), 2-18, 1981.

(36.a). Guba, E.G. e Lincoln Y.S., Fourth Generation Evaluation. Sage Publications Inc., 1989. 
(37). Gustafson D.H. et al.: "Measuring Quality of Care in Psychiatric Emergencies: Constructiohn and Evaluation of a Bayesian Index". Heath Services Research 28:2, 1993.

(38). Hafner, H. e Heiden, W.: "The Evaluation of Mental Health Care Systems". Br. J. Psychiatry 155, 12-17, 1989.

(39). Hafter, S.: "Quality Assurance and Utilization Review of Individual Medical Psychoterapies". em M.R. Mattson (ed.): Manual of Psychiatric Quality Assurance, American Psychiatric Ass., 1992.

(40). Hagedorn, H.J. et al.: A Working Manual of Simple Program Evaluation Techniques for Community Mental Health Care Centers. N.I.M.H., D.H.E.W. Publication (ADM) 76-404, 1976.

(41). Hall, J.e Dornan, M.C.: "What Patients Like About Their Medical Care and How Often They Are Asked: A Meta-Analysis of the Satisfaction Literature". Social Science and Medicine 27(9), 935-939, 1988.

(42). Hamilton J.D. et al.: "Quality Assessment and Improvement in Group Therapy". Am. J. Psychiatry 150:2, 1993.

(43). Hamilton, J.M.: "Introduction to the American Psychiatric Association's Assurance and Utilization Review". M.R. Mattson (ed.): Manual of Psychiatric Quality Assurance", American Psychiatric Ass., 1992.

(44). Harding, T. et al.: "Mental disorders in primary health care: a study of their frequency and diagnosis in four developing countries", Psychological Medicine 10, 231-241, 1980. 
(45). Hastings, G.E. et al.: "Peer Review Checklist: Reproductibility and Validity of a Method for Evaluating the Quality of Ambulatory Care". Am. J. Public Health 70(3), 222-228, 1980.

(46). Health Partial Care Programs". Health Services Research 25(2), 389-420, 1990.

(47). Hine F.R. et al.: "Effectiveness of Psychoterapy: Problems of Research on Complex Phenomena". Am. J. Psychiatry 139:2, 1982.

(48). Horgan, C.M.: "Specialty and general ambulatory mental health services comparison of utilization and expenditures", Archives of General Psychiatry 42, 565-572, 1985.

(49). Horowitz, M. J. et al.: "Comprehensive Analysis of Change after Brief Dynamic Psychoterapy". Am. J. Psychiatry 143:5, 1986.

(50). Ibern, P.: "La Mesura de la Satisfacció en els Serveis Sanitaris". Gaceta Sanitaria 31:6, 1992.

(51). Kelstrup, A. et al.: "Satisfaction with Care reported by Psychiatric Inpatients". Acta Psychiatr. Scan. 87, 1993.

(52). Kendal, M.: Multivariate Analysis. London: Charles Grifin, 1980.

(53). Kessler, R., Brown R. e Broman, C.: "Sex diferences in psichiatric help seeking: evidence from four large-scale surveys", Journal of Health and Social Behaviour 22, 49-64, 1981. 
(54). Kessler R., Cleary P. e Burke, J.: "Psichiatric desorders in primary care", Archives of General Psychiatry 42, 583-587, 1985.

(55). Lebow, J.: Models for evaluating services at community mental health centers", Hospital and Community Psychiatry 33-12, 1010-1015, 1982.

(56). Lebow, J.L. e Newman, F.L.: "The Utilization of Simple Measures in Mental Health Program Evaluation". Evaluation and Program Planning 10(3), 189-190, 1987.

(57). Lebow, J.L.: "Assessing Consumer Satisfaction in Mental Health Treatment Settings: A Guide for the Administrator". Administration in Mental Health 12(1) 3-14, 1984

(58). Lebow, J.L.: "Acceptability as a Simple Measure in Mental Health Program Evaluation". Evaluation and Program Planning 10(3), 191-195, 1987.

(59). Lebow, J.L.: "Client Satisfaction with Mental Health Treatment: Methodological Considerations in Assessment" Evaluation Review 7(6) 729-752, 1983.

(60). Lebow, J.L..: "Research Assessing Consumer Satisfaction with Mental Health Treatment: a Review of Findings". Evaluation and Program Planning 6, 211-236, 1983.

(61). Lewis, C.: "Can medical records in developing countries be used to measure quality?" 8th International Symposium on Quality Assurance in Health Care, Washington D.C. 1991. 
(62). Linn M.W. e Linn, B.S. : "Narrowing the Gap between Medical and Mental Health Evaluation". Medical Care XIII:7, 1975.

(63). Lorefice L.S. et al.: "Consumer Evaluation of a Community mental Health Service, I: Care Delivery Patterns". Am. J. Psychiatry 139:10, 1982.

(64). Luft, L.L et al.,.: "Effects of Peer Review on Outpatient Psychotherapy. Therapist and Patient Follow-Up Survey". Am. J. Psychiatry 133:8, 1976.

(65). Lund, K.A. et al.: "Satisfaction with Care Reported by Psychiatric Inpatients". Acta Psychiatr Scand. 87, 1993.

(66). Lyons, T.F. e Payne, B.C.: "The Relationship of Physicians' Medical Recording Performance to Their Medical Care Performance". Med. Care 12(8), 714-720, 1974.

(67). MacDonald, L., Ochera, J., Leibowitz J. and McLean, E.: "Community Mental Health Services from the user's perspective: An evaluation of the Doddington Edward Wilson (DEW) mental health service", The international Journal of Social Psychiatry 36-3, 183-193, 1990.

(68). Mari, J.: "Psychiatric morbidity in three primary medical care clinics in the city of Sao Paulo". Social Psychiatry 52, 583-587, 1985.

(69). Morlino, M.M. et al.: "Patients Dropping out of Treatment in Italy". Acta PSychiatr. Scand. 92, 1995. 
(70). Mattson, M.R.: "Quality Assurance; A Literature Review of a Changing Field". Hosp. Community Psychiatry 35(6), 605-616, 1984.

(71). May, P.R.: "Cost-Efficiency of Mental Health Delivery Systems". AM. J. of Public Health 60:11, 1970.

(72). McAulife, W.E.: "Measuring The Quality of Medical Care: Process versus Outcome". Millbank Mem. Fund. Q. 57(1), 118-152, 1979.

(73). McAulife, W.E.: "On the Statistical Validity of Standards Used in Profile Monitoring of Health Care". Am. J. Public Health 68(7), 645-651, 1978.

(74). McAulife W.E.: "Studies of Process-Outcome Correlations in Medical Care Evaluations: A Critique". Medical Care XVI:11, 1978.

(75). McGrew, J.H. et al.: "A Multisite Study of Client Outcomes in Assertive Community Treatment". Psychiatric Services 46:7, 1995.

(76). Michel K. e Kolakowska, T.: "A survey of prescribing psychotropic drugs in two psychiatric hospitals". British Journal of Psychiatry 138, 217-221, 1981

(77). Ministério da Saúde - DINSAM: Manual de Orientação para Programas e Serviços de Saúde Mental, Brasilia D.F., 1988.

(78). Ministério do Trabalho e Previdência Social- INPS: Manual de Serviço Para Assistência Psiquiátrica S.A.M. 304.3, 1973. 
(79). Neale, M.S. e Rosenheck, R.A.: "Therapeutic Alliance and Outcome in a VA Intensive Case Management Program". Psychiatric Services 46:7, 1995.

(80). Nie, N.H. et al.: SPSS: Statistical Package for the Social Sciences. New York, NY: Mc Graw-Hill, 1975.

(81). Norquist G. et al.: "Quality of Care for Depressed Elderly patients Hospitalized in the Specialty Psychiatric Units or General Medical Wards". Arch. Gen. Psychiatry 52, 1995.

(82). Padilla, P. e Pelaez, O.: "Detección de Transtornos Mentales en el Primer Nivel de Atención Médica". Salud Mental 8, 66-72, 1985.

(83). Palmer, R.H. e Nesson, H.R.: "A Review of Methods for Ambulatory Medical Care Evaluations". Med. Care 20(8), 758-751, 1982.

(84). Panerai, R. e Peña, J.: Evaluación de Tecnologías en Salud. Metodologías para Países en Desarrollo. Organización Panamericana de Salud-OMS, 1990.

(85). Panerai, R.B. et al.: "Estimativa de Efetividade de Tecnologias Perinatais". Rio de Janeiro: Cadernos de Saúde Coletiva da UFRJ, 1988.

(86). Peace, K. e Mellsop, G.: "Alcoholism and Psychiatric Disorder". Australian and New Zealand Journal of Psychiatry 21, 1987.

(87). Pickett S.A. et al.: "Factors Predicting Patients' Satisfaction with managed Mental Health Care". Psychiatric Services 46:7, 1995. 
(87.a). Pitta, A.M.F. et al.: "Determinantes da Qualidade de Serviços de Saúde Mental em Municípios Brasileiros - Estudo da Satisfação com os Resultados das Atividades Desenvolvidas por Pacientes, Familiares e Trabalhadores dos Serviços". J. Bras. Psiq. 44:9, 1995.

(88). Riedel, D.C. et al.: Patient Care Evaluation in Mental Health Programs. Cambridge, Mass.: Ballinger Pub. Co., 1974.

(89). Roberts, J.S. et al.: "A History of the Joint Commission on Accreditation of Hospitals". J.A.M.A. 258(7), 936-940, 1987.

(90). Rodriguez, A.: "The effects of contemporary economic conditions on availability and quality of mental health services" em G. Stricker and A. Rodriguez (eds): Handbook of Quality Assurance in Mental Health. New York: Plenum Press, 1988.

(91). Rodriguez, A.R.: "Psychological and Psychiatric Peer Review at CHAMPUS". American Psychologist 38, 1983.

(92). Roemer, M.I. e Montoya-Aguilar, C.: Quality Assessment and Assurance in Primary Health Care. Genebra, SW: W.H.O., 1988.

(93). Rounsaville, B.J. et al.: "Psychopatology as a Predictor of Treatment Outcomes in Alcoholics". Arch.Gen. Psychiatry 44:6, 1987.

(94). Roy-Birne, P. et al.: "A Psychiatrist-Rated Battery of Measures for Assessing the Clinical Status of Psychiatric Inpatients". Psychiatric Services 46:4, 1995. 
(95). Ruggeri, M. e Dalla'agnola, R.: "The Development and use of the Verona Expectations for Care Scale (VECS) and the Verona Service Satisfaction Scale (VSSS) for Measuring Expectations and Satisfaction with Community-based Psychiatric Services in Patients, Relatives and Professionals". Psychological Medicine 23, 1993.

(96). Sachs, L.: Applied Statistics: A Handbook of Techniques. New York, NY: Springer-Verlag, 1984.

(97). Salgado, L.D.B.: El Proceso de Evaluación: Una Revisión Bibliográfica". Salud Mental 8(2), 11-16, 1985.

(98). Scally, G. et al.: "Quality Assurance - New Wine in old Bottles". The Society of Community Medicine, 1988.

(99). Schinnar, A.P. et al.: "Organizational Determinants of Eficiency and Efectiveness in Mental Health Partial Care Programs". Health Services Research 25(2), 389-420, 1990.

(100). Schulberg, H.C.: "Quality of Care Standards and Professional Norms". Am. J. Psychiatry 133(9), 1047-1051, 1976.

(101). Segal, S.P. et al.: "Factors in the Quality of Patien Evaluations in General Hospital Psychiatric Emergency Services". Psychiatric Services 46:11, 1995. 
(102). Shapiro S., Skinner E., Kessler L., Korf M., Gorman P., Tischler G., Leaf P., Bneham L., Cottler, L. e Regier, D.: "Utilization of Health and Mental Health Services - Three Epidemiologic Catchment Area Sites". Archives of General Psiquiatry 41: 971-978, 1984.

(103). Sherman, P.S.: "Simple Quality Assurance Measures". Evaluation and Program Planning 10(3), 227-230, 1987.

(104). Shwed, H.J., et al.: "Medicaid Audit: Crisis in Confidenciality and the Patient-Psychiatrist Relationship". Am. J. Psychiatry 136:4A, 1979.

(105). Siegel, S.: Estatística não Paramétrica. Mac Graw Hill do Brasil, 1975.

(106). Slater, V. et al.: "A Satisfaction with Mental Health Care Scale". Compr. Psychiatry 23(1), 68-74, 1982.

(107). Smith, M.E.: "A Guide to the Use of Simple Process Measures". Evaluation and Program Planning 10(3), 219-225, 1987.

(108). Starfield, B.: "Health Services Research: A Working Model". N. Engl. J. Med. 289(19), 132-136, 1973.

(109). Tancredi, F.B. et al.: "Estudo de Apreciação de Programas com Ações Integradas de.Saúde - Projeto Niterói, Brasil". Mimeo, 1988

(110). Tanner, B.: "Factors influencing client satisfaction with mental health services", Evaluation and Program Planning 4: 279-286, 1981. 
(111). Taube, C.A. et al.: "New Directions in Research on Assertive Community Treatment". Hosp. Community Psychiatry 41(6), 642-647, 1990.

(112). Thompson, J.W. et al.: "Initial Level of Care and Clinical Status in a Managed Mental Health Program". Hospital and Community Psychiatry 43:6, 1992.

(113). Tillman, H.: "Hennepin County C.M.H.C. "Tell-It-Like-It-Was" Questionaire" in A Working Manual of Simple Program Evaluation Techniques for C.M.H.C. Centers. NIMH, DHEW Publication (ADM) 76-404, 1976.

(114). Torres, A.R., Pompei, M.S. e Kerr-Correa, F.: "Avaliação da Implantação de um Serviço de Saúde Mental em um Centro de Saúde". Revista da ABP-APAL 11(4), 1989.

(115). Torres, A.R.: "Avaliação do Sub-Programa Retorno Geral do Ambulatòrio de Psiquiatria de Faculdade de Medicina de Botucatu". Apresentado na Jornada Científica da Associação dos Docentes de Botucatu UNESP-,Botucatu, SP, 1989.

(116). Ware, J.E. et al.: "Defining and Measuring Patient Satisfaction with Medical Care". Evaluation and Program Planning 6, 1983.

(117). Weiner, J.: Notas sobre o curso: "Introduction to Methods for Health Services Research and Evaluation". The Johns Hopkins University School of Hygiene and Public Health, 1987-88. 
(118). Weiss, D.S. et al.: "A Proposed Method for Measuting Change Beyond Symptoms". Arch. Gen. Psychiatry 42, 1985.

(119). Weissman, MM. e Myers, J.K.: "Clinical Depression in Alcoholism". Am.J. Psychiatry 137:3, 1980.

(120). Wells, K. et al.: "Sociodemographic factors and the use of outpatient mental health services", Medical Care 24, 75-85, 1986.

(121). Widman, D.E.: "Recent Changes in JCAH Standards Affecting the Accreditation of Psychiatric Facilities". Hospital ande Community Psychiatry 35:12, 1984.

(122). Wilkinson, G. et al.: "An Evaluation of Community-Based Psychiatric Care for People with Treated Long-Term Mental Illness". British Journal of Psychiatry 167, 1995.

(123). Williamson, J.W. et al.: Priority Setting in Quality Assurance Reliability of Staf Judgements in Medical Institutions". Med. Care 16(11), 931-940, 1978.

(124). Williamson, J.W.: Assessing and Improving Health Care Outcomes: The Health Accounting Approach to Quality Assurance. Cambridge, Mass.: Ballinger Pub. Co., 1978.

(125). Williamson, J.W.: "Evaluating Quality of Patient Care: A Strategy Relating Outome and Process Assessment". J.A.M.A. 218(4), 564-569, 1971. 
(126). Williamson, J.W.: "Formulating Priorities for Quality Assurance Activity: Description of a Method and Its Application". J.A.M.A. 239(7), 631-637, 1978.

(127). Witt, A.: "Desempenho Organizacional: Avaliação Comunitária". Revista Paulista de Hospitais 29(10), 292-302, 1981.

(128). Zusman, J. e Ross, E.R.R.: "Evaluation of the Quality of Mental Health Services". Arch. Gen. Psychiat. 20(3), 352-357, 1969.

(129). Zusman, J.: "Quality Assurance in Mental Health Care". Hosp. Community Psychiatry 39(12), 1286-1290, 1988.

(130) SAS: Statistical Analysis Software, Users manual, 1995

(131). Organização Mundial da Saúde: Classificação Internacional de Doenças Revisão 1975- Vol.I. Ministério da Saúde, U.S.P., O.P.A.S., São Paulo, Brasil, 1980.

(132). Wilson, G.F.: "An Evolution of Cost-Control Approaches to Health Care", em Mattson, M.R. (ed.): Manual of Psychiatric Quality Assurance, American Psychiatric Ass., 1991.

(133). Stricker, G. e Rodriguez, A. (eds): Handbook of Quality Assurance in Mental Health. New York: Plenum Press, 1988

(134). Tyrer, P. : "Drug Treatment of Psychiatric Patients in General Practice". British Medical Journal 2, 1978. 
(135). Gray, S.H. : "Quality Assurance and Utilization Review of Individual Medical Psychoterapies". Em M.R. Mattson (ed): Manual of Psychiatric Quality Assurance, American Psychiatric Association, 1991. 
7. Anexos 


\section{Anexo I}

Tipos de atividades Desenvolvidas no Ambulatório de Saúde MENTAL:

1. Triagem - 6 períodos semanais de 4 hrs (efetuado por auxiliar de enfermagem treinada);

2. Atendimento de emergência - todos os dias, inclusive sábados e domingos (plantões);

3. Atendimento ambulatorial psiquiátrico - constituido de 10 períodos semanais de 4 hrs;

4. Atendimento de serviço social - constituido de 10 períodos semanais de $4 \mathrm{hrs}$;

5. Atendimento psicológico - constituido de 10 períodos semanais de 4 hrs;

6. Atendimento de terapia ocupacional - constituido de 8 períodos semanais de 4 hrs;

7. Atendimento de orientação educacional - constituido de 6 períodos semanais de 4 hrs;

8. Atendimento de enfermagem - constituido de 1 periodo semanal de 4 hrs;

9. Grupo de alcoolistas e familiares - 2 grupos semanais ( 1 masculino e 1 feminino), de 2 hrs - coordenado por assistente social;

10. Grupo de familiares de alcoolistas - 2 grupos quinzenais, de 2 hrs coordenado por assistente social;

11. Grupo de orientacão conjugal - 1 grupo quinzenal de $2 \mathrm{hrs} \mathrm{-} \mathrm{coordenado}$ por assistente social;

12. Grupo de terapia ocupacional de ambulatório para psicótico - 1 grupo semanal de 1 e $1 / 2$ hrs - coordenado por terapêta ocupacional; 
13. Grupo de terapia ocupacional para deficientes intelectuais - 1 grupo semanal de 2 hrs - coordenado por terapêuta ocupacional;

14. Grupo de familiares de deficientes intelectuais - 1 grupo mensal de 2 hrs - coordenado por terapêuta ocupacional e assistente social;

15. Grupo de psicoterapia para adultos - 1 grupo semanal e 1 grupo quinzenal de 2 hrs cada - coordenado por psicóloga e assistente social;

16. Grupo de adolescentes - 1 grupo semanal de 2 hrs - coordenado por psicóloga;

17. Grupo de pré-adolescentes ( $5^{a}$ e $6^{a}$ séries) com dificuldades escolares e psicomotoras - 2 grupos semanais de 1 hora - coordenado por pedagoga;

18. Grupo de crianças matriculadas no Ciclo Básico - 2 grupos semanais de 1 hora - coordenado por pedagoga;

19. Grupo de crianças matriculadas na $3^{a}$ e $4^{a}$ séries -2 grupos semanais de 1 hora - coordenado por pedagoga;

20. Grupo de criancas matriculadas no pré-primário - 1 grupo semanal de 1 hora - coordenado por pedagoga;

21. Grupo de orientação à hipertensos - 1 grupo semanal de 2 hrs - coordenado por assistente social;

22. Grupo de crianças com problemas emocionais - 1 grupo semanal de 1 e $1 / 2$ hrs - coordenado por psicóloga;

23. Grupo de relaxamento - 2 grupos semanais de 2 horas.

Os residentes de psiquiatria participam dos grupos de alcoolistas e de vários outros grupos psicoterápicos, sendo responsáveis pela medicação quando necessário. 
TRANSTORNOS NEUTÓ́tTCOS, TRANSTORNOS DA PERSONALIDADE E OUTROS TRUNSTORNOS MENTAIS Nĩo-PSICóturos (300-316)

\section{Transtornos neurbticos}

A distinçāo entre neurose e psicose $t$ dificil e continua sujeita a discussåo. Entretanto, a denominasão foi mantida tendo em vista seu emprego generalizado. Os transtomos neuróticos sáo transtomos mentais sem uma base orgănica demonstrável nos quais o paciente pode apresentar uma razoável compreensão e uma experiencia inalterada da realidade, náo a confundindo com suas experiências morbidas subjetivas e suas fantasias. O comportamento pode estar muito afetado, apesar de comumente permanecer dentro de limites socialmente aceitaveis, porem, a personalidade náo se desorganiza. Suas principais manifestaçōes incluem ansiedade excessiva, sintomas histéricos, fobias, sintomas obsessivos e compulsivos, e depressão.

\subsection{Estados de ansiedade}

Värias combinaçōes de manifestaçōes fisicas e mentais de ansiedade que não podem ser atribuidas a um perigo real e que ocorrem em lorma de ataques a pànico. $\lambda_{s}$ vezes outras características neuróticas, tais como sintomas obses. sivos ou histéricos, podem estar tambem presentes, mas sem dominar o quadro clínico.

Neurose de ansiedade

Reação ansiosa

Ataque

Estado

de pânico

Exclui: neurastenia (300.5)

$$
\text { transtornos psicofisiológicos (306.-) }
$$

\subsection{Histeria}

Transtornos mentais nos quais alguns motivos, que o paciente parece năo perceber, produzem quer uma limitaçāo do campo da consciència quer dusturbic da funçāo motora ou sensorial os quais podem representar uma vautagem psichenos conversivos ou dissociativos. ünicos sintomas consistem em distúrbios psicogenéticos da funcấo de alsuma parte do corpo, por exemplo, paralisia, tremor, cegueira surdez ou convulsōes. parte do corpo, por exentiva, paralsia, tic mas proeminente mento do canipo da consciência que parece servir a um propósito inconsciente. mento do canipo da consciencia que parece servir a um proposito inconsciente, mudanças dranditicas, embora essencialmente superficiais, da petsonalidade. algumas vezes $\mathrm{n} 2$ forma de fugas [estado errante]. O comportamento pode imitar psicose, ou, melhor, a idéia que o paciente tem de psicose.

Astasia-abasia histérica

Histeria SOE

llisteria de conversão

Personalidade múltipla

Reação de conversāo

Neurose de renda

Reação ou estado dissociativo

Exclui: anorexia nervosa (307.1)

rcação de ajustamento (309.-)

reação global a sobrecarga emocional (308.-)

personalidade histérica (301.5)

transtnmos neimfisinltimime 1,3nt - 1 
300.2 Estado fobtico

Ectadoe neurbicos com modo anormalmente intenso de certos objetos ou de chuscies erpeclfices que normalmente nlo produziriam tal efeito. Se a anande teode a eppliharete de uma situaça ou objetos especificos para um contom to mas amplo de clrcunsthocies, tormese idéntica ou semelhante no ctadoida ansiodade e deve rer clawificada como tal $(300.0)$.

Azprofíbiai

Claustrofobia

Fobia de animais

Eobiin SOE

Histeria de ansiedade

Eivellut: estado de ansiedade $(300.0)$ fobies obsessivas (300.3)

300.3. Transtomas obsessivo-compulsivos

Eutudor now quais o sintoma saliente 6 um sentimento de compulsáo subjetiva - - qual o paciente deve resistir - para efetuar alguma açắo, insistir num

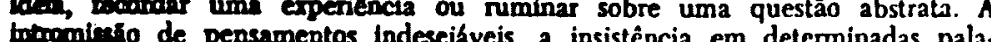
ou idelos pensamentos pelo paciente como inapropriadas ou ceres de ponsamento sa percebldas ou idtine obeessivas sapophos dade entretanto procedentes do proprio eu. Os atos obsessivos podem ser drace arer-a pereamento on impulsos indescibveis podem conduzit a uma seve lut in

Neurose anancástica

Neurose compulsiva

Exclui: sintomas obsessivo-compulsivos que ocorrem (na, nos) depressāo endógena (296.1) esquizofrenia (295.-) estados orgânicos, por exemplo, encefalite

\section{\$00.4 Depressão neurótica}

Trnnstorso neuntico caracterizado por uma depressáo desproporcional que geralmente se apresenta depois de uma experiencia dolorosa; não inclui entre suns caracteristcas Idelas dolisntes nem alucinaçes, e, frequientemente, ha uma preocupacio com o trauma psiquico que precedeu a doença, por exemplo, a perce com frequi que presente com frequencla $e$ os estados combinados de ansiedade e depressa prem sor incluldos aqui. A disthaça entre heurose depressiva e psicose de pressiva nalo deve basear-se apenas no grau de depressto psichticas e sobre as perturbaçes do comportamento do paciente.

\section{Depressāo ansiosa Estado depressivo neurótico}

Depressão reativa

Reação depressiva

Exclui: depressão SOE (311)

psicose maniaco-depressiva, tipo depressivo (296.1)

psicose reativa depressiva (298.0)

reaçāo de ajustamento com sintomas depressivos (309.0)

\subsection{Neurastenia}

Transtorno neurótico caracterizado por fadiga, irritabilidade, cefaléia, depressão, insònia, dificuldade de concentraçáo e falta de capacidade para o prazer [anedonia]. Pode seguir-se a ou acompanhar uma infecçäo ou um estado de esgotamento, ou apresentar-se em consequiência de uma sobrecarga emocional continua. Caso a neurastenia esteja

Debilidade nervosa

Exclui: depressão neurótica (300.4) estado de ansiedade $(300.0)$ transtomos mentais não psicóticos especificados conseqũentes a lesão cerebral orgânica (310.-) transtomos psicofisiológicos (306.-)

300.6 Sindrome de despersonalização

Transtornos neuróticos com estado desagradável de percepcăo distorcida, na qual objetos externos ou partes do proprio corpo sáo percebidos como que alterados em sua qualidade, irreais, remotos ou automatizados. $O$ paciente tem consciència da natureza subjetiva da mudança pela qual passa. A despersonalizaçāo pode ocorrer como uma das caracteristicas de diversos transtornos mentais, incluindo depressão, neurose obsessiva, ansiedade e esquizofrenia; nesse caso tal afeção náo deve ser classificada aqui mas na categoria principal correspondente.

Desrealizaçāo (neurótica)

300.7 Hipocondrio

Transtorno neurótico em que as características marcantes săo preocupaçāo excessiva com a própria saúde em geral ou com a integridade e o funcionamento de alguma parte de seu corpo, ou, com menor frequencia, com sus mente. Esta geralnente associada a ansiedade e depressão. Pode ocorrer conıo uma das caracteristicas de un transtomo mental grave $e$, nesse caso, não deve ser classificada aqui mas na categoria principal correspondente.

Exclui: esquizofrenia (295.-)

histeria (300.1)

neurastenia (300.5)

psicose maniaco-depressiva, tiro depressivo (296.1)

transtorno obsessivo (300.3)

300.8 Outros transtornos neuróticos

Transtomos neuróticos não classificados em outra parte, por exemplo, a neurose ocupacional. Os pacientes com neurose mista nāo devem ser classificados nesta categoria mas de acordo com os sintomas piedominantes que apresentam. Neurose ocupacional, inclusive a cãimbra dos escritores

Neurose psicastênica

Psicastenia

Transtorno de Briquet

300.9 Nāo especificadós

Para set usado somente como último recurso.

Neurose SOE

Psiconeurose SOE 
Transtornos leves, on tzansitórios de duração maior que as reaçóes ao "stress" (308.-) us quais ocorrem em individuos de qualquer idade sem nenhum trans. torno mental aparente e pré-existente. Tais transtornos são muitas vezes relativaniente circunscritos ou especilicos de deteminadas situaçoes; geralmente são reversiveis e duram apena? poucos meses. Comumente relacionam-se de perto no tempo e em contendo a estado de "stress" tais como perda de ente queridn, migraçāo ou experiencia de separaçăo. As reaçoés a estados tensionais mais acentuados de duraçáo maior que alguns dias tambèm sáo incluidas aqui. Nas crianças, estes transtornos não estāo associados a distorçōes importantes do desenvolvimento.

Exclui: reaçio aguda a estado tensional accntuado (308.-) Iranstornos neuróticos (300.-)

309.0 Reação depressiva breve

Estados de drpressão, nüo classificiveis como maniuco-depressivos, neuróticos un psicóticos, peralmente transiturios, nos quais as sintonias depressiven rela. cionam-se de perto no tempo e ell conteido a algum evento cstressante.

Reaçäo de tristeza

Exclui: depressão neurótica (300.4)

psicose depressiva psicogenetica (29S.0)

psicuses afetivas (296.-)

reaçäo depressiva prolongada (300.1)

309.1 Reaçióo depressiva prolongada

¿ Estados de depressăo, não especificáveis como maniaco-depressivos, psicíticos ou neuroticus, geralmente de longa duração, desenvolvendo-se geralnente en assuciucáo a expursico prolongada a una siluaş̃o estressimte.

Exclui: depressão neurótica (300.4)

psicose depressiva psicogenćtica (298.0)

psicoses afetivas (296.-)

reação depressiva breve $(309.0)$

309.2 Com distúrbios predominantes de outras emoçōes

Estados que atendem os critérios gerais para a reaçäo de ajustamento, nos quais os sintomas principais são de tipo emocional lansiedade, medo, afliçāo, mas nao cspccifica

Ansiedade anormal devida a Choque de culturas

separação

\subsection{Com distúrbios prodorisiantes de conduto}

Transtomos leves ou transitórion. owe atendem os critérios gerais para a reacilo de a/ustamento, nos quals o princpeal distúrbio envolve um distúrbio de con-
duta. Por exemplo, uma reaçlo de tristeza na adolesctacis resultando num transtomo astressivo ou anti-social eria incluida aqui.

Exclui: comportamento dissocial sem transtorno psiquiátrico manifesto (V71.0)

distúrbio de conduta SOE (312.-)

transtorno da personalidade com manifestaçōes sociopáti-

cas ou associais predominantes (301.7)
309.4 Com distúrbtos mirtos das emoçōes e da conduto Transtornos que stendem a defiziça geral, nos quais ambos os diuturblos das emopbes e da conduta săo caractertsticas importanten.

309.8 Outra

Hospitalismo na infância SOE

Reação de ajustamento com mutismo eletivo

309.9 Não especificado

Reação de adaptação SOE 


\section{CLASSIFICACAO SUPLEMENTAR DE FATORES QUE} EXERCEM INFLUENCL SOBRE O ESTADO DE SAODE E DE
OPORTUNIDADES DE CONTATO COM SERVIÇOS DE SAUDE

Esta classificaçāo deve ser usada nos casos enı que circunstâncias outras jue não uma doença ou lesĩo classificável nas categorias 001-999, a parte principal da CID, ou na classificação suplementar E, scjam registradas como "problemas" ou "diagnósticos". Isto pode ocorrer de duas maneiras principais:

a) . Quando um individuo, que nāo está docnte no momento, entra em contato com os serviços de saúde para alguma finalidade específica, tal como a doação de umn órgão ou tecido, para receber vacinaçāo profilática ou para discutir um problema que não se constitui, por si só, em doença ou lesão. Tal fato raramente ocorrerá entre pacientes internados em hospitais mas será relativamente conum entre pacientes de ambulatório, pacientes de médicos de fanília, de clínicas de saúde, etc. Nessas circunstâncias, permite-se 0 uso do código $\mathrm{V}$ para as tabulaçōes de causa única.

b) Quando existe alguma circunstância on problema que influencia o estado de saúde do indivíduo mas que naao se cinstitui. por si só, em doença ou lesão, naquele momento. Tais fatores podein ser descobertos durante levantamcntos populicionais, e'm que o indivíduo pode ou nāo estar doente no momento do levantamento, ou podem ser registrados como fator adicional a ser levado en mnta quando o indivíduo receber cuidados de saúde por causa de alguma quaindo o individuo receber cuidados de saúde por causa de alguma
doenç̧a ou lesāo. Nessas circunstâncias o código $\mathrm{V}$ deve ser usado apenas como código suplementar e não deve ser o escolhido para uso em tabulaçōes primárias de causa única. Constituem-se em "vi'nplos destas circumstâncias uma história individual de certas duenç̧as. on $\mathrm{um}$ indivíduo portador de uma válvula cardíaca artificial in situ.

\section{V61 Outras circunstàncias familiares}

Inclui: quando estas circunstâncias ou o te ncr pelas mesmas quer atingindo a pessoa diretamente envolvida ou a outras, são mencionadas como a razāo, justificada ou não, da procura ou do recehimento de aconselhamento ou cuidados médicos

V61.0 Dissoluçāo familiar

\section{Afastamento \\ Divórcin}

V61.1 Problemas conjugais

Conflitos conjugais

Exclui: problemas relacionados a:

funçāo sexual (V41.7)

transtornos psicossexuais (302.-)
.V61.2 Problensas entre-pais e filhos

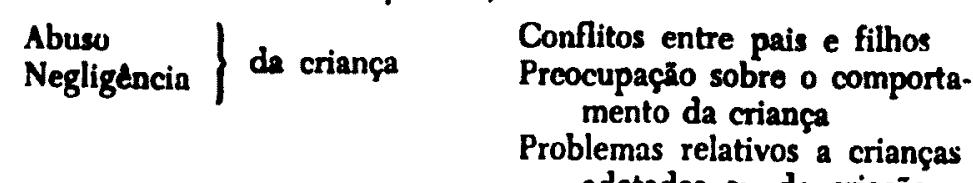

Problemas relativos a criança
adotadas ou de criação

Exclui: efeitos de maus tratus a criança (995.5)

V61.3 Problemas com pais ou sogros idosos

V61.4 Problemas de saúde na família

Alcoolismo na familia

Cuidados a

Presença de pessoa doente ou inválida na familia ou na casa

V61.5 Multiparidade

V61.6 Ilegitimidade ou gravidez ilegítima

V61.7 Outras formas de gravidez nāo desejada

v61.8 Outras

V61.9 Nāo especificadas

\section{v62 Outras circunstancias psicossociais}

Inclui: quando estas circunstâncias ou o temor pelas mesmas, quer atingindo a pessoa diretamente envolvida ou a outras, são mencionadas como a razão, justificada ou não, da procura ou do recebimento de aconselhamento ou cuidados médicos

Exclui: trauma psicológico anterior (V15.4)

V62.0 Desemprego

Exclui: quando 6 problema principal constitui-se em reciısos materiais inadequados (V60.2)

V62.1 Efeitos adversos do ambiente de trabalho

V62.2 Outras circunstancias $c /$ desajustamentos ocupacionais Insatisfaçāo no emprego Problemas de escolha de carreira V62.3 Circunstancias educacionais

Insatisfaçāo no ambiente Limitaçōes relativas a educaçäo iscolar 
V62.4 Desajustamento social

$\left.\begin{array}{ll}\text { Discrininaçaio politica, religio- } & \begin{array}{l}\text { Isolamento } \\ \text { sa ou sexual }\end{array} \\ \text { Perseguição }\end{array}\right\}$ social

Privação cultura

V62.5 Circunstancias leguis

Litlgio, demanda

Processo

Prisão, detenção

V62.6 Recuse de tratamento por razōes religiosas ou de consciéncia

v62.8 Outras tensóes psicológicas ou físicas mio classificadas em outra parte

V62.9 Nāo especificadas

V40 Problemas mentais de comportamento

V40.0 Problemas de aprendizado

V40.1 Problemas de comunicação [inclusive da linguagem]

$\checkmark 40.2$ Outros problemas mentais

V40.3 Outros problemas de comportamento

V40.9 Problemas mentais ou de comportamento náo especificados

V15.4 Trauma psicológico

Exclui: história de quadros mentais classificáveis em 290-316 ( V1l)

V11 Antecedentes do histótia pescoal de transtorno mental 
Anexo III

UNESP - FACULDADE DE MEDICINA DE BOTUCATU

DEPARTAMENTO DE NEUROLOGIA E PSIQUIATRIA

DISCIPLINA DE PSIQUIATRIA - CASO NOVO

Data:

Nome:

R.G.:

Idade:

Sexo:

Cor:

Previdência:

Proced. Remota:

Proced. Recente (end):

Est. Civil:

Grau de Instrução:

Profissão:

Religião:

Encaminhado por :

Q.D.:

H.M.A.: 


\section{Perturbações Associadas:}

Antecedentes Familiares: (mãe, pai, irmãos, outros parentes, anote doenças psiquiátricas):

Antecedentes Familiares na Infância: 


\section{Antecedentes Pessoais:}

a) Desenvolvimento inicial:

b) Comportamento durante a infância:

c) Escolaridade:

d) Conduta na Escola:

e) Ocupações: 
f) Adolescência: (Atitude em relação ao crescimento, companheiros, família e à autoridade, comportamentos rebeldes, ingestão de drogas, periodos de depressão ou isolamento, etc.):

g) Antecedentes sexuais (idade do inicio da puberdade, menarca, reações, fantasias, atitudes homo e heterosexuais, distúrbios da sexualidade, técnicas anticoncepcionais, satisfação, etc.):

h) Antecedentes conjugais: ( $\mathrm{n}^{\circ} \mathrm{e}$ duração de namoros, noivados, casamentos, idade, etc., data das mortes dos cônjuges, divórcios ou separações, etc.):

Filhos: (Lista cronológica das gravidezes, incluindo abortos, Atitudes em relação aos filhos, etc.):

$\longrightarrow$


Antecedentes mórbidos:

Antecedentes Psíquicos: (incluindo internações em Hosp. Psiquiátricos):

Uso e abuso de Alcool, fumo e outras drogas:

Comportamento Antisocial:

Condições de vida atuais (incluindo renda familiar): 
Lazer:

Exame Físico (incluindo neurológico) - dados positivos:

EXAME PSÍQUICO: especifique sempre com suas palavras todos os itens do ex. psíquico no espaço ao lado.

1. Aspecto:

1. Descuidado, despenteado

2. Trajes em desalinho, sujos

3. Trajes atípicos

4. Carac. Fisicas incomuns

2. Postura:

5. Flácida

6. Rígida

7. Inadequada, bizarra

3. Movimentação:

8. Aumentada, acelerada, inquieto:

9. Agitado:

10. Diminuída, lentificada:

11. Estuporoso: 
4. Nivel de Consciência:

12. Sonolência, torpor, coma

13. Turvação da consciência

14. Estreitamento, est. crepuscular:

5. Estado cognitivo: (Atenção, memória, orientação e inteligência)

15. Desorientado em relação a si mesmo

16. Desorientado em relação ao espaço

17. Desorientado em relação ao tempo

18. Diminuição da atenção espontânea

19. Diminuição da concentração

20. Diminuição da memória de fixação

(até 10 segundos)

21. Diminuição da memória de evocação:

(recente até 3 meses)

22. Deficiência intelectual:

(especifique o grau)

6. Fala/Discurso

23. Mutismo

24. Lentificação

25. Accleração, aumento, fuga de idéias

26. Desagregação, bloqueios

27. Incoerência, falta de objetividade

28. , confabulações 
7. Pensamento:

29. Fobias

30. Obsessividade, compulsividade

31. Ideação ou atos suicidas

32. Delírios em relação ao ambiente

33. Delírios em relação a si mesmo

8. Senso-Percepção:

34. Ilusões

35. Alucinações em relação ao ambiente

36. Alucinações em relação a si mesmo

Afetividade:

37. Humor deprimido

38. Humor exaltado

39. Ansiedade, medo, ambivalência

40. Raiva, hostilidade

41. Inadequação afetiva

10- A) Pagmatismo - Psicomotricidade (hipobulia, hiperbulia, abulia, a obidiência automática, ecopraxia, negativismo, estupor, agitação psicomotora, ambitendência, atividade pragmática...): 
B) Juízo crítico (crítica do próprio estado mórbido, valorização das idéias e fenômenos...)

44. Dificuldade ou exagero em admitir a existência de problemas psicológicos

45. Dificuldade para lidar com as atividades quotidianas

46. Dificuldade para tomar decisões

11. Atitudes diante do entrevistador

47. Dominação

48. Submissão

49. Hostilidade, provocação

50. Desconfiança

51. Inadequação

12. Reações do entrevistador:

52. Sentimentos positivos, controlados

53. Sentimentos positivos, não controlados

54. Sentimentos negativos, controlados

55. Sentimentos negativos, não controlados

Exames subsidiários: 
Súmula: (Resumir, valorizando e/ou discutindo os dados mais importantes de toda a observação):

Hipótese(s) Diagnóstica(s):

Conduta (incluindo encaminhamentos):

Observações: 
Atendido por:

(nomes legíveis)

Docente responsável:

Data: I__ Horário: 


\section{Anexo IV}

FACULDADE DE MEDICINA DE BOTUCATU -UNESP

DEPARTAMENTO DE NEUROLOGIA E PSIQUIATRIA

\section{PROJETO: AVALIAÇÃO DA QUALIDADE DA ASSISTÊNCIA AMBULATORIAL EM SAÚDE MENTAL: UM ESTUDO DAS RELAÇÕES ENTRE PROCESSO E RESULTADO FINAL}

Formulário I: Identificação do Paciente c Revisão do Prontuário.

01- Questionário n:

Nome : RG:

Endereço: Rua: $n^{\circ}$

Bairro: Fone.

Outra Referência (end. antigo):

Fone recados:

Data de Nascimento:

0.2- Nome do Revisor:

Data da Revisão:

Questões 3-25. Relativas ao Caso Novo

0.3- Data do Caso Novo:

0.4- Idade do Caso Novo:

$0.5-\operatorname{Sexo}$

0 - Masculino

1 - Feminino

9 - n.a./Prejudicado 


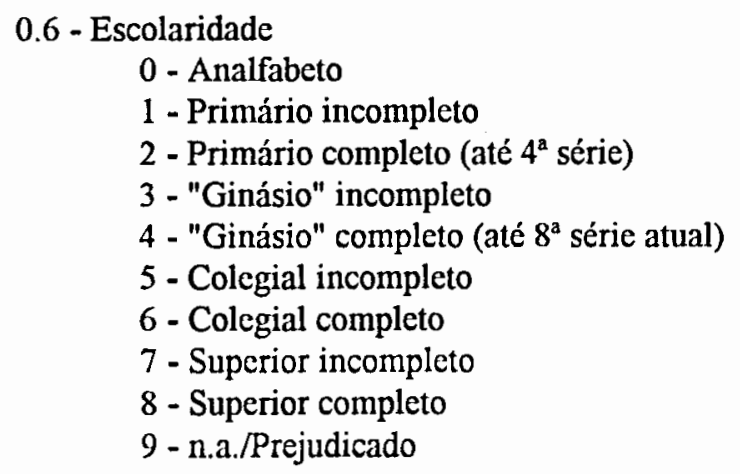

0.7 - Procedência Recente

0 - Urbana - Botucatu

1 - Rural - Botucatu

2 - Urbana - S. Manoel

3 - Rural - S. Manoel

9 - n.a./Prejudicado

0.8 - Estado Civil

0 - Solteiro

1 - Casado

2 - União/livre

3 - Desquitado/divorciado

4 - Viúvo

5 - Outro

9 - n.a./Prejudicado

0.9 - Ocupação (pelo C.N. - Status no início do tratamento)

$0-\mathrm{A}$

$1-\mathrm{B}$

$2-\mathrm{C}$

$3-\mathrm{D}$

$4-E$

$5-\mathrm{F}$

6 - Prendas domésticas

7 - Desempregado

8 - Inativo (Aposentado/Pensionista)

9 - n.a./Prejudicado

escrever por extenso a ocupação

10 - Preenchimento (Existência) da História Clínica e Antecedentes (Caso Novo)

0 -não

I - Sim, completo

2 - Sim, incompleto

9 - n.a./Prejudicado

11 - Preenchimento do Exame Físico

0 -não

1 - Sim, completo 
2 - Sim, incompleto

9 - n.a./Prejudicado

12 - Preenchimento do Exame Psíquico

0 -กão

1 - Sim, completo

2 - Sim, incompleto

9 - n.a./Prejudicado

13 - Presença de Hipótese Diagnóstica (ou equivalente) no Caso Novo

0 -não (ver observação ${ }^{4}$ )

1 - Sim, apenas 1 diagnóstico psiquiátrico

2 - Sim, + de um diagnóstico psiquiátrico

3 - Sim, diagnóstico psiquiátrico + não psiquiátrico

4 - Sim, diagnósticonão psiquiátrico (ver observação ${ }^{5}$ )

9 - n.a./Prejudicado

14 - Diagnóstico Psiquiátrico Principal (CID-9)

99 - n.a./Prejudicado

(Escrever por extenso)

15 - Diagnóstico Psiquiátrico Secundário (ou associado)

99 - n.a./Prejudicado

(Escrever por extenso)

17 - Diagnósticonão Psiquiátrico (CID-9)

99 - n.a./Prejudicado

(Escrever por extenso)

18 - Pedido de Exames Subsidiários/Complementares (incluir laboratoriais/ EEG/ E.C.G./ Tomo/ $\mathrm{Rx} /$ Testes Psicológicos).

0 -não

1 - Sim, (ver manual cod.)

99 - n.a./Prejudicado

(escrever por extenso todos)

19 - Pedido de Interconsulta ou Encaminhamento para outra(s) Clínica(s).

0 -não

1 - Sim (ver manual cod.)

99 - n.a./Prejudicado

(Escrever por extenso)

${ }^{4}$ Caso seja alternativa ( 0 -não); ir para questão 18 (q. $14,15,16,17=$ n.a.)

${ }^{5}$ Caso seja alternativa 4; ir para questão $17(14,15,16=$ n.a.) 
20 - Anotação da Conduta (ou tratamento prescrito)

0 -não

1 - Sim (ver manual cod.)

99 - n.a./Prejudicado

(Anotar todas as condutas sejam elas farmacológicas, psicoterápicas -grupo individual/relaxamento- internações, ou outros encaminhamentos)

99 - n.a./Prejudicado

21 - Caso Tratamento seja medicamentoso, qual(es) a(s) droga(s)?
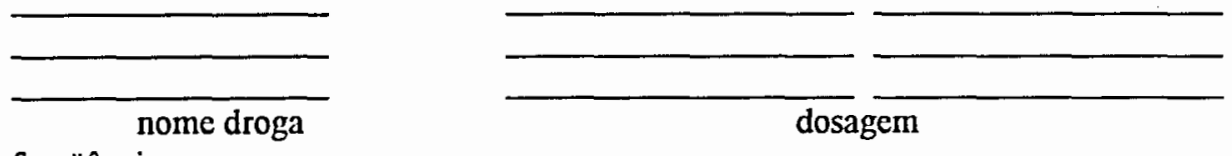

freqüência

(Anotar por extenso nome da droga, qual a dosagem (em $\mathrm{mg}$ ), qual a freqüência (quantas vezes).

99 - n.a./Prejudicado

22 - Frequiência de Administração da Droga (quantas vezes ao dia?)

$0-1$ vez

$1-2$ vezes

$2-3$ vezes

$3-4$ vezes

$4-+$ de 4 vezes

9 - n.a./Prejudicado

23 - Indicação de Psicoterapia ou outra técnica não medicamentosa (ex.: relaxamento)

0 - Não

1 - Sim, P. Grupal

2 - Sim, P. Individual

3 - Sim, Relaxamento

99 - n.a./Prejudicado (ver manual cod. para tipo de grupo)

24 - Espaço de Tempo entre o Aparecimento dos Primeiros Sintomas e a Data do Caso Novo (em meses):

\footnotetext{
(Anotar por extenso)

99 - n.a./Prejudicado
}

25 - Profissional que Efetuou o Caso Novo

0 - Psiquiatra diretamente

1 - Psiquiatra/Supervisão de residentes

2 - Psiquiatra/Supervisão de internos

3 - Residente de psiquiatria /sem que esteja anotado quem o supervisionou

9 - n.a./Prejudicado

26 - Sentimentos do Entrevistador

$0-+$ controlados

1- + não controlados

2 - - controlados

3 - - não controlados

$9-\mathrm{n} \quad$.a./Prejudicado 


\section{QUESTÕES 27 -41, REFERENTES À EVOLUÇÃO (PÓS-CASO NOVO)}

27 - Tratamento: Situação por ocasião da avaliação (Revisão)/Razão para interrupção.

0 - Em tratamento

1 - Alta médica

2 - Alta a pedido

3 - Abandono ou interrup̧̧̃o não esclarecida

9 - n.a./Prejudicado

28 - Duração total do tratamento - em meses (do Caso Novo até Alta/Revisão/Interrupcao).

(Anotar por extenso)

99 - n.a./Prejudicado

29 - Número Total de Visitas ao Serviço

99 - n.a./Prejudicado

(Anotar por extenso)

30 - Número Total de Faltas Anotadas (no Prontuário)

99 - n.a./Prejudicado

(Anotar por extenso)

31 - Tipo(s) de Tratamento(s) a que foi submetido ${ }^{6}$

0 - Farmacológico

1 - Psicoterapia individual (P.I.)

2 - Psicoterapia grupal (P.G.)

3 - Relaxamento

4 - Internação

5 - Associação ou + de um tipo de tratamento mesmo que concomitantes (vide manual)

99 - n.a./Prejudicado

33 - Caso tenha se submetido à Psicoterapia individual (P.I.)

(nome do profissional)

(duração em meses)

99 - n.a./Prejudicado

34 - Caso tenha se submetido à Psicoterapia Grupal (P.G.)

(tipo de grupo)

(duração em meses)

99 - n.a./Prejudicado

${ }^{6}$ Questões 31-36 referem-se à tipos e duração de tratamentos 
35 - Caso tenha se Submetido a Relaxamento

$$
\begin{gathered}
\text { (duração em meses) } \\
99 \text { - n.a./Prejudicado (ver manual) }
\end{gathered}
$$

36 - Caso tenha sido internado em Hospital-dia

$$
\begin{aligned}
& \text { (número de vezes) } \\
& 9 \text { - n.a./Prejudicado }
\end{aligned}
$$

(duração/meses)

38 - Caso Paciente tenha feito Psicoterapia Individual (questão 33) ou Psicoterapia Grupal (questão 34); qual a freqüência prescrita?:

$$
\begin{aligned}
& 0 \text { - semanal } \\
& 1 \text { - quinzenal } \\
& 2 \text { - mensal } \\
& 3 \text { - variável } \\
& 4 \text { - outra } \\
& 9 \text { - n.a./prejudicado }
\end{aligned}
$$

39 - Caso tenha sido encaminhado para P.I. ou P.G., qual o espaço de tempo entre o encaminhamento e o início da psicoterapia:

$$
99 \text { - n.a./Prejudicado }
$$

OBS: Questão 40: Codificar em função das questões 31-36

40 - Ao longo de todo o tratamento qual(s) o(s) tipo(s) de profissional(s) envolvido(s) ${ }^{7}$ : 0 - Psiquiatra (duração em meses):

1 - Não Psiquiatra (duração em meses):

99 - n.a./Prejudicado

41 - Ao longo de todo o tratamento qual(s) o(s) tipo(s) de droga(s) utilizada(s)? (anotar nome)

$$
99 \text { - n.a./Prejudicado }
$$

\footnotetext{
${ }^{7}$ Ver manual para associações e vide OBS. acima
} 
42 - Continuidade com o mesmo médico/número de vezes atendido pelo mesmo profissional.

0 - menos de 3 vezes

1 - de 3 a 6 vezes

2 - de 7 a 12 vezes

3 - de 13 a 18 vezes

$4-$ de 19 a 24 vezes

$5-+$ de 24 yezes

9 - n.a./Prejudicado

43 - Continuidade com um Mesmo Profissional não médico / número de vezes atendido pelo mesmo profissional.

0 - menos de 3 vezes

1 - de 3 a 6 vezes

2 - de 7 a 12 vezes

3 - de 13 a 18 vezes

4 - de 19 a 24 vezes

5 - + de 24 vezes

9 - n.a./Prejudicado

44 - Características das anotações nos retornos

0 - completas

1 - Parcialmente completas (com o mínimo)

2 - Muito incompletas

9 - n.a./Prejudicado

45 - Melhora /piora com o tratamento (percepção do médico)

0 - Muito pior

1 - Pior

2 - Inalterado

3 - Melhor

4 - Muito melhor

9 - n.a./Prejudicado

${ }^{8}$ vide manual 


\section{Anexo V}

\section{FORMULÁRIO II - ENTREVISTAS DOMICILIARES}

Questionário $\mathrm{n}^{\circ}$

Nome:

R.G.:

Endereço atualizado: Rua: $\mathrm{n}^{\mathrm{o}}:$

Bairro: Fone:

Data de Nascimento: 1 Caso novo $\mathrm{em}^{9}$ :

Questionário $\mathrm{n}^{\mathrm{0}}$ :

Obs: Todas as questões contidas na Parte 1 e Parte 2 deste formulário, referem-se apenas ao tratamento psiquiátrico/psicológico que o entrevistado recebeu no ambulatório de Psiquiatria (Bloco I) da Faculdade de Medicina de Botucatu, nos anos 1989 e 1990.

Esclarecer bem o paciente a esse respeito antes de iniciar a entrevista

Parte 1 - Percepção da melhora/piora com o tratamento

Obs: vide observação anterior antes de formular a questão abaixo ver a data do Caso Novo para completar abaixo

${ }^{9}$ Obs: Preencher antes da entrevista 
01. Com relação ao problema psiquiátrico ou psicológico ("dos nervos") que você apresentava há ano(s) quando procurou tratamento no Ambulatório de Psiquiatria (Bloco I) da Faculdade, você acha que:

0 . os sintomas pioraram muito com o tratamento

1. os sintomas pioraram com o tratamento

2. os sintomas ficaram inalterados (na mesma) com o tratamento

3. os sintomas melhoraram com o tratamento

4. os sintomas melhoraram muito com o tratamento

9. n.a./n.r.

(anotar comentários do paciente)

02. Caso você tenha interrompido o tratamento, qual foi a razão para isso?

9. n.a./n.r.

03- Durante o periodo em que você apresentou os sintomas de problema dos "nervos citado acima, você utilizou outros serviços de psiquiatria para tratar desse problema?

0. Não

1. Sim, Centro de Saúde I

2. Sim, Centro de Saúde Escola

3. Postos de Saúde

4. PAM

5. Ambulatório do Hosp. Psiquiátrico CMC. 
6. Hospitais não psiquiátricos (Santa Casa, Hospital da Sorocabana)

7. Médico particular

8. Serviços fora de Botucatu

9. Outros recursos fora do sistema de saúde tradicional (Centro Espírita, Terreiros

de Umbanda, Benzedeiras, etc.)

10. Outros

99. n.a./n.r.

04. Solicitar o cartão de consultas para o paciente, e anotar abaixo todos os dias que teve consulta no ambulatório da Psiquiatria (Bloco I). Anotar consultas na Psiquiatria, Psicologia, Serviço Social (SS), Terapia Ocupacional (TO) e Orientação Educacional (EO).

PARTE 2: Satisfação com o Tratamento

01. Você considera que chegar ao ambulatório de Psiquiatria da Faculdade considerando sua localização é:
0. Muito dificil
1. dificil
2. mais o menos
3. fácil
4. muito fácil
5. n.a./n.r.

02. O tempo que levou para marcarem sua primeira consulta na Psiquiatria foi: (Leve em conta para responder, o que você achava da urgência do seu caso): 

0. muito demorado
1. demorado
2. mais ou menos
3. rápido
4. muito rápido
9. n.a./n.r.

03. Como você foi tratado pelos funcionários do ambulatório que o receberam para a consulta (atendentes, funcionários que receberam o cartão e marcam consulta)?
0. Atenderam muito mal
1. atenderam mal
2. atenderam mais ou menos
3. atenderam bem
4. atenderam muito bem
9. n.a./n.r.

04. O que você achou dos horários que marcavam para você:

0. muito ruins

1. ruins

2. mais ou menos

3. bons

4. muito bons

n.a./n.r.

05. O que você achou do lugar onde esperava a consulta? (Pense em termos de conforto e de utilização de banheiros e água).

0 . muito ruim

1. ruim

2. mais ou menos

3. bons

4. muito bom

n.a./n.r. 
06. O que você achou do lugar onde esperou a consulta?
0. muito sujo
1. sujo
2. mais ou menos
3. limpo
4. muito limpo
9. n.a./n.r

07. De modo geral, o que você achou do tempo que esperava para ser atendido nos dias das suas consultas?
0 . muito demorado
1. demorado
2. mais ou menos
3. rápido
4. muito rápido
9. n.a./n.r.

08. O que você achou do consultório em que você foi atendido:
0 . muito desconfortável
1. desconfortável
2. mais ou menos
3. confortável
4. muito confortável
9. n.a./n.r.

9. O consultório em que você foi atendido era:

0 . muito sujo

1. sujo

2. mais ou menos

3. limpo

4. muito limpo

9. n.a./n.r. 
10. Você acha que o médico/profissional que o atendeu, prestava atenção às suas queixas e informações?

0 . era muito desatento

1. era desatento

2. mais ou menos

3. era muito atencioso

9. n.a./n.r.

11. O médico que o atendeu forneceu informações sobre o seu problema?

0. nenhuma informação

1. quase nenhuma informação

2. algumas informações

3. muitas informações

4. todas as informações

9. n.a./n.r.

12. Você acha que as explicações fornecidas pelo médico sobre o seu problema foram:

0. muito difíceis de entender

1. dificeis de entender

2. mais ou menos

3. fáceis de entender

4. muito fáceis de entender

9. n.a./Prejudicado

13. Você precisou remarcar consulta alguma vez? (Se não, vá para a questão 14). Quando você precisou remarcar consulta foi:

0 . muito dificil

1. dificil

2. mais ou menos

3. fácil

4. muito fácil

5. n.a./n.r. 
14. Você já precisou ser atendido na emergência da Psiquiatria? (se não, vá para questão 15). Quando você precisou de atendimento de urgência na Psiquiatria foi:

0 . muito difícil de ser atendido

1. dificil de ser atendido

2. mais ou menos

3. fácil de ser atendido

4. muito fácil de ser atendido

9. n.a./n.r.

15. Você acha que o médico/profissional "acertou" no seu tratamento psiquiátrico/psicológico?

0 . errou totalmente

1. errou

2. mais ou menos

3. acertou

4. acertou totalmente

9. n.a./n.r.

16. O tratamento que você recebeu no ambulatório de Psiquiatria era o que você esperava?

0 . foi muito pior do que esperava

1. foi pior do que esperava

2. mais ou menos

3. foi melhor do que esperava

4. foi muito melhor do que esperava

9. n.a./n.r.

17. Você acha que sua situação/problema se modificou desde que você iniciou tratamento no ambulatório de Psiquiatria?

0 . piorou muito

1. piorou

2. ficou na mesma

3. melhorou

4. melhorou muito

9. n.a./n.r. 
18. Você recomendaria os serviços deste ambulatório para um amigo, caso ele pedisse a sua opinião?

0. nunca recomendaria

1. não sei

2. recomendaria

3. recomendaria totalmente

4. n.a./n.r.

19. Se necessário, você voltaria à se tratar neste ambulatório?

0 . nunca mais voltaria

1. dificilmente voltaria

2. nâo sei

3. voltaria

4. sem dúvida voltaria

9. n.a./n.r.

20. De modo geral, como você se sentiu com relação ao tratamento Psiquiátrico/Psicológico que você recebeu no ambulatório de Psiquiatria da Faculdade de Medicina?

0. muito insatisfeito

1. insatisfeito

2. mais ou menos

3. satisfeito

4. muito satisfeito

9. n.a./n.r. 
01. Qual a escolaridade do chefe da familia?

0 . analfabeto

1. primário incompleto

2. primário completo (até 4a. série)

3. ginásio incompleto

4. ginásio completo (até 8a. séric atual)

5. colegial incompleto

6. colegial completo

7. superior incompleto

8. superior completo

02. Qual o trabalho do chefe da familia?

9. n.a./n.r.

03. Quantas pessoas moram ou vivem na casa?

04. Quantas pessoas colaboram com dinheiro para as despesas da casa?

\begin{tabular}{llll}
$N^{0}$ & Grau/Parentesco & 1 & Rend. Mensal/Salário \\
1 & 1 & 1 \\
\hline 1 & 1 & 1 \\
\hline 1 & 1 & 1
\end{tabular}




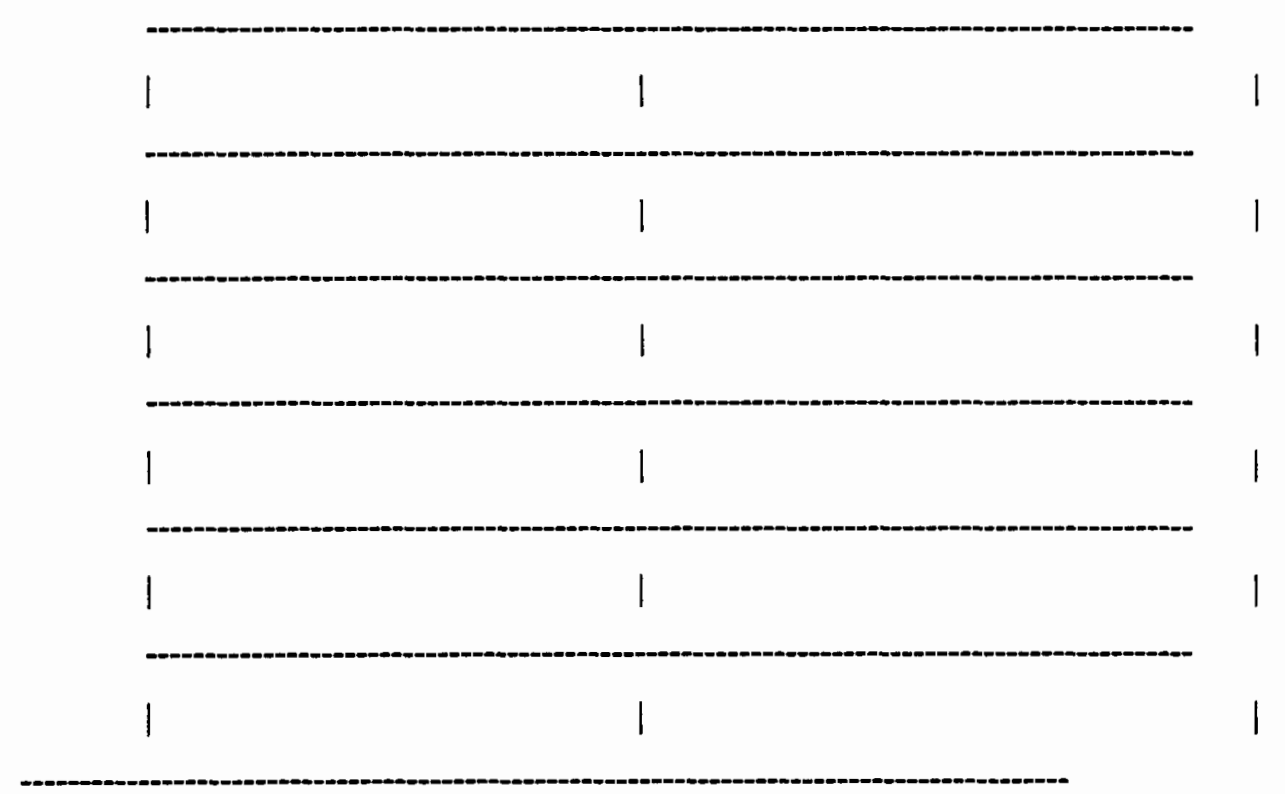

Total da renda familiar:

Obs.: As duas anotą̧̃̃es abaixo, serão feitas posteriormente.

Salário do mês:

Renda per cápita: 